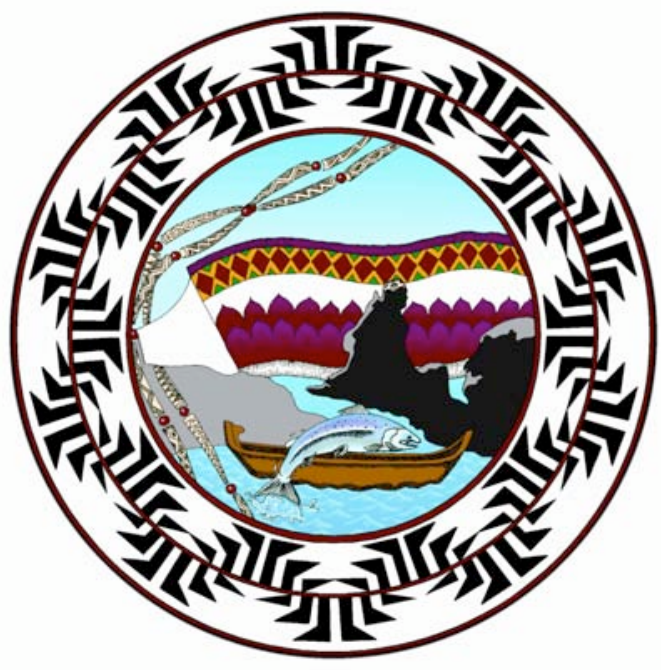

Yurok Tribe

\section{Tribal Utility Feasibility Study}

June 2007

\section{Final Report}

Presented to

U.S. Department of Energy

Tribal Energy Program

Award \#DE-FG36-03G013117

Project Officer: Lizana Pierce

lizana.pierce@go.doe.gov

Prepared by:

Schatz Energy Research Center Humboldt State University

Arcata, CA 95521

Technical Contact:

James Zoellick

jiz1@humboldt.edu

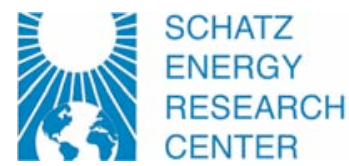




\section{Project Data}

Project Title:

Covering Period:

Date of Report:

Recipient Organization: Yurok Tribe

Award Number:

Partners:

Technical Contact:

Business Contact:

DOE Project Officer:

\section{Tribal Utility Feasibility Study}

February 3, 2006 - June 30, 2007

June 30, 2007

DE-FG36-03G013117

Yurok Tribe, Schatz Energy Research Center

Schatz Energy Research Center

Richard Engel, Research Engineer

Jim Zoellick, Senior Research Engineer

Humboldt State University

Arcata, CA 95521-8299

(707) 826-4345

Richard Engel's email: rae7001@humboldt.edu

Jim Zoellick's email: jiz1@humboldt.edu

Yurok Tribe

190 Klamath Blvd

Klamath, CA 95548

(707) 482-1350

Dustin Jolley, Engineer

(707) 482-1350 ext. 357

djolley@yuroktribe.nsn.us

Lizana K. Pierce, lizana.pierce@go.doe.gov 


\section{Table of Contents}

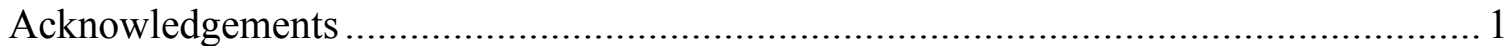

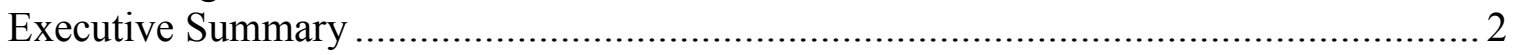

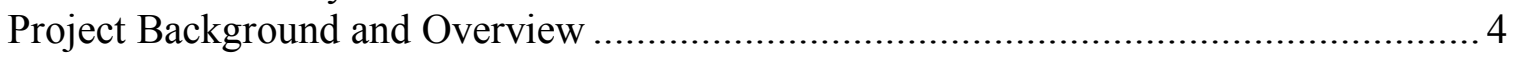

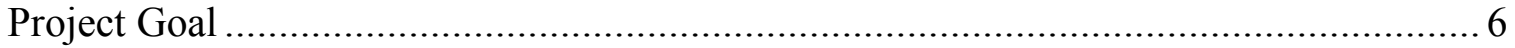

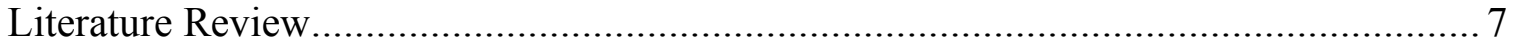

Description of Activities Performed

Inventory of Renewable Energy Resources .................................................... 8

Creation of a Yurok Energy Geographic Information System (YEGIS) ..........9

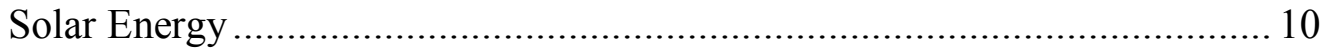

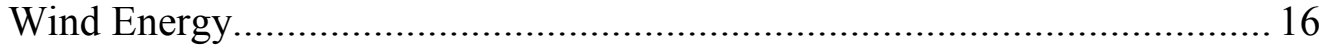

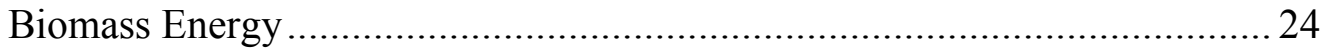

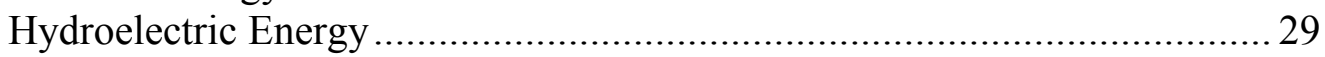

Making Renewable/Distributed Energy Systems Available.............................. 42

Providing Maintenance and Repair to Renewable Energy Systems .................... 55

Providing Energy Efficiency Services to Homes and Businesses ........................ 57

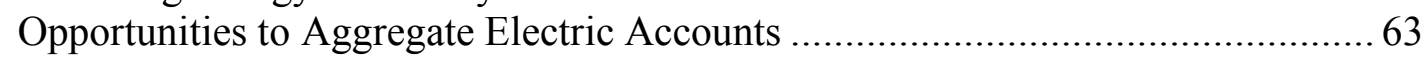

Opportunities to Generate Revenue with Renewable Energy............................. 66

Billing for Energy Services Provided By Tribe ............................................... 71

Incorporating Energy Services into the Tribal PUD ..................................... 74

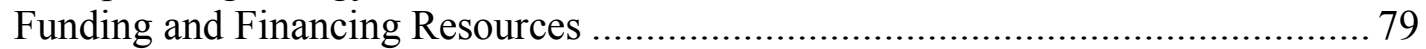

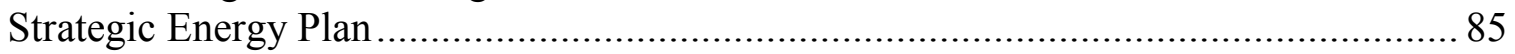

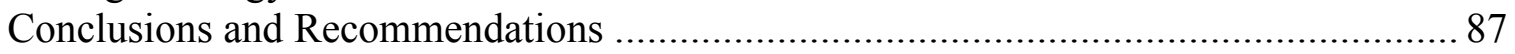

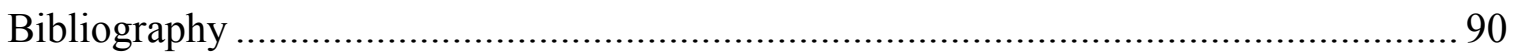

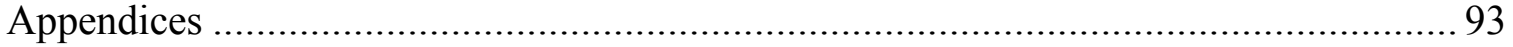




\section{Figures}

Figure 1. Solar Energy Potential in California (NREL, May 2004) .............................. 11

Figure 2. Notchko Remote Automated Weather Station, Yurok Reservation.................. 12

Figure 3. Location of Solar Monitoring Sites Relative to Yurok Reservation ................. 13

Figure 4. Average Daily Solar Insolation for Sites Near the Yurok Reservation............. 14

Figure 5. Example Solar Access Diagram Using a SolarPathfinder............................ 15

Figure 6. Wind Speed Classes in the Vicinity of the Yurok Reservation ........................ 18

Figure 7. Wind Speed Potential in the Vicinity of the Yurok Reservation ...................... 19

Figure 8. Wind Monitoring Stations in Vicinity of the Yurok Reservation.................... 20

Figure 9. Mean Monthly Wind Speeds from Selected Sites ...................................... 21

Figure 10. Mean Hourly Wind Speeds from Selected Sites ...................................... 21

Figure 11. Wind Speed Frequency Distribution for Horse Mountain.......................... 22

Figure 12. Wind Speed Frequency Distribution for Smith River Hills.......................... 22

Figure 13. Wind Speed Frequency Distribution for Kneeland Prairie.......................... 23

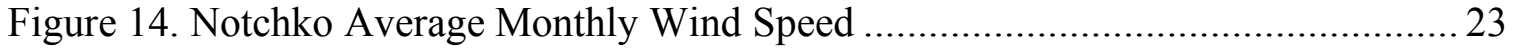

Figure 15. Biomass Resources Available in California. ...........................................25

Figure 16. Land Ownership On and Adjacent to the Yurok Reservation .......................26

Figure 17. Yurok Creeks Ranked by Basin Area...................................................... 32

Figure 18. Yurok Creeks Ranked by Peak Flow ....................................................... 33

Figure 19. Yurok Creeks Ranked by Stream Gradient.............................................. 34

Figure 20. Yurok Creeks Ranked by Potential Head ..................................................... 35

Figure 21. Yurok Creeks Ranked by Rainfall ......................................................... 36

Figure 22. Sample Map Showing Parameters Used in GIS Watershed Analysis............. 38

\section{Tables}

Table 1. Overview of Renewable Energy Resources on Yurok Reservation....................9

Table 2. Wind Data from Sites Near the Yurok Reservation .................................... 20

Table 3. Estimated Biomass Energy Potential on Yurok Reservation.......................... 29

Table 4 Creeks on Yurok Reservation Ranked by Multiple Criteria ............................ 31

Table 5. Broad Estimates of Power and Energy Potential On Yurok Streams................. 39

Table 6. Single Day Low Flow Estimates .................................................................. 39

Table 7. Economic Incentives for the Installation of Renewable Energy Systems .......... 44

Table 8. California Solar Initiative Incentives............................................................ 45

Table 9. Off-Grid Renewable Energy System Equipment and Installation Cost ............ 49

Table 10. Monthly Cost to Customer Vs. Cost Recovery by Tribe .............................. 50

Table 11. Annual Labor Hours for Renewable Energy Program Staff .......................... 51

Table 12. Maintenance Program Options ................................................................ 56

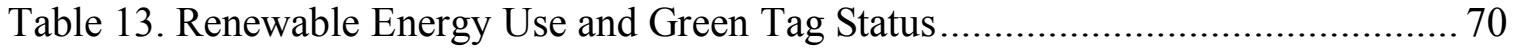

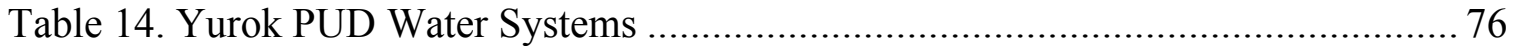




\section{Acknowledgements}

The Schatz Energy Research Center would like to thank the Yurok Tribe for their assistance in preparing this report. Especially helpful were:

- Richard Myers, Tribal Council

- Dustin Jolley, Tribal Engineer

- Peggy O’Neill, Planning Director

- Micah Gibson and Monica Hiner, Tribal Environmental Program

- Doris Timm, Director of the Fiscal Department

- Sandra Lowry and Jonathan Jackson, Yurok Indian Housing Authority

- Tony O'Rourke and Elaina Supahan, GIS Specialists

- Robert Nulph, Public Utility District

- Dan Gale, Fisheries

- Ron Reed, Forestry 


\section{Executive Summary}

The Schatz Energy Research Center (SERC) assisted the Yurok Tribe in investigating the feasibility of creating a permanent energy services program for the Tribe. The original purpose of the DOE grant that funded this project was to determine the feasibility of creating a full-blown Yurok Tribal electric utility to buy and sell electric power and own and maintain all electric power infrastructure on the Reservation. The original project consultant found this opportunity to be infeasible for the Tribe. When SERC took over as project consultant, we took a different approach. We explored opportunities for the Tribe to develop its own renewable energy resources for use on the Reservation and/or offReservation sales as a means of generating revenue for the Tribe. We also looked at ways the Tribe can provide energy services to its members and how to fund such efforts.

We identified opportunities for the development of renewable energy resources and energy services on the Yurok Reservation that fall into five basic categories:

- Demand-side management - This refers to efforts to reduce energy use through energy efficiency and conservation measures.

- Off-grid, facility and household scale renewable energy systems - These systems can provide electricity to individual homes and Tribal facilities in areas of the Reservation that do not currently have access to the electric utility grid.

- Village scale, micro-grid renewable energy systems - These are larger scale systems that can provide electricity to interconnected groups of homes and Tribal facilities in areas of the Reservation that do not have access to the conventional electric grid. This will require the development of miniature electric grids to serve these interconnected facilities.

- Medium to large scale renewable energy development for sale to the grid - In areas where viable renewable energy resources exist and there is access to the conventional electric utility grid, these resources can be developed and sold to the wholesale electricity market.

- $\quad$ Facility scale, net metered renewable energy systems - These are renewable energy systems that provide power to individual households or facilities that are connected to conventional electric utility grid.

Our key recommendations are:

- Continue to look for opportunities to develop renewable energy resources on the Reservation, in particular solar electric, micro-hydroelectric, wind, and forest biomass.

- Conduct in-depth, site-specific feasibility studies to examine investment in gridor village-scale renewable energy development. First priority should be hydroelectric, then biomass, and finally wind energy resources.

- Make use of the Yurok Energy GIS created by SERC to map and analyze energy development opportunities.

- Develop and fund a maintenance program for renewable energy systems.

- Consider establishing a program to install renewable energy systems (solar electric and micro-hydroelectric) for off-grid Tribal residences. 
- Make the Yurok Public Utility District responsible for managing Tribal energy services.

- Ensure clear agreements on who owns and pays for renewable energy systems the Tribe provides to its members.

- Create a fair and enforceable system to bill Tribe members for energy services.

- Ensure energy efficiency in existing homes by providing weatherization services. Explore creating relationships with Redwood Community Action Agency and Del Norte Senior Center to provide weatherization services through these existing agencies.

- Establish and enforce a Tribal energy code to ensure energy efficiency in all new construction on the Reservation. Adopt California's Title 24 Energy Code as the Yurok Tribe Energy Code.

- Pursue funding and install renewable energy systems on Tribal facilities where economically feasible.

- Monitor local progress on the formation of a Community Choice Aggregator. Consider joining a local Joint Powers Authority and participating in Community Choice Aggregation if the opportunity arises.

- Identify and secure funding to pay for Tribal energy services.

- Identify and cultivate an energy program champion within the Yurok Tribe who can lead the effort to establish and maintain a Tribal energy program over the long term.

- Take action soon to ensure continuity and make best use of resources already invested. 


\section{Project Background and Overview}

The Yurok Tribe is the largest Tribe in California, with nearly 5,000 enrolled members, about 1,200 of whom live on the Reservation. It is also the poorest California Tribe. The Yurok Reservation is located in coastal northwestern California and has a total area of 56,585 acres, situated along the lowermost 44 miles of the Klamath River and extending outward for one mile on either side of the river. Tribal landholdings on the reservation are mixed in a "checkerboard" pattern with non-Tribal fee lands. More than $70 \%$ of the Reservation lands are held by non-Tribal owners. Tribal plots are typically small, ranging from 20 to 200 acres each. Residents of the Reservation live in small village clusters and remote homesteads. A few of the most isolated homes are accessible only via the river or on foot.

The Tribe was first recognized by the federal government in 1993 and is governed by a nine-member elected council that includes a chair, vice-chair, and seven district representatives. The Tribe employs over 200 staff and maintains Tribal offices at both ends of the Reservation, in Klamath and Weitchpec, as well as an off-Reservation satellite office in Eureka.

The Yurok Tribe has serious need for development of its energy resources and infrastructure. Tribe members, particularly those living on the Reservation, have inadequate access to electric power, disproportionately low household income, and disproportionately high household energy costs. On the Reservation, a recent survey showed that households are spending an average of $\$ 328$ per month on home energy (compared to $\$ 124$ U.S. average). This cost disparity is due to a number of factors at work on the Reservation, including isolation, limited fuel choices, inadequate weatherization, and antiquated and inefficient appliances. Exacerbating the problem, average yearly household income on the Reservation is only about $\$ 9,000$ (compared to $\$ 43,318$ U.S. median). Approximately $62 \%$ of household incomes on the Reservation fall below the US Department of Health and Human Services poverty level. These facts emphasize the need for access to affordable energy services on the Reservation.

The Tribe has been working for many years to provide basic energy services to Tribal members on the Reservation. Because of the remote location of the Reservation in a deep canyon along the Klamath River between its confluence with the Trinity River and the Pacific Ocean, grid electricity is still unavailable to a substantial portion of the Reservation's residents, causing hardship for Tribal members and severely thwarting economic development. The Reservation's location, straddling two counties in the remotest corners of two large utility companies' service territories, presents numerous difficulties in providing adequate and consistent energy services to all residents. Efforts to promote sustainable development on the Reservation are impossible without a reliable and affordable source of electrification.

Previous Tribal efforts at energy planning and development include the creation of a strategic energy plan, work with the Native American Renewable Energy Education Project (NAREEP) to examine ways to electrify unserved portions of the Reservation, 
work with Kelso Starrs and Associates to explore the possibility of developing a "wireless" utility to provide off-grid electricity service, a renewable energy options analysis conducted by technical staff from the US Department of Energy and National Laboratories, a human capacity building project funded by the US DOE Tribal Energy Program, and a preliminary biomass feasibility study funded by the USDA Forest Service. Much progress has been made toward building human capacity within the Tribe, identifying energy needs and available renewable energy resources on the Reservation, and exploring the Tribe's various energy options. Identified renewable energy resources include biomass, hydro, solar, and possibly wind.

Work also continues on the construction of electrical distribution lines to serve the unelectrified portion of the Reservation. This work is being done under a US Rural Utility Service grant. Although progress is being made on the line extension, it is not without difficulty. One key issue is obtaining all the required right-of-way power line easements. Per-mile costs of installing power lines in this rugged landscape have exceeded estimates. It will likely be many years before a power line extension covering this entire region will be completed.

The Tribal Utility Feasibility Study began On February 3, 2006 and concluded on June 30, 2007. The Yurok Tribe initially hired Winzler \& Kelly Consulting Engineers under this DOE grant to perform a feasibility study on forming a Tribally operated conventional electric utility. The economic driver behind this idea was the perceived opportunity for the Tribe to wheel electric power across the Yurok Reservation, which is located on the boundary between Pacific Power and PG\&E service territories. Pacific Power's access to inexpensive Pacific Northwest hydropower makes their retail and wholesale electric rates substantially lower than PG\&E's. However, Winzler \& Kelly concluded that the wheeling opportunity was not available to the Tribe, and the consultant ended their contract with the Tribe, leaving approximately half of the DOE grant funds unspent.

At that time, the Yurok Tribe approached the Schatz Energy Research Center (SERC) about using the remaining grant funds to perform a redirected study on developing the Tribe's renewable energy resources and providing energy services to Tribe members. SERC and the Tribe worked together to craft a new list of tasks that fit within the original project scope of work and were acceptable to DOE. The redirected focus was to explore options for developing a non-conventional Tribal energy services utility that could provide services that were currently lacking on the Reservation. The focus of this nonconventional utility would be to provide energy efficiency and renewable energy services.

The scope of work agreed to by the Tribe, SERC and DOE consists of nine tasks:

1. Perform a general inventory of renewable energy resources available for development on the Reservation.

2. Develop a plan for making renewable and distributed energy systems available to on- and off-grid homes and businesses on the Reservation. 
3. Develop a plan for providing scheduled maintenance and repairs to existing and new renewable and distributed energy systems on the Reservation.

4. Develop a plan for providing energy efficiency services to homes and businesses on the Reservation.

5. Investigate opportunities to aggregate customer accounts for the purpose of purchasing bulk electric power for homes and businesses on the Reservation.

6. Research opportunities to develop renewable energy sources on the Reservation in order to generate revenue.

7. Develop a plan for billing of homes and businesses on the Reservation for the above energy services.

8. Determine the steps necessary to incorporate all of the above services into the existing structure of the Tribal public utilities district.

9. Investigate funding and financing resources for proceeding with implementation of the planned Yurok Tribal Energy Services Program.

Once the contract was implemented, SERC began our analysis. This report documents the results of our work and serves to fulfill the requirements of our contract.

\section{Project Goal}

The original objectives of this study were to: 1) determine the feasibility of the Yurok Tribe becoming a electric power utility, 2) determine the best form of utility organization to create, and 3) determine the steps and resources necessary for establishing the utility. As mentioned above, the original contractor on this project, Winzler and Kelly Consulting Engineers, found that the development of a traditional Tribal electric utility was infeasible. Consequently, SERC was hired to redirect the focus of the project and to explore options for developing a non-conventional Tribal energy services utility that could provide services that were currently lacking on the Reservation, namely energy efficiency and renewable energy services.

As stated in the project scope of work agreed to by the Tribe, SERC, and DOE, the project's revised goal is "to develop a plan for delivering energy services to Tribe members on the Yurok Reservation using the mechanism of the existing Tribal utility district.” This goal was achieved by carrying out the nine tasks listed in the scope of work (see Project Overview).

\section{Literature Review}

With the help of Tribal staff, we were able to identify a number of past studies and reports that examine specific energy resources on the Reservation. These are discussed in some detail under the corresponding energy resource subsections within the "Description of Activities Performed" section of this report. We found that the past work that was done on investigating Yurok energy alternatives is substantial, and reviewing and building on 
this work became a key task. In addition to the documents described later in this report that address one specific technology, some other documents we found useful included:

- Yurok Tribe Strategic Energy Plan. This document is not a true strategic plan but rather a set of notes and brainstorm lists from a strategic energy planning session for the Yurok Tribe hosted by the Council of Energy Resources Tribes in 2003. A majority of the Tribal Council and numerous Tribal staff participated in the workshop. The plan states that forming a Tribal utility is a high priority for the Tribe. Renewable energy, energy efficiency, and job creation in the energy sector were also identified as priorities.

- Arne Jacobson's memos and reports from his work with the Yurok Tribe as an employee of Kelso-Starrs and Associates in 1998-99. Dr. Jacobson, who is now a co-director at SERC and engineering faculty member at Humboldt State University, spent extensive time in the field helping the Tribe to identify and meet household energy needs in the Reservation's off-grid areas. His reports helped us to identify key issues and hurdles, particularly the difficulties the Tribe faces in collecting revenues to make household off-grid energy systems financially selfsupporting. These reports are discussed in greater detail in the section on "Billing for Energy Services Provided By Tribe" later in this report.

- Community Context and Technology Options in the Yurok Tribal Electrification Project. This Master's Thesis prepared by Chris Greacen from UC Berkeley explored options for providing basic electricity services to approximately 80 households in the remote upriver section of the Reservation. Mr. Greacen's work examined issues and motivations of different groups involved in the electrification project, and conducted engineering and economic analyses to examine eight technology options for electrification, including gasoline/propane generators, solar, micro-hydro, village scale hydro, and electric utility line extension.

- $\quad$ Phase I Report on Renewable Energy Options for the Yurok Indian Reservation. This is the report on a rapid field survey of renewable energy resources on the Reservation, performed in June 2000 by a team of renewable energy specialists from Sandia National Laboratories, Western Area Power Administration, and the Idaho National Engineering and Environmental Laboratory. The team looked at the Tribe's ongoing efforts to extend grid power to remote areas on the Reservation, as well as solar and hydropower potential. They made separate recommendations for each of four areas on the upper reservation:

$\circ$ For the area between Weitchpec and Tully Creek, they recommended a utility line extension (this has been accomplished).

○ For the Cappell/Notchko area, they recommend a village hydropower system using Cappell Creek.

- For the Wautec area and Jack Norton School, they recommend a photovoltaic/engine generator hybrid system with possible integration of hydropower. They also recommended adding battery storage for the existing generator system at the school.

- For the less densely populated areas of the upper Reservation outside these village clusters, they recommended individual household-scale solar electric systems, with backup generators as needed. 
Full citations for these and other documents described in this report are provided in the bibliography at the end of the report.

\section{Description of Activities Performed}

\section{Inventory of Renewable Energy Resources}

After discussions with Tribal staff and reviewing existing reports on previous energy studies done on the Reservation, we chose to examine solar energy, wind energy, forest biomass, and small scale hydropower in depth as the resources most likely to be viable for Tribal development.

- The solar energy resource on the Reservation is approximately 4 to 4.5 $\mathrm{kWh} / \mathrm{m}^{2} /$ day. This is relatively low by California standards, but adequate to make solar electric systems viable, especially where they can be matched with winter-peaking hydropower in hybrid power systems. One site-specific limitation for solar electricity on the Reservation is that many homes are located in wooded areas or deep in the river canyon, where shading may be a serious problem. We performed solar site analyses at 35 residential locations on the Reservation and found that on average, shading only reduced the potential solar resource by $22 \%$, with minimal shading at many sites. To assess the available solar resource, SERC acquired solar resource data from a number of data collection sites on and near the Reservation.

- Wind energy is most likely to be viable on the coastal headlands near the Klamath River mouth or on ridges immediately outside the Reservation boundary along the east side of the Klamath River canyon. Based on limited available data, it appears unlikely that most locations on the Reservation experience the 11 to $13 \mathrm{mph}$ average wind speeds needed for commercial wind development. However, wind speeds are highly site-specific, and extended on-site monitoring is needed before an informed decision can be made. SERC helped the Tribe to prepare a proposal to the DOE Tribal Program seeking funding for an in-depth wind energy feasibility study. At this time the Tribe is awaiting word from DOE on whether the project will be funded.

- Forest biomass is abundant on the 63,000-acre Reservation. One limitation is that over $70 \%$ of Yurok Reservation lands are owned by private, non-Tribal timber companies. Access to biomass from these lands would require an agreement with the landowner. Nearby Six Rivers National Forest is striving to reduce wildfire risk through fuels reduction thinning operations. They are interested in supporting biomass energy projects in the area and may be willing to provide the Tribe access to materials removed from the National Forest lands. The Yurok Tribe Forestry Program also generates considerable amounts of biomass waste that could be used for energy production. SERC assisted the Tribe in preparing a funding proposal to the Bureau of Indian Affairs' Division of Energy and Mineral Development to conduct an in-depth 
biomass energy feasibility study. The proposal was short-listed by DEMD, but at this time funds for selected projects are not available.

- Hydroelectric power is also a widely available resource on Yurok lands. Many individual households already make use of hydropower as a primary or secondary electric source via microhydro systems, typically less than $2 \mathrm{~kW}$. Using a hydrologic model and limited verifiable flow data, we estimate the total developable hydropower potential on the Klamath River tributary streams that cross the Reservation to be approximately $18 \mathrm{MW}$. However, there are numerous hurdles to developing hydropower on the Reservation, including high capital costs, potential impacts to anadromous fisheries, right of way access to streams that cross multiple properties, proximity to loads, and access to power transmission infrastructure.

Table 1 provides a summary of the renewable energy resource potential on the Yurok Reservation. Each of these renewable resources is discussed in greater detail below.

Table 1. Overview of Renewable Energy Resources on Yurok Reservation

\begin{tabular}{|c|c|c|c|c|c|}
\hline Resource & $\begin{array}{l}\text { Development } \\
\text { Potential }\end{array}$ & $\begin{array}{c}\text { Technology } \\
\text { Status }\end{array}$ & $\begin{array}{l}\text { Geographic } \\
\text { Location }\end{array}$ & $\begin{array}{c}\text { Scale/ } \\
\text { Application }\end{array}$ & Comments \\
\hline $\begin{array}{l}\text { Wind } \\
\text { electricity }\end{array}$ & $\begin{array}{l}\text { Small to } \\
\text { moderate, not } \\
\text { yet quantified }\end{array}$ & Mature & $\begin{array}{l}\text { Requa hill, } \\
\text { inland } \\
\text { ridgetops }\end{array}$ & Sales to grid & $\begin{array}{l}\text { Resource not } \\
\text { fully evaluated, } \\
\text { need } \\
\text { transmission } \\
\text { access, few } \\
\text { viable sites }\end{array}$ \\
\hline $\begin{array}{l}\text { Biomass } \\
\text { electricity }\end{array}$ & $\begin{array}{l}\text { Moderate, } 400 \\
\text { to } 700 \mathrm{~kW} \text {, } \\
2.7 \text { to } 4 \\
\text { million } \\
\mathrm{kWh} / \mathrm{yr}\end{array}$ & $\begin{array}{c}\text { Mature at } \\
\text { large scale, } \\
\text { developing } \\
\text { at small } \\
(<100 \mathrm{~kW}) \\
\text { scale }\end{array}$ & $\begin{array}{l}\text { Resource } \\
\text { throughout } \\
\text { Reservation, } \\
\text { limited } \\
\text { locations for } \\
\text { energy } \\
\text { facilities }\end{array}$ & $\begin{array}{l}\text { Village } \\
\text { scale, sales } \\
\text { to grid }\end{array}$ & $\begin{array}{l}\text { May require } \\
\text { access to } \\
\text { resources on } \\
\text { non-Tribal } \\
\text { lands to be } \\
\text { viable }\end{array}$ \\
\hline $\begin{array}{l}\text { Hydro- } \\
\text { electricity }\end{array}$ & $\begin{array}{l}\text { Large, up to } \\
18 \mathrm{MW}, 160 \\
\text { million } \\
\mathrm{kWh} / \mathrm{yr}\end{array}$ & Mature & $\begin{array}{l}\text { Klamath } \\
\text { tributary } \\
\text { streams }\end{array}$ & $\begin{array}{l}\text { Village } \\
\text { scale, sales } \\
\text { to grid, } \\
\text { facility/ } \\
\text { household } \\
\text { scale } \\
\end{array}$ & $\begin{array}{l}\text { Numerous } \\
\text { barriers to } \\
\text { development }\end{array}$ \\
\hline $\begin{array}{l}\text { Solar } \\
\text { electricity }\end{array}$ & $\begin{array}{l}\text { Moderate, } 200 \\
\text { to } 500 \mathrm{~kW}, \\
0.2 \text { to } 0.5 \\
\text { million } \\
\mathrm{kWh} / \mathrm{yr}\end{array}$ & Mature & $\begin{array}{l}\text { Throughout } \\
\text { Reservation }\end{array}$ & $\begin{array}{l}\text { Facility/ } \\
\text { household } \\
\text { scale }\end{array}$ & $\begin{array}{l}\text { Resource best } \\
\text { inland, locally } \\
\text { limited by } \\
\text { shading }\end{array}$ \\
\hline
\end{tabular}




\section{Creation of a Yurok Energy Geographic Information System (YEGIS)}

At an early stage of this project it became clear that visual mapping of renewable energy resources on the Reservation would be of value in performing this study and in conveying our findings to Tribal decision makers. The use of Geographic Information System (GIS) software was identified as the preferred way to accomplish this. We created a multi-layer GIS using ESRI's ArcInfo software. We received valuable technical support from the Yurok Tribe's GIS team, Tony O'Rourke and Elaina Supahan, in initiating this work and now have a free-standing Yurok Energy GIS (YEGIS) we have developed at SERC. In addition to mapping locations of energy resources on the Reservation, we have been able to map other features of the Reservation with significance to energy development. We have also used GIS to track our field work as part of the separate Human Capacity Building project.

To date we have used the GIS to map in detail:

- wind resources on the Reservation using data files provided by the National Renewable Energy Laboratory;

- estimated power potential for all the major streams on the Reservation, using a hydrologic model and physical data about the watersheds;

- $\quad$ property boundaries, home locations, and existing utility power infrastructure information of value in determining the logistical hurdles to developing energy resources at specific sites (map included in Appendix 1);

- locations of energy audits performed as part of the Human Capacity Building project (map to be provided as part of separate final report on that project).

Some of the maps included in this report were created using the YEGIS. The YEGIS is being provided to the Tribe in electronic format and can be used to develop additional maps as data sets are updated or using additional data sets already in the Tribe's possession. A conceptual model for the types of data that could be used to populate the YEGIS is presented in Appendix 10. We recommend that the Tribe continue to develop the YEGIS as more data become available.

\section{Solar Energy}

Solar energy can be collected to provide heat (for space heating, heating water, cooking, etc.), or it can be used to directly produce electricity via a photovoltaic (PV) device. Both solar water heating systems and solar electric systems are well-established, commercially available technologies that can provide an economical source of renewable energy given favorable conditions.

Figure 1 shows a map of California depicting the average annual solar energy potential throughout the state. The North Coast of California, including the Yurok Reservation, receives about 4 to $4.5 \mathrm{kWh} / \mathrm{m}^{2} /$ day on average throughout the year. While this is not as much available sunlight as is experienced in many other parts of the state, it is certainly adequate for most solar energy systems. People often ponder whether or not solar energy works or is cost effective on the North Coast, and the answer is "yes." While a given system will not produce as much power here as a comparable system located in a sunnier part of the state, systems here do work and can pay for themselves. This is evidenced by the fact that people in Humboldt County have installed 3.5 more grid-connected rooftop solar energy systems on a per capita basis than people in the rest of the state. 

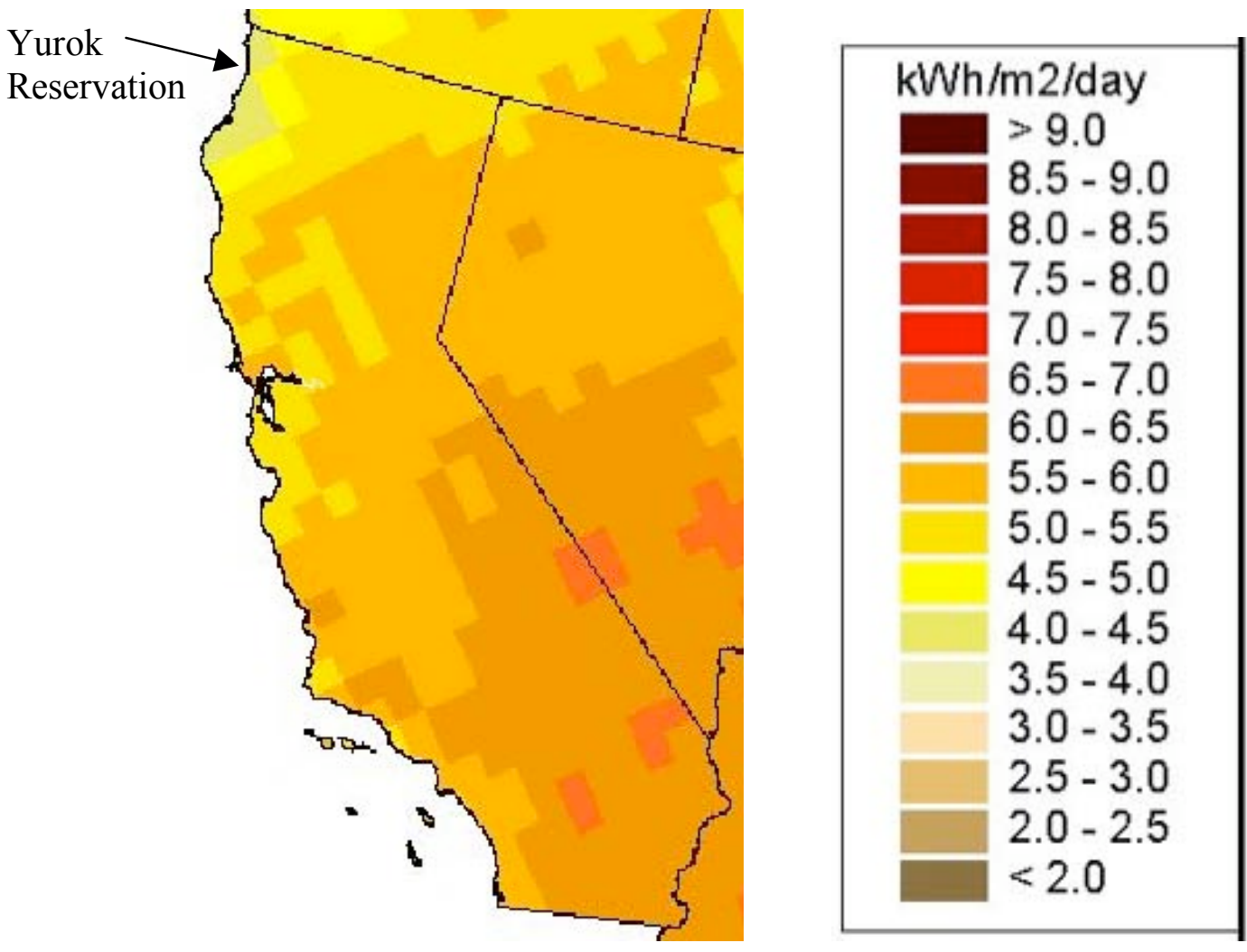

Figure 1. Solar Energy Potential in California (NREL, May 2004)

(South facing surface, tilt equal to latitude)

There are numerous data sources to draw on to estimate the potential solar energy resource for the North Coast of California and the Yurok Reservation. These include solar data for Arcata (Arcata Airport) and Crescent City (Crescent City Airport) that are part of the National Solar Radiation Database and are available from the National Renewable Energy Laboratory (NREL). The solar data for these sites are not directly measured, but instead are modeled based on other meteorological parameters. The Arcata site is considered a Class 1 site, and the Crescent City site a Class 2 site. Class 1 stations have the highest quality solar modeled data, while Class 2 stations have lesser quality data (Class 3 sites have the least reliable data).

Some directly measured solar radiation data has also been collected on California's North Coast. This includes data collected by the California Energy Commission between 1971 and 1975 at Butler Valley, CA. Another directly measured solar data set is available from the Schatz Energy Research Center (SERC) at Humboldt State University. SERC has been measuring solar radiation data on a south facing surface sloped at $30^{\circ}$ above the horizontal in Trinidad, CA since 1990. Finally, the Yurok Tribe has been collecting solar radiation data on a horizontal surface at their Notchko Remote Automated Weather Station (RAWS) site since 2003. Figure 2 shows a photo of the Notchko RAWS site. 
Figure 2. Notchko Remote Automated Weather Station, Yurok Reservation

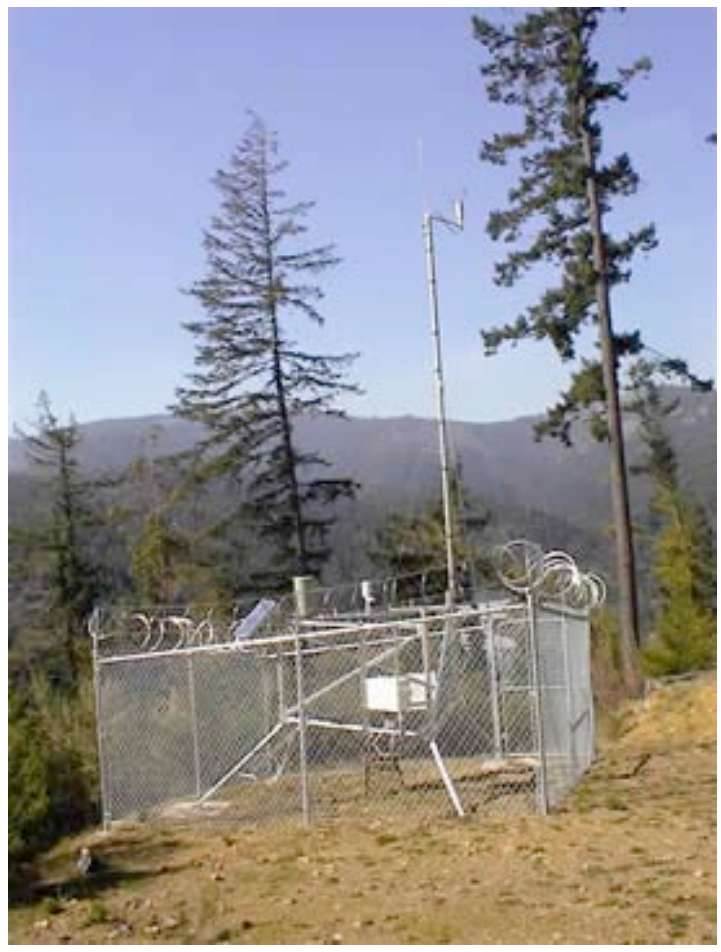

Figure 3 shows the location of the various solar monitoring stations with respect to the Yurok Reservation. The Arcata Airport and Trinidad are located on the coast about 25 miles southwest of the southern end of the Reservation, and the Crescent City Airport is located on the coast and about 18 miles north of the northern boundary of the Reservation. Butler Valley is located about 15 miles inland from the coast, which is comparable to the distance the southern end of the Yurok Reservation is from the coast. Butler Valley is about 30 miles southwest of the southern boundary of the Reservation. The Notchko RAWS site is centrally located on the Yurok Reservation. These sites should provide a rather representative picture of the solar energy potential on the Yurok Reservation.

Based on the available data for the area, the average annual daily insolation for Yurok Reservation is estimated to be about 4 to $4.5 \mathrm{kWh} / \mathrm{m} 2 /$ day (or 4 to 4.5 peak sun hours per day). Figure 4 shows a plot of monthly insolation values on a surface facing due south and sloped at $30^{\circ}$ above the horizontal for four of the identified solar monitoring sites. The data for each of these four sites shows very close agreement. The average annual daily insolation for these four sites varies between 4.1 and $4.4 \mathrm{kWh} / \mathrm{m} 2 /$ day, with the largest deviations occurring in the peak summer months of July and August. This larger deviation during these months is to be expected, as the coastal sites are typically experiencing dense summer fog during these periods while the inland sites are more or less free of fog. 
Yurok Tribe

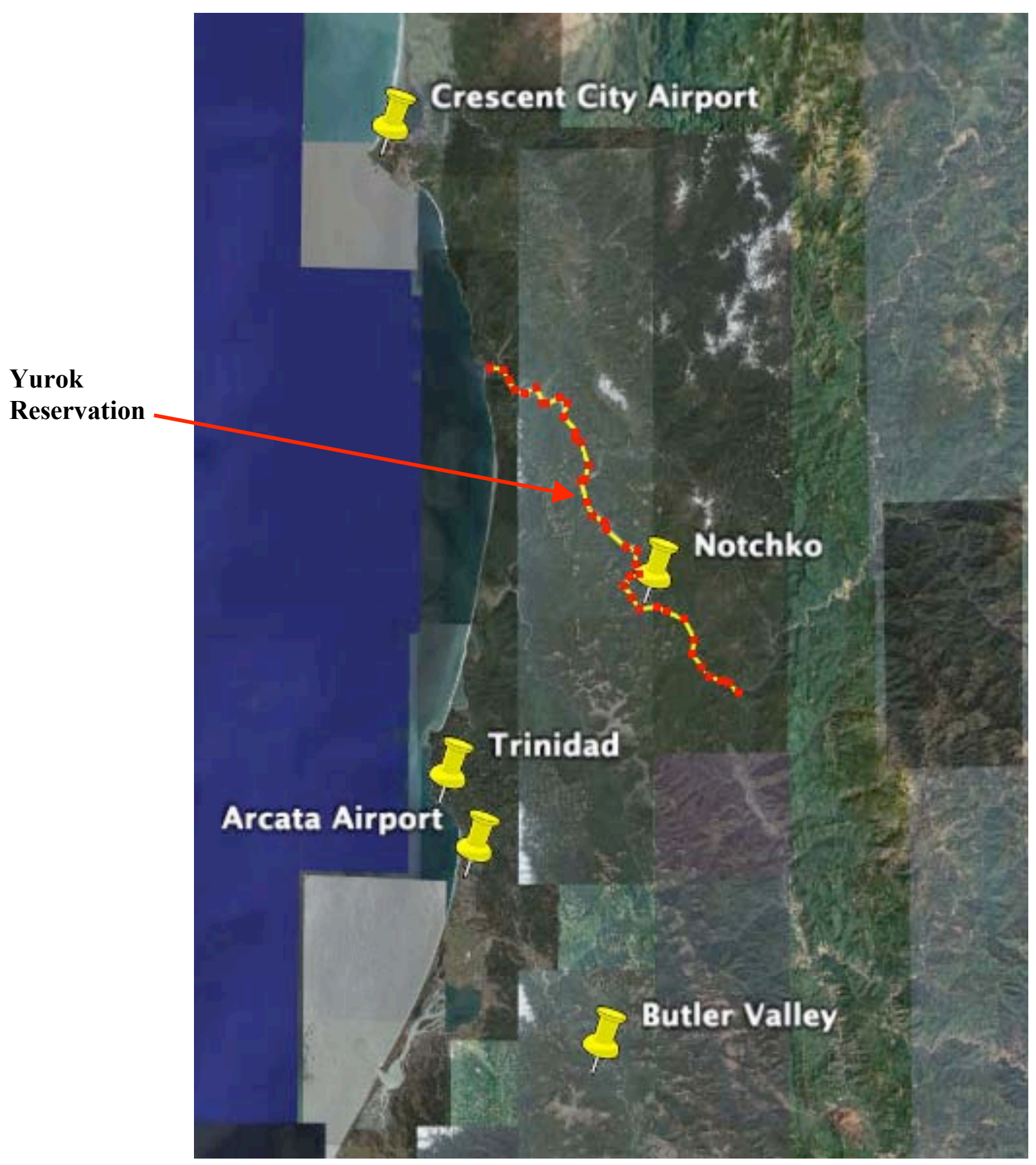

Figure 3. Location of Solar Monitoring Sites Relative to Yurok Reservation 


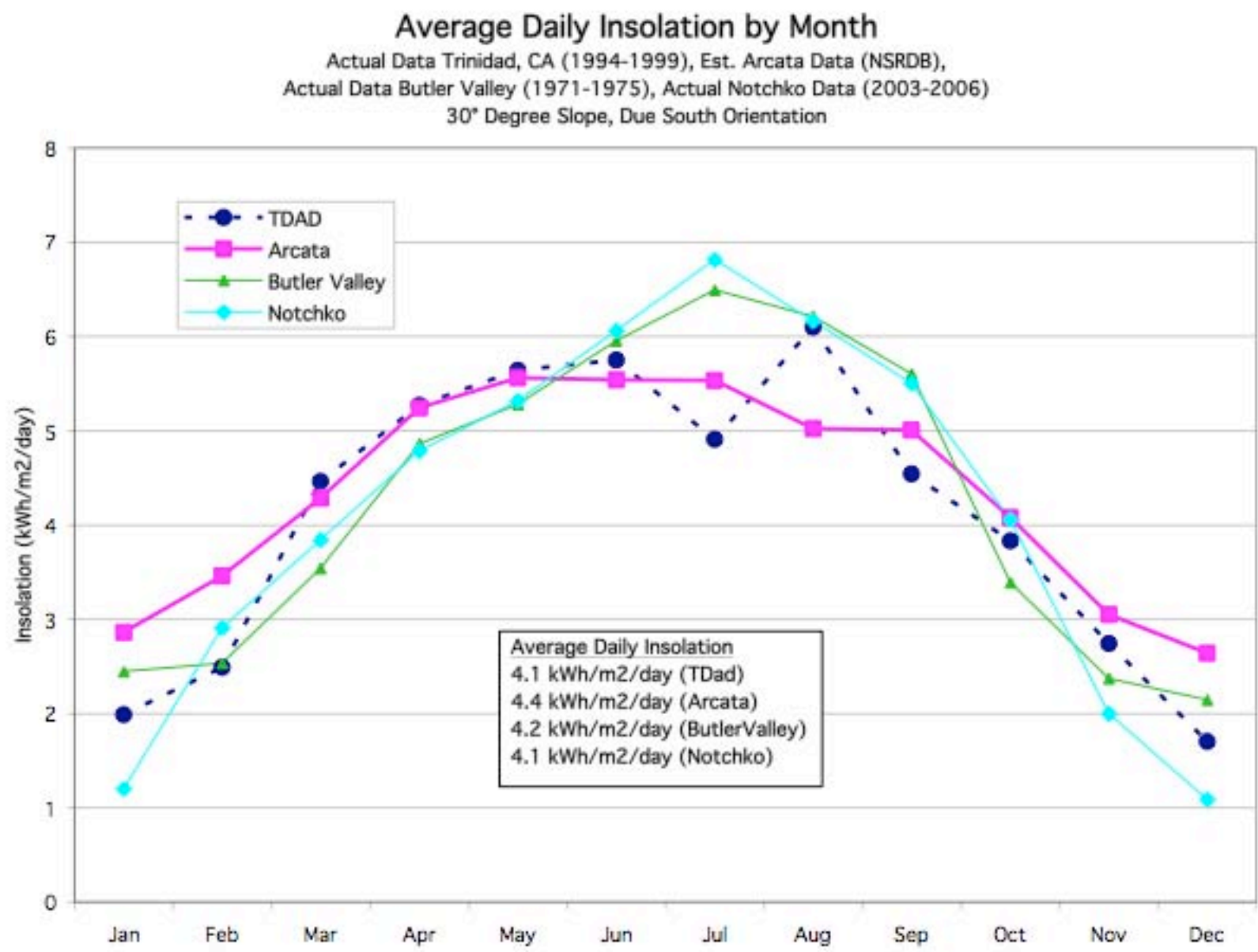

Figure 4. Average Daily Solar Insolation for Sites Near the Yurok Reservation

Note that these solar data assume clear solar access (no shading of the solar collector surface). Most of the Yurok Reservation is heavily forested and is located in the Klamath River canyon, where mountain ridges can shade areas for many hours early and late in the day. Shading from trees and mountain ridges should be avoided to the extent possible. Before a solar energy system is installed, the collector site should be evaluated for adequate solar access. This can be accomplished most easily using a device called a Solar Pathfinder. The Yurok Tribal Engineer has such a device. The Solar Pathfinder is placed where the solar collector is intended to be located and a picture of the sky dome is used to determine what hours of the year by month are shaded. A good solar site should have clear solar access between about 9 AM and 3 PM solar time ${ }^{1}$. Figure 5 shows a solar access plot obtained using a Solar Pathfinder. At this site the sun is shaded between the hours of $10 \mathrm{AM}$ and noon (solar time), as well as after 2:30 PM solar time in the winter months; this is not a good solar site.

\footnotetext{
${ }^{1}$ Solar time is different than clock time. Solar time is relative to solar noon, the point at which the sun is due south at it's highest point in the sky; 9 AM solar time corresponds to 3 hours before solar noon, and 3 PM solar time corresponds to 3 hours after solar noon. The Solar Pathfinder presents data based on solar time.
} 


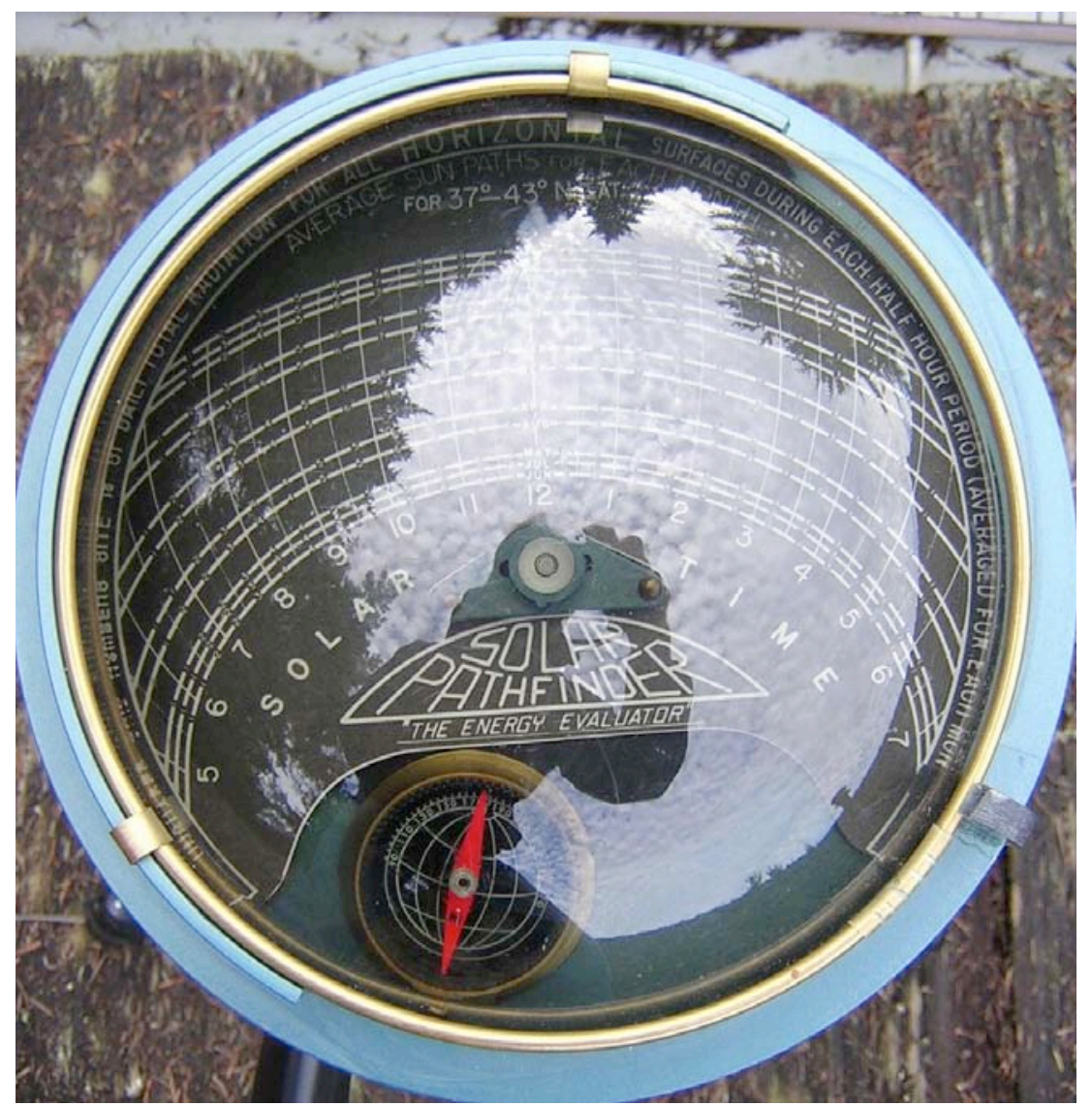

Figure 5. Example Solar Access Diagram Using a SolarPathfinder

One additional source of information on the Reservation's solar resource comes from work we performed concurrently with the Tribe as part of the separately funded Human Capacity Building project. As part of that project, solar resource measurements were made at many locations on the Reservation using a Solar Pathfinder tool. The project team acquired Pathfinder Assistant software for processing the data collected at these sites. Pathfinder data were collected at 35 residential and community properties. At some locations, multiple sites were evaluated. In total, 58 Pathfinder measurements were taken at the 35 locations. Many of these sites have excellent solar potential. Solar exposure at each site was estimated as a percentage of what the exposure would be if there were no shading at the site at any time of year from horizon to horizon. Values ranged from a minimum of $15 \%$ of this theoretical maximum to a maximum of $97 \%$, with an average solar exposure of $78 \%$. Using regional solar energy availability data built into the Pathfinder Assistant software, we were able to estimate average daily energy availability in at these locations, based on an array oriented due south and tilted at latitude ( $40.8^{\circ}$ above horizontal). The values ranged from $0.66 \mathrm{kWh}$ per square meter per day to 4.36 $\mathrm{kWh}$ per square meter per day, with an average value of $3.48 \mathrm{kWh}$ per square meter per day.

The slope and orientation of a solar collector also affects its ability to collect solar energy. On the Yurok Reservation a collector slope of $30^{\circ}$ is optimal for year round energy collection and a slope of $15^{\circ}$ to $55^{\circ}$ is acceptable (lose no more than about $5 \%$ of 
the available solar resource). Shallower slopes are preferred in the summer when the sun is high in the sky, and steeper slopes in the winter when the sun is lower in the sky. For off-grid systems the limiting time of year is typically the wintertime when there is less sun and electrical energy use is higher. Therefore, off-grid systems will benefit from steeper collector slopes of $40^{\circ}$ to $50^{\circ}$. It is also possible to adjust the collector slope for the optimal angle on a seasonal basis if the collector mounting rack allows for adjustment.

The optimal collector orientation is typically facing due south, though orientations between about $45^{\circ}$ to the east or the west of south are acceptable (again lose no more than about $5 \%$ of the available solar resource). If the collector location is shaded in morning, then a southwest facing collector will be favorable, and vice versa for a collector area that is shaded in the afternoon. In addition, locations that are frequently foggy or cloudy in the morning and experience clearing in the afternoon will benefit from a southwest facing slope.

The solar energy resource on the Reservation is best suited to facility or household scale applications. Therefore, an estimate of the maximum solar electricity generation potential on the Reservation can be made by assuming most or all Tribal facilities and households will be equipped with systems. There are approximately 250 Tribal households on the Yurok Reservation. Assuming that 50\% to 100\% of these households are equipped with $1.5 \mathrm{~kW}$ solar electric systems, this would result in 190 to $375 \mathrm{~kW}$ of installed solar electric capacity. Tribal facilities could likely support another $100 \mathrm{~kW}$ of solar electric capacity. This results in an estimated total solar electric potential on the Reservation of nearly 200 to $500 \mathrm{~kW}$. Assuming an average solar insolation of 4 peak sun hours per day and a average system derate factor ${ }^{2}$ of $70 \%$, these systems could produce 200 to $500 \mathrm{MWh} / \mathrm{yr}$ on average.

\section{Wind Energy}

Wind generators capture a portion of the kinetic energy in the wind and convert it to electrical power. Wind generators are a well proven technology that can provide an economical source of electricity given the right conditions. Wind generators are available in sizes ranging from less than one kilowatt of electrical capacity for residential scale projects up to 2-3 MW for large-scale commercial wind farms.

The wind energy resource on the Yurok Reservation has not yet been assessed; however, indications are that there may be a favorable wind resource for small to medium scale wind development. The Tribe currently has a proposal pending with the DOE Tribal Energy Program to assess the wind resource on the Reservation and determine the feasibility of installing one or more wind turbines to produce power for sale off the Reservation. It is also possible that small-scale residential wind energy systems may be appropriate on a few select sites on the Reservation.

\footnotetext{
${ }^{2}$ There are numerous factors that decrease the power output from a solar electric system below its rated output. These include increased module temperature, inverter efficiency, dirt and dust, voltage drop in the system, and battery efficiency.
} 
The California Energy Commission has studied the wind resource in California extensively and the National Renewable Energy Lab has also characterized California's wind resource. These studies indicate that the northwest corner of California, where the Yurok Reservation is located, is predominantly characterized by class 1 through class 4 wind power class ratings. NREL data for the Yurok Reservation and the area in the immediate vicinity classify most of the area as Class 1, with some select areas as high as Class 4 and above (see Figure 6). According to NREL, areas designated class 3 or greater are suitable for most wind turbine applications, class 2 areas are marginal, and class 1 areas are generally not suitable (with some exceptions). Figure 7, from the California Energy Commission Wind Atlas, shows areas near the Reservation with 11-14 mph average wind speeds (class 1 to class 5).

Various wind speed data sources for the area surrounding the Reservation are shown in Table 2. Figure 8 shows the location of each of these wind data sites with respect to the Yurok Reservation. Figure 9 presents mean monthly wind speeds for six of these sites, and Figure 10 shows mean hourly wind speeds for five of the sites. These data indicate that School House Peak and Kneeland Prairie are two of the best sites. Both are located on coastal ridge tops. School House Peak is located only about 5 miles away from the Reservation boundary, whereas Kneeland Prairie is substantially further away (34 miles from the Reservation boundary). Figures 11, 12, and 13 show the wind speed frequency distributions for three of the listed sites.

The Yurok Tribe Environmental Program's (YTEP's) Real-Time Monitoring Program is another source of wind speed data for the Yurok Reservation. YTEP collects wind speed data at three locations on the Reservation. These monitoring stations log standard meteorological data, including wind speed and direction. It should be noted that the anemometers at these locations are placed very near to ground level ( $<15$ feet height), so the data are not necessarily a good indication of the available wind resource. Figure 14 presents mean monthly wind speeds for the Notchko site.

In summary, there is not likely to be a tremendous wind energy resource available for development on the Yurok Reservation; however, there may be select sites that display favorable conditions to support a medium scale system for off-reservation power sales. According to the American Wind Energy Association (AWEA), a minimum annual average wind speed of 11 to $13 \mathrm{mph}$ is necessary before even considering commercial wind project development. Other key site related issues to consider include access to electrical transmission lines, access to land, site considerations, and zoning and permitting requirements. These and many other issues will be thoroughly examined in the proposed wind energy feasibility study that has been submitted to the DOE Tribal Energy Program. Small-scale residential wind energy systems may also be shown to be appropriate at select sites on the Reservation. AWEA estimates that annual average wind speeds of 7 to $9 \mathrm{mph}$ can be adequate for off-grid wind energy applications. 


\section{Wind Speed Class on Yurok Reservation}

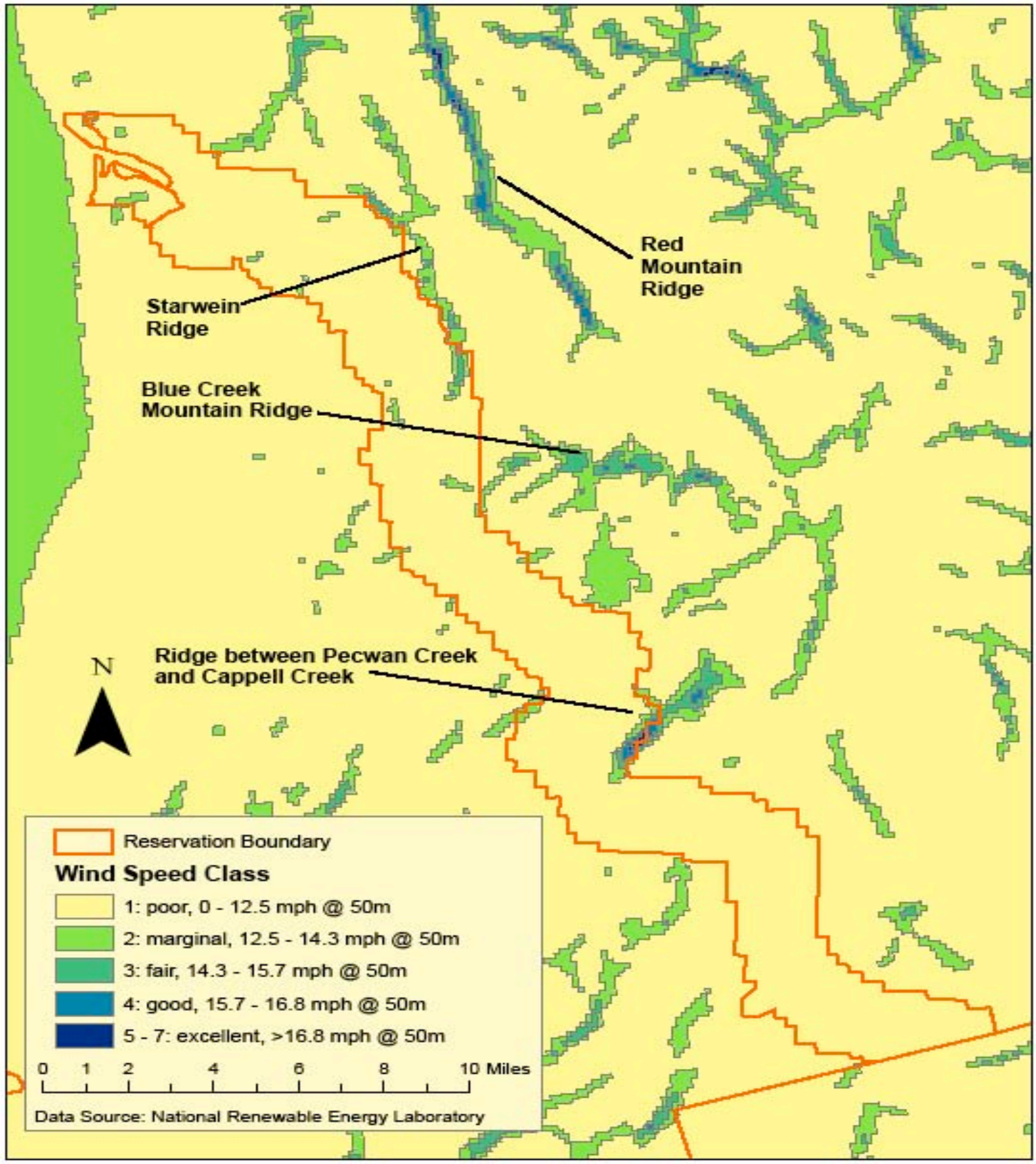

Figure 6. Wind Speed Classes in the Vicinity of the Yurok Reservation 


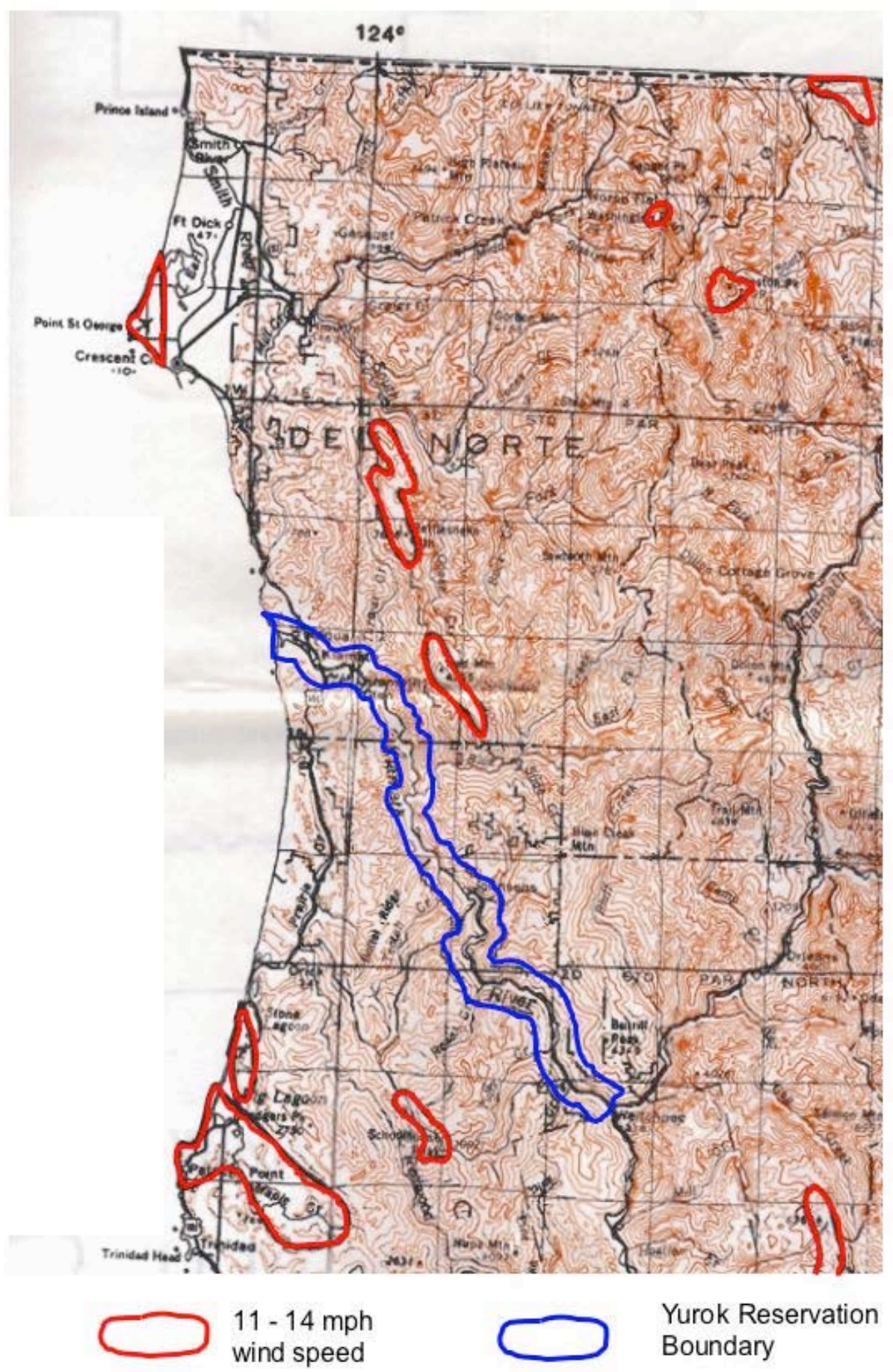

Figure 7. Wind Speed Potential in the Vicinity of the Yurok Reservation Source: California Energy Commission Wind Atlas, April 1985 
Table 2. Wind Data from Sites Near the Yurok Reservation

\begin{tabular}{|c|c|c|c|c|c|c|c|c|}
\hline \multicolumn{9}{|c|}{ Wind Data from Sites Near the Yurok Reservation } \\
\hline County & Station Name & Lat & Long & Elev $(\mathrm{ft})$ & $H t(f t)$ & $\begin{array}{r}\text { Mean WS } \\
(m p h)\end{array}$ & $\begin{array}{r}\text { Dist from Res } \\
(\mathrm{mi})\end{array}$ & $\begin{array}{l}\text { Wind } \\
\text { Class* }\end{array}$ \\
\hline Humboldt & School House Peak LO & 4112 & 12354 & 3090 & & 13.2 & 5 & 4 \\
\hline Humboldt: & Kneeland Prairie & 4044 & 12358 & 2672 & 33 & 10.6 & 34 & 2 \\
\hline Del Norte & Camp Six LO & 4154 & 12354 & 3880 & & 10.1 & 26 & 2 \\
\hline Del Norte & Ship Mountain LO & 4142 & 12348 & 5300 & & 10.1 & 15 & 2 \\
\hline Humboldt: & Brush Mountain LO & 4054 & 12342 & 3990 & & 10 & 19 & 2 \\
\hline Del Norte & Crescent City FAA & 4147 & 12414 & 56 & 26 & 9.4 & 18 & 1 \\
\hline Del Norte & Gasquet RS & 4154 & 12400 & 380 & & 9.4 & 25 & 1 \\
\hline Del Norte & Smith River Hills & 415442 & 1240330 & 2100 & 33 & 7.3 & 24 & 1 \\
\hline Humboldt: & Horse Mountain & 405230 & 1234400 & 4950 & 33 & 7.2 & 21 & 1 \\
\hline Humboldt: & Eureka WBO & 4048 & 12410 & 40 & 90 & 6.9 & 34 & 1 \\
\hline Humboldt & Arcata & 4059 & 12406 & 228 & 45,20 & 6.4 & 23 & 1 \\
\hline Humboldt & Willow Creek & 4106 & 12336 & 460 & & 5.9 & 8 & 1 \\
\hline Humboldt & Arcata CAA & 4054 & 12406 & 226 & & 5.7 & 27 & 1 \\
\hline
\end{tabular}

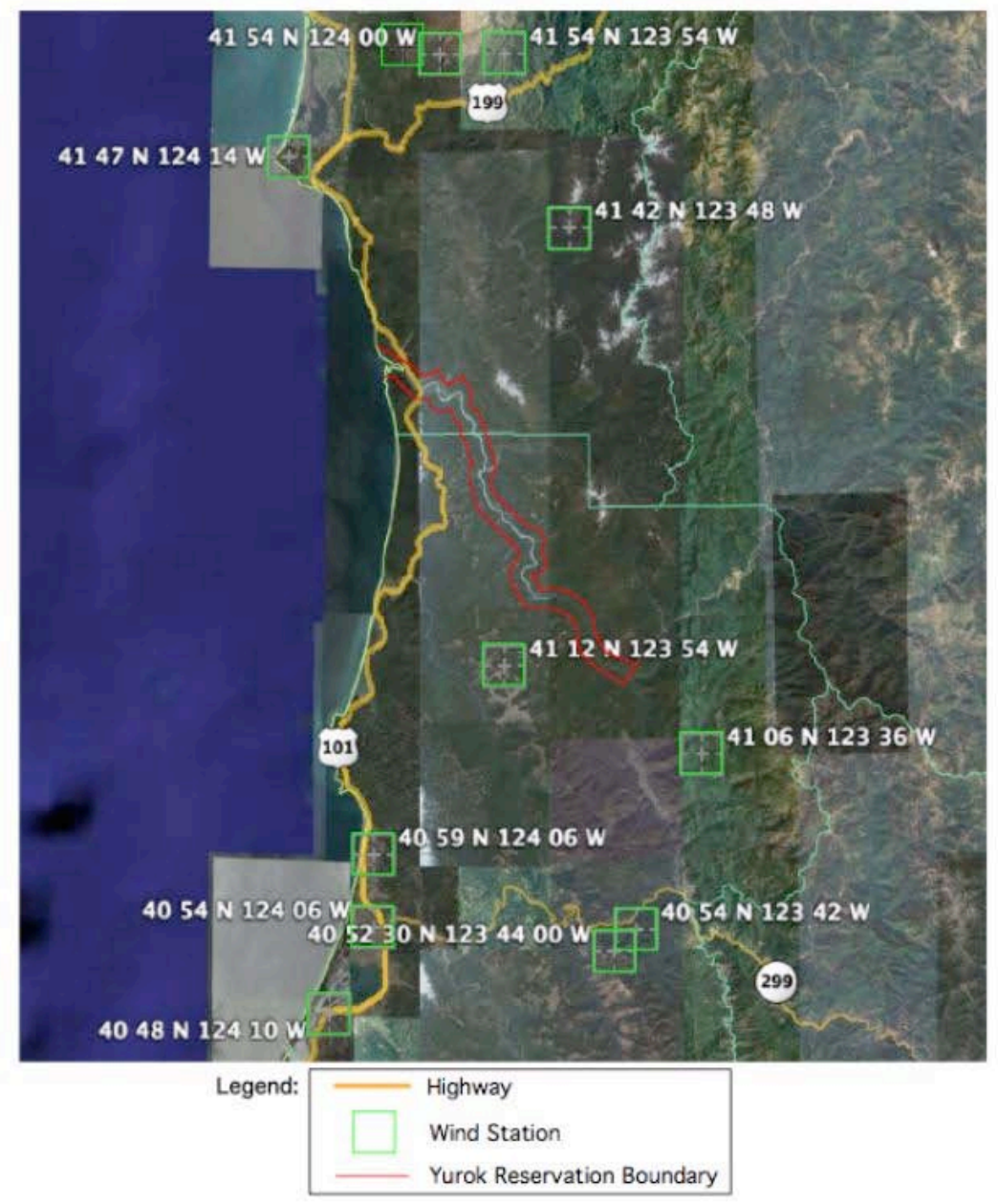

Figure 8. Wind Monitoring Stations in the Vicinity of the Yurok Reservation 


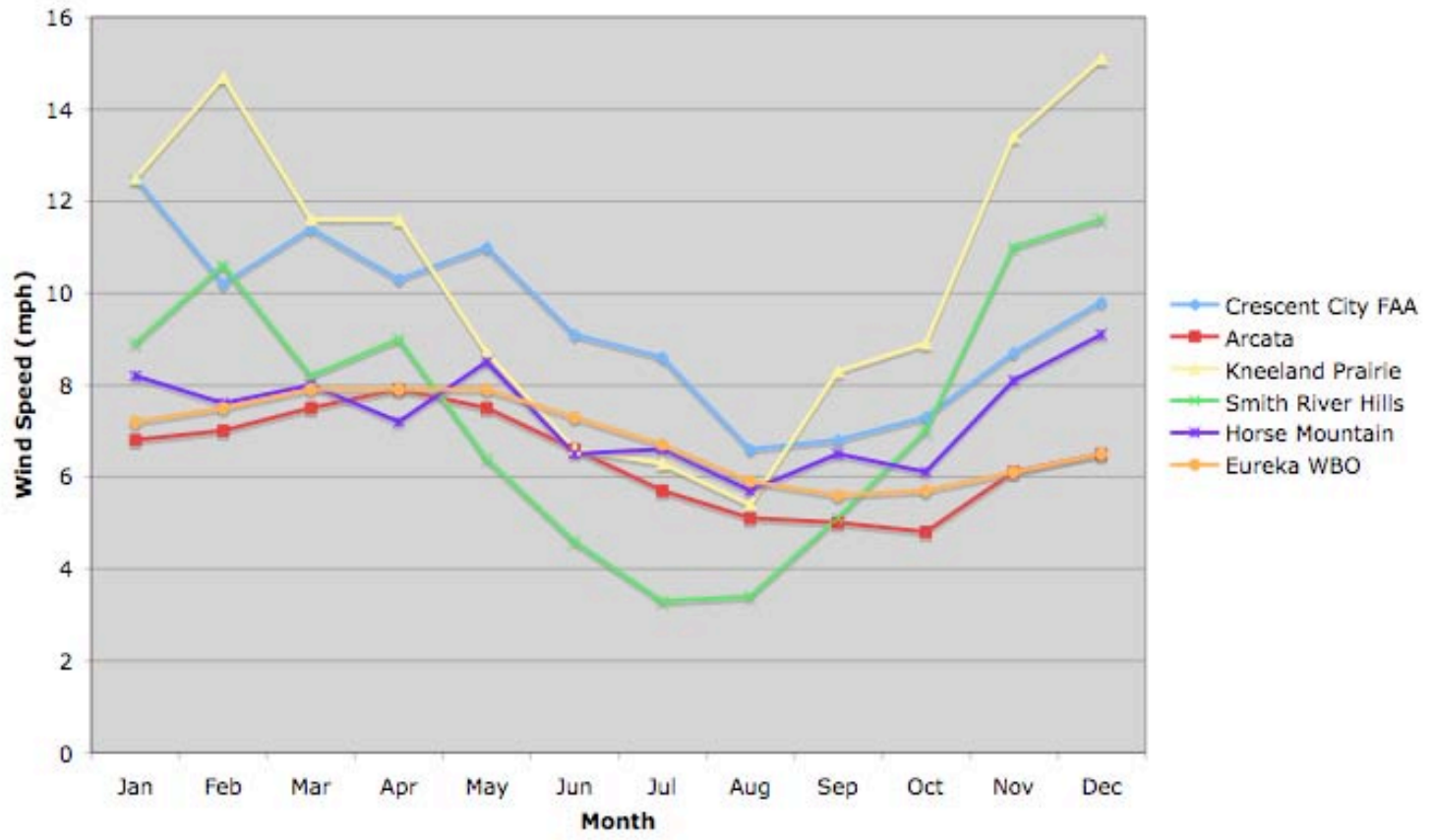

Figure 9. Mean Monthly Wind Speeds from Selected Sites

(Source: California Energy Commission Wind Atlas, April 1985)

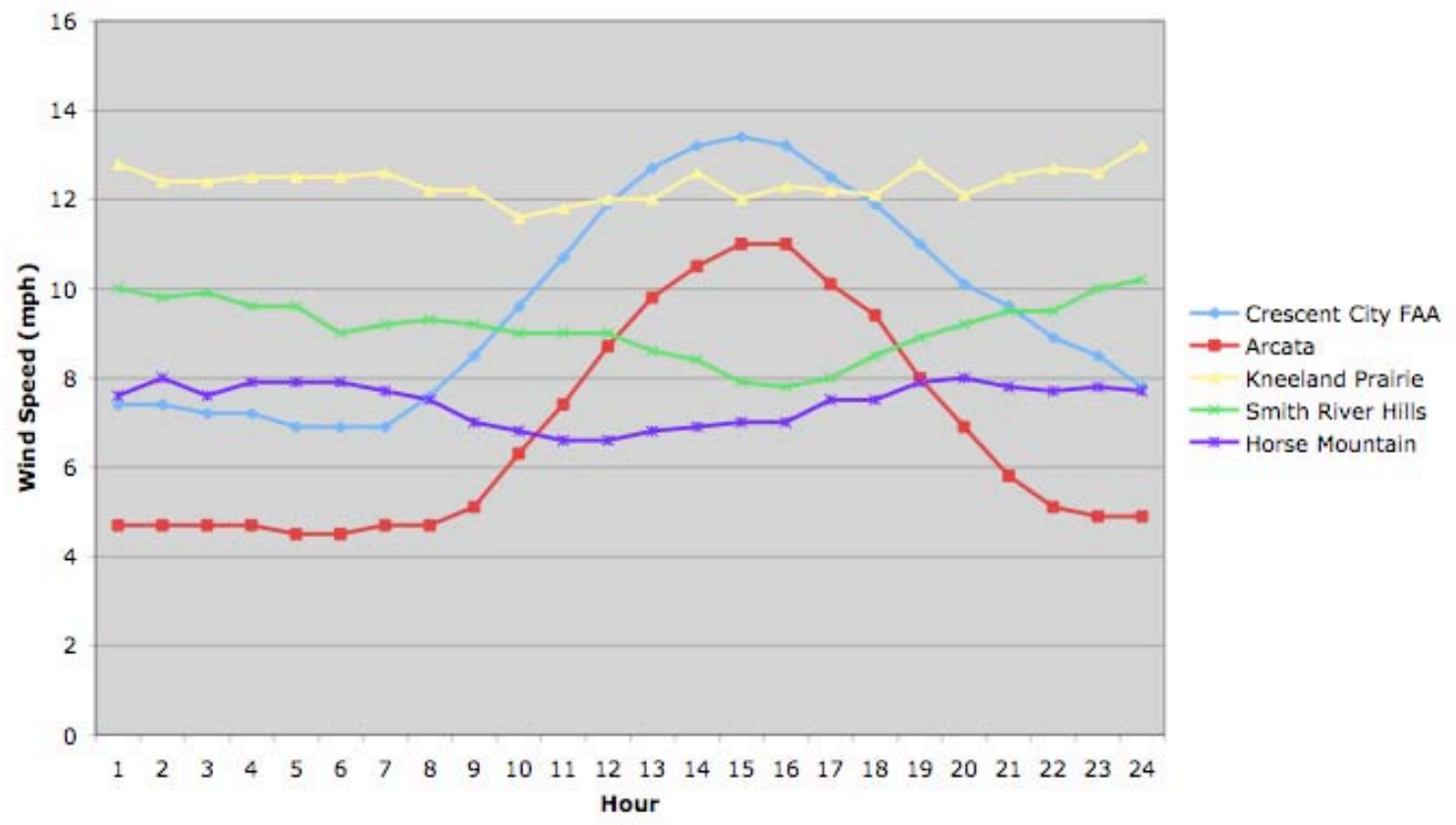

Figure 10. Mean Hourly Wind Speeds from Selected Sites

(Sources: California Energy Commission Wind Atlas, April 1985 and Wind Energy Assessment for Northwestern California: Three Interim Reports, California Energy Commission, June 1982) 


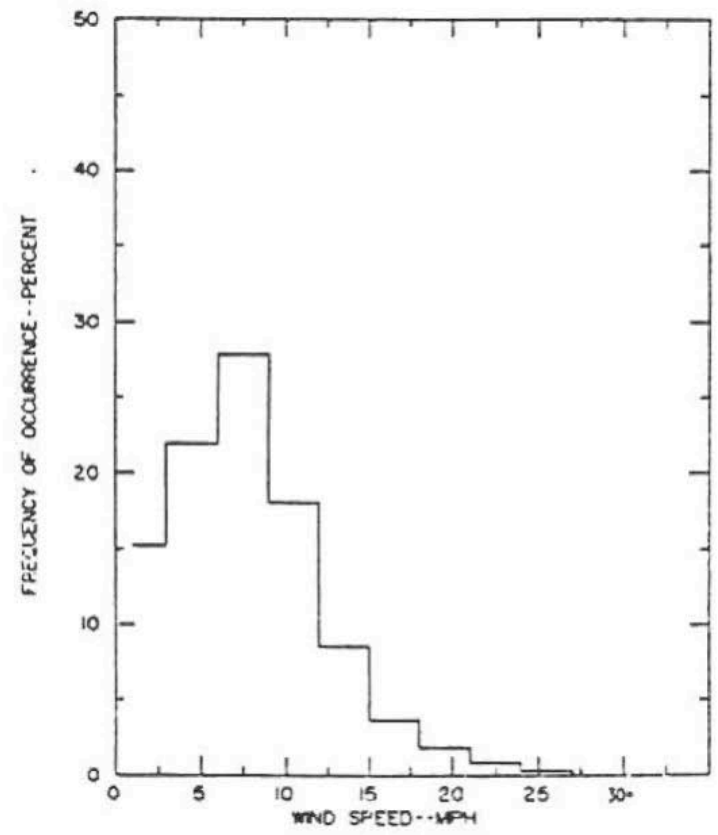

Figure 11. Wind Speed Frequency Distribution for Horse Mountain

(Source: Wind Energy Assessment for Northwestern California: Three Interim Reports, California Energy Commission, June 1982)

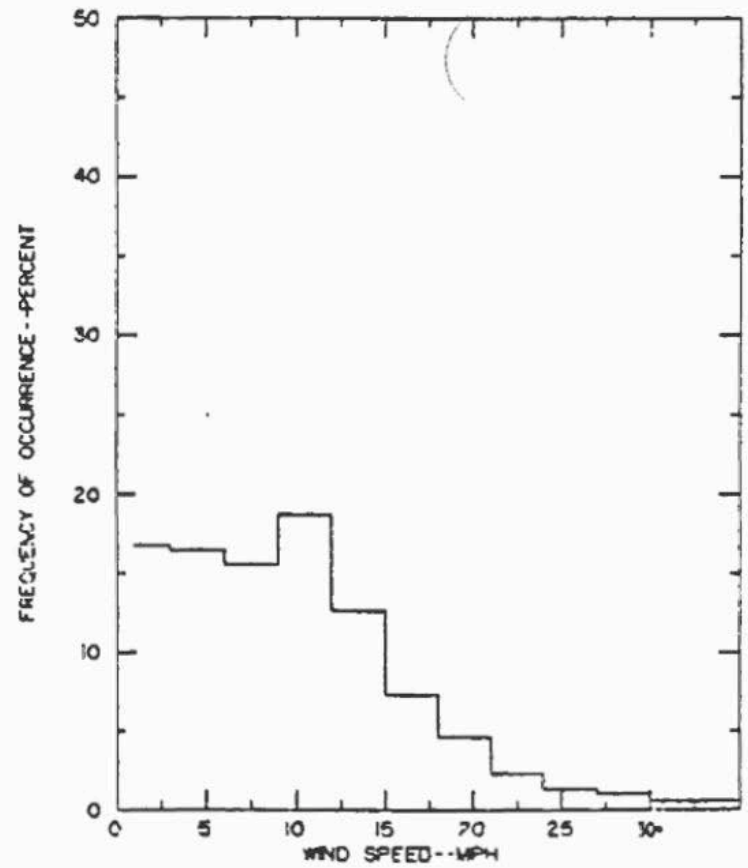

Figure 12. Wind Speed Frequency Distribution for Smith River Hills

(Source: Wind Energy Assessment for Northwestern California: Three Interim Reports, California Energy Commission, June 1982) 


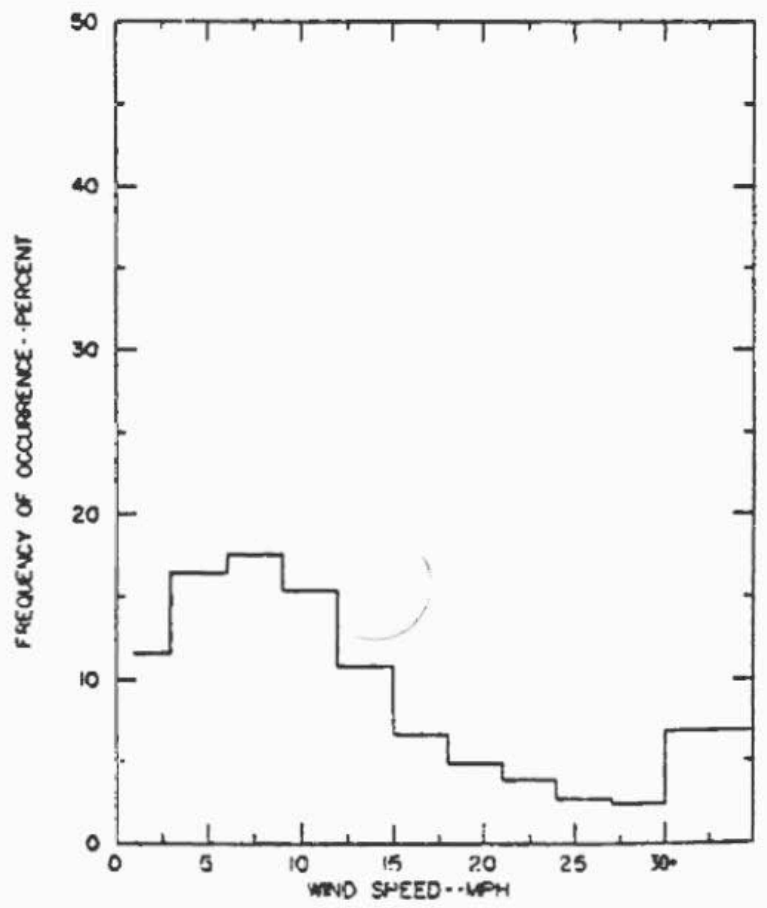

Figure 13. Wind Speed Frequency Distribution for Kneeland Prairie (Source: Wind Energy Assessment for Northwestern California: Three Interim Reports, California Energy Commission, June 1982)

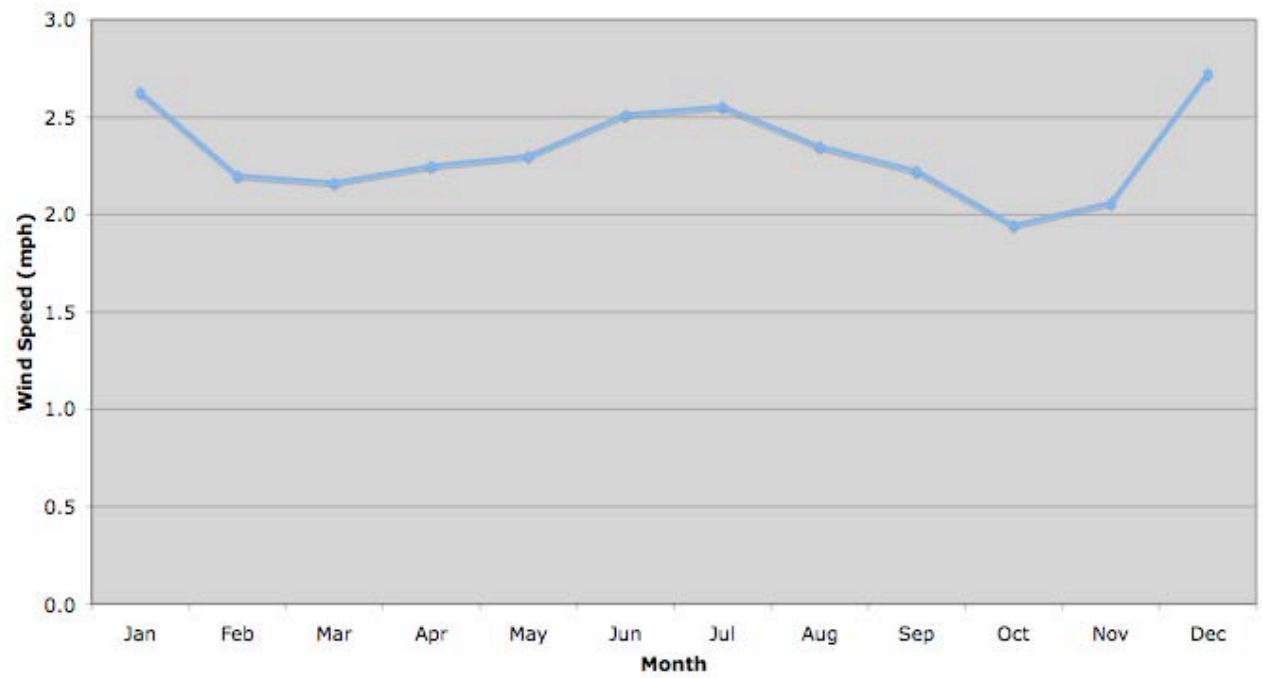

Figure 14. Notchko Average Monthly Wind Speed (Dec. 2002 - June 2006) (Source: Yurok Tribe Environmental Program Real-time Monitoring Program) 


\section{Biomass Energy}

Biomass is a renewable energy source derived from plant material or animal waste. It can include tree and plant crops and forestry, agricultural, and urban wastes. On California's North Coast, biomass resources come primarily from residues generated by the forest products industry. The main sources are mill wastes, residue from timber harvest operations, and material from forest fuels treatment/thinning operations. These biomass sources already contribute significantly to Humboldt County's energy needs, with electricity generated from forest biomass supplying more than $30 \%$ of the county's electricity needs. A substantial amount of biomass is also used in the form of firewood for heating.

Biomass resources can be burned directly to produce heat, or they can be converted into a variety of gaseous, liquid, or solid fuels. When burned, a biomass energy source can deliver heat, electrical power, or combined heat and electrical power. Firewood is already used extensively on the Reservation to provide space heating. The most likely opportunities for new uses of biomass energy on the Yurok Reservation include the production of heat and/or electric power to serve specific facilities (e.g., a Tribal office or school), the production of electricity to serve a village-scale micro-grid, or the production of electricity for sale off the Reservation. The technology is available and the economics can be favorable for these types of projects given the right conditions. The Tribe currently has a proposal pending with the Bureau of Indian Affairs to examine the feasibility of these types of projects on the Reservation.

The 63,000 acre Yurok Reservation is mostly forested, with small percentages of the land occupied by river bar, small prairies, and homesteads. Conifer species are dominant, including Sitka Spruce and Western Hemlock near the river mouth and redwood and Douglas-fir upriver. Hardwood species include red alder near the river mouth, and tanoak, madrone, and mixed oak species upriver. Overall, Douglas-fir is the dominant timber species, making up about $90 \%$ of the total timber volume. The Tribe or its members manage only about 5,000 acres of the reservation as trust or allotment land, with most of the remaining land belonging to Green Diamond Resource Company (formerly Simpson Timber). Most of the reservation lands have been heavily logged over the past half-century. The small amount of remaining old growth forest is concentrated mainly on Tribal lands. Tribal landholdings on the reservation are mixed in a "checkerboard" pattern with non-Tribal fee lands, requiring reciprocal access agreements among the Tribe, Green Diamond, and other landholders. Tribal plots are typically small, ranging from 20 to 200 acres each.

The biomass energy resource potential for the Yurok Tribe is very good. This includes on-Reservation resources, as well as off-Reservation resources in the local vicinity. Humboldt County is the leading timber harvest county in California with more than $20 \%$ of the state's total. According to the National Renewable Energy Laboratory (NREL), Humboldt County, where the majority of the Yurok Reservation lies, produces 200-250 green metric tonnes/km2/year of biomass suitable for energy production (Figure 15). This is the second highest intensity level in NREL's six-level national ranking of U.S. counties' biomass production. 


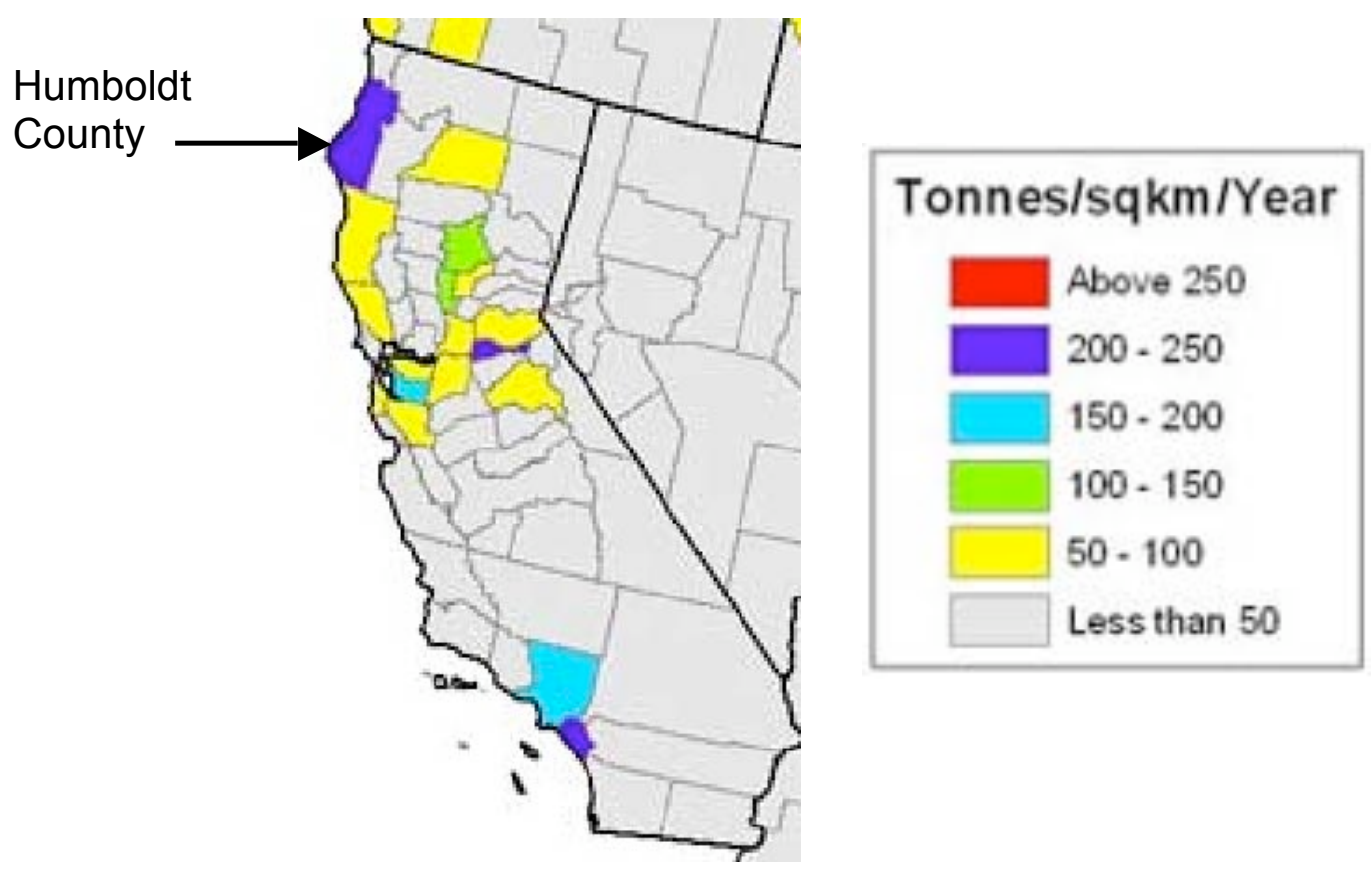

Figure 15. Biomass Resources Available in California (NREL, 2005).

Available biomass resources for the Tribe are likely to be residue from timber harvest operations and material from forest fuels treatment/thinning operations. Biomass resources could come from on the Reservation, or from surrounding private forestlands, Six Rivers National Forest, and Redwood National Park (see Figure 16 for a map showing property ownership status in the vicinity of the Yurok Reservation). Many of these forest land owners are currently pursuing forest fuel reduction efforts.

In 2003, TSS Consultants prepared a preliminary biomass feasibility study for the Tribe. The TSS study estimated that over 12,000 green tons per year would be available from a region within a 25 mile radius of Wautec. Assuming a moisture content of $50 \%$, this resulted in an estimate of 6,000 bone dry tons (BDT) per year. It was estimated that this would be enough fuel for a 700 to $800 \mathrm{~kW}$ biomass electric power facility. This estimate did not include waste from the one saw mill located within a 50 mile haul radius from Wautec, the Simpson Timber Company saw mill in Orick. The mill waste material from this facility is already being sold to existing markets, so it is unlikely that this would be an economical source of fuel. The TSS study assumed that there would be $13 \mathrm{BDT} /$ acre available from forest thinning and fuel reduction efforts. Biomass residues from commercial timber operations were estimated at $900 \mathrm{BDT} /$ million board feet of harvested timber. They used historic timber harvest levels for the four counties that are in the vicinity of the Wautec area (Del Norte, Humboldt, Siskiyou, and Trinity) and assumed that only $1 \%$ of the harvest activities would contribute to the Wautec biomass fuel supply. 
ESRI ArcExplorer 2.0

Land Ownership On and Adjacent To Yurok Reservation

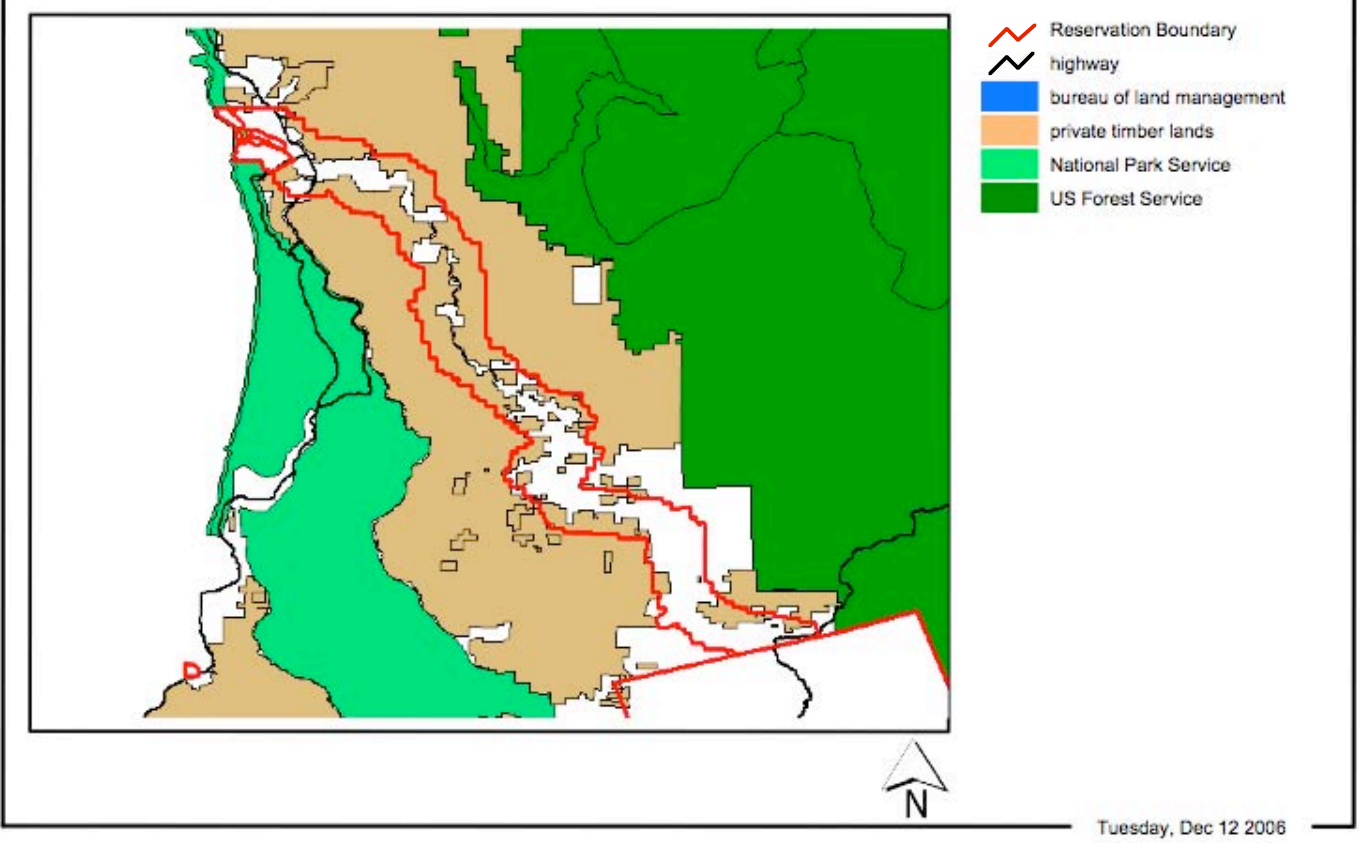

Figure 16. Land Ownership On and Adjacent to the Yurok Reservation (map data from mapcruzin.com)

The USDA Forest Service National Fire Plan Economic Action Program funded the TSS study. The study initially focused on developing a commercial scale, revenue generating biomass power facility to be sited near Klamath, at the downriver end of the Reservation. At the time the study was conducted, the consultant determined there was no willing buyer for the generated power for a grid-connected generator. The study was then realigned to consider a small $(15-50 \mathrm{~kW})$ off-grid biomass facility to provide power and heat for the Jack Norton School in Wautec, which is currently powered by diesel generators. However, this concept was also deemed infeasible for two principal reasons:

1. At the time no biomass-fired generator was commercially available in the desired size range. The smallest available units were sized at 100-200 kW.

2. Compared to replacing the existing diesel generator set, a biomass powered system was not deemed economically viable.

However, many of the conclusions of the TSS report are worth revisiting due to changing conditions that may make biomass energy a more favorable proposition at this time. The changing conditions include:

- At the time of the study, the two major electric utilities in the area were in a state of flux. Pacific Gas and Electric Company was undergoing bankruptcy proceedings, and Pacific Power was on the verge of selling off its California holdings. Since then, the energy industry in California has become relatively stable, and the utilities may be more willing to consider buying power from the 
Tribe. PG\&E has recently taken steps to make it easier for renewable power generators to sell energy to the utility as they work to meet the requirements of California's Renewable Portfolio Standard, which was established in 2002.

- With concern about wildfire on the rise, federal, state and local governments have all instituted programs to more aggressively address forest fuels reduction. Goals to reduce forest fuels are being promulgated in the National Fire Plan (established in 2000) and the President's Healthy Forest Initiative (established in 2002). Forest fuel reduction efforts are currently a major focus of the USDA Forest Service, including the Six Rivers National Forest (SRNF), which is adjacent to the Yurok Reservation. Local fuel reduction efforts are also being promoted as part of the Humboldt County Master Fire Protection Plan.

- Interest in biomass-to-energy conversion is also increasing, and more companies are developing or selling biomass-compatible generators. A preliminary scan of the industry suggests there are more small-scale biomass-fired generators on the market now than there were prior to 2003. Biomass combustion/generators are also available from places like India, where the industry is thriving and units are available in a wide range of capacities.

- The State of California issued a Bioenergy Action Plan in July 2006, calling on the state's Energy Commission and Public Utilities Commission to reduce barriers to the use of bioenergy.

All of these developments make it more likely for a biomass energy project to be viable on the Yurok Reservation. Accordingly, the Tribe has submitted a proposal to the Bureau of Indian Affairs (BIA), Division of Energy and Mineral Development, to conduct a comprehensive biomass energy feasibility study. The proposal received favorable reviews and the BIA indicated they would to fund the proposal, but they do not currently have the funds available. It is possible the project could be funded during a future funding cycle.

Recent data obtained from SRNF indicate the availability of significant biomass resources in the vicinity of the Reservation. SRNF performed fuel treatments on approximately 1400 acres in 2006, plan to treat a similar amount of acreage in 2007, and expect treated acreage to escalate as they expand their fuel reduction efforts. In 2006 the Orleans District of SRNF, which is in close proximity to the Yurok Reservation and encompasses approximately 500,000 acres, saw 114 acres treated and over 3,200 green tons of biomass eliminated (approximately 28 green tons/acre). The material, predominantly Douglas Fir, Tan Oak, and oak species, was predominantly piled by hand or machine and then burned in place. Assuming a moisture content of 50\%, this effort would have generated 1,600 BDT of biomass material. This would be enough fuel to support about a $175 \mathrm{~kW}$ electric generating plant. SRNF is currently proposing to treat an additional 2,900 acres of forest in the Orleans District.

Perhaps the most secure source of potential biomass fuel is the portion that is directly controlled by the Tribe. This would include forest harvest residues from timber harvested as part of the Yurok Forestry Program, as well as biomass from fuel reduction efforts undertaken by the Tribe. The Yurok Tribe's Forestry Program employs seven staff and is 
actively involved in managing timber sales and reforestation/restoration projects on both Tribal and allotment lands, a total of about 5,000 acres. The program also works in wildland fire fighting and prevention, including wildland-urban interface fuels reduction treatments, fuel breaks, roadside brush removal, and early release efforts ${ }^{3}$. The Forestry Program's activities are guided by the Yurok Indian Reservation Forest Management Plan, prepared by consultant Pacific Meridian Resources and last updated in 1996.

Existing conifer volume on Tribal lands is estimated to be 91 million board feet (MMBF), with another $25 \mathrm{MMBF}$ on allotment lands. Current annual harvest levels from Yurok Forestry Program managed lands are about 1.2 MMBF. The amount of slash generated by these operations is not currently being tracked. However, the TSS study stated, "Based upon TSS' experience in this region, it is estimated that approximately 0.9 bone dry tons (BDT) of forest residue (limbs, tops, and sub-merchantable stems) could be generated for each thousand board feet (MBF) of timber harvested." Based on this estimate, approximately 1,100 BDT/year of biomass could be made available from Tribal timber harvest operations. Additional biomass could be made available from early release efforts on lands that have been recently harvested. It is important to note that over $80 \%$ of the acreage managed by the Tribal Forestry Program is in the upriver area of the Reservation above the 20 mile line that delineated the former Klamath River Reservation, and the majority of this land is accessible from Highway 169. This means that transportation of this biomass resource to areas in the upriver section of the Reservation should be practical.

The Tribal Forestry Program is also involved in biomass removal for fire safety and prevention. This includes clearing biomass from around structures in the wildland-urban interface, clearing fire breaks, and clearing brush along roadsides. Brush is cleared in a 100 -foot radius around structures. Most of this material is either piled and burned or hauled away. When desired by the resident, the material can be chipped and scattered; however, this is not always possible because it is hard to get the chipper in to remote locations. The Tribal Forestry Program maintains a fuel break in the Cappell area called the Cappell shaded fuel break. In the fuel break trees are limbed up to six feet high and trees are cleared to a spacing of six feet apart. The removed biomass is lopped and scattered or piled and burned. Finally, roadside brushing involves clearing a $20 \mathrm{ft}$ swath on each side of the road. Overall, it is estimated that the Yurok Tribe Forestry Program treats more than 100 acres per year. Assuming that $13 \mathrm{BDT} /$ acre are made available from these fuel treatments, this would result in 1,300 BDT per year of biomass material.

Table 3 gives estimates of the electricity production and generating capacity that could be supported on the Yurok Reservation from various biomass fuel sources. Note that the biomass resource estimates from the Yurok Tribe Forestry Program and the SRNF Orleans District fuel reduction efforts are independent resources (i.e., these resource estimates are additive). The TSS study estimate includes these other two sources, though

\footnotetext{
${ }^{3}$ Early release efforts involve the removal of biomass brush in areas that have recently been logged in order to promote growth of preferred species. Three to five years after an area has been logged unwanted brush is removed from a five foot radius around young trees that are being encouraged to grow. The unwanted brush is lopped and scattered.
} 
the assumptions used in deriving the TSS study resource estimates are different than those used to develop the other resource estimates shown here.

\section{Table 3. Estimated Biomass Energy Potential on Yurok Reservation ${ }^{4}$}

\begin{tabular}{|l|c|c|c|}
\hline Biomass Fuel Source & BDT/yr & MWh/yr & kW capacity \\
\hline $\begin{array}{l}\text { On and off Reservation sources } \\
\text { within 25 mile radius of Wautec } \\
\text { (TSS study estimate) }\end{array}$ & 6,000 & 4,000 & 660 \\
\hline $\begin{array}{l}\text { Yurok Reservation only (Tribal } \\
\text { Forestry Program operations) }\end{array}$ & 2,400 & 1,600 & 260 \\
\hline $\begin{array}{l}\text { SRNF Orleans District fuel } \\
\text { reduction efforts only }\end{array}$ & 1,600 & 1,100 & 175 \\
\hline
\end{tabular}

It should be noted that Six Rivers National Forest and other local, state, and federal agencies are stepping up efforts to decrease wildfire risk by reducing fuel loadings in the forests and are looking for uses for the newly generated biomass residue. Biomass energy is one area that is getting a lot of attention. There are strong opportunities for collaborative efforts with these groups, as well as for potential funding.

\section{Hydroelectric Energy}

Given the unique geography of the Yurok Reservation, it is natural that the Tribe consider possibilities for developing hydroelectric power on their lands. The Reservation boundaries encompass the lands stretching out one mile on either side of the Klamath River over the nearly fifty miles between the Klamath's confluence with the Trinity River and its mouth at the Pacific Ocean. Nearly fifty creeks enter the Klamath within the Reservation boundaries. However, most of these creeks' headwaters are located off the Reservation, higher up the walls of the Klamath River canyon.

A few homes on the Reservation already make use of hydroelectric power by way of small, off-grid Pelton wheel microhydro systems. These systems are either stand-alone or used in a hybrid configuration with solar power and/or a generator. These small hydropower systems are typically DC with battery storage, a charge controller, an AC inverter, and a dump load such as an electric resistance heater to absorb excess power when the batteries are fully charged.

Hydroelectric power is a sensitive topic for the Yurok community. The Tribe has historically been dependent on salmon runs and other fish species found in the Klamath River. The river and its tributaries are of profound spiritual and cultural importance to the Yurok. Some of the creeks include sacred sites, such as the jump dance area at the mouth of Pecwan Creek, near the center of the Reservation. The Tribe is currently campaigning for the removal of hydropower-generating dams located on the mainstem of the Klamath River upstream of the Reservation. These dams are believed to be one of the major factors in declining salmon runs on the river. Understandably, this issue may cause the Tribe to view proposals for any type of new hydropower development with some

\footnotetext{
${ }^{4}$ Assumes a biomass heat content of 11.5 MMBTU/BDT, an energy conversion efficiency of $20 \%$, and a capacity factor of $70 \%$.
} 
skepticism. Hydroelectric power development of any type and at any scale on the Yurok Reservation must take into account fisheries and cultural issues.

Many of the tributary creeks to the Klamath are important spawning grounds for salmon and other anadromous species. However, the steep gradients and natural barriers in these creeks mean that anadromous fish may only be found in the lower reaches of many of the creeks. We met with Tribal fisheries specialist Dan Gale to discuss fish habitat implications of hydro power development. Dan is generally supportive of hydro as an energy source for the Tribe if fisheries concerns are addressed. In general he favors development of the shorter, steeper drainages entering the Klamath on its eastern bank, as these streams tend to have natural fish barriers quite low in their drainages. In particular, Dan identified, Pecwan, Cappell, and Ma Wah Creeks as drainages where fisheries concerns would be minimal above their lower reaches. Dan also expressed concern about the timing of water diversions. He suggested that hydro projects might have to reduce or even halt diversions during late summer and fall to maintain needed instream flows.

Determining which creeks should be developed is a complex process that must take into account:

- the energy resource available at each creek,

- the proximity and size of electric loads in the area,

- proximity to existing or planned power infrastructure,

- potential environmental impacts associated with the specific creek.

Hydroelectric power is a function of both flow rate and elevation head. Flow rate is in turn dependent on the size of the catchment area, local climate including rainfall and snowpack, and physical characteristics of the watershed such as vegetation cover, soils and geology. Hydrologists Waananen and Crippen developed a model for predicting peak runoff events that uses area, precipitation, and altitude data. The model uses a set of equations specific to each region of California with empirically derived multipliers and exponents based on watershed characteristics typical to that region. We used the California North Coast Region equation set and ArcInfo software to predict peak flows for each creek. Peak flows are not adequate to predict yearly energy production, but they do allow us to rank the creeks in terms of their expected relative runoff levels.

Table 4 shows rankings of 52 creeks and major creek forks on the Reservation according to:

- basin area;

- peak flow;

- stream gradient;

- potential head (as measured between two reference points used in the Waananen and Crippen model); and

- average rainfall over each basin.

Figures 17, 18, 19, 20 and 21 show rankings for the creeks that fall in the top 20 for each of these categories. 


\section{Table 4. Creeks on Yurok Reservation Ranked by Multiple Criteria}

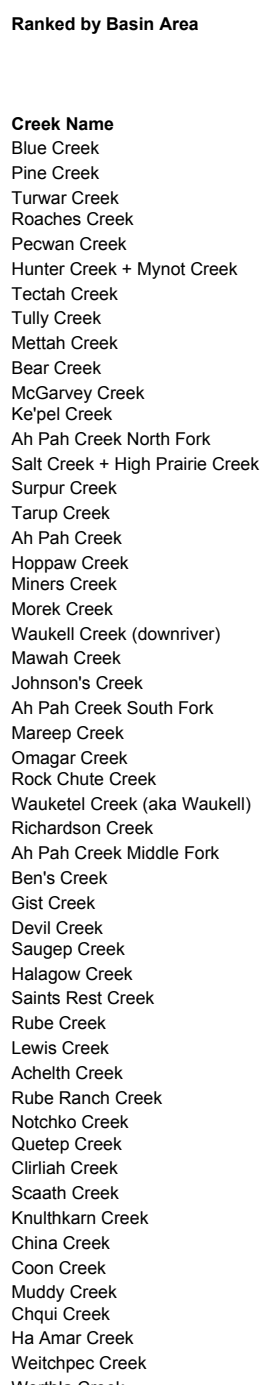

\begin{tabular}{|c|c|}
\hline \multirow{3}{*}{$\begin{array}{r}\text { aasin area } \\
(\mathrm{mi} 2)\end{array}$} & |Ranked By Peak Flow \\
\hline & \\
\hline & Creek Name \\
\hline 125.52 & Blue Creek \\
\hline 49.08 & Hunter Creek + Mynot Creek \\
\hline 31.8 & Pine Creek \\
\hline 29.34 & Roaches Creek \\
\hline 27.5 & Turwar Creek \\
\hline 23.43 & Pecwan Creek \\
\hline 19.84 & Tectah Creek \\
\hline 17.6 & McGarvey Creek \\
\hline 10.09 & Tully Creek \\
\hline 9.18 & Ah Pah Creek North Fork \\
\hline 8.85 & Mettah Creek \\
\hline 8.5 & Bear Creek \\
\hline 6.7 & Salt Creek + High Prairie Creek \\
\hline 5.9 & Tarup Creek \\
\hline 5.77 & Waukell Creek (downriver) \\
\hline 5.07 & Ke'pel Creek \\
\hline 4.87 & Surpur Creek \\
\hline 4.33 & Hoppaw Creek \\
\hline 4.17 & Ah Pah Creek \\
\hline 4.04 & Morek Creek \\
\hline 3.2 & Richardson Creek \\
\hline 3.09 & Miners Creek \\
\hline 2.87 & Johnson's Creek \\
\hline 2.48 & Omagar Creek \\
\hline 2.44 & Ah Pah Creek South Fork \\
\hline 2.25 & Mawah Creek \\
\hline 1.95 & Mareep Creek \\
\hline 1.78 & Ah Pah Creek Middle Fork \\
\hline 1.65 & Saugep Creek \\
\hline 1.64 & Wauketel Creek (aka Waukell) \\
\hline 1.34 & Rock Chute Creek \\
\hline 1.27 & Devil Creek \\
\hline 1.1 & Halagow Creek \\
\hline 1.09 & Gist Creek \\
\hline 1.08 & Ben's Creek \\
\hline 0.99 & Achelth Creek \\
\hline 0.88 & Saints Rest Creek \\
\hline 0.78 & Knulthkarn Creek \\
\hline 0.77 & Notchko Creek \\
\hline 0.73 & Clirliah Creek \\
\hline 0.69 & Rube Creek \\
\hline 0.65 & Scaath Creek \\
\hline 0.65 & Lewis Creek \\
\hline 0.61 & Quetep Creek \\
\hline 0.58 & Rube Ranch Creek \\
\hline 0.56 & Coon Creek \\
\hline 0.55 & China Creek \\
\hline 0.53 & Muddy Creek \\
\hline 0.39 & Ha Amar Creek \\
\hline 0.36 & Chqui Creek \\
\hline 0.25 & Worthla Creek \\
\hline
\end{tabular}

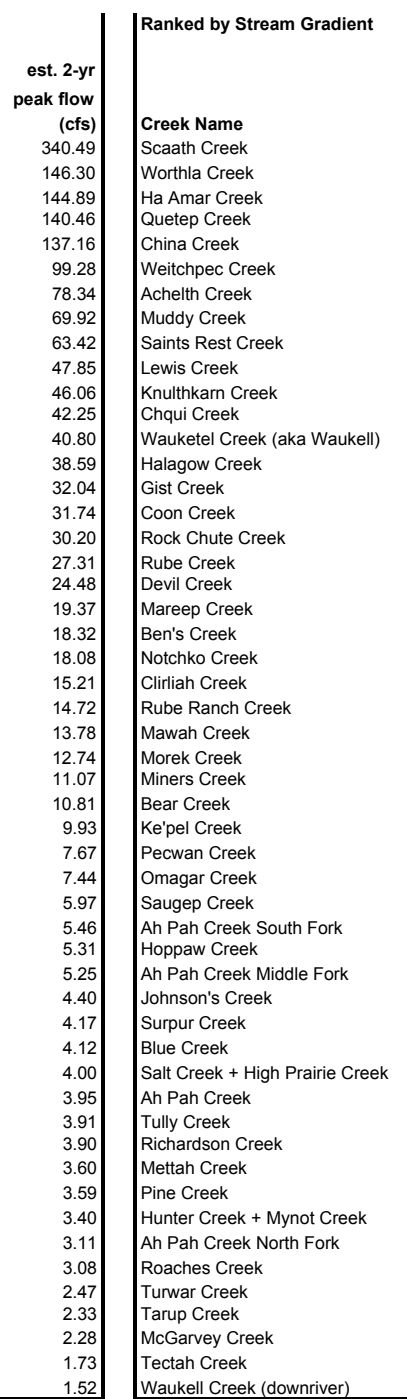

\begin{tabular}{|c|c|}
\hline & Ranked by Potential Head \\
\hline $\begin{array}{r}\text { stream } \\
\text { gradient }\end{array}$ & \\
\hline $\begin{array}{r}\text { gradient } \\
(\%)\end{array}$ & \\
\hline $44.19 \%$ & Blue Creek \\
\hline $40.40 \%$ & Pecwan Creek \\
\hline $39.98 \%$ & Rock Chute Creek \\
\hline $36.30 \%$ & Ben's Creek \\
\hline $35.65 \%$ & Gist Creek \\
\hline $31.08 \%$ & Mawah Creek \\
\hline $30.57 \%$ & Lewis Creek \\
\hline $28.41 \%$ & Bear Creek \\
\hline $27.66 \%$ & Mareep Creek \\
\hline $27.36 \%$ & China Creek \\
\hline $27.06 \%$ & Wauketel Creek (aka Waukell) \\
\hline $26.94 \%$ & Saints Rest Creek \\
\hline $26.40 \%$ & Achelth Creek \\
\hline $25.25 \%$ & Quetep Creek \\
\hline $25.25 \%$ & Ke'pel Creek \\
\hline $25.25 \%$ & Morek Creek \\
\hline $24.38 \%$ & Halagow Creek \\
\hline $24.15 \%$ & Rube Creek \\
\hline $23.85 \%$ & Scaath Creek \\
\hline $23.31 \%$ & Pine Creek \\
\hline $22.81 \%$ & Miners Creek \\
\hline $22.45 \%$ & Rube Ranch Creek \\
\hline $22.10 \%$ & Ha Amar Creek \\
\hline $21.96 \%$ & Coon Creek \\
\hline $20.52 \%$ & Muddy Creek \\
\hline $16.34 \%$ & Devil Creek \\
\hline $14.85 \%$ & Notchko Creek \\
\hline $14.35 \%$ & Chqui Creek \\
\hline $13.23 \%$ & Weitchpec Creek \\
\hline $13.06 \%$ & Worthla Creek \\
\hline $11.66 \%$ & Hoppaw Creek \\
\hline $10.40 \%$ & Knulthkarn Creek \\
\hline $10.10 \%$ & Tully Creek \\
\hline $9.47 \%$ & Johnson's Creek \\
\hline $9.47 \%$ & Clirliah Creek \\
\hline $9.30 \%$ & Turwar Creek \\
\hline $7.58 \%$ & Surpur Creek \\
\hline $6.71 \%$ & Ah Pah Creek South Fork \\
\hline $4.73 \%$ & Omagar Creek \\
\hline $4.59 \%$ & Ah Pah Creek Middle Fork \\
\hline $4.53 \%$ & Hunter Creek + Mynot Creek \\
\hline $4.46 \%$ & Roaches Creek \\
\hline $3.73 \%$ & Mettah Creek \\
\hline $3.44 \%$ & Salt Creek + High Prairie Creek \\
\hline $3.23 \%$ & Tectah Creek \\
\hline $3.22 \%$ & Saugep Creek \\
\hline $3.08 \%$ & Ah Pah Creek North Fork \\
\hline $3.06 \%$ & Tarup Creek \\
\hline $3.03 \%$ & Ah Pah Creek \\
\hline $2.30 \%$ & McGarvey Creek \\
\hline $1.94 \%$ & Richardson Creek \\
\hline $1.68 \%$ & Waukell Creek (downriver) \\
\hline
\end{tabular}

\begin{tabular}{r|} 
\\
potential \\
head \\
(H85-H10) \\
4600 \\
3000 \\
2800 \\
2800 \\
2800 \\
2600 \\
2600 \\
2500 \\
2400 \\
2400 \\
2300 \\
2300 \\
2300 \\
2300 \\
2200 \\
2200 \\
2200 \\
2200 \\
2100 \\
2000 \\
2000 \\
2000 \\
1900 \\
1800 \\
1800 \\
1700 \\
1600 \\
1600 \\
1600 \\
1600 \\
1500 \\
1500 \\
1400 \\
1400 \\
1400 \\
1200 \\
1200 \\
1200 \\
1200 \\
1200 \\
1100 \\
1000 \\
900 \\
900 \\
800 \\
700 \\
600 \\
600 \\
600 \\
400 \\
300 \\
200 \\
\hline
\end{tabular}




\section{Yurok Creeks Ranked by Basin Area}

(20 largest basins shown)

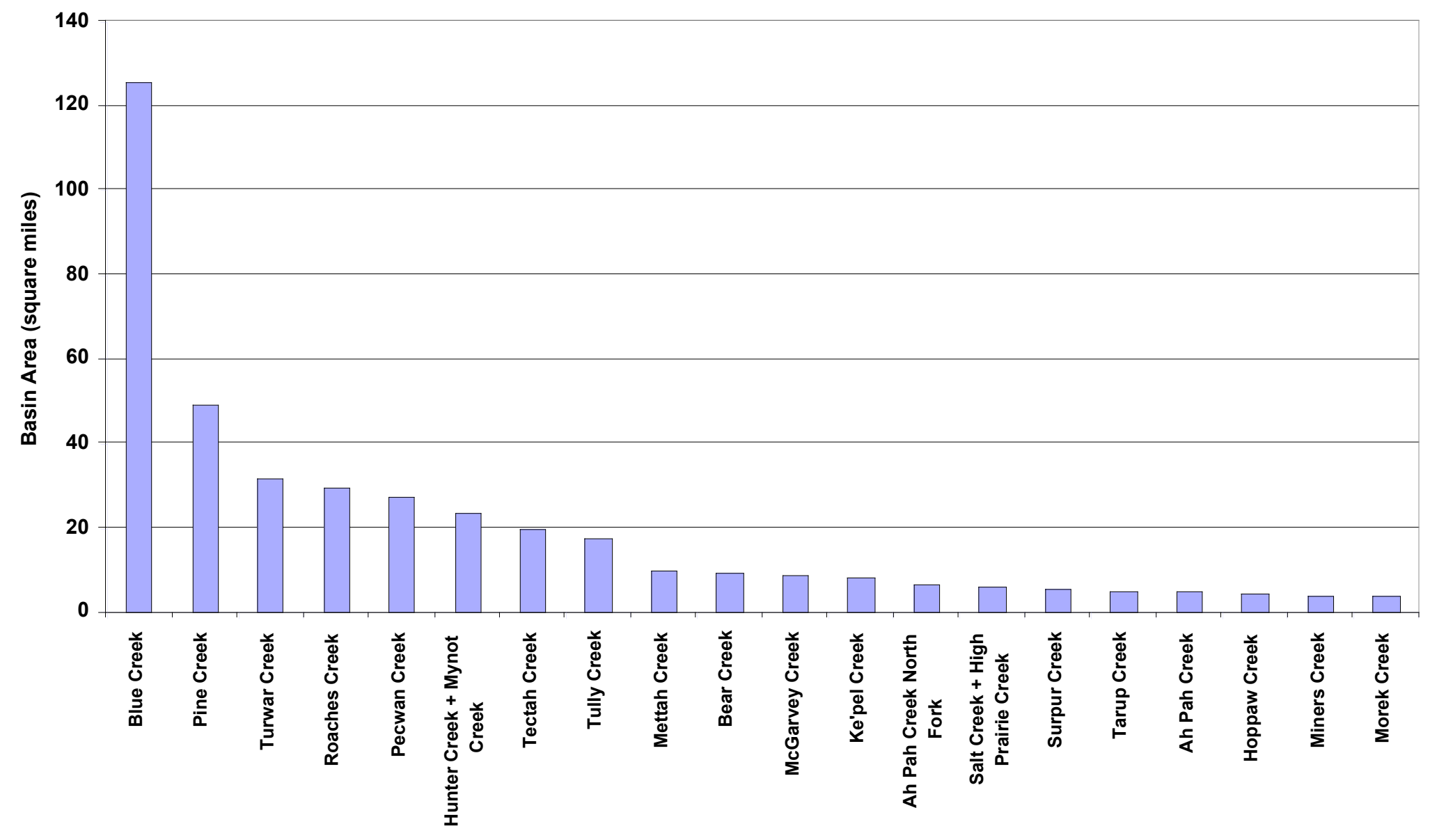

Figure 17. Yurok Creeks Ranked by Basin Area 


\section{Yurok Creeks Ranked by Peak Flow}

(20 highest peak flows shown)

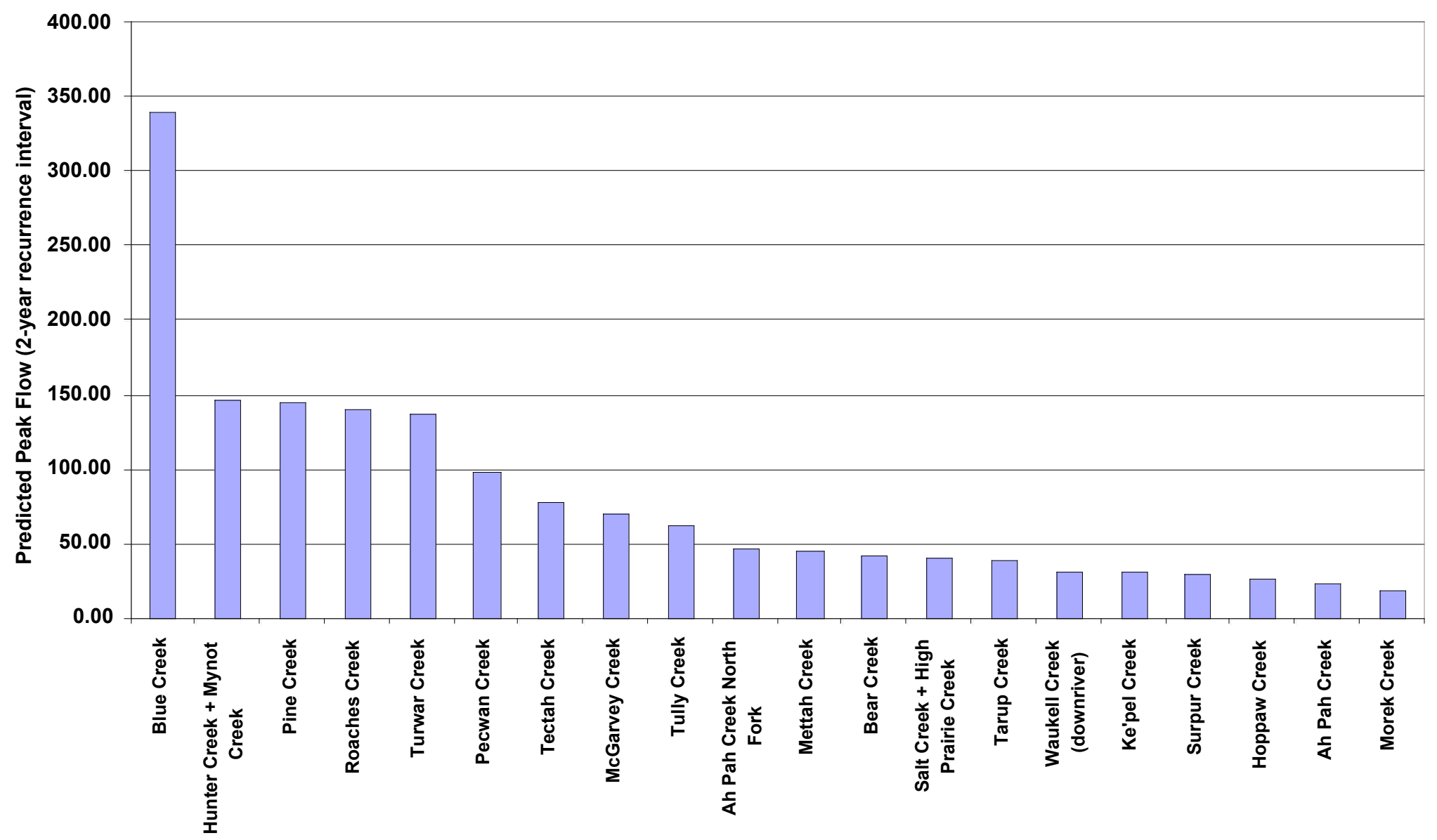

Figure 18. Yurok Creeks Ranked by Peak Flow 
Yurok Creeks Ranked by Stream Gradient

(20 steepest creeks shown)

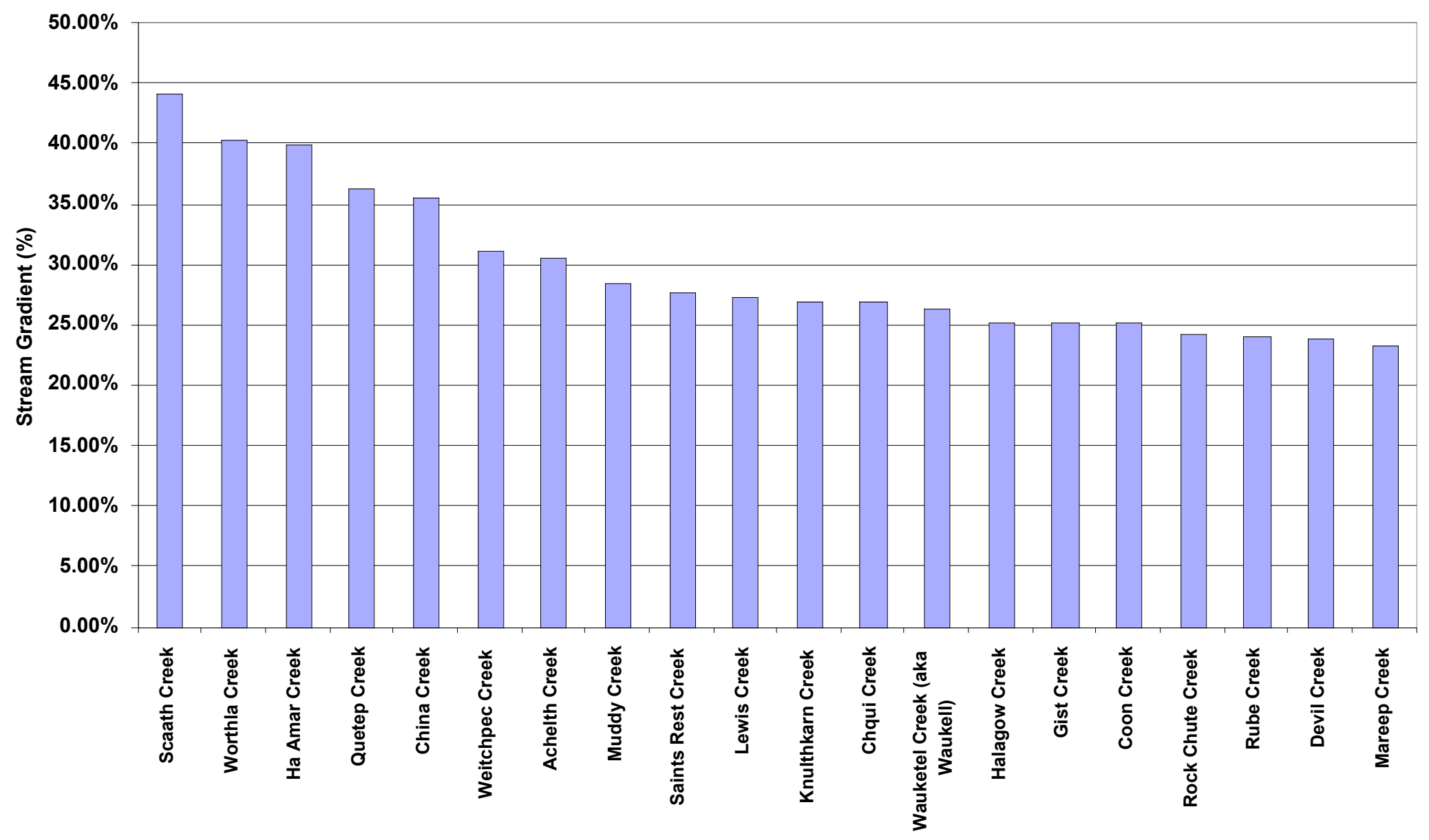

Figure 19. Yurok Creeks Ranked by Stream Gradient 


\section{Yurok Creeks Ranked by Potential Head}

(20 greatest elevation heads shown)

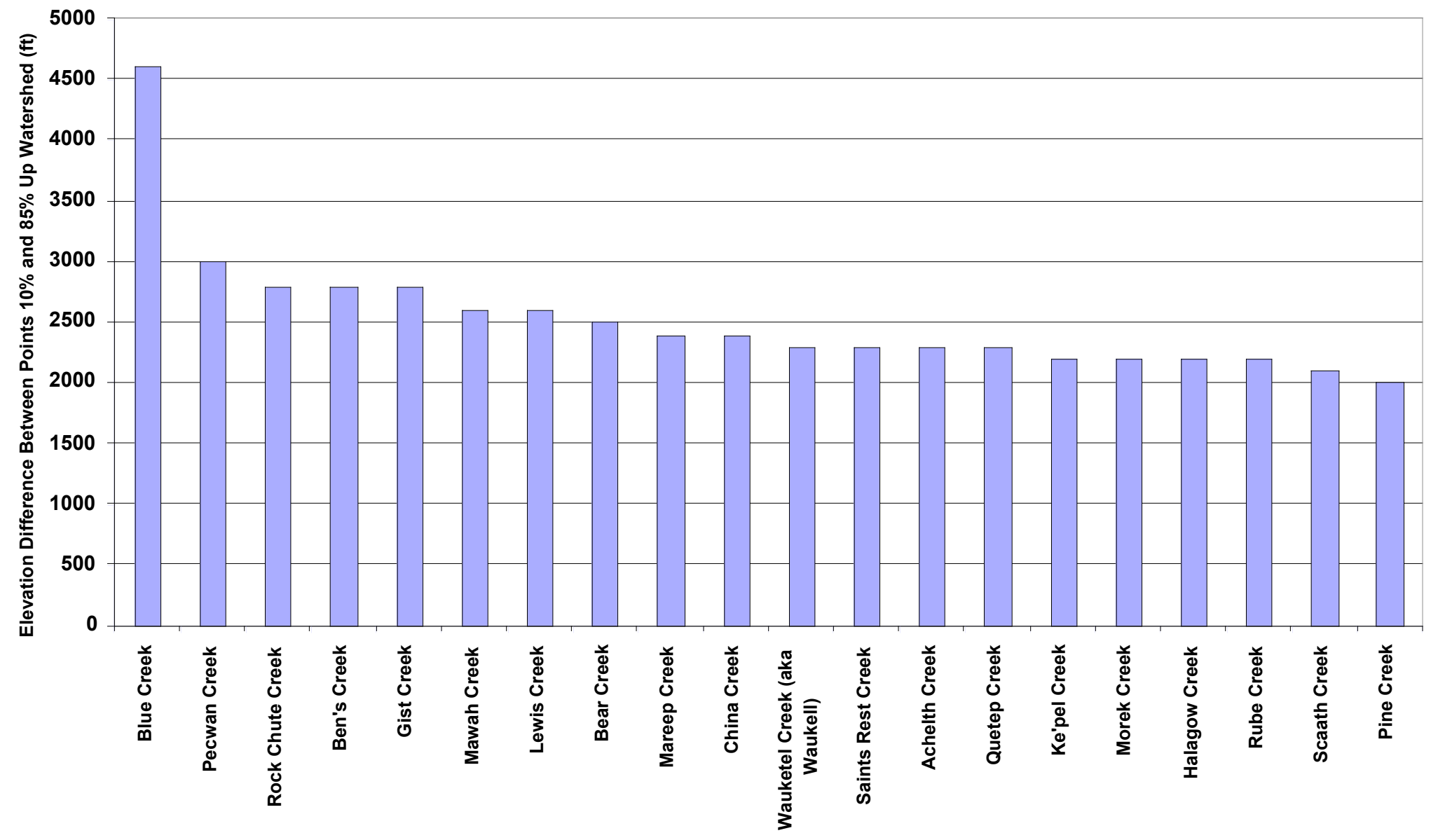

Figure 20. Yurok Creeks Ranked by Potential Head 


\section{Yurok Creeks Ranked by Rainfall}

(20 rainiest creeks shown)

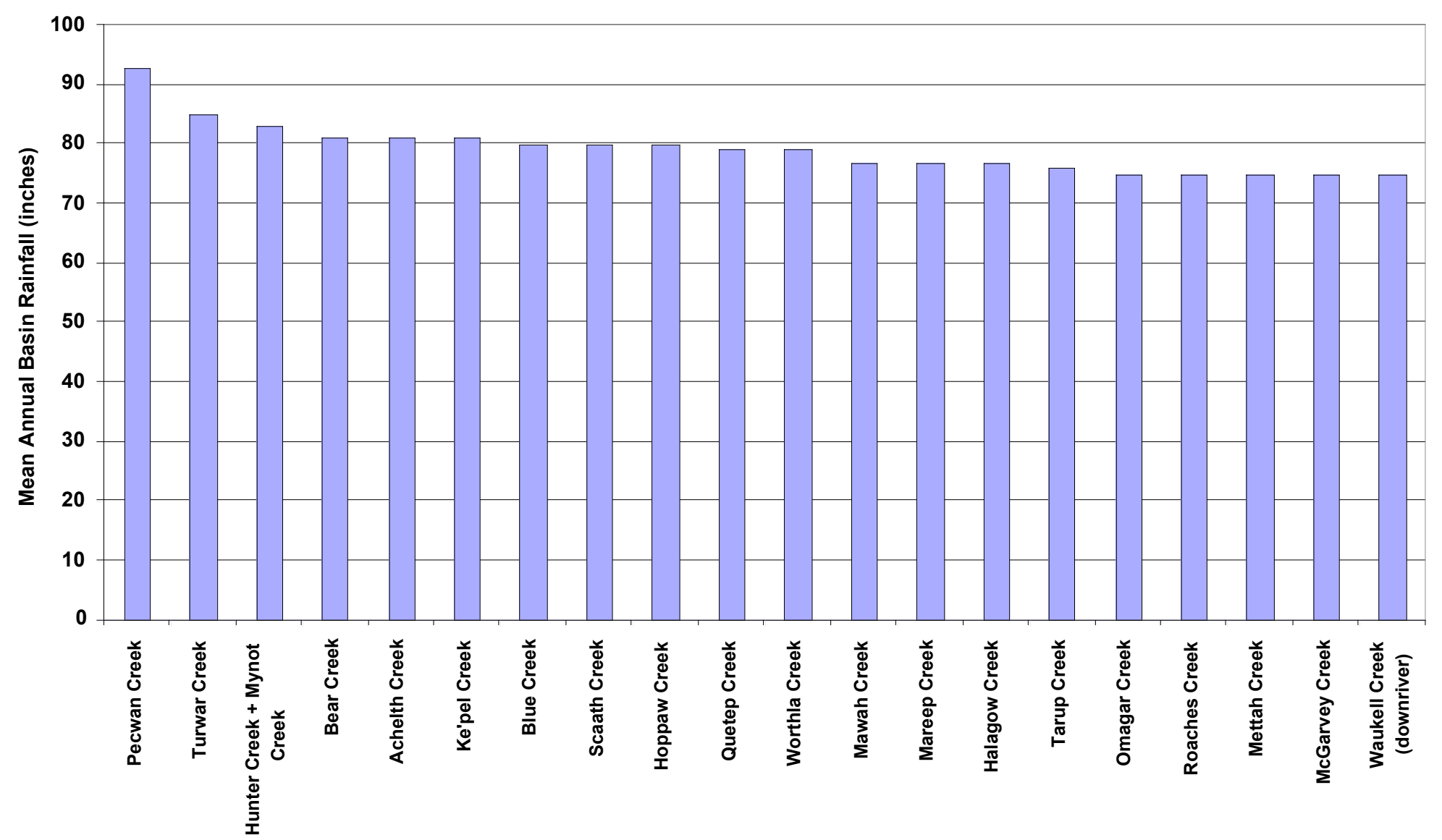

Figure 21. Yurok Creeks Ranked by Rainfall 
Figure 22 shows a sample map focusing on one of the streams, Moreck Creek. Separate GIS map layers show the creek channel, the Reservation boundary, the creek watershed boundary, elevation contours, and precipitation contours. Also shown are two elevation reference points used in the Waananen and Crippen model, which are located $10 \%$ and $85 \%$ of the way along a straight line connecting the creek mouth and the farthest ridge top at the headwaters of the creek. The elevations of these points were also used to rank the creeks according to their potential head.

In general, basin size is the single best indicator of predicted flow. The very large watersheds such as Blue Creek and Pine Creek can be expected to yield the highest flows. These large basins also tend to offer a large total head. However, given the long distances from ridge top to creek mouth (over 20 miles in the case of Blue Creek), it is not feasible to take advantage of the full potential head. Smaller, steeper watersheds such as Lewis Creek or Rock Chute Creek offer substantial head over a much shorter horizontal distance (on the order of two to three miles), making it more economically feasible to construct a diversion and penstock. Note, however, that there is almost an inverse relationship between stream gradient and predicted peak flow, i.e. the steepest creeks tend to have small basins and generate the lowest discharge rates.

These head and flow criteria analyzed in the Waananen and Crippen model are helpful in making a rapid comparison of the creeks on the Reservation and perhaps eliminating those with the least potential for development. Determining which creeks should ultimately be developed and in what manner is much more complex, and must take into account other factors such as economics, environmental and cultural impacts, and the geography, demographics and infrastructure of the Reservation. These analyses must be done on a case-by-case basis for each of the most promising creeks.

However, as an additional exercise to infer power generation potential using the limited available data, we performed the following analysis:

- For the three creeks for which multi-year flow data are available (McGarvey, Blue and Turwar Creeks), we determined the ratio of average measured yearround flow to the two-year peak flow derived from the hydrologic model.

- We used the mean of these three ratios as a scaling factor to estimate mean annual flow on all the other creeks based on their predicted two-year peak flows.

- We assumed diverted flow would be $50 \%$ of average flow.

- We estimated net generating head for each creek by assuming net head is $85 \%$ of gross head, and gross head is $20 \%$ of the elevation difference between the two control points used in the hydrologic model to estimate the average elevation of each stream channel. 
Hydropower Analysis for Moreck Creek

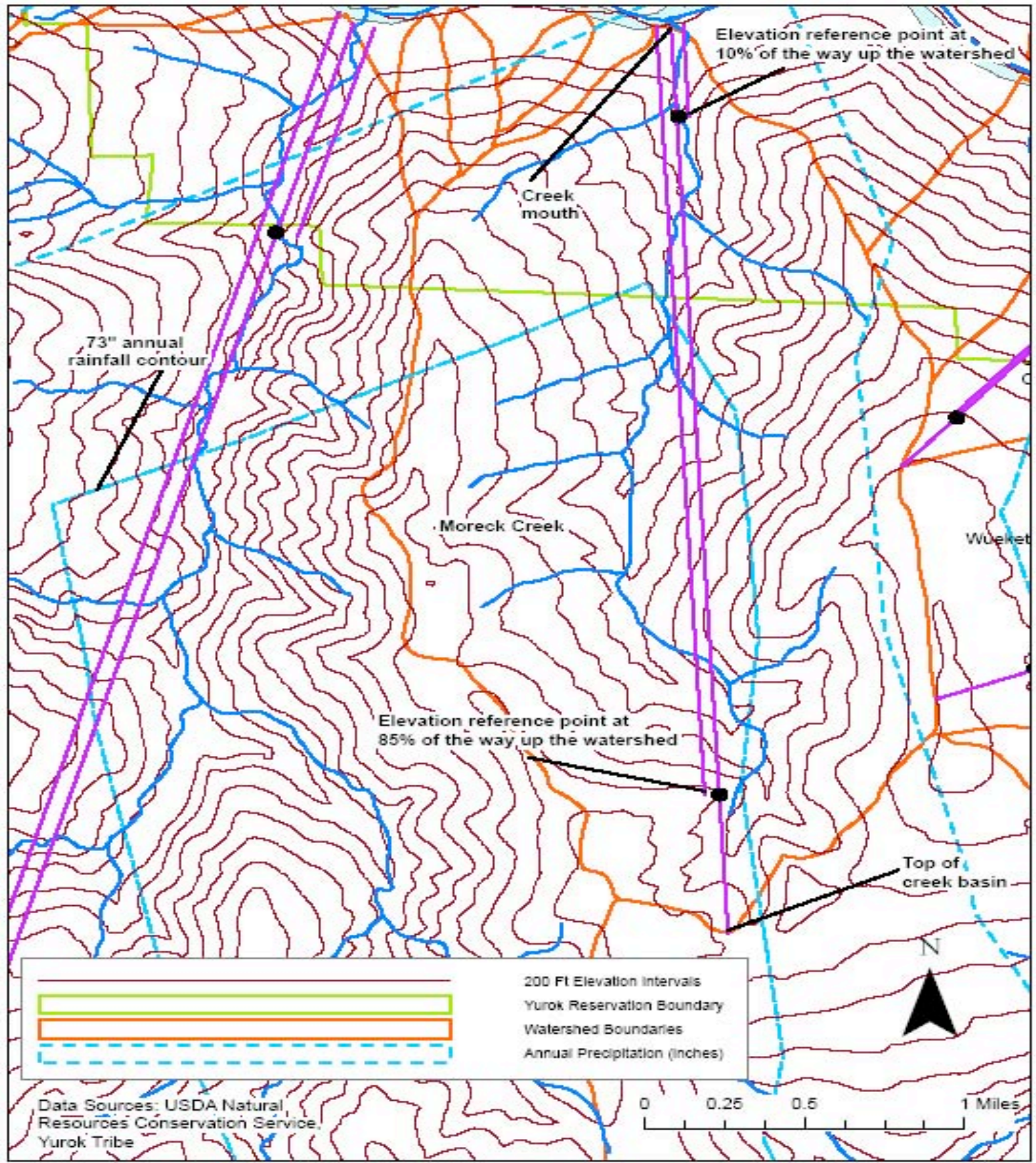

Figure 22. Sample Map Showing Parameters Used in GIS Watershed Analysis 
Using these steps and assumptions, we estimated the power and energy potentials shown in Table 5. The estimated power generation potential for all 52 streams studied is approximately $18 \mathrm{MW}$, yielding some 150 million $\mathrm{kWh}$ per year. By comparison, the six existing dams on the mainstem of the Klamath River have a total capacity of approximately $151 \mathrm{MW}$. Keep in mind that the estimates for the creeks' potential are based on the hypothetical situation in which all of the streams are developed for hydropower. As our study makes clear, there are numerous good reasons why this should not and will not happen. Nonetheless, we believe it is useful to get a sense of scale by estimating the Reservation-wide hydropower potential.

Table 5. Broad Estimates of Power and Energy Potential On Yurok Streams

\begin{tabular}{|l|r|r|c|}
\hline Streams examined & 52 & & \\
\hline Total of All Creeks & Power (kW) & $\begin{array}{r}\text { Energy } \\
\text { (kWh/year) }\end{array}$ & Creek \\
\hline Creek w/ Maximum Potential & 17,895 & $156,756,315$ & -- \\
\hline Creek w/ Minimum Potential & 7,737 & $67,779,371$ & Blue Creek \\
\hline Average of All Creeks & 12 & 105,448 & Weitchpec Creek \\
\hline
\end{tabular}

A critical factor in designing hydroelectric systems is the yearly minimum flow for the creek of interest. A stand-alone hydro system's dependable year-round capacity will be a function of this minimum flow, minus whatever flow must be kept in the dewatered reach of the creek to minimize environmental impact. In November 2006, just prior to the beginning of the winter rainy season, our project team made a one-day field survey of most of the creeks located between Weitchpec and Wautec to gain a sense of these annual low flows. Our observations are summarized in Table 6.

\section{Table 6. Single Day Low Flow Estimates}

\begin{tabular}{|c|c|c|c|c|c|c|c|c|}
\hline Creek & Time & Lat & Long & Method & Flow (GPM) & Flow (CFS) & Weather & Comments \\
\hline Weitchpec & $10: 30 \mathrm{AM}$ & 41.18916 & 123.70924 & $\mathrm{~N} / \mathrm{A}$ & dry & & mostly clear & \\
\hline Gist & 10:35 AM & 41.19211 & 123.71445 & bucket & 309 & 0.69 & mostly clear & $\begin{array}{l}\text { split stream into } 3 \text { channels \& added flows, added } \\
10 \% \text { for uncaptured flow }\end{array}$ \\
\hline Bens & $11: 09 \mathrm{AM}$ & 41.19485 & 123.71846 & bucket & 185 & 0.41 & mostly clear & \\
\hline Pine & $11: 40 \mathrm{AM}$ & 41.19355 & 123.75442 & $\begin{array}{l}\text { Global/ } \\
\text { Pygmy }\end{array}$ & 30,000 & 66.84 & partly cloudy & $\begin{array}{l}\text { used Pygmy \& Global velocity meters, agreed pretty } \\
\text { well }\end{array}$ \\
\hline Pecwan & $3: 31 \mathrm{PM}$ & & & visual & big & & mostly cloudy & big creek, less flow than Pine Cr. On this date \\
\hline Knulthkarn & 3:45 PM & 41.337 & 123.854 & bucket & 82 & 0.18 & light rain & $\begin{array}{l}14.92 \text { mi marker on road, source for John Trull's } \\
\text { hydro system }\end{array}$ \\
\hline Unnamed & 3:52 PM & 41.31931 & 123.84908 & bucket & 88 & 0.20 & light rain & $\begin{array}{l}16.38 \text { mi marker on road, just downriver of Ha Amar } \\
\text { Cr. }\end{array}$ \\
\hline Ha Amar & 4:04 PM & 41.31612 & 123.84869 & bucket & 88 & 0.20 & $\begin{array}{c}\begin{array}{c}\text { overcast, just after } \\
\text { rain }\end{array} \\
\end{array}$ & $16.65 \mathrm{mi}$ marker on road \\
\hline Unnamed & 4:10 PM & 41.313 & 123.851 & bucket & 53 & 0.12 & overcast & $\begin{array}{l}16.79 \text { mi marker on road, GPS coords approximate } \\
\text { (no signal @ creek) }\end{array}$ \\
\hline Unnamed & 4:20 PM & 41.30776 & 123.86169 & visual & small & & overcast & $17.66 \mathrm{mi}$ marker on road \\
\hline Roach & 4:33 PM & & & visual & big & & overcast & $\begin{array}{l}\text { seen from across Klamath R, flow looks comparable } \\
\text { to Pecwan Cr }\end{array}$ \\
\hline Devil & 4:40 PM & & & visual & 60 & 0.13 & overcast & visual estimate \\
\hline Mawah & 4:44 PM & 41.27041 & 123.78542 & visual & fairly big & & overcast & waterfall just above road, painted bridge \\
\hline Chqui & 4:50 PM & 41.26552 & 123.77971 & visual & fairly small & & overcast & (time approximate) \\
\hline Coon & 4:50 PM & 41.26311 & 123.77557 & visual & small & & overcast & $\begin{array}{l}\text { slightly too big for bucket measurement (time } \\
\text { approximate) }\end{array}$ \\
\hline Miners & 4:51 PM & 41.24799 & 123.77216 & visual & fairly big & & overcast & \\
\hline Rube & 4:54 PM & 41.2403 & 123.76821 & visual & small & & overcast & could be bucket measured \\
\hline Rube Ranch & 4:58 PM & 41.22834 & 123.77158 & visual & small & & overcast & could be bucket measured \\
\hline Burrill & 5:01 PM & 41.21732 & 123.76216 & visual & small & & overcast & could be bucket measured \\
\hline Unnamed & 5:02 PM & 41.21232 & 123.75918 & visual & fairly big & & overcast & $\begin{array}{l}\text { between Burrill \& Rock Chute Crs, barely small } \\
\text { enough for bucket msmnt }\end{array}$ \\
\hline Rock Chute & 5:03 PM & 41.21157 & 123.75797 & visual & fairly big & & overcast & \\
\hline
\end{tabular}


The Yurok Tribe Environmental Program (YTEP) has established an environmental monitoring network with a number of stations that track water quality, stream flow, air quality and other factors at several locations around the Reservation. As of 2007, stream flow is being measured at four permanent stations, near the mouths of Blue, McGarvey, Tully and Turwar Creeks. In addition to archiving these data, YTEP publishes annual hydrological monitoring reports and makes the data available online in real time. The online data can be accessed via an interactive map at: exchange.yuroktribe.nsn.us/lrgsclient/stations/stations.html, and the reports are available at: www.yuroktribe.org/departments/ytep/Water.htm

The Tribe hopes to establish and maintain additional monitoring stations in the future but does not currently have funds available to do so.

Several studies have been performed in the past to look at how hydroelectric power development on specific creeks on the Yurok Reservation could benefit individuals and/or the Tribe as a whole. Brief summaries of these studies follow. (Note: multiple spellings are in use for some creek names on the Reservation; for example, Cappell and Ke'pel are alternate spellings for the same creek name.)

Achelth and Pecwan Creek Studies by Chris Greacen, 1997

In his master's thesis, University of California Berkeley graduate student Chris Greacen considered both engineering and socio-economic aspects of off-grid energy development for the Yurok Reservation. The project considered two village scale designs to serve the Wautec area: a $20 \mathrm{~kW}$ DC hydroelectric power system for Achelth Creek and a $50 \mathrm{~kW}$ AC hydro system for Pecwan Creek. The Pecwan system was considered the best option in terms of lowest per-household cost and greater year-round reliability. (Note that, in his later work, Arne Jacobson expressed concern that Greacen may have significantly overestimated minimum flows on Pecwan Creek.)

Pecwan and Cappell Creek Studies by Kelso Starrs, 1998-99 Arne Jacobson and Kelso Starrs and Associates examined hydro power development potential on Cappell and Pecwan Creeks. The Cappell system design is based on $400 \mathrm{ft}$. of head and a base flow of $5 \mathrm{cfs}$. Output could range from $25 \mathrm{~kW}$ to $150 \mathrm{~kW}$ depending on several design variables. An economic analysis is not provided. Potential problems associated with developing Cappell Creek include multiple land owners, lack of road access to the creek, and the need for FERC licensing. Fish habitat was not expected to be a problem at the proposed project site.

Jacobson notes that development of Pecwan Creek, like many creeks on the Reservation, would call for collaboration with Simpson/Green Diamond, the large timber company that owns most of the land on and adjacent to the Reservation. Jacobson and Yurok Tribe staff installed and calibrated a temporary gauging station on Pecwan Creek and collected data for several months during summer and fall 1998. 
Multiple Creek Study by DOE Team, 2000

In their Phase I Report on Renewable Energy Options for the Yurok Indian Reservation, a team of energy specialists from Sandia National Laboratories, Idaho National Engineering and Environmental Laboratory, and Western Area Power Administration made a rapid assessment of the Yurok Reservation's renewable energy potential. They examined head and flow for seven creeks: Pine, Tully, Mawan, Cappell, Pecwan, Meta, and Miners. Of these, they concluded that Pine, Mawan, Cappell and Miners Creeks have the best power generation potential. They also looked at Blue Creek and speculated that it might have power generation potential of some $200 \mathrm{~kW}$, but they noted that its remoteness and cultural value to the Tribe might render it undevelopable. The authors also describe a study done by private firm Verdant Power on the possibility of using Verdant's run-of-the-river hydrokinetic power generation equipment in the Klamath mainstem. Verdant concluded that the Klamath River's depth and flow were not a good match for their company's equipment.

Pecwan Creek Study by Humboldt Engineering, 2000

Humboldt Engineering looked at both Pecwan and Cappell Creeks, recommending that only Pecwan Creek be developed, since it showed greater flow and head than Cappell Creek. The recommended design draws water from both main forks of Pecwan Creek to generate $940 \mathrm{~kW}$ at a flow rate of $10 \mathrm{cfs}$. Estimated project cost is $\$ 1.25$ million, with $\$ 180,000$ per year in expected revenues.

Ke'pel Creek Study by Milt Ludington, 2001

Mr. Ludington estimated that a $50 \mathrm{~kW}$ project built on Ke'pel Creek would cost $\$ 534,000$, not including power distribution infrastructure. Based on this cost $(\$ 10.68$ per watt), the consultant recommended against project development.

Miners Creek Study by Greenwood Engineering, 2004

This study was commissioned by a private property owner with access to Miners Creek. The consultant proposed several alternative scenarios, some requiring rights of way on adjacent property. The designs range from 15 to $40 \mathrm{~kW}$, costing $\$ 120,000$ to $\$ 167,000$ to develop.

HSU Engineering Students' Studies, 2007

Teams of senior-level environmental resources engineering students at Humboldt State University analyzed hydropower potential for several creeks on the Reservation during the spring of 2007, with mentoring and assistance from Yurok Tribe staff and SERC staff. Their final reports, as well as their data and computer models used to perform their analyses, have been provided to the Tribe separately. They considered two different development approaches: a) hydropower connected directly to the grid as a revenuegenerating opportunity for the Tribe, and b) village-scale hydropower connected to a local mini-grid to supply a cluster of homes in a remote area. 
The teams' conclusions are that

- Pecwan and Pine Creeks offer the best opportunities

- Pecwan Creek development (134 kW) would feed a local mini-grid to supply power to the village of Wautec and the Jack Norton Elementary School

- Pine Creek development (1800 kW) would sell power into PG\&E's grid

Based on the students' work, previous engineering reports, discussion with Tribe members and staff, and our own observations, we agree with the students' conclusions that these creeks are among the best hydro development opportunities on the Reservation. The students did identify numerous issues, particularly environmental and cultural impacts and high capital costs, which may make the projects infeasible. With funding from DOE or some other source, we recommend the Tribe perform more in-depth feasibility analyses of these opportunities and, if the analyses are favorable, develop these resources. The students' methodologies could also be applied in the future to perform similar analyses of other creeks on the Reservation.

\section{Making Renewable/Distributed Energy Systems Available on the Reservation}

There are many opportunities for the use of facility-scale (residential or commercial) renewable energy systems on the Yurok Reservation. The primary resources for these facility scale systems are likely to be solar and micro-hydro energy resources, though small scale wind power systems may also offer opportunities in select cases. Many homes on the Yurok Reservation are located in remote areas not currently served by the electric grid, and small-scale, distributed renewable energy systems can provide electricity to these residents. Energy audits of homes on the Reservation in 2006 identified 11 renewable energy systems that are currently serving off-grid homes in the upriver area, and it is believed there are several more systems located on the Reservation.

Off-grid renewable energy systems can provide tremendous value to Tribal households, offering affordable electric power without the noise and pollution produced by gasoline or propane generators. It is also possible to integrate renewable energy systems into homes and facilities that are connected to the electric grid. Although these systems can lower monthly energy bills and lessen environmental impacts, these systems typically take many years to pay for themselves and are therefore usually only installed by people with ample disposable income. Consequently, we recommend that efforts to promote the use of renewable energy systems in Tribal households focus on off-grid applications. The real need on the Reservation is in remote, off-grid areas where people do not currently have access to reliable electric power. There is no significant need for renewable energy systems in Tribal households that are already connected to the grid. On-grid applications that can make sense for renewable energy system installations are for Tribal facilities. Installation of systems on Tribal facilities will benefit all Tribal members and will allow the Tribe to gain experience with them and to set an example by modeling their use. 


\section{$\underline{\text { Solar Electric }}$}

A typical off-grid solar electric system will include solar electric modules (also called photovoltaic or PV modules), batteries for energy storage, a controller to regulate the charging of the batteries, and an inverter to produce 120 VAC grid-quality electricity. Because solar electric systems cannot typically provide for all the electricity needs of a household in the wintertime, they are usually supplemented with a back-up generator. Grid-connected solar electric systems include all the same components, though the batteries and charge controller are optional and are only necessary if power is desired during an electric grid power outage. Most on-grid systems do not include batteries. The typical size for a residential solar electric system is 1 to $3 \mathrm{~kW}$.

\section{Micro-Hydro}

For sites on the Reservation where there is a nearby creek with adequate water flow and elevation drop, a micro-hydro electric system can be a very good fit. In locations where the creek runs dry in the summer months, micro-hydro systems can be paired with solar electric systems to provide year round power.

Micro-hydro systems consist of an intake high up on the creek, a pipeline (or penstock) that conveys the water down to the turbine, and a turbine that spins a generator to produce electricity. Electrical power output can be either alternating or direct current. Most low flow, high head systems (the type that would typically be installed on small creeks on the Yurok Reservation) produce a DC output current. The energy from the turbine-generator is then stored in a battery (like with a solar electric system). An inverter is used to produce AC electricity for common household loads. Like the solar electric system described above, the micro-hydro system requires the use of a controller to regulate the charging of the batteries. This is typically accomplished using a diversion load controller and a diversion load, such as an air heater. When the batteries are fully charged the diversion load controller shunts the power from the generator to the air heater. Note that it is critical that the diversion load always be operable because the hydro-turbine can be seriously damaged if it is allowed to spin freely without being connected to an electrical load. For this reason air or water heaters are common choices for a diversion load. A light bulb is not a good choice because when it burns out the load is disconnected and the turbine can spin freely.

The rated power output of a micro-hydro generator can be relatively small and still provide adequate energy production for a household. This is because a micro-hydro system produces electricity 24 hours per day. A comparable solar electric system would require a much higher rated power output. For example, a $200 \mathrm{~W}$ micro-hydro system can be expected to produce over three kilowatt-hours of useful AC electricity per day. For comparison, a solar electric system with a DC rating of about $1 \mathrm{~kW}$ could be expected to produce a comparable amount of useful AC electricity on average throughout the year.

$\underline{\text { Wind }}$

In a few select sites on the Reservation wind power might make sense. According to AWEA, an annual average wind speed of 7 to $9 \mathrm{mph}$ is typically necessary for viable off- 
grid wind power installations. Facility scale wind energy systems can range in capacity from less than a kilowatt up to about $100 \mathrm{~kW}$. Wind energy systems consist of a tower, a turbine, and power conditioning and electrical switchgear. Off-grid wind energy systems typically include batteries for storage and are electrically similar to micro-hydroelectric systems that include a diversion load and a diversion load controller to regulate the charge on the batteries.

$\underline{\text { Available Economic Incentives }}$

Numerous economic incentives are available for people who install renewable energy power systems in California. These include federal, state, and local utility incentives. However, these incentives can vary greatly based on the type of system, the location of the installation, and whether or not the system is connected to the local electric grid.

Table 7 lists the available economic incentives by utility and system type. Grid-connected solar electric systems are eligible for the most incentives; wind energy systems are eligible for fewer incentives, and micro-hydro system are not eligible for any incentives. Only tax credits are available for off-grid systems. Rebate programs for solar electric and wind are only available in PG\&E's service territory.

Table 7. Economic Incentives for the Installation of Renewable Energy Systems

\begin{tabular}{|c|l|l|l|l|}
\hline Utility & On/Off-Grid & Solar Electric & Wind & Micro-hydro \\
\hline $\begin{array}{c}\text { Pacific Gas \& } \\
\text { Electric } \\
\text { (PG\&E) }\end{array}$ & On-grid & $\begin{array}{l}\text { Net metering } \\
\text { CSI rebate } \\
\text { Tax credit }\end{array}$ & $\begin{array}{l}\text { Net metering } \\
\text { ERP rebate }\end{array}$ & \\
\cline { 2 - 5 } & Off-grid & Tax credit & & \\
\hline $\begin{array}{c}\text { Pacific Power } \\
\& \text { Light } \\
\text { (PP\&L) }\end{array}$ & On-grid & $\begin{array}{l}\text { Net metering } \\
\text { Tax credit }\end{array}$ & Net metering & \\
\cline { 2 - 5 } & Off-grid & Tax credit & & \\
\hline
\end{tabular}

Grid-connected solar and wind electric systems are eligible for a net metering rate with either PP\&L in Del Norte County or PG\&E in Humboldt County. Net metering is available for both residential and commercial customers. Net metering allows a customer to spin their meter backwards when their wind or solar electric system is producing more power than they are using. This results in a credit on their bill. Customer's bills are trued up on an annual basis. Customers are required to pay a minimum charge of about $\$ 5$ per month regardless of how much power they produce. If the electricity generated by the customer exceeds the electricity provided by the utility over the 12-month period, the utility keeps the excess power without compensation to the customer. Therefore, it is in the customer's best interest not to oversize their grid-connected solar or wind electric system. Micro-hydro electric systems are not eligible for net metering. For more information on net metering see PG\&E's website at: http://www.pge.com/suppliers_purchasing/new_generator/

The Energy Policy Act of 2005 established a 30\% tax credit for the purchase and installation of a solar electric or solar hot water system. This tax credit is available to 
residential or commercial customers for both on- and off-grid applications. The credit is capped at $\$ 2000$ for residential customers; there is no cap for commercial customers. The tax credit is set to expire at the end of 2008, though there is pending federal legislation to extend it through 2016. If the credit is not extended after 2008 it will revert to a $10 \%$ credit for the commercial sector only. If the credit exceeds a claimants tax liability for a given year it can be carried forward to the succeeding tax year. Wind and micro-hydro electric systems are not eligible for federal tax credits. For more information on tax credits see: http://www.gosolarcalifornia.ca.gov/csi/tax_credit.html

There are currently two rebate programs available in California that offer incentives for small scale renewable energy systems, the California Solar Initiative (CSI) and the Emerging Renewables Program (ERP). The CSI provides rebates for the purchase and installation of grid-connected solar electric systems. This program is currently only available in PG\&E's service territory, though the State expects it to be available to PP\&L customers in the next year or two. Rebate levels for the Weitchpec area as of July 1, 2007 are shown in Table 8. As more people participate in the program and more systems are installed, the rebate levels will go down. Current rebate levels can be found at http://www.csi-trigger.com/. Note that the EPBB rebate levels shown on this website must be reduced by a geographic correction factor of 0.78 for the Weitchpec area.

Table 8. California Solar Initiative Incentives

\begin{tabular}{|l|c|c|}
\hline & $\begin{array}{c}\text { Expected Performance } \\
\text { Based Buydown (EPBB) }\end{array}$ & $\begin{array}{c}\text { Performance Based } \\
\text { Incentive (PBI) }\end{array}$ \\
\hline Residential & $\$ 1.95 /$ watt & $\$ 0.39 / \mathrm{kWh}$ \\
\hline Commercial & $\$ 1.48 / \mathrm{watt}$ & $\$ 0.26 / \mathrm{kWh}$ \\
\hline Government/Non-Profit & $\$ 2.07 / \mathrm{watt}$ & $\$ 0.37 / \mathrm{kWh}$ \\
\hline
\end{tabular}

The CSI program offers two incentive types. The Expected Performance Based Buydown is a one-time rebate that is based on the rated capacity of the installed system. The Performance Based Incentive requires direct metering of the system and payments are made on a monthly basis over a five-year period based on the actual energy produced by the system. The PBI is available to any program participant upon request, and is mandatory for systems $\geq 100 \mathrm{~kW}$ in capacity. Installed equipment must be approved by the California Energy Commission and must carry a minimum 10-year warranty. Systems must be installed by an appropriately licensed contractor. Alternatively, owner installed systems are allowed provided proper permits are obtained and pertinent codes are followed.

The CSI program also offers separate but similar rebates for solar electric systems installed on newly constructed homes. These rebates involve an additional requirement that the home be built to be at least $15 \%$ more energy efficient than a comparable home built to the current Title 24 State Energy Code. The CSI program is also working to develop specific incentives for new affordable housing and existing low-income housing. California also has legislation pending that may establish a rebate program for solar hot water systems. For more information on the CSI program see: 
http://www.gosolarcalifornia.ca.gov/index.html or

http://www.pge.com/about_us/environment/solar/csi.html

The Emerging Renewables Program offers rebates for small, grid-connected wind electric systems (up to $50 \mathrm{~kW}$ ). Rebates of $\$ 2.50$ /watt are available for systems rated at up to 7.5 $\mathrm{kW}$, with additional $\$ 1.50$ /watt incentives available for increments between $7.5 \mathrm{~kW}$ and $30 \mathrm{~kW}$. Installed equipment must be approved by the California Energy Commission and must carry a minimum 5-year warranty. Systems must be installed by a licensed contractor to receive the full rebate. Owner installed systems are allowed, but the incentive level is reduced by $15 \%$. For more information on the Emerging Renewables Program see: http://www.consumerenergycenter.org/erprebate/

Possible Tribal Program to Make Renewable Energy Systems Available Thirty or more renewable energy systems have been installed in remote, off-grid applications in the upriver area of the Reservation over the past two decades. A few systems have been financed and installed by residents without assistance from the Tribe, while most systems have been installed under the direction of the Tribe using Tribal and/or outside funding sources. However, the Tribe has never had a formal program to support the design, purchase, installation, and maintenance of renewable energy systems on the Reservation. Such a program could help more residents obtain systems. Such a program could also save the Tribe and its residents money and could help ensure that systems are properly designed, installed, and maintained over time.

We think that the critical aspects of a successful program are as follows:

1. Properly designed/sized and installed systems,

2. Successful customer education and active customer involvement,

3. Regular system maintenance,

4. Adequate long-term funding with acceptable monthly fee paid by customer,

5. Competent, well-trained program staff.

In this section we discuss possible options for a Tribal energy program that could help residents obtain and maintain renewable energy systems on the Reservation. A program could include all or any of the following activities: financing, designing, purchasing, installing, and maintaining renewable energy systems. We recommend that a Tribal program cover all of these activities and focus on facility/household scale solar electric and micro-hydro electric systems because these systems show the greatest promise on the Reservation. We also recommend that a program focus on off-grid systems. While ongrid systems can help residents reduce their electric bills, the economic payback on these systems is marginal, even with available rebates and tax credits. In addition, there are many Yurok residents who live in remote, off-grid locations that do not have adequate access to electrical service. Although the Tribe is working hard to extend grid electric services to many of these Tribe members, the electric line extension project is costly and is progressing slowly. It will be a long time before some residents get access to grid power, and there are numerous residents who live in remote areas that will likely never receive grid power. The value a renewable energy system offers these residents is so much greater than what a grid-connected customer can expect that it makes no sense to 
spend limited resources at this time on a program promoting grid-connected renewable energy systems.

A Yurok Tribe program that helps Tribe members obtain and maintain renewable energy systems for off-grid applications can offer many benefits. The most likely reason that more people don't already have such systems is the high initial cost. A typical off-grid solar electric system can cost $\$ 10,000$ or more. A Tribal program can help overcome this high initial cost in a couple of ways.

First, the Tribe can finance the initial cost of these systems and then collect fees from customers over the life of the system to cover part or all of the system costs. The section below on Funding and Financing Resources discusses various funding sources that might be used to help support such a program, such as federal grants, private foundation funding, Tribal funds, and/or revenue from the wholesale sale of electric power. Regardless how much money is available from outside funding sources it is recommended that program participants pay at least a nominal fee to help off-set program costs. This will look favorable to any outside funders. Perhaps more importantly, this tends to give program participants a sense of ownership and responsibility for their renewable energy systems and makes it more likely that they will care for them properly.

Secondly, the Tribe can lower the installed cost of these systems by buying the equipment at wholesale prices. The Tribal Engineer has already established the Yurok Tribe as a dealer (Customer No. 22047) with AEE Solar, Inc. in Redway, CA. AEE Solar (formerly Alternative Energy Engineering) is a highly reputable local supplier that has been selling renewable energy equipment since 1979 . They carry quality equipment at competitive prices and provide strong customer service, including design and technical assistance. AEE Solar's wholesale discount is approximately $30 \%$. In addition, they offer another 2-3\% volume discount for larger orders (e.g., 10 or more PV modules, 10 or more batteries, 3 or more inverters, etc.). This is not intended as an endorsement of AEE Solar, but rather it is an acknowledgement that the Tribe already has a relationship established with this firm and it is unlikely the Tribe will find substantially better pricing or better local service for renewable energy equipment.

Perhaps one of the greatest assets of a Tribal renewable energy program is that it will require that the Tribe develop the expertise within the Tribal staff and larger Tribal community to install and maintain renewable energy systems. This is critical to the success of any program. Once this knowledge base is developed locally it will be much easier to support an installation program and to provide ongoing maintenance services. In the initial program stages, the Tribe could hire a contractor to provide standardized system designs, staff training, and technical assistance with installation and maintenance/repair services. As the program matures, it is expected that Tribal staff could eventually handle all of these tasks.

Probably the most critical element of a Tribal renewable energy program is a strong maintenance program. We recommend that all program participants be required to utilize Tribal program maintenance services. A lack of system maintenance is the number one 
reason that existing renewable energy systems on the Reservation have fallen into disrepair. This topic is discussed more fully in the next section "Providing Maintenance and Repair to Renewable Energy Systems."

Another critical component of a Tribal renewable energy program will be customer education. Customers must understand the importance of energy efficiency and conservation and how it relates to the performance of their renewable energy system. In order for systems to work well over a long period of time, people have to learn to live within their energy budget. Consequently, customers should be encouraged to purchase compact fluorescent lamps and other energy efficiency products, and to use energy wisely. This includes turning off unnecessary appliances and minimizing phantom loads. Customers must learn to gauge their battery state of charge and manage their loads accordingly so as not to discharge the battery too deeply. Customers must also understand the importance of using a back-up generator to charge their batteries when needed. One of the key causes of reduced battery life is discharging the batteries too deeply and then leaving them in a low state of charge. Batteries must be equalized periodically and the water level in flooded lead acid batteries must be maintained or they will suffer serious damage. When water is added to batteries, it must be deionized or distilled water.

We estimated the cost of operating a Tribal renewable energy program and explored various cost recovery options, including full and partial payment by program participants. The envisioned program would involve the design, purchase, installation, and maintenance of renewable energy systems in off-grid applications on the Reservation. We examined three standardized system types: a 1,400 watt solar electric system, a 700 watt solar electric system, and a hybrid solar/micro-hydro electric system that includes 700 watts of solar electric modules and a 300 watt hydro turbine. The 1,400 watt solar electric system and the hybrid solar/micro-hydro system would provide comparable electrical service (approximately $4 \mathrm{kWh} /$ day on average). The 700 watt solar electric system would provide approximately half as much usable electricity $(2 \mathrm{kWh} /$ day on average) as the other two systems. These system sizes should provide enough electricity for a small family (2-4 people) who make thoughtful and efficient use of their electricity resource.

Table 9 presents the estimated initial equipment cost and installation labor cost for each system. Also shown are the total initial equipment and labor costs assuming 25 systems are installed. These costs assume the Tribe purchases the equipment at the dealer's wholesale price. Labor costs are based on Tribal Public Utility District labor rates. It is estimated that 25 systems could be installed for less than $\$ 440,000$. The average monthly maintenance costs over the lifetime of these systems is expected to be approximately $\$ 75$, $\$ 60$, and $\$ 60$ for the 1,400 watt, 700 watt, and hybrid systems, respectively. Approximately $\$ 20 /$ month is associated with the cost of three routine maintenance checkups per year, and the remaining cost is to cover expected repair and replacement services as equipment wears out. This results in a total monthly maintenance cost of about $\$ 1700$. See the following section for further discussion of maintenance costs and 
activities. See Appendix 2 for details on the initial and maintenance costs associated with these systems, as well as other assumptions used in the economic analysis.

Table 9. Off-Grid Renewable Energy System Equipment and Installation Cost

\begin{tabular}{|r|r|r|r|r|r|}
\hline System Type & Equip. Cost & $\begin{array}{r}\text { Installation } \\
\text { Cost }\end{array}$ & $\begin{array}{r}\text { Estimated } \\
\text { \# Systems }\end{array}$ & $\begin{array}{r}\text { Total } \\
\text { Equipment } \\
\text { Cost }\end{array}$ & $\begin{array}{r}\text { Installation } \\
\text { Cost }\end{array}$ \\
\hline Off-grid PV 1400 W & $\$ 15,200$ & $\$ 3,800$ & 15 & $\$ 228,000$ & $\$ 57,000$ \\
\hline Off-grid PV 700 W & $\$ 9,000$ & $\$ 3,000$ & 5 & $\$ 45,000$ & $\$ 15,000$ \\
\hline Micro-hydro/PV & $\$ 12,150$ & $\$ 6,000$ & 5 & $\$ 60,750$ & $\$ 30,000$ \\
\hline & & & & $\$ 333,750$ & $\$ 102,000$ \\
\hline
\end{tabular}

We recommend that the Tribe bill participating households for renewable electricity using a flat fee that is based on system electrical capacity as shown in Table 10. This is consistent with the way the Navajo Tribal Utility Authority bills for their off-grid solar and wind electric services. This will generally reflect the level of service provided to the customer, as higher capacity systems will provide greater electricity service. In addition, this simplifies the program and lowers the cost of system installation and program administration by eliminating the need for installing and reading electric meters. In 1998/99, the Tribe briefly tried to meter off-grid systems with no success (see discussion "Billing for Energy Services Provided by the Tribe" section below).

If the Tribe could secure outside funding for the initial equipment and installation costs, then they could bill the program participants for all or part of the monthly maintenance costs, thereby ensuring the economic viability of the program over the long term. Table 10 shows the required monthly cost to the customer to cover various program costs. The options examined include having the customer pay: 1) the full cost, 2) ongoing maintenance plus initial equipment cost (everything but the installation cost), 3) the installation and ongoing maintenance costs, 4) the full ongoing maintenance costs (routine maintenance checkups as well as repair work), or 5) only the routine maintenance checkup cost. Note that although the maintenance costs associated with the hybrid system are expected to be slightly less than for the 1400 watt solar electric system, it is recommended that the monthly fees for these two systems should be the same because these two systems are expected to provide the same level of electrical service. It is recommended that the customer pay the full maintenance costs associated with these systems and the Tribe find funding to cover the initial equipment and installation costs. However, this may be unrealistic due how much Tribal households will be willing or able to afford. During the Tribe's earlier attempt to bill for off-grid energy services, consensus determined that a monthly fee of $\$ 85$ was too high. A fall back position is to have the customer pay for routine maintenance checkups only, and then pay for additional repair services on an "as needed" basis. See the "Providing Maintenance and Repair to Renewable Energy Systems" section for further discussion about possible customer billing options. 
Table 10. Monthly Cost to Customer Vs. Cost Recovery by Tribe

\begin{tabular}{|c|c|c|c|c|c|}
\hline & \multicolumn{5}{|c|}{ Cost Recovered by Tribe } \\
\hline System Type & Full & $\begin{array}{r}\text { O\&M + } \\
\text { Equipment }\end{array}$ & $\begin{array}{r}\text { O\&M + } \\
\text { Installation }\end{array}$ & $\begin{array}{r}\text { Full O\&M } \\
\text { Cost }\end{array}$ & $\begin{array}{r}\text { Routine } \\
\text { O\&M Cost }\end{array}$ \\
\hline Off-grid PV $1400 \mathrm{~W}$ & $\$ 180$ & $\$ 160$ & $\$ 95$ & $\$ 75$ & $\$ 20$ \\
\hline Off-grid PV $700 \mathrm{~W}$ & $\$ 130$ & $\$ 110$ & $\$ 75$ & $\$ 55$ & $\$ 20$ \\
\hline Micro-hydro/PV & $\$ 180$ & $\$ 160$ & $\$ 95$ & $\$ 75$ & $\$ 20$ \\
\hline
\end{tabular}

The monthly costs shown in Table 10 were derived based on the full life-cycle cost of each of the systems. Depending on the cost recovery scenario, this included the initial equipment and installation cost, the ongoing routine maintenance costs, the recurring equipment repair and replacement costs. Labor and travel costs we determined using the current cost rates for the Yurok Tribe Public Utility District (PUD). Time value of money calculations were made using a net discount rate of $5 \%$ and a system design life of 30 years. For complete details on the system costs see the calculation spreadsheets in Appendix 2.

Regarding ownership of the systems, it is recommended that the Tribe should retain ownership unless the customer was to pay the full system cost. As noted later in this report, it is very important from the outset of any program that it be made clear who owns the equipment and what the responsibilities are of the Tribe and the participating customer. To that end, it is recommended that a simple contract be executed between the Tribe and the customer that clarifies the following points:

- The Yurok Tribe owns the system.

- The customer is responsible for paying a flat monthly fee (due by a certain day each month). Failure to pay the monthly fee will result in the system being turned off or, in severe cases, repossessed.

- The customer is responsible for proper care and use of the system (running the generator to keep the batteries charged as needed, maintaining the water level in the batteries, etc.).

- The Tribe will make three routine maintenance visits per year to conduct a system checkup and basic system maintenance.

- The Tribe is responsible for system repairs and equipment replacement as necessary provided the system has not been abused.

Requirements to Set-Up a Tribal Renewable Energy System Program The establishment of a Yurok Tribe renewable energy system program will require parttime Tribal staff with specific skills, proper tools, and the use of a Tribal vehicle for making field visits. We estimate that two part-time field staff will be required. Perhaps the two existing PUD staff could take on the tasks outlined here, or perhaps new staff would need to be hired. We estimate the following annual time requirements for a Tier 1 and a Tier 2 maintenance staff person to install and maintain 25 off-grid renewable energy systems (see Table 11). 
Table 11. Annual Labor Hours for Renewable Energy Program Staff

\begin{tabular}{|ll|c|c|}
\hline & & Tier 1 Staff & Tier 2 Staff \\
\hline System Installation & (3) $1.4 \mathrm{~kW} \mathrm{PV}$ & $192 \mathrm{hrs}$ & $192 \mathrm{hrs}$ \\
& (1) $0.7 \mathrm{~kW} \mathrm{PV}$ & $56 \mathrm{hrs}$ & $56 \mathrm{hrs}$ \\
& (1) PV/hydro & $104 \mathrm{hrs}$ & $104 \mathrm{hrs}$ \\
\hline Routine Maintenance & $200 \mathrm{hrs}$ & \\
\hline Repair & $100 \mathrm{hrs}$ & $60 \mathrm{hrs}$ \\
\hline
\end{tabular}

The labor hours in Table 11 assume that five systems (three $1.4 \mathrm{~kW} \mathrm{PV} \mathrm{systems,} \mathrm{one} 0.7$ kW PV system, and one hybrid PV/micro-hydro system) will be installed each year over the first five years. Over the first five years the total time requirement for the Tier 1 staff position is expected to grow from $17 \%$ to $31 \%$ of a full-time position. Over the same time period the total time requirement for the Tier 2 staff position is expected to grow from $17 \%$ to $20 \%$ of a full-time position. Once the system installations are complete, the Tier 1 staff requirements will drop to $14 \%$ of a full time position, and the Tier 2 staff requirements will drop to $6 \%$ of a full-time position for on-going maintenance and repair activities. In addition to these two field staff, some modest amount of staff time will be required to prepare and maintain paperwork, place equipment orders, generate and mail monthly bills, and handle accounts receivable and accounts payable business. This administrative work is expected to require no more than 1 to 2 days per month and we expect that it can be folded into the existing administrative work for the PUD.

The skill level requirements for the Tier 1 and Tier 2 field staff should include basic electrical contractor skills, experience with low and high voltage AC and DC electrical systems, basic house wiring skills, general carpentry skills (framing and simple foundations), basic plumbing skills (for the micro-hydro system), knowledge of the electrical code, and knowledge of safe electrical system practices. Additional basic knowledge about solar electric and micro-hydroelectric systems will also be important. Some of these skills could be learned on the job with proper supervision. Formal training in renewable energy system installation is advised. Two potential training opportunities are:

1. Solar Energy International - SEI is located in Carbondale Colorado. They have been offering renewable energy training workshops throughout the world for last 16 years. Their offerings include multi-day, one-week and two-week trainings in solar electric, wind, and micro-hydro system design and installation. SEI has earned a strong reputation as one of the premier training groups.

2. Solar Living Institute - Closer to home, the Solar Living Institute is located in Hopland, CA. Their offerings include multi-day and weeklong trainings in solar electric system design and installation.

It would also be a good idea for at least one of the field staff to get certified by the North American Board of Certified Energy Practitioners (NABCEP) as a PV installer. The NABCEP PV installer certification is a voluntary certification that provides a set of 
national standards by which PV installers with skills and experience can distinguish themselves.

In addition to trained field staff, it would be advantageous to the Tribe to have a qualified engineer on staff that is familiar with renewable energy power systems. This staff member could direct the overall installation and maintenance program, provide project oversight and supervision, and conduct field inspections. This staff member could also be in charge of system design work. If a qualified Yurok staff member is not available to perform these tasks, the Tribe could hire an outside contractor to prepare standardized system designs, provide technical assistance, and conduct on-site field inspections to make sure that systems are installed properly, safely, and in accordance with pertinent building and electrical codes.

One unique issue that system installers are likely to face in remote areas of the Reservation is the existence of sub-standard, non-code compliant building and electrical systems. Staff will need to address this on a per case basis. In some cases minor repairs may suffice. In other cases the housing department may be called in to resolve existing building or electrical problems before the renewable energy system is installed. Still in other cases it may be determined that facility in question is not appropriate for a renewable energy system installation. Particular areas of concern include roof structures (if PV modules are to be mounted on the roof), and house wiring and electrical systems.

Other Tribal Renewable Energy System Programs

There are a few American Indian Tribes who have initiated renewable energy system programs to serve their residents. These include the Navajo, Hopi, Rosebud Sioux and Oneida Tribes. The most well known and successful efforts have occurred on the Navajo and Hopi Reservations in Arizona, New Mexico, and Utah.

The Navajo Tribal Utility Authority (NTUA) has installed over 350 solar electric systems for off-grid Tribal residences since 1993. System capacities have varied from 240 watts in the early days to 880 watts in more recent years. Customers pay a flat monthly fee for their systems. Currently there are about 220 photovoltaic accounts. The fee varies from a low of $\$ 40 /$ month for a 240 watt PV system to a high of $\$ 147 /$ month for an 880 watt PV system with a propane gas generator. Other system options are an 880 watt PV-wind hybrid system for $\$ 75 /$ month and a lease-to-purchase option on a 640 watt PV system for $\$ 95 /$ month over 15 years. The basis for these fees has varied over time and has included the projected O\&M costs for the system and the amortized capital cost of the equipment. Program participants are required to enter into a Solar Photovoltaic Agreement with the NTUA. NTUA electricians perform maintenance on all systems.

The different system types evolved over time, but in each phase of the project there has been standardized system types. This greatly simplifies the system design, procurement, installation, and on-going maintenance tasks. System design features that have allowed NTUA to keep program costs down include:

- Array, battery box and inverter were mounted on steel skid that could be moved into place. 
- Skid was fully integrated off-site so that the only wiring done on-site was connecting the system power to the residence.

- Propane generators were dropped due to excessive maintenance costs and small wind turbines were integrated into the hybrid system instead.

- Batteries were fully charged before deployment.

In 2003 and 2004, sixty-three 880 watt PV-wind hybrid systems were assembled on the Navajo Nation to create local jobs and build local human capacity. The system parts were shipped to the Reservation and fully integrated before transferring the system to the site.

NTUA has received technical support for their program from Sandia National Laboratory and the Southwest Development Institute. This has included training, design and testing services, development of O\&M procedures, and use of college interns. Funding support for the NTUA program has come from the US Department of Energy, the Western Area Power Administration, and the US Department of Agriculture Rural Utility Service. The NTUA has also appropriated money from their General Fund to support the program. NTUA has hired and trained staff to install and maintain the systems and has also developed in-house financing for a lease-to-own program. Another big component of the NYUA solar program is customer education to ensure that residents know how to properly operate and care for their systems and manage their electrical loads to keep the battery charge level balanced.

Learning more details about the NTUA program and perhaps modeling a program after it may be a very good opportunity for the Yurok Tribe. Larry Ahasteen is the current program manager at NTUA and he indicated that they would be happy to provide information and assistance to the Yurok Tribe to help them get a program started.

Two other non-Tribal solar electric programs have also been started on the Navajo and Hopi Reservations, NativeSUN and Native American Photovoltaics, Inc. These programs followed different models from the NTUA.

NativeSUN is a Hopi solar electric enterprise. It was created by the Hopi Foundation, a non-profit corporation that is separate from the Hopi tribal government. The Hopi Foundation's mission is to create technical proficiency and employment opportunities that can develop into for-profit businesses at the appropriate time. The Hopi Solar Enterprise, which later became NativeSUN, was the first project of the Hopi Foundation. NativeSUN installs and maintains solar electric systems for residential and small and medium sized commercial customers. Small residential systems are typically rated at about 500 watts and provide sufficient electricity for basic lighting and small appliance needs. Standard residential systems are typically from $1 \mathrm{~kW}$ to $2 \mathrm{~kW}$ in size. NativeSUN has installed 300 to $400 \mathrm{PV}$ systems over the last ten years, the majority of these being small residential scale systems.

The NativeSUN model is a commercial enterprise. Customers must pay the full price for their equipment and services. Although maintenance contracts are available at a modest cost, maintenance is typically provided for on an as needed basis. Consequently, the 
program relies heavily on strong customer training. Residents are trained to care for their system themselves. The most common technical problem they face is loss of water in the flooded lead-acid batteries due to battery charging and the warm, arid climate. By properly training residents on how to maintain the water levels in their batteries they have effectively doubled the life of the battery systems. Residents are also trained to manage their electrical loads and keep a balanced state of charge on their batteries.

A popular financing program for NativeSUN is a layaway program where customers put $25 \%$ of the system price down and then they receive the system when they have fully paid it off. NativeSUN also tried a low or zero interest revolving loan program that was unsuccessful. People had trouble paying their bills and it was too hard to police the program. Households are very spread out and it was too expensive to travel to residences in an attempt to collect the monthly fees that were in arrears.

The NativeSUN business model is designed to be easily replicated by other tribes. They offer franchise agreements, training programs, administrative services, volume discounts on equipment, and other services to help other tribes get a similar program started.

Native American Photovoltaics (NAPV) was a non-profit organization made possible through support from the Navajo Tribal Utility Authority and the US Department of Energy. NAPV financed, installed, and serviced approximately twenty PV power systems for remote, off-grid residences on the Navajo Nation. The standardized systems were sized at $1.2 \mathrm{~kW}$, which was adequate to serve the basic needs of off-grid living. The NAPV installation and maintenance crew was made up of all local Navajos.

The program was setup so that clients paid $\$ 50$ per month for ten years toward the purchase of the systems. At the end of the contract period they owned the system. The monthly fee also included regular system maintenance. Payments by customers were generally made on time. In fact, program staff felt that a significant number of residents would be able to make payments as high as $\$ 150$ per month, including a $\$ 2000$ down payment. They had plans for expanding the program and providing larger capacity systems (approximately $2 \mathrm{~kW}$ ); however, it appears that the expansion plans never materialized.

The Rosebud Sioux Tribe in South Dakota has also initiated a renewable energy program to serve their residents. Instead of solar electric systems, however, this program provides simple passive solar heating systems that heat air for space heating. There is no thermal storage, so the units only provide heat when the sun is shining. The units are supplemental heating systems that help to lower heating bills in the harsh, cold South Dakota winters.

The Rosebud Sioux partnered with Trees, Water \& People (TWP), a non-profit group whose mission is to help communities sustainably manage their natural resources. The Sioux and TRP created a solar collector manufacturing facility on the Pine Ridge Reservation. The facility operates under the name Lakota Solar Enterprises and is led by Lakota elder Henry Red Cloud. This facility has created job opportunities on the 
Reservation and provides solar collectors for the renewable energy program. A team that has been trained by TWP installs the solar systems. The effort is funded by donations through Alternative Gifts International (AGI), a non-profit organization that organizes alternative gift giving. AGI provides the opportunity to give a life-sustaining gift in someone's name that can help abolish poverty or renew the environment. For the Lakota Sioux solar heating project, $\$ 440$ will buy one solar heater.

Finally, the Oneida Tribe of Indians from Oneida, WI, was funded in 1999 by the US Department of Energy to implement a solar energy project on their Reservation. Plans were to install 52 solar hot water systems and 18 PV systems in Tribal homes.

Homeowners were to receive financial assistance toward the installation of the systems. The systems were to be installed by trained Tribal personnel. The project did accomplish the installation of some systems; however, once the project began it became apparent that most Tribal members were hesitant to invest $\$ 3,000$ to $\$ 6,000$ in solar energy systems. So, the project focus was shifted to promote energy efficiency in Tribal facilities and homes through energy audits.

\section{Providing Maintenance and Repair to Renewable Energy Systems}

Many renewable energy systems have been installed on the Reservation over the past 25 years, both independently and as part of Tribal programs. Unfortunately, many of these systems have fallen into disrepair. The need for renewable energy system maintenance and homeowner education is obvious. This need was cited in both the Sandia National Labs renewable energy options report and in Christopher Greacen's master's thesis that examined technology options for the Yurok Tribe electrification project. Even Tribal Council members have stated that, while installation of new renewable energy systems is desirable, priority should be given to renovating and maintaining existing systems. It makes no sense to spend time and money installing renewable energy systems on the Reservation if they are not going to be maintained.

In 1998, Arne Jacobson (working for Kelso-Starrs and Associates) along with Tribal staff conducted a house-to-house survey of approximately 100 off-grid homes in the upriver section of the Reservation. This survey identified 29 renewable energy systems: 18 solar electric systems, five micro-hydro systems, and six PV/micro-hydro hybrid systems. However, in the summer of 2006, when energy audits were performed in the same area of the Reservation as part of the DOE funded Human Capacity Building Project, only 11 of these systems could still be accounted for. Most of the other systems had been removed, were not operating, or the house was vacant. Of the systems that were still operational, numerous systems were in need of maintenance. One system had a main wire from the micro-hydro generator that was literally hanging from its connection point. Another system had an incorrectly wired battery bank. A third system had an incorrectly wired PV array and a deeply discharged battery bank. Still another system had an inoperable generator and dead batteries. And one system had a PV array that was becoming shaded by overgrown trees. These examples are a clear demonstration of the ongoing need for system maintenance. 
However, while there is a clear need for maintenance services, it may still be difficult to get people to pay for maintenance services. It's kind of like selling insurance. People say, "Why should I pay for something I may never use?" Well, paying for preventive maintenance is like buying insurance. People don't see a need for it when their system is working fine. Unfortunately, waiting until something goes wrong is typically much more expensive and inconvenient, and can seriously shorten the life of the equipment.

Possible options for a maintenance program fall into the following three categories shown in Table 12. The monthly fee associated with each case is based on the O\&M costs presented in Table 10. Option 1, the standard maintenance contract, costs the customer $\$ 20$ per month for three periodic maintenance checkups per year. If repair work is needed, this is charged separately at a rate of $\$ 27.50$ per hour plus the cost of parts. Option 2 is the full service maintenance contract. For $\$ 75$ per month the customer receives three periodic maintenance checkups per year and all repair costs are covered (including parts and labor). Under the fee for service option, the customer only pays when repair work is needed. The customer is charged at $\$ 27.50$ per hour plus the cost of parts.

Table 12. Maintenance Program Options

\begin{tabular}{|c|c|c|}
\hline $\begin{array}{c}\text { Maintenance Program } \\
\text { Option } \\
\end{array}$ & What is covered? & What are the costs? \\
\hline \multirow{2}{*}{$\begin{array}{l}\text { 1. Standard } \\
\text { maintenance } \\
\text { contract* }\end{array}$} & $\begin{array}{l}\text { Periodic maintenance } \\
\text { checkups ( } 3 \text { times per year) }\end{array}$ & $\$ 20 / \mathrm{mo}$ \\
\hline & Repair work as needed & $\begin{array}{c}\text { Labor@ } @ \$ 27.50 / \mathrm{hr}+\text { parts, as } \\
\text { needed }\end{array}$ \\
\hline $\begin{array}{l}\text { 3. Full service } \\
\text { maintenance } \\
\text { contract }\end{array}$ & $\begin{array}{l}\text { Full service maintenance } \\
\text { checkups and repairs, parts } \\
\text { and labor included }\end{array}$ & $\$ 75 / \mathrm{mo}$ \\
\hline 4. Fee for service* & Repair work as needed & $\begin{array}{c}\text { Labor@ @ } \$ 27.50 / \mathrm{hr}(\$ 50 \mathrm{~min}) \\
+ \text { parts, as needed }\end{array}$ \\
\hline
\end{tabular}

* Note: Repair work costs (parts and labor) could be financed over time.

For a newly installed system that is part of the Tribal renewable energy program (i.e., the system belongs to the Tribe), it is recommended that participants be required to sign up for a scheduled maintenance plan, either option 1 or 2 . For customers with existing systems, it is recommended that they be allowed to choose from all three options.

The staffing requirements for a maintenance program have already been outlined in the above section "Making Renewable/Distributed Energy Systems Available on the Reservation," as have the required job skills and training needs. A list of suggested tools for the maintenance program is presented in Appendix 3. A list of routine maintenance tasks is presented below:

- Check electrolyte level in batteries, add distilled water if needed

- Clean terminals on batteries 
- Check displays on inverters/charge controllers for any fault codes, perform basic troubleshooting, report any unsolvable problems

- Clean solar panels

- Check hydro systems for flow, clear intakes as needed

- Prune trees/shrubs to maintain clear solar access

- Read meters used to track energy use

- Help resident to perform occasional equalization charge on batteries

- Report the need for major maintenance/repair (damaged/missing equipment, batteries in need of replacement, etc.)

- Watch for unsafe conditions (exposed wiring, generator too close to living space, etc.) and work $\mathrm{w} /$ resident to correct

- Be on the lookout for situations where residents are putting too much load on their systems and regularly over-discharging batteries, advise resident on ways to avoid this problem.

- Answer residents' questions about their equipment

A detailed maintenance task list is given in Appendix 4. The maintenance task list is based on information from Sandia's Stand-Alone PV System Operation and Maintenance Manual and Solar Energy International's Photovoltaics: Design and Installation Manual.

\section{Providing Energy Efficiency Services to Homes and Businesses}

Energy efficiency services for homes and businesses can include two main categories: 1) weatherization and other energy efficiency improvement for existing homes, and 2) assurance of energy efficiency in new construction and building renovations. The first of these categories is addressed in the Yurok Tribe's other First Steps project, "Human Capacity Building In Energy Efficiency and Renewable Energy System Maintenance for the Yurok Tribe." Key findings of that project were: 1) based on field assessments of Yurok homes, there is a substantial need for weatherization on the Reservation, and 2) increased use by the Tribe of existing low-income weatherization services offered by the Redwood Community Action Agency in Humboldt County and the Del Norte Senior Center in Del Norte County is the fastest and most cost-effective way for the Tribe to meet that need (as opposed to creating, funding and staffing a new Tribal weatherization program). The final report for that project will discuss weatherization options in greater detail. This project will thus focus on the need for energy efficiency in new construction and major renovations.

Requiring greater energy efficiency in new construction can raise initial costs. However, it has been demonstrated in some cases that choosing more efficient building envelope materials or construction techniques can actually reduce first costs, because the reduction in heat transfer in and out of the envelope may justify specifying smaller, less expensive heating and cooling equipment. Where appropriate efficiency measures do increase initial costs, energy savings can repay these costs within a reasonable time period (typically less than five years). 
Tribal Energy Code and/Or Yurok Indian Housing Authority Energy Policy

One important mechanism for assuring efficient new buildings on the Reservation would be the introduction of a Yurok Tribe energy code, which would encourage or require energy-efficient building practices through prescriptive and/or performance-based approaches. The National Tribal Justice Resource Center (www.tribalresourcecenter.org) maintains a searchable online database of Tribal laws and codes. A search of the database shows that numerous Tribes have adopted energy efficiency codes. It appears that most Tribes have simply adopted voluntarily the prevailing state or regional code in effect in their area.

The Yurok Indian Housing Authority (YIHA) manages approximately 100 units of housing, both single and multi-family, stick-built and modular. About half of those housing units are on the Reservation, located both upriver and downriver. Several of these homes have been built by the YIHA in recent years. All of the YIHA units are on the electric grid. The YIHA has an eight-member construction crew on payroll and already has experience with meeting energy needs on the Reservation. For example, its 2005 Indian Housing Plan identified "provide energy related improvements" as part of Objective 2.2 in its 1-Year Plan and earmarked $\$ 50,000$ of its projected $\$ 3.4$ million Indian Housing Block Grant for energy-related improvements to affordable housing. These improvements included installing woodstoves in homes and upgrading homes' electrical systems for connection to the utility in areas where grid power is newly becoming available.

SERC staff spoke with YIHA director Sandra Lowry, who said neither the Tribe nor the YIHA currently has its own energy code in effect. YIHA construction is guided by the Uniform Building Code. YIHA does informally use some standard efficiency practices, such as installing low-e vinyl framed windows and building shell insulation, and upgrading furnaces to more efficient models. Ms. Lowry says her department is open to the idea of adopting an energy policy, provided that any fiscal impacts such as increased construction costs or code enforcement activities can be identified. This will allow her to budget for these cost increases in her annual Indian Housing Plan (IHP).

Ms. Lowry stated that the YIHA is happy to endorse a Tribal energy code to be adopted by the Tribal government that would apply to all construction on the Reservation. However, she also noted that the Housing Authority is essentially autonomous - they are a 501(c)3 nonprofit, separate from the Tribal government. She says the YIHA can act unilaterally to adopt its own internal energy efficiency policy that will govern YIHA construction without waiting for the Tribal Council to implement a Reservation-wide code, and she is interested in doing so.

New residential construction on the Yurok Reservation that is managed by the YIHA currently conforms to the U.S. Department of Housing and Urban Development's (HUD) energy code. HUD uses the 1992 Model Energy Code (MEC) as its energy efficiency standard, as documented in HUD's Minimum Property Standards for Housing. Possibilities for a Yurok Tribe energy code and/or YIHA energy policy include:

- Continue to use the HUD-approved 1992 MEC (do-nothing alternative) 
- Upgrade to a more current federally-recognized energy standard (e.g. 2006 International Energy Conservation Code (IECC)

- Develop a Yurok Tribal energy code "from scratch"

- Adopt Title 24, Part 6 of the California Code of Regulations (aka "Title 24") energy efficiency standards

- Adopt the Energy Star Building Performance Standard or other standard that exceeds Title 24 requirements

Continuing to use the 1992 MEC would require the least effort on the Tribe's part but would not improve energy efficiency in new construction. Upgrading to the 2006 IECC would result in some energy savings but would potentially create logistical hurdles in working with HUD, as they are still working under the 1992 MEC. Compliance of a home building design with any version of MEC/IECC can be determined using free public domain software called RESCheck, available from www.energycodes.gov. This software calculates thermal conductivities and surface areas of building envelope materials (referred to as UA) and mechanical system efficiencies to determine whether a building design is compliant.

In-progress and upcoming YIHA projects are numerous and show there is ample opportunity for an energy policy to deliver savings across the Reservation:

- Three homes in progress at Klamath town site. These will be three bedroom, $1400 \mathrm{ft}^{2}$ homes. Foundations have been poured. Remaining work has not gotten underway yet.

- Crescent City. 15 homes to be demolished; due to zoning regulations that have come into effect since original construction, the number of replacement homes to be built will probably be closer to 10 .

- Orcutt property near Pecwan. Approximately 10 homes to be built in the area. Still several years away, the property is not under YIHA control. Homes may or may not be reached by grid power extension by the time they are built. This development may be a candidate for village scale renewable power - it has two major creeks nearby and good solar access.

- Bennett property in Klamath. YIHA plans to build about 22 units, a mix of apartments and single family homes. Approximately three four-plexes, plus about twelve three-bedroom $1300-\mathrm{ft}^{2}$ homes. The project is contingent on putting the land in Tribal trust.

Since much of the YIHA's planned construction will be off-reservation and subject to city building department permits, they will need to meet Title 24 on these projects. So in a way, it is simpler for the YIHA to adopt a Title 24 compliance policy for all their projects, even though they are technically exempt when they build on the Reservation.

Writing a Custom Energy Code: The Samish Experience

Developing a custom energy code for the Yurok Tribe may be problematic, as it would take up significant staff time and be unlikely to yield greater energy savings than can be achieved by adopting an existing standard. However, the Samish Tribe of Washington State have adopted an energy efficiency code for new and altered residential buildings, which is being provided to the Yurok Tribe separately from this report, as we have been 
asked not to distribute the document to the general public. The Samish code's requirements for equipment efficiency and thermal performance of building shell elements are not consistent with California's Title 24 standards. In some cases the Samish codes are more strict, sometimes they are less strict, and sometimes they are the same as Title 24. (Comparison with Title 24 is complicated by the fact that Title 24 uses multiple climate zones, two of which include parts of the Yurok Reservation, and Title 24 offers multiple compliance options with different energy performance values for equipment and materials.) This inconsistency is likely to cause confusion and communication problems in working with California-based contractors accustomed to Title 24. For this reason, we do not recommend adopting the specific numeric provisions of this code, such as insulation levels and heating and cooling equipment efficiencies.

Another difficulty with the Samish code is that (despite the code's claim that its "provisions provide flexibility to permit the use of innovative approaches and techniques to achieve efficient use and conservation of energy") the requirements are generally prescriptive and do not permit the degree of flexibility for the builder that is found in Title 24's popular performance-based compliance option. Under the Title 24 performance method, a builder can use less efficient materials or equipment in some applications to meet a specific objective (e.g. extra windows to take advantage of a view) if higher efficiency is incorporated elsewhere in the design, allowing the building to meet overall efficiency goals.

Despite these issues, the Samish code is worth looking at as an example of a code written by a Tribe (based on their state's energy code and the International Energy Conservation Code). Some of the non-quantitative provisions, such as the passive solar design guidelines in Section 7.XXX.004 and the electrical recommendations in Section 7.XXX.007, would make excellent additions to a Yurok energy code.

SERC staff spoke with Samish Tribe Environmental Director Christine Woodward, who was responsible for development and implementation of this code. She reports that no new construction has taken place under the code since it was adopted approximately one year ago. Thus it is not yet possible to measure the code's impact. Ms Woodward reports that the process of developing and adopting the code was straightforward, with no significant political hurdles.

\section{California Title 24 and Energy Star Standards}

SERC recommends that the Tribe and YIHA immediately adopt Title 24 as the Tribal energy standard so as to synchronize with the rest of the state, in the process improving substantially upon the 1992 MEC currently in force for HUD-supported new construction on the Reservation. The Tribe would realize significant energy savings with this change. Adopting Title 24 should not create logistical problems with respect to architects and building contractors, as they are already accustomed to complying with Title 24 when they work elsewhere in California.

In the longer term, the Tribe should set a goal of adopting the Energy Star Building Performance Standard for all new construction. The Energy Star standard would result in 
buildings $30 \%$ to $50 \%$ more efficient than the MEC and $15 \%$ more efficient than Title 24 . A webcast sponsored by HUD, titled New Construction Techniques: Energy Star Qualified New Homes, Green Building and Renewable Energy will take place on September 18, 2007. For more information on this and other HUD energy training webcasts, visit:

www.hudenergytraining.com/

Under Title 24, builders can choose to meet energy standards through either a prescriptive or a performance approach. Using the prescriptive approach, the builder must use materials that meet minimum energy efficiency standards throughout the building. With the performance approach, the builder has greater flexibility in choice of materials but must demonstrate through a building simulation that overall energy performance will meet the code requirements. The performance approach is more popular because it allows builders to make tradeoffs in order to incorporate design elements desired by the client, such as more window area in certain orientations than the prescriptive approach would permit. Title 24 compliance through the performance approach is somewhat more complex than for MEC/IECC and is determined using proprietary software such as EnergyPro, which is available for purchase from www.energysoft.com/energypro.htm or MICROPAS, available from www.micropas.com.

Note that local building contractors are accustomed to documenting compliance with Title 24. Most either have staff who perform the calculations or they use consultants who specialize in Title 24 compliance calculations. In general, the Tribe would likely hold contractors responsible for demonstrating compliance rather than Tribal staff performing the calculations. In some cases, such as for construction managed by the YTHA, the Tribe may choose to hire their own Title 24 consultant.

One issue to be aware of if the Tribe adopts the Title 24 energy code as-is is that it will require different compliance measures for buildings located on different parts of the Reservation. Title 24 uses 16 climate zones, with energy efficiency requirements differing depending on the zone in which a building is located. The Yurok Reservation includes portions of zones 1 and 2, with most of the Reservation, including the coastal areas, located in zone 1 . Weitchpec is in zone 2 . The boundary between zones 1 and 2 on the Reservation is a north-south line running immediately east of the Tully Creek residential area on the west bank of the Klamath River. For the most part, zone 1 requirements are more cold climate-oriented, with a focus on stopping heat loss to outdoors. The zone 2 requirements assume a warmer climate and in comparison focus more on stopping heat gains from outdoors. For example, in zone 1 there is no restriction on solar heat gain coefficient (SHGC) for windows, while in zone 2 SHGC cannot exceed 0.40. Also, the ceiling or roof insulation requirement for zone 1 is R-38 with no radiant barrier needed, while in zone 2 it is R-30 with a radiant barrier required. This distinction between zones 1 and 2 should help the Tribe to ensure appropriate building measures across the Reservation, as the climates in Klamath and Weitchpec are certainly quite different. Of course, the Tribe is under no obligation to use the zone boundaries developed by the State of California and could instead set its own zone boundary based on local knowledge of micro-climates on the Reservation. However, the use of at least 
two climate zones on the Reservation is recommended, given the important differences in microclimate across the Reservation.

Energy Provisions in the Yurok Gaming Compact

As of this writing, a Tribal-State Gaming Compact between the Yurok Tribe and the State of California is currently undergoing ratification by the state legislature. One provision of the compact, Section 6.4.2(b), reads:

In order to assure the protection of the health and safety of all Gaming Facility patrons, guests, and employees, the Tribe shall require the Gaming Facility, and any expansion, modification, or maintenance of such Gaming Facility, to meet or exceed the California Building Code and the Public Safety Code applicable to Del Norte County as set forth in Titles 19 and 24 of the California Code of Regulations, as those regulations may be amended during the term of this Compact, including, but not limited to, codes for building, electrical, energy, mechanical, plumbing, fire, and safety ("the Applicable Codes"); provided that the Tribe need not meet any standard that specifically applies in name or in fact solely to tribal gaming facilities.

In order to assure compliance with the Applicable Codes, in all cases where said codes would otherwise require a permit for non-tribal construction, the Tribe shall require inspections to assess compliance, and in that connection, shall (i) employ appropriate plan checkers or review firms that are either California licensed architects or engineers with relevant experience or are on the list, if any, of approved plan checkers or review firms provided by Del Norte County and (ii) employ project inspectors that are currently either certified as Class 1 inspectors by the Division of the State Architect or as Class A inspectors by the Office of Statewide Health Planning and Development or their successors. Alternatively, the Tribe can reach agreement with the County of Del Norte for the County's building inspectors to examine, at the Tribe's expense, all aspects of the Gaming Facility, or any expansion, modification, or maintenance thereof, in order to assess compliance with the Applicable Codes. In either case, the Tribe shall require the inspectors to report in writing any failure to comply with the Applicable Codes to both the Tribal Gaming Agency and the State Designated Agency. The plan checkers, review firms, and project inspectors shall be referred to as "Inspector(s)." Without limiting the rights of the State under this section, reference to Applicable Codes is not intended to confer jurisdiction upon the State or the County. [emphasis added]

This language from the compact provides a convenient and legally tested ${ }^{5}$ template for the Tribe to voluntarily expand Title 24 energy codes to non-gaming facilities, as well as an enforcement mechanism (though naturally enforcement power for non-gaming facilities would lie ultimately with the Tribe, not the Tribal Gaming Agency). The Tribal Council could adopt a resolution using similar language to apply the energy code requirements, as well as other construction codes as desired, to all construction on the Reservation.

\footnotetext{
${ }^{5}$ Several compacts already in effect governing other California Tribes use the same language.
} 
Making Allowance for Special Conditions on the Reservation

In some cases, all propane or kerosene combustion appliances on the market that meet an energy code may require electricity to operate, making them an inappropriate choice for the remote, power outage-prone reservation. A Tribal energy code should make allowance for this. For example, the Tribe has had problems with kerosene heaters, which require electricity to operate - they can't heat the house when the power goes out, which happens often and can last for days or even weeks. It is not surprising that woodstoves are popular for home heating on the Reservation.

YIHA staff acknowledge other energy performance problems with recent homes built on the reservation, such as heat registers near the ceiling that fail to heat the home adequately, and homes with high ceilings that are difficult to heat and maintain. YIHA would like to see energy policies that address these issues.

Code Management and Enforcement

If the Tribe implements an energy code, it will be necessary to provide plan-checking and enforcement to ensure code compliance. The Tribe's planning department is already moving toward having a full building permitting process with dedicated staff. They are already doing permitting to hook up to drinking water systems, and will soon be doing the same with wastewater systems (both permitting of hookups to central wastewater collection systems and permitting of on-site treatment systems, i.e. septic). Building permitting will happen eventually, either via the department's own staff or contracted out, as some smaller local governments do. Field inspection and enforcement will also be required. It will be relatively straightforward to include energy plan review and field enforcement as part of these services, as counties and cities in the region already do.

\section{Opportunities to Aggregate Electric Accounts}

In the first phase of this project, Winzler and Kelly found that it was not feasible for the Yurok Tribe to establish a conventional Tribal electric utility. A conventional Tribal electric utility owns and operates the transmission and distribution grid that provides power to its customers and typically owns energy generation facilities, though some power may be purchased through the wholesale power market. A conventional Tribal electric utility is responsible for running all aspects of the its utility business, including metering, billing, customer service, operation and maintenance of the power supply and distribution infrastructure, and administration of all power purchase and transmission contracts and agreements. This is a serious undertaking for any Tribe.

In California there is now a new opportunity available to municipal governments and joint powers authorities (JPAs), and potentially to Tribes as members of JPAs. This new arrangement is known as Community Choice Aggregation, or CCA. In 2002, California law established CCA with the passage of AB 117. CCA allows California cities and counties, or groups of cities and counties that form a JPA, to aggregate their electric loads and supply electricity to all customers within their boundaries. To accomplish this the local government entity becomes a Community Choice Aggregator that procures electricity for its customers. The CCA can either generate its own electricity or purchase 
it on the wholesale market. Unlike a municipal utility, the CCA does not own or operate the transmission and distribution system and is not responsible for customer billing or meter reading. Instead, the local electric utility continues to serve these functions.

The value of forming a CCA is that it gives the local community control over where it buys its electricity. The CCA can shop around for the cheapest power available, or for the "greenest" power available; it's their choice. The CCA also has local control over setting retail electric rates and distributing public benefits funds. Under CCA, decisions about generation sources, rates, and public benefits will be made locally and the CCA will be held accountable to local customers. The potential benefits of forming a CCA are: 1) increased use of renewable energy, especially local resources, 2) lower rates, and 3) local economic growth.

One of the main opportunities is for CCAs to develop their own local renewable energy resources at lower rates than could be realized under conventional investor owned utilities. A CCA can generate power at any location where they have access to renewable energy resources and can then negotiate transmission agreements to transmit the power to their customers. CCAs can potentially accomplish this at lower cost because they can obtain cheaper capital through the use of local government financing, such as revenue bonds. In addition, CCAs do not need to make a profit for shareholders and do not have to pay income taxes. By developing local renewable energy resources CCAs can keep energy dollars in the local community, create local jobs, and achieve goals for increased use of renewable energy and lower greenhouse gas emissions.

It has been found that communities wanting to form CCAs must have a sufficient number of customers to realize the potential benefits. In order to have leverage as an electricity buyer the CCA must have an adequate customer base. While there is no magic number that defines what this "adequate" customer base is, it is expected that a population base of on the order of 100,000 people would be necessary. Even then, forming a CCA does not come without potential risks. The biggest risk associated with CCAs is that rates could end up being higher. However, well-managed power purchasing and development should mitigate this risk. The CCA can develop a well-balanced portfolio of resources that include both short- and long-term contracts and CCA financed new generation projects. CCAs can also create a rate stabilization fund that can hold prices down when there is volatility in the wholesale power market. The operation of a CCA is a serious undertaking. If the local government aggregation does not have the needed expertise and resources to perform the necessary functions, such as procuring generation resources, they can contract out these functions to a third party operator.

One major question that remains to be answered is whether or not American Indian Tribes are eligible to participate in the CCA process. The CCA legislation enables local municipalities or JPAs to establish a CCA. We contacted California Administrative Law Judge Kim Malcolm who is presiding over the CCA implementation process. According to Judge Malcolm, the CCA statute refers to cities and counties; however, it does not explicitly define CCA status as being limited to cities and counties. Section 366.2(b) refers to a "public agency" more generally. According to Judge Malcolm, the best way to 
obtain a formal opinion from the CA Public Utilities Commission (CPUC) is to file a motion as part of the CPUC proceeding on Community Choice Aggregation. This motion could request clarification on whether an Indian Tribe or group of Tribes in California is eligible to form a CCA.

Another possibility is for an Indian Tribe to join a JPA along with other municipal entities. However, there are legal question about the viability of this approach as well. The Hoopa Tribe has been battling for years to gain access to gain membership to the Humboldt County Association of Governments, a local JPA in here in Humboldt County. A California law passed in the 1980's cleared the legal hurdle to the Tribe's membership by declaring it a public agency; however, the HCAOG board has repeatedly deadlocked on the issue and has yet to grant membership to the Hoopa Tribe.

Nonetheless, a precedent has been set for California Tribes being able to join JPAs. The Hoopa Tribe did establish a JPA with the County of Humboldt in 1995 to cooperate on law enforcement matters. There is currently legislation pending in the CA Assembly (AB 847) that would authorize the Yurok Tribal Council to enter into a JPA with public agencies for the purpose of preservation and restoration of fish stocks on the Klamath River and Fisheries in the Klamath River Basin. Two other California Tribes have also gained a public entity designation according to CA statute. This includes the Torres Martinez Desert Cahuilla Indians for participation in the Salton Sea Authority, and the Elk River Tribal Council in Del Norte County for a JPA to finance a new sewer plant. Another bill (AB 1747) was passed in 2005 that granted the Rumsey Band of the Wintun Tribe authority to participate in a JPA with UC Davis, Yolo County Flood Control and Water Conservation District, and the City of Davis among others. Unfortunately, the Governor vetoed this bill. Another Assembly Bill (AB 169) is currently pending in the legislature. This bill would provide the 16 federally recognized Indian tribal governments could participate in the Southern California Association of Governments.

The CCA process in California is brand new, and to date no municipalities have completed the process of forming a CCA. However, many communities are well along in the process. The typical steps required to start a CCA are: 1) adopt an ordinance to form a CCA (this provides legal standing and complete access to utility customer data), 2) secure funding to prepare an implementation plan and develop a request for proposals for power purchase, 3) get bids for power, 4) approve the CCA ordinance, 5) award the power purchase contracts, 6) file an implementation plan and get it approved, 7) file a binding notice of intent to operate a CCA.

The community that is furthest along in the CCA process is the San Joaquin Valley Power Authority (SJVPA), a JPA in the central valley of California that includes Kings County, the City of Fresno, and others. SJVPA has submitted their implementation plan to the CPUC and had it approved. They intend to file their binding notice of intent and begin operating their CCA in the fall of this year. The City of San Francisco has developed an implementation plan, and the plan, as well as a corresponding ordinance, have been approved by their Board of Supervisors. Many other communities in California have begun this process as well. 
In terms of CCA opportunities for the Yurok Tribe, it is clear that they would have to join with others to make this arrangement feasible. One possibility is to join a local JPA. Local governments and individuals in Humboldt County are just beginning to explore the opportunities for forming a CCA. If this process were to move forward, it would be in the Yurok Tribe's best interest to get involved in the discussion and explore the opportunity for participating. If the Yurok were to join a CCA, they could develop power anywhere on the Reservation and feed it into the local electric grid for use by members of the CCA. This opportunity is discussed further in the next section.

\section{Opportunities to Generate Revenue with Renewable Energy}

As discussed in the "Inventory of Renewable Energy Resources" section of this report, the Yurok Tribe may have some good opportunities to develop renewable power resources on the Reservation for sale to the electric power grid. Hydro, biomass and wind are the most likely candidates for such development, and funding requests have been submitted to DOE and BIA to study the feasibility of developing these resources. In this section we outline the opportunities the Tribe has for selling renewable power to the electric grid should it choose to develop some if its renewable energy resources.

The current electricity market in California is deregulated at the wholesale level, but still regulated at the retail level. California briefly experimented with the deregulation of the retail electricity market, but that experiment was a complete disaster that left the state's economy reeling. At this point the majority of California's retail electric customers continue to be served by investor-owned utilities that operate as regulated monopolies. Other customers in the state may be served by a municipal utility or an electric cooperative. The Yurok Tribe is served by two investor-owned utilities: Pacific Gas and Electric (PG\&E) in Humboldt County, and Pacific Power and Light (PP\&L) in Del Norte County. These utilities have franchise agreements to provide power throughout their service territories and they are obliged to serve all consumers and to charge reasonable retail prices that are approved by the CPUC.

These utilities generate some power at their own facilities and also purchase power on the open wholesale electricity market. Power is typically purchased via long-term contracts to meet the majority of their needs, with the remainder being purchased under short-term agreements, including day ahead purchases and spot market purchases to meet peak power needs on ten-minute intervals. The price paid for short-term wholesale electricity is based on a competitive market price that is somewhat regulated and monitored by the California Independent System Operator (CAISO) and the CPUC. The CAISO manages the flow of electricity on the transmission grid and the scheduling of power deliveries. They provide for open and nondiscriminatory access to the transmission grid so that generators who make wholesale power sales can schedule the delivery of power over the transmission system.

\section{Retail Generation}

Renewable power can be fed to the electric grid by both retail and wholesale generators. Retail generation is limited to distributed generators and is governed by California Electric Rule 21. Rule 21 specifies certain interconnection requirements and applies to 
customers who install generators to reduce the amount of power they purchase from the utility. This includes net metering customers as discussed in the "Making Renewable/Distributed Energy Systems Available on the Reservation" section. Net metering is available to solar, wind, biogas, and fuel cell generators less than $1 \mathrm{MW}$ in capacity. The other retail generators allowed to "sell" power to the grid include those selling "over the fence" to an immediately adjacent property or selling to a state or local public agency per CA Public Utilities Code Section 218. However, this CPUC Section 218 provision requires an independent transmission connection between facilities. The power cannot be transmitted between sites on the utility grid.

However, a new bill introduced into the state legislature, SB 451, would allow any city, county, or joint powers agency to generate renewable electricity at one location and receive a bill credit at another location. This legislation would essentially allow net metering for all of a local government's accounts as if they were aggregated into one account. Like with net metering, the local government's electric bills would be trued up on an annual basis. Excess credit could be carried forward from one month to the next, but at the end of the annual cycle any excess electrical production would become the property of the electric utility without compensation to the local government.

\section{Wholesale Generation}

Renewable power can also be sold to the grid at wholesale rates. In California renewable power is typically sold to the local utility under a Qualifying Facility (QF) contract or a Renewable Portfolio Standard (RPS) contract. Wholesale renewable power can also be sold on the open wholesale market to any willing buyer provided transmission access can be adequately scheduled. However, rates on the open wholesale market are generally not as favorable as will be received under a QF or RPS contract. Rates for wholesale power also vary based on the availability of the supplied power. For example, is it being sold as as-available, baseload, peaking, or dispatchable power? Intermittent renewables like solar and wind power will be sold as-available. Biomass power would likely be sold as baseload power, though it may depend on how the biomass energy plant is run.

A Qualifying facility $(\mathrm{QF})$ is a generating facility that meets the requirements of QF status under the Public Utility Regulatory Policy Act of 1978 (PURPA) and has obtained certification of its QF status. Small power production facilities ( $\leq 80 \mathrm{MW}$ in capacity) whose primary energy source is renewable (hydro, wind, solar, biomass, waste, geothermal) are eligible for QF status. There is no minimum capacity for a QF facility. Once a facility has obtained QF status, the local host utility is required to buy power from the QF at the host utility's avoided cost rate. The avoided cost is the incremental cost to an electric utility of electric energy or capacity which, but for the purchase of power from the $\mathrm{QF}$, the host utility would have generated itself or purchased from another generator.

The Federal Energy Policy Act of 2005 modified the obligatory purchase requirements for power generated by a QF. If the QF has nondiscriminatory access to competitive short-term and long-term wholesale energy markets and open access to transmission and interconnection services, then the host utility is no longer required to purchase power from the QF at it's avoided cost rate. However, the Federal Energy Regulatory 
Commission has determined that QF's with a capacity less than $20 \mathrm{MW}$, regardless of where they are located, do not have access to competitive wholesale markets. Therefore, all host utilities are still required to purchase power from QF's smaller than $20 \mathrm{MW}$. PG\&E's avoided cost rate for QF's in 2007 range from about $\$ 0.06 / \mathrm{kWh}$ to $\$ 0.08 / \mathrm{kWh}$ depending on the type of power, the season, and the time of day. Over the last five years the seasonal average has ranged from a low of $\$ 0.02 / \mathrm{kWh}$ to a high of $\$ 0.13 / \mathrm{kWh}$.

In 2002, California enacted legislation that established the Renewable Portfolio Standard (RPS). The RPS requires retail sellers of electricity to purchase $20 \%$ of their electricity from renewable resources by 2010, and has set a goal of 33\% renewables by 2020 . Eligible renewable resources include biomass, solar, wind, and hydropower $(\leq 30 \mathrm{MW})$, among others. The California Energy Commission, in collaboration with the CPUC, implements the state's RPS.

Because the state anticipated that renewable energy resources might cost more than conventional energy resources, they established a system to help offset the incremental cost of renewables. This system is known as supplemental energy payments (SEPs). Each year the CPUC establishes a Market Price Referent (MPR) that establishes the market value of renewable power. The 2005 MPR for power coming on-line in 2006 was $\$ 0.083 / \mathrm{kWh}$ for a 10 year term, $\$ 0.082 / \mathrm{kWh}$ for a 15 year term, and $\$ 0.083 / \mathrm{kWh}$ for a 20 year term. Prior to the establishment of the annual MPR, eligible RPS generators will bid to provide power to requesting utilities. When an RPS generators bid is selected, the purchasing utility will pay the full bid price if it is at or below the MPR. If the bid price is above the MPR, the utility will pay the MPR price and SEPs will be used to make up the difference. The money to fund the SEPs comes from the public benefits surcharge fund that all electric ratepayers pay into.

While the SEPs may seem like a good idea to compensate for higher priced renewable power, in practice they are not working very well. Evidently it is not easy for an RPS generator to collect their SEPs, and there is no guarantee the money will be received. For this reason it is hard to secure financing for a new renewable energy project if the project will rely in part on SEPs as part of its revenue stream. In practice this means that all successful RPS generators are bidding at or below the MPR.

PG\&E has 2007 solicitation out for RPS power. They are particularly interested in dispatchable power, but will consider offers for other types of power as well, such as asavailable and baseload. Desired contract terms are 10, 15 or 20 years. Minimum capacities for as-available and baseload power is $1 \mathrm{MW}$, though there is a chance they would make exceptions to this capacity requirement.

We spoke with PG\&E's Power Purchasing Department and they indicated that PG\&E is looking for any sources of renewable power that they can find. They indicated that there are likely ways to arrange to sell renewable power to PG\&E regardless of the capacity of the project. They suggested that when a project opportunity is being seriously considered that the Tribe should contact the Power Purchasing Department and begin discussions 
about how to get the power into the grid. They also indicated that there is supposed to be a new power purchase arrangement in the works for generators smaller than $1 \mathrm{MW}$.

There is also recent and pending legislation in California that aims to make it easier for public agencies to sell renewable power to the grid and offset cost of their own power purchases. AB 1969 was signed into law in 2006 and allows water and wastewater agencies to install renewable electrical generation $(\leq 1 \mathrm{MW})$ on or adjacent to their water and wastewater facilities and to sell power back to the grid at the market price as defined by the MPR discussed above. The generator must be sized no larger than to offset all or part of the facilities power demands. More recent legislation that is currently before the legislature (AB 946) would expand the above provisions for water and wastewater facilities and allow them to locate the generation facility on any land that they own, lease or control instead of requiring the generator to be located on the same or adjacent property to the water and/or wastewater facility.

Renewable Energy Production Incentive

The Renewable Energy Production Incentive (REPI) was originally authorized in 1992 and expired in 2003. However, the Energy Policy Act of 2005 reauthorized appropriations for REPI for fiscal years 2006 through 2026. Eligible generators include solar, wind, and biomass, among others. Eligible entities include electric cooperatives, public utilities, state governments, Indian tribal governments, and Native Corporations that sell the projects electricity to someone else. Qualifying facilities are eligible for annual incentive payments of $\$ 0.015 / \mathrm{kWh}$ (1993 dollars and indexed for inflation) for the first ten year period of operation, subject to the availability of annual appropriations.

\section{Renewable Energy Certificates (Green Tags)}

In theory, renewable energy should be marketable directly to the grid as a premium-value product. In practice, this may be difficult. One possible solution is to sell the green power at standard market rates and sell the environmental attribute separately. This is done using tradable renewable energy certificates, also referred to as green tags. In some states, people can choose what type of power they would like to buy. In other areas people are not afforded this choice. Green tags is a way that people anywhere in the country can choose to purchase the environmental attributes of renewable power. According to DOE, at least one Tribe, the Rosebud Sioux, have already generated Tribal revenues through sales of green tags.

Certification is a critical component of the green tags system, as buyers need to be assured the environmental attribute they are paying for is verifiable and is not being fraudulently sold to multiple buyers. The Green-e program has been set up to do just this. Green-e is a nationally recognized program for independent certification and verification of renewable energy products. Because green tags separate the environmental attribute from the renewable electricity, it is important to keep track of that attribute and make sure that it is only sold or claimed once. Table 13 lists various ways renewable energy can be used or sold and identifies whether the green tags are separately available for sale or have already been claimed. 
Table 13. Renewable Energy Use and Green Tag Status

\begin{tabular}{|l|c|}
\hline Renewable Energy Use & $\begin{array}{c}\text { Green Tag Available for } \\
\text { Sale/Claim? }\end{array}$ \\
\hline $\begin{array}{l}\text { Off-grid power use, no claim } \\
\text { for Green Tag }\end{array}$ & Yes \\
\hline $\begin{array}{l}\text { Net metering, no claim for } \\
\text { Green Tag }\end{array}$ & Yes \\
\hline $\begin{array}{l}\text { Off-grid power use or net } \\
\text { metering, using renewable } \\
\text { energy as claim for carbon } \\
\text { offset }\end{array}$ & No \\
\hline $\begin{array}{l}\text { Sell power as a Qualifying } \\
\text { Facility }\end{array}$ & $\begin{array}{c}\text { Depends on contract terms. } \\
\text { If utility is counting renewable } \\
\text { power toward meeting their } \\
\text { RPS goals or carbon dioxide } \\
\text { emission reductions, then the } \\
\text { Green Tags are not available } \\
\text { for sale or claim }\end{array}$ \\
\hline $\begin{array}{l}\text { Sell power via Renewable } \\
\text { Portfolio Contract }\end{array}$ & \multicolumn{1}{c|}{ No } \\
\hline $\begin{array}{l}\text { Sell power to wholesale } \\
\text { electricity market, not sold as } \\
\text { "green" power }\end{array}$ & \\
\hline
\end{tabular}

DOE listed 28 separate green tag products on the market as of July 2006, most of which are for wind energy. Certificates are also available for other forms of renewable energy, energy efficiency, and carbon-sequestering reforestation projects. The price premium paid by consumers for the listed products ranged from 0.5 to 7.5 cents per $\mathrm{kWh}$. The amount paid to the generator for the green tags would obviously be somewhat less.

It is noteworthy that one company that sells green tags, NativeEnergy LLC, specializes in marketing of green tags associated with renewable energy projects on Tribal lands. NativeEnergy states on their web page: "We are Native American majority-owned. The Intertribal Council On Utility Policy, a non-profit organization of Great Plains Tribes, holds a majority equity interest in NativeEnergy."

The sales of green tags are usually accomplished in two steps. First the renewable electricity generator sells the green attributes at a wholesale price to a commercial or wholesale marketer, like NativeEnergy. The green tags are later sold at a retail price to an electricity end user. DOE's Green Power Network web site listed 52 national commercial and/or wholesale green tag marketers as of June 2007. For more information see: http://www.eere.energy.gov/greenpower/about/index.shtml 


\section{Billing for Energy Services Provided By Tribe}

The Tribe has long recognized that it will be necessary to use some form of cost recovery mechanism to meet the ongoing costs of providing energy services to Tribe members. However, the actual implementation of billing for energy services, specifically for residential solar energy systems, has been problematic.

During 1998-99, Arne Jacobson, now a member of SERC staff and assistant professor in Humboldt State University's environmental resources engineering department, assisted the Yurok Tribe in renewable energy development as a subcontractor to energy consultant Kelso-Starrs and Associates. He filed a series of memos and reports during this time that detailed his efforts to, among other things, help the Tribe implement a system for billing Tribe members for the use of home solar electric systems. A brief summary of relevant points from these reports follows.

March 16, 1998 report: Seven 720-Wp pilot solar electric systems had been installed recently. Arne visited five of these sites. All of them were receiving periodic maintenance. At this time, billing for use and maintenance of the systems had not been implemented. The Tribe's planning director described the billing issue as "sticky" and explained that the Tribal Council was working on a solution.

March 31, 1998 report: Describes Tribal Council discussion on creating a billing system for solar electric systems provided by the Tribe. The Tribe would pay the entire up-front cost of the systems, with the billing intended only to recover maintenance costs. Council was concerned about ability to pay among low-income upriver residents. The proposed billing system would have a fixed component plus a per-kWh rate. The rate could be tiered, with seasonal changes in the $\mathrm{kWh}$ allowance at each tier to allow for more abundant energy in summer months. Ability to pay issues could be addressed by helping residents to reduce expenditures on other fuels such as propane through energy efficiency measures, thus leaving more household funds available for solar electric costs. (Helping Tribe members to increase their access to federal Low Income Home Energy Assistance Program [LIHEAP] funds was also a strategy explored at the time.) Another approach would be to offer a variety of system sizes according to residents' ability to pay.

April 22, 1998 report: States that a memo is being prepared for circulation that outlines billing options.

December 22, 1998 report: In December 1998 the Tribal Council adopted a billing ordinance drafted by Kelso-Starrs. Arne and Tribal staff began visiting Tribal households served by solar electric systems provided by the Tribe to discuss how these families with existing systems would be brought into the billing system.

January 22, 1999 report: Arne continued meeting with families that would be impacted by the billing ordinance. The consensus was that the $\$ 85$ monthly charge set forth in the ordinance was too high and these families would prefer to remove their systems rather than pay this fee. Arne explained that another option would be to trade down to a smaller 
system and pay $\$ 50$ to $\$ 65$ a month, but residents were not interested in this solution. The Tribe identified an electrical contractor to install meters on the systems not already equipped with meters.

April 22, 1999 report: Implementation of the billing plan moved ahead, with meter readings set to begin on May 1 . Bills were to be sent out May 15, with payment due June 10. During the first three billing months, a flat $\$ 85$ monthly fee would be charged, with a per-kWh charge being added to that in subsequent months.

In addition to these periodic briefing reports, Arne also submitted a 16-page report to the Tribe, Yurok Alternative Energy Systems Billing Options: Preliminary Recommendations. The report compared expected costs and revenues and logistical pros and cons for different billing options, including flat, metered, and mixed billing. Arne recommended the use of a mixed billing system, where users would pay a flat rate up to a certain $\mathrm{kWh}$ usage, then pay a per-kWh rate for additional consumption. The report also explored the possible use of rebates and fines to encourage responsible use of off-grid power systems.

In May 1999 Tribal Planning's then-Director Sef Murguia sent out a letter to households with Tribe-provided energy systems announcing the implementation of a monthly billing system. For most of the households, which had been provided by the Tribe with standardized 720-watt photovoltaic systems, the bill would consist of a flat fee of $\$ 85$ per month. If monthly usage exceeded $135 \mathrm{kWh}$, the bill would include an additional charge of $\$ 0.50$ per $\mathrm{kWh}$ above the $135 \mathrm{kWh}$ baseline. Reportedly, the system users objected to this proposed billing plan. It is believed that no payments were actually collected.

Ultimately, the billing system was not successful and was abandoned. Although an initial set of bills was issued with Mr. Murguia's May 1999 letter, it is not believed that any revenues were collected by the Tribe following a negative reception from the billed households. At this time, no scheduled maintenance of existing renewable energy systems is being provided by the Tribe. In some cases, particularly for elders' households, the Tribe is providing corrective maintenance, repairs, or even replacement of equipment on an as-needed basis, but no consistent, dedicated funding source covers this.

Dr. Jacobson recently provided the following insight regarding the failure of the billing system to catch on:

The history of how the RE [renewable energy] systems were delivered to households and people's understandings of who owned them was a central part of the problem in establishing a billing program. The original systems (installed before I was hired; in 1995-97, I believe) were installed at households with all expenses paid by the Tribe, but ownership of the equipment was ambiguous. The households thought that the systems were a gift (i.e. that they were the owners), but the Planning Dept. of the Tribe maintained that the Tribe retained ownership. This was one of the central points of contention in setting up a billing system, and it was never resolved. The fact that the first systems were apparently "given" to some households made it difficult to set up a different relationship for subsequent 
installations. As a result, the problem propagated over time. I'd be interested to know what the current arrangement is when systems are installed (i.e. what do the homeowners understand about who owns them and how does this compare with what the Tribe thinks?).

It is critical that in any future installations of energy systems where the Tribe is covering some or all of the cost, ambiguity about system ownership must be avoided. It is also critical that all parties (the Tribe, the residents, and any contractors) share a clear understanding of who is responsible for future maintenance and repairs and whether the system user will incur any ongoing usage fees.

The prospect of new revenue sources, including the resolution of the Hoopa-Yurok Settlement Fund and a Tribal compact to allow gambling on the Yurok Reservation for the first time, may point the way to long-term funding for renewable energy system maintenance. Another possibility may be the development of intermediate-sized, grid-tied renewable energy systems, with the revenues generated by these systems reserved for supporting the O\&M costs of off-grid power systems elsewhere on the Reservation. Numerous other funding opportunities are listed in the "Funding and Financing Resources" section below.

Nonetheless, an argument can be made that the energy users themselves should pay at least a portion of their systems' maintenance costs, in part because the users are the ones who benefit. Furthermore, it has been demonstrated in many instances that even a modest investment in an energy system by the user acts as an incentive to care for the system rather than take it for granted.

As discussed in the next section of this report, the Yurok Tribe's best prospect for managing a Tribal energy services program is to integrate it into the existing Tribal public utility district (PUD). This district currently works with the Tribe's fiscal department to manage billing for water supply and solid waste removal services.

SERC staff interviewed Yurok Tribe Finance Director Doris Timm about energy services billing. Doris was very supportive of the concept and said it could easily be folded into the fiscal department's existing accounts receivable system for drinking water and solid waste collection (at central container sites).

She thought an energy billing system could be modeled on their experience with water -they initially have used a flat billing system of $\$ 28$ a month. The Tribe serves nearly 250 water customer connections. This summer the Tribe is beginning a switch to usage-based billing, starting with the Terwer water supply system. Doris's main concern about the change is how it will affect revenue. She says the existing water billing barely covers expenses, so they certainly don't want to see revenue go down. On the other hand, the Tribe wants to encourage conservation so as not to exceed their system capacities. Water rates may need to be adjusted iteratively to achieve the required revenue/usage balance.

Water billing began when the Tribal PUD was established in 1998. The original, informal billing system was updated in late 2002. Customers now receive computer-printed bills 
on cardstock with a detachable stub that is returned with payment, as is typical for municipal water utilities. The bill shows service start and end dates, previous account balance and current amount due. Spaces are already provided on the bill for meter reading values and unit consumption, although this section is not yet being used under the present flat rate arrangement. It appears it would be a simple matter to add energy billing information with only minor modification of the existing bill format. A sample water bill is included in Appendix 6. Where energy services are to be provided in the future to homes already served by a metered Tribal water system, the incremental cost of reading an energy use meter at the site would be very minor.

The Tribe has a system for dealing with non-payment of water bills, which is definitely a concern in providing any utility service to a community: people get two warning letters, then a door hanger with a five-day notice before service is cut off. The PUD has had to turn off service to customers. Doris said three households had just been shut off for nonpayment the week that we spoke. She feels overall the downriver water systems are working well in terms of customer cooperation, but she feels people upriver need more education regarding system use and bill payment obligations.

The Tribe will need to proceed cautiously but firmly in designing, implementing, and enforcing a billing system. Any billing system needs to have teeth - the reality is that people won't pay consistently unless the Tribe shows it's willing to cut service to nonpaying customers. This is in some ways more complicated for the Tribe than with other more urban communities, given close family and neighbor ties among Tribe members and staff and community-wide sensitivity about cutting service to very low income families and vulnerable populations such as elders and children.

Despite the fact she understands the above concerns as well as anyone, Doris was very upbeat about the prospects for the Tribe taking on energy services billing with respect to Tribe-owned renewable energy systems serving individual households or clusters of homes. She was aware there had been resistance to the idea in the past and expected there would be more grumbling if and when such a system is implemented. But from her experience with water billing she feels it is doable and did not raise any serious red flags.

Looking at the experiences of other Tribes, the Navajo have created a very successful program for providing off-grid residential PV systems for remote homes. The Yurok Tribe should learn more about the Navajo Tribal Utility Authority program and perhaps model a program after it. Larry Ahasteen, the current program manager at NTUA, indicated he would be happy to provide information to the Yurok Tribe.

\section{Incorporating Energy Services into the Tribal Public Utilities District}

Need and Precedent for Incorporating Energy Services into the PUD

As discussed earlier in this report, past experience has shown that simply installing renewable energy systems and leaving maintenance up to residents does not work well. Scheduled maintenance provided by the Tribe would improve reliability and longevity of the systems. However, the Tribe will only embrace the creation of a permanent Tribal 
energy services program that provides such maintenance if it can be done in a costeffective manner that does not create an undue financial or administrative burden for the Tribe.

Compared with creating a new department from scratch, there will be considerable cost savings to the Tribe if it can incorporate the energy program into an existing department or program, particularly if existing staff can take on some or all of the energy program responsibilities while still carrying out their present duties. The Tribal Public Utilities District (PUD) is the obvious choice to host the energy program, in order to avoid unnecessary duplication of tasks and costs within the Tribal organization. Furthermore, the PUD's experience with providing water, wastewater, and garbage collection services equips the district to take on another type of utility service, albeit a less conventional one.

The Yurok Tribe's PUD was created under a Yurok Tribal Utility Authority and Public Utility District Ordinance in 1998 and currently provides drinking water via five water systems on the Reservation, as well as solid waste collection via centralized container sites. The water systems pre-date the creation of the PUD and were previously maintained on a volunteer basis by community members.

The Yurok Tribe has clearly considered the incorporation of energy services into the PUD since the District's inception. The Yurok Tribal Utility Authority and Public Utility District Ordinance, drafted in February 1997 states "The services provided by the Yurok Public Utility District shall include alternative energy systems..." (Section 5.01) and "At some future date the Utility Authority may elect to assume responsibility to provide other community development or public utility services [besides current water, sewerage and garbage] as the needs of the Yurok Reservation and the customer population base warrants." (Section 5.05) See Appendix 7 for the complete ordinance.

\section{PUD Staffing, Organization, and Infrastructure}

The Tribe has two full-time water system maintenance staff, including a certified operator (who also serves as the PUD's superintendent) and a technician. Both of these personnel are supervised by the Tribal engineer, who acts as the PUD's supervisor and general manager. Together, these staff operate and maintain the five water systems scattered across the Reservation. The PUD is overseen by the Yurok Tribal Council, who act as the PUD's board of directors.

If the PUD takes on energy services, the Tribe will need to make a commitment to training and supporting PUD staff in this added role. SERC queried three Tribal staff closely involved in day-to-day management of the PUD to hear their thoughts on adding energy to the PUD's roles: PUD Superintendent Robert Nulph, Tribal Engineer Dustin Jolley, and Fiscal director Doris Timm, who oversees customer billing for the PUD. Opinions on the idea were mixed. We heard that payment would be difficult to enforce and that current staff would not have enough time or the necessary skills to take on the proposed responsibilities without extensive training. It appears likely that one new dedicated staff position would be needed within the PUD to oversee the energy systems and that energy system revenues might not be adequate to support this position without 
some Tribe subsidy. On the other hand, we heard that folding the billing for energy systems into the existing water billing setup would probably be straightforward. Attitudes toward adding energy services to the PUD were generally positive.

Energy system maintenance needs were described in an earlier section titled "Providing Maintenance and Repair to Renewable Energy Systems." Training would be required to prepare PUD staff to perform some of the outlined tasks. The training format and content could be similar to the training provided to Tribe members and energy program staff by SERC engineers in May/June 2006. SERC is available to provide this training to PUD staff under a separate contract if the Tribe so desires.

Billing for energy provided by Tribe-owned systems should be handled by the Tribe's finance department. Finance Director Doris Timm says she is willing to take this on, and her department's growing experience with metering and billing for water service has given them the capability to carry out the same responsibility with energy services.

An additional role for PUD/energy program staff could be weatherizing homes. This would be appropriate if the Tribe elects to increase weatherization services and decides to perform this function in-house instead of contracting it out to the Redwood Community Action Agency and/or the Del Norte Senior Center, an option we discuss in the separate final report on the Human Capacity Building project. Further training would be needed to perform this role. The training could also be provided by SERC or through any weatherization training program, such as PG\&E offers periodically at their Stockton Training Center. See www.pge.com $/ 003$ save energy $/ 003$ c edu train/stockton/ for more information.

Locations of the existing water systems are important with respect to expanding the PUD to encompass energy services. Several of the water systems serve villages or clusters of off-grid homes in the same areas where need for household electric systems is greatest. See Table 14.

Table 14. Yurok PUD Water Systems

\begin{tabular}{|l|c|c|c|c|r|}
\hline System Name & Location & $\begin{array}{c}\text { On/Off } \\
\text { Grid }\end{array}$ & $\begin{array}{c}\text { Water } \\
\text { Source }\end{array}$ & $\begin{array}{c}\text { Approximate } \\
\text { \# of } \\
\text { Connections } \\
\text { Served }\end{array}$ & $\begin{array}{r}\text { Production/ } \\
\text { Storage } \\
\text { Capacity }\end{array}$ \\
\hline $\begin{array}{l}\text { McBeth/Blake } \\
\text { Terwer) }\end{array}$ & Downriver & On & Well & 155 & $\begin{array}{r}120 \mathrm{gpm}, \\
220,000 \mathrm{gal}+ \\
10,000 \mathrm{gal}\end{array}$ \\
\hline Requa & Downriver & On & Well & $\begin{array}{r}25+\text { Requa } \\
\text { Resort }\end{array}$ & $\begin{array}{r}30 \text { gpm, } \\
3000 \text { gal }+ \\
3,500 \text { gal }\end{array}$ \\
\hline Weitchpec & Upriver & On & Gist Cr. & 25 & $\begin{array}{r}33 \text { gpm, } \\
60,000 \text { gal }\end{array}$ \\
\hline Ke'pel/Notchko & Upriver & Off & Ke'pel Cr. & 23 & $\begin{array}{r}40,000 \text { gal + } \\
10,000 \text { gal }\end{array}$ \\
\hline Wautec & Upriver & Off & Achelth Cr. & 19 & 25,000 gal \\
\hline
\end{tabular}


Many other aspects of the existing PUD organization will lend themselves well to providing user fee-based energy services. The PUD's "Water Service Rules and Regulations" would need to be rewritten to encompass energy services, but as it is written it lays out policies and procedures for metering, billing and payment, disconnection of service for nonpayment or abuse of service, access to customer premises by PUD employees, dispute resolution, and extension of service to new customers. Many of these policies and procedures will lend themselves well to electric service.

Another potential benefit of expanding the PUD's scope to include electric power service is that the Tribe has expressed interest in the past in having electric power supplied to the PUD's off-grid community water systems for purposes of onsite and/or remote system monitoring and control (see for example March 8, 2004 memo from Yurok Tribe planning department staff member Frank Masten to PUD superintendent Robert Nulph). This could become more feasible if the Tribe's functions of supplying both water and electric power in remote locations were integrated under the PUD.

The Tribe's experience with operating, maintaining, and billing for use of its water systems will be of value in setting up a Tribal energy services utility within the PUD. However, there are important differences between providing water and providing electric energy that will need to be taken into account:

- With a water system, the great majority of the physical infrastructure is at a central location. Aside from taking meter readings, it is seldom necessary for PUD staff to visit the individual households served. With decentralized household-scale energy systems, all or most of the physical infrastructure will be located on the householder's property. This will increase per-household cost of service and may mean increased logistical difficulty in accessing equipment when repairs or maintenance are needed.

- Since the energy equipment is located on customer property, a service shut-off for non-payment of bills may require actual repossession of equipment, not just closing and locking a valve as with water supply. It is possible to install a lockable disconnect switch on the renewable electricity system, thereby preventing the resident from utilizing the system.

- Small community-scale water supply systems are very common in rural areas in the U.S. There is less precedent for providing off-grid energy services as part of a PUD. The Tribe will have to innovate in order to make the program work well.

- The cost per unit of off-grid electric energy (or flat service rate, if that is used initially) will likely be several times higher than utility grid electricity, unless the Tribe is willing to permanently provide a significant subsidy. This may cause complaining and accusations of overcharging from customers. PUD staff will need to be prepared to educate customers about why these higher charges for electricity are necessary and justified.

Despite these hurdles, we think it is possible for the Tribe to develop a working program. There are examples of other Tribes, namely the Navajo and Hopi, who have successfully 
implemented these types of programs. In fact, the Navajo Tribal Utility Authority has even offered assistance to the Yurok Tribe in the development of a successful program. Certainly there is a lot that could be learned from the Navajo program.

Costs, Revenues and Operating Budget

According to the PUD's 2008 budget, expected costs are \$186,000 total, broken down as follows:

- $\$ 73,000$ for staff wages

- $\$ 30,000$ for indirect costs

- $\$ 22,000$ for fringe benefits and payroll tax

- $\$ 20,500$ for vehicles and vehicle insurance

- $\$ 16,000$ for supplies

- $\$ 24,500$ for other costs

At this time, all PUD customers pay a flat rate of $\$ 28$ per household per month for water service. The Tribe is moving toward metered rates across the whole system. This will begin with metered service on the Terwer system starting summer 2007, followed by the Ke'pel/Notchko and Requa systems. Typical yearly income is as follows:

- $\$ 60,000$ from BIA (has been a constant amount for several years)

- $\$ 30,000$ to $\$ 60,000$ subsidy from Tribe's discretionary funds

- The remainder comes from customer revenues. These revenues, currently about $\$ 83,000$ per year from the approximately 250 household customers, are expected to reach about $\$ 150,000$ per year once water metering is fully implemented, allowing the Tribe to reduce its subsidy for water service.

Impacts on the PUD from adding energy services would include some additional costs, mainly for staffing, supplies, and travel to remote homesites. Our analysis of a set of hypothetical household renewable energy systems, detailed under task 3, "Providing Maintenance and Repair to Renewable Energy Systems," showed an expected range of monthly maintenance costs of $\$ 60-\$ 75$ per home for full service maintenance that covers routine checkups, as well as repair and replacement costs. It is anticipated that, once the power line extension project currently underway is completed, approximately 30 homes on the Reservation will still need off-grid power systems to meet their electric needs (this figure is based on a 2005 map by Tribal GIS specialist Tony O'Rourke showing home locations and planned power grid extensions).

Thus, an overall yearly budget for maintenance service could be in the range of $\$ 22,000$ to $\$ 27,000$. Such costs could be offset at least partly by new revenues collected from customers served. Note that the spreadsheet used to estimate maintenance costs includes many assumptions about wages, unit costs for materials and transportation, miles driven, maintenance frequency, etc. Tribal staff should check these numbers and make any needed adjustments to the spreadsheet to improve the accuracy of the cost estimates. 


\section{Funding and Financing Resources}

The Schatz Energy Research Center has investigated opportunities for continued funding to help the Yurok Tribe develop its energy program and a possible energy services utility. This investigation has focused on:

- Helping the Tribe to develop and submit a proposal to the Department of Energy seeking funding to perform a feasibility study on development of the Tribe's wind and small hydro power resources;

- Helping the Tribe to develop and submit a proposal to the Bureau of Indian Affairs seeking funding to perform a feasibility study on development of the Tribe's biomass power resources;

- Identifying and making initial inquiries to private foundations interested in supporting energy development projects on Tribal lands; and

- Looking for and alerting Yurok Tribe staff about other miscellaneous funding opportunities identified through listserv subscriptions, web searches, and personal networking.

Proposals to BIA and DOE for Feasibility Studies

During the course of the project, SERC assisted the Yurok Tribe in preparing and submitting two proposals for federal funding. The first, a proposal to the Bureau of Indian Affairs' Division of Energy and Mineral Development to conduct a feasibility study on biomass energy, was submitted in December 2006. The Tribe requested $\$ 132,896$. The second proposal, submitted in February 2007 to the Department of Energy's Tribal Program, requested $\$ 150,000$ to conduct a feasibility study on wind and small hydroelectric power development. The one-page proposal summaries included with both of these proposals are attached to this report.

The Yurok Tribe received word from DEMD that their biomass proposal was short-listed for funding. However, due to an unanticipated funding shortfall, funds are not being awarded by DEMD for these projects at this time. An announcement is expected in summer 2007 regarding funding awards for the DOE feasibility study proposals.

Contacts with Private Foundations

In January 2007 SERC performed a search of the Foundation Center's online database of private foundations, using Humboldt State University's subscription to this fee-based service (see foundationcenter.org/findfunders/fundingsources/fdo.html). We identified 36 foundations whose giving criteria appeared to match the needs of the Yurok Tribe. We sent out inquiries to all of these foundations, contacting 24 of them by email and 12 by letter. We received responses from 20 of the foundations. Eleven of the foundations contacted encouraged the Tribe to follow up with foundation staff and/or complete their formal grant application process. These foundations include:

1. HP Corporate Giving Program

2. Surdna Foundation, Inc.

3. The Educational Foundation of America

4. Blue Moon Fund, Inc.

5. Funding Exchange, Inc. 
6. Sidney Stern Memorial Trust

7. American Indian Youth Running Strong, Inc.

8. Seventh Generation Fund (see discussion below)

9. International Partners in Mission

10. AMB Foundation

11. ABB Foundation, Inc.

Tables showing all the foundations we contacted and profiles from the Foundation Center's database on the organizations we recommend for follow-up by the Tribe are included as Appendix 8.

Based on advice from Chris Peters of Seventh Generation Fund (see below), SERC has elected not to follow up with these foundations, leaving it to the Tribe to pursue a direct relationship with these potential funders. A spreadsheet summarizing the results of our foundation outreach is included with this report. We have also provided the Tribe with all of the contact information and grant application materials we collected from the interested foundations.

Meeting with Seventh Generation Fund

One of the private foundations we contacted, Seventh Generation Fund, is based in Arcata, just down the street from SERC. Seventh Generation was the first foundation to respond to our initial inquiry. Their president and CEO, Christopher Peters, invited SERC staff to meet with him and his staff at their office on January 11. Chris told us what he knew about private foundation funds that were already being used or sought by the Yurok Tribe, e.g. support from the Lannan Foundation for the Tribe's legal efforts to have the Klamath River dams removed, and potential support from the Ford Foundation for a proposed Tribal park.

Our main take-home message from the meeting was that it is critical that foundations be approached by the Tribal community rather than by an intermediary such as a contractor or consultant. Even the Tribal government is likely to have less credibility and less appeal to potential private sector donors than a grassroots group of Tribe members. Chris observed that foundations typically are not eager to provide matching funds for federal grants. He suggested creating a local advisory board to solicit and direct community involvement.

Chris extended the offer that Seventh Generation Fund might be able to offer a small grant (on the order of $\$ 5,000$ or less) to the Yurok Tribe as seed money for printing, supplies, travel, and other expenses related to launching a fund-raising campaign for the Yurok Tribe energy program.

Chris also identified a few foundations he felt are worth approaching that we had not discovered in our search of the Foundation Center's database:

- First Nations Development Institute/Eagle Staff Fund

- Columbia Foundation 
- California Endowment (provided most of the funding for construction of United Indian Health Services' Potawot Health Village, a recent, major infrastructure project that serves principally Yurok Tribe members)

- Charles Stewart Mott Foundation

- Ford Foundation

- Public Welfare Foundation

- Jesse Smith Noyes Foundation

- Nathan Cummings Foundation

The spreadsheet included in Appendix 9 provides contact information for these foundations.

DOE Tribal Energy Program Website's Information on Funding for Tribes

The DOE Tribal Energy Program website provides information resources and links for Tribes seeking other forms of support or funding for their energy projects. These resources are classified under three categories: a) grants, b) project financing, and c) renewable energy certificates (green tags).

Grants. The Tribal Energy Program web page lists a number of federal agencies that at times offer funding opportunities that could be applicable to development of Tribes' energy programs or projects. The master web resource for accessing federal funding announcements is grants.gov. A search of this database on April 30, 2007 revealed only one explicitly energy-related funding opportunity that could be applicable to the Yurok Tribe (a USDA Rural Business Cooperative Service grant for "Renewable Energy Systems and Energy Efficiency Improvements Grants), and the deadline for that specific opportunity is coming too soon to permit a proposal to be developed. However, it is recommended that Tribal energy program staff search this database frequently so as not to miss important funding opportunities.

Another useful database for seeking energy-related funding from government sources is the Database of State Incentives for Renewables and Efficiency (DSIRE), which despite its name includes local, state, utility, and federal resources. This database is aimed primarily at the consumer looking for rebates or other incentives for renewables or energy efficiency. DSIRE is worth searching occasionally to identify programs of use to the Tribe or individual members. DSIRE is available on the web at:

www.dsireusa.org

Another useful resource linked to the DOE Tribal Energy Program's grants page is an EPA document titled "Funding Opportunities: A Directory of Energy Efficiency, Renewable Energy, and Environmental Protection Assistance Programs." This program lists many state and federal funding opportunities that can be searched through such online databases as grants.gov and DSIRE. The document also lists several private foundations that fund energy projects. After screening the list of foundations, we identified two that are a possible match for the Yurok Tribe and which had not been previously identified by searching the Foundation Center website or consulting with Seventh Generation Fund:

- Kirsch Foundation 
- Strategic Environmental Project Pipeline (StEPP) Foundation

Information on these foundations is included in the accompanying spreadsheet.

Project Financing. The Yurok Tribe may be able to fund a substantial portion of its energy development efforts with government or private sector grants that do not need to be repaid. Internal Tribal funds may meet an additional portion of the costs. The remainder can be financed through loans and other mechanisms that allow the Tribe to avoid paying all costs up-front. Several of these financing mechanisms are discussed here.

- Loans. If the Tribe chooses to pursue a loan to finance an energy development activity, there are numerous resources available. Many of these are discussed on the DOE Tribal Programs web page.

- USDA Rural Community and Economic Development Loans and Loan Guarantees. We contacted the office that runs this program to request additional information but did not receive a response.

- Bureau of Indian Affairs. The BIA's Loan Guaranty Program will guarantee loans of up to $\$ 500,000$ to individuals, partnerships and corporations, or up to $\$ 5.5$ million for Tribes. See www.doi.gov/bia/Loan\%20Guaranty\%20Brochure.pdf for details.

- Indian Home Loan Guarantee Program (HUD). Also known as the Section 184 program, this loan guarantee program was established by Congress specifically to assist Tribes and Tribe members in securing loans for home ownership or rehabilitation. Neither the Tribe nor the Housing Authority currently makes use of this program. However, YIHA Director Sandra Lowry reports that the Housing Authority is in the final stages of creating a new financial institution, to be known as the Yurok Alliance for Northern California Housing (YANCH) that will home buying assistance for Yurok Tribe members. The project is being supported by a $\$ 100,000$ startup grant for staffing, training and technology from the U.S. Department of the Treasury's Community Development Financial Institutions Fund. YANCH will initially be capitalized with $\$ 200,000$ to create a revolving loan fund. Some portion of the $\$ 90$ million in Hoopa-Yurok Settlement Act funds recently awarded to the Yurok Tribe may be used to increase capitalization of this fund. Ms. Lowry says that YANCH is also potentially a lender for home improvements, including energy efficiency upgrades. For more details on the Indian Home Loan Guarantee Program, see: www.hud.gov/offices/pih/ih/homeownership/184/

- Title VI Tribal Housing Activities Loan Guarantee Program (HUD). Agencies such as Tribal housing authorities that receive Indian Housing Block Grants (IHBGs) can use this program to secure loans from lenders that require a federal guarantee. According to the HUD web page, only 32 Tribes in the U.S., 13 of them in Alaska, have taken advantage of this program. No Tribes in California have used the program to date. In at least one case, the Northwest Inupiat Housing Authority in Alaska, this program was used specifically for energy efficiency upgrades. For more details, see: www.hud.gov/offices/pih/ih/homeownership/titlevi/ 
- REFIN. The American Council on Renewable Energy (ACORE) has created a Renewable Energy Finance Network (REFIN). In 2004, REFIN published a national directory of funding and financing sources suitable for renewable energy and energy efficiency projects. The 218-page directory lists 195 organizations described as "players" in the field of renewable energy and energy efficiency financing. The organizations are primarily private investment firms interested in clean energy, with a smaller number of consulting, legal, governmental, and non-profit entities listed. The directory includes a matrix showing which types of financing mechanisms are offered by each organization and which energy resource types are of interest to each organization. Following the matrix is a set of more detailed descriptions of the companies and organizations, including contact information and geographic focus. A search on words such as "native," "tribe" and "tribal" found only Native Energy LLC, which sells Renewable Energy Certificates.

- Small Business Administration (SBA). The SBA offers financing opportunities such as direct loans and loan guarantees to Tribal projects that are set up as small business ventures. Access to SBA financial assistance might thus be an incentive for the Tribe to set up its energy services program as one or more small businesses. The SBA's definition of a "small business" depends on the business sector. The size standard can be in terms of average annual receipts, number of employees, or some other factor. For example, a business involved in generation, transmission, or distribution of electric power is considered small if its total output is less than 4 million megawatt-hours per year. Most businesses that provide services, including home equipment repair and maintenance, are defined as small if average annual receipts are less than $\$ 6.5$ million. (Source:

www.sba.gov/idc/groups/public/documents/sba_homepage/serv_sstd_tablepdf.pdf) For more information on applying for SBA financial assistance, see www.sba.gov/services/financialassistance/index.html

- First Nations Oweesta Corporation. This organization offers capital on loan to Tribal financial institutions that in turn lend the funds out to Tribe members. This could be of value to the Yurok Tribe if it were, for example, to create a revolving loan fund to help Tribe members to make energy-related home improvements, as some local governments and municipal utility companies do. Capital loans from Oweesta range from $\$ 50,000$ to $\$ 250,000$, have terms of 3 to 5 years, and carry fixed annual interest rates of 3 to $5 \%$. Rates depend on the assessed risk level for a specific loan. Loans cannot exceed $10 \%$ of the recipient institution's total capital.

- Native American Bank (NAB). NAB, jointly owned by 26 Tribes and Tribal organizations, provides loans primarily to native people and communities. They have over $\$ 85$ million in assets and experienced a 40\% growth rate in 2006. NAB's 2006 annual report shows they are active in lending for business development and home mortgages. For more information, see www.nabna.com. 
An upcoming event, the Seventh Semiannual Native American Finance Conference, is scheduled for October 15 and 16, 2007 in Ledyard, CT. The conference will include sessions on developing green energy and other Tribal energy resources. For more details see:

http://secure.imn.org/ conference/im/index2.cfm?page=agenda.cfm\&sys_code $=2007103$ 1_PF_0019\&header $=$ on

The American Council on Renewable Energy (ACORE) hosts an annual Renewable Energy Finance Forum, with the 2007 event having taken place June 20-21 in New York City. Contact ACORE at www.acore.org for information on future forums. 


\section{Strategic Energy Plan}

In December of 2003, the Yurok Tribe convened a two day workshop to develop a strategic energy plan. The Council of Energy Resource Tribes facilitated the workshop. Twenty people participated in the workshop, with representation across most all Tribal departments. The resulting strategic plan is included in Appendix 5. The plan is modest in scope and short on detail, but it does present a picture of what key staff and council members felt were the key priorities for the Tribe to address regarding energy issues. Some of the key goals identified in the workshop were:

- implement energy efficiency upgrades in housing,

- get houses ready for electrical power,

- develop a Tribal energy utility,

- establish a Tribal energy policy,

- generate electrical power to meet Tribal needs and for sale to generate revenue,

- create jobs and an educated workforce,

- develop energy funding opportunities, and

- create, define and communicate the vision.

Since the strategic energy plan was developed, additional work has taken place to further the Tribe's energy vision. This includes the work performed under two DOE funded First Steps projects: this utility feasibility study and a concurrent human capacity building project. Activities performed under these projects include staff training, community education and outreach, energy audits of Tribal homes, an energy needs assessment, identification of funding resources, an assessment of renewable energy resource development opportunities, and the development of plans to provide Tribal energy services for energy efficiency and renewable energy systems. In addition, proposals have been submitted to DOE and BIA to conduct detailed feasibility studies of hydro, wind and biomass resource development opportunities.

We recommend the following activities to keep the Yurok Tribe's energy vision moving forward:

- $\quad$ solidify the Tribe's vision for an energy program and develop a detailed implementation plan,

- seek additional funding to support the establishment of a Yurok Tribe Energy Program,

- establish the energy program as part of the Tribe's Public Utility District,

- establish and enforce energy efficiency and green building standards in all new construction on the Reservation,

- work to upgrade the energy efficiency of existing construction on the Reservation,

- continue with the electric utility line extension,

- develop a program to install and maintain off-grid renewable energy systems,

- conduct detailed feasibility studies for the development of hydro, wind and biomass resources, 
Yurok Tribe

Tribal Utility Feasibility Study

June 2007

- pursue renewable resource development as appropriate, both to serve onReservation needs as well as for sale off the Reservation as a means of generating revenue, and

- install renewable energy systems on Tribal facilities where economically feasible. 


\section{Conclusions and Recommendations}

As our study shows, the Yurok Tribe has numerous opportunities to develop its own energy resources for the benefit of the Tribe. There is also great potential benefit for the Tribe in developing its organizational capacity to provide energy services to Tribe members. Earlier research performed under this grant by a different consultant, Winzler \& Kelly Consulting Engineers, found that it was not feasible for the Tribe to create a conventional electric utility company. We do not have access to a detailed report by Winzler \& Kelly that led them to this conclusion. However, it is not a surprising conclusion, given the high cost of providing service to the Reservation, the low income levels among Tribe members, and their dispersed locations across the Reservation. To develop the programs and services we recommend, it will be necessary for the Tribe to identify short- and long-term sources of funding, be they internal discretionary funds, grants, ESCO-type financing, or income from revenue-generating energy projects on the Reservation.

We identified opportunities for the development of renewable energy resources and energy services on the Yurok Reservation that fall into five basic categories:

- Demand-side management - This refers to efforts to reduce energy use through energy efficiency and conservation. Energy efficiency measures are almost always more cost-effective than the development of new energy sources. Therefore, it is best to focus first on improving energy efficiency levels in Tribal homes and facilities. If new energy sources are to be developed, implementing energy efficiency measures first will reduce the required capacity of the new energy system, lowering costs and making the project more financially feasible.

- Off-grid, facility and household scale renewable energy systems - These systems can provide electricity to individual homes and Tribal facilities in areas of the Reservation that do not currently have access to the electric utility grid. Solar electric and micro-hydro electric systems offer the greatest opportunity.

- Village scale, micro-grid renewable energy systems - These are larger scale systems that can provide electricity to interconnected groups of homes and Tribal facilities in areas of the Reservation that do not have access to the conventional electric grid. This will require the development of miniature electric grids to serve these interconnected facilities. Areas on the Reservation that appear to offer the best opportunity for village scale systems are the Wautec, Notchko, and McKinnon Hill areas. The most likely resources for development are biomass and hydro power.

- Medium to large scale renewable energy development for sale to the grid - In areas where viable renewable energy resources exist and there is access to the conventional electric utility grid, these resources can be developed and sold to the wholesale electricity market. Biomass and hydroelectric resources are the most likely candidates for this type of development. Power would most likely be sold to the local electric utility (PG\&E in Humboldt County and PP\&L in Del Norte County). Revenue from the sale of electric power could then be used to support other energy services on the Reservation. 
- Facility scale, net metered renewable energy systems - Facility scale renewable energy systems can also provide electric power to homes and facilities that are already connected to the conventional electric utility grid. These systems are sized, at a maximum, to offset the facility's energy use. Through an arrangement called net metering, power produced by the renewable energy system can spin the electric meter backwards, effectively crediting the facility's electric bill. This credit can then be used up at a later date. Only wind and solar electric systems are eligible for net metering, and solar is the most likely resource to be viable on the Reservation in this capacity. Because the economic payback for net metered systems is typically long (10 to 20 years), the most likely opportunity on the Reservation for net metered systems is on Tribally owned facilities.

Our key recommendations are:

- The Tribe should continue to look for opportunities to increase environmentally and culturally responsible development of renewable energy resources on the Reservation.

- Solar electric power continues to be of greatest value for onsite use at remote, off-grid homes, with generators and/or micro-hydroelectric generators for supplementary power.

- Grid-tied solar electric generation is a key opportunity for Tribal facilities, though its value lies more in technology demonstration than in cost savings.

- Biomass, hydropower and wind electric power generation make the most sense to develop at strategically chosen, centralized locations. Site selection criteria include availability of the resource, and proximity to loads (e.g. homes) and/or power transmission lines.

- Development of hydroelectric, biomass, and wind energy for power sales to the grid and/or for village-scale mini-grid applications should be preceded by more in-depth, site-specific feasibility studies. Hydroelectric and biomass energy appear to have the greatest potential.

- The Tribe should make use of the Yurok Energy GIS (YEGIS) created as part of this project to map and analyze energy development opportunities, energy services provided across the Reservation, and other energy-related information and activities. We suggest that the YEGIS database be further developed as more information is collected.

- The Tribe should consider establishing a program to install solar electric and micro-hydroelectric systems for off-grid Tribal residences.

- A consistent program for maintenance of renewable energy systems needs to be developed and funded in order to keep existing and future systems running properly.

- Energy services should be the responsibility of the Yurok Public Utility District. The PUD should be given the staffing and budgetary resources it needs to take on this responsibility.

- Where Tribe members are provided energy services such as off-grid power systems, there must be a clear agreement between the Tribe and the resident from the outset about who owns the equipment, who is responsible for 
maintenance and repairs, and what user fees if any the resident is expected to pay.

- The Tribe should create a fair and enforceable system to bill Tribe members for energy services, to be administered by the Tribe's finance department.

- The Tribe should ensure energy efficiency in existing and new homes.

$\circ$ For existing homes, this need should be met using a Reservation-wide weatherization program (discussed in the separate Human Capacity Building final report).

- For new construction, the Tribe should adopt an energy efficiency code applying to all construction on the Reservation. The most straightforward way to achieve substantial energy savings would be the adoption of California's Title 24 energy efficiency code. The Yurok Indian Housing Authority should adopt an energy efficiency policy for its own construction projects consistent with the requirements of the Tribe's Reservation-wide code. The Tribe and the Housing Authority should consider eventual upgrade to Energy Star Building Performance Standard.

- The Tribe should monitor the progress of discussions in the local community regarding Community Choice Aggregation (CCA). If a local Joint Powers Authority is formed to implement CCA, the Tribe should consider participating.

- The Tribe should make a concerted effort to fund these recommended actions, making use of the funding information provided in this report.

As consultants to the Tribe, our primary concern in the near term is continuity. We are nearing the end of our contracts with the Tribe, and the Tribe does not have immediate funding in hand to continue working with us or to implement all of our recommendations. We will remain available to the Tribe to answer questions or make clarifications about our work after delivery of this report. We urge the Tribe to study carefully this report and our separate final report on the Human Capacity Building project (to be completed by July 31,2007$)$ and look for recommendations and actions that can be implemented in the near term at minimal cost.

Finally, in our research of other Tribal energy programs we found one common theme was present in every successful program: the presence of an energy program champion within the Tribe. Successful energy programs developed by the Navajo, Hopi, and Sioux all had Tribal members who championed these programs. We suggest that the Yurok Tribe needs to find and/or develop an energy program champion within the Tribe, someone who is passionate about the work and will be present in the community over the long haul to nurture the program along and maintain continuity. 


\section{Bibliography}

Awards for the 2003 Native American Initiatives: Native American Technical Assistance (NATA) Component and Native American CDFI Development (NACD) Program. Community Development Financial Institutions Fund. www.cdfifund.gov/awardees/pdf/2003/nata_nacd_awards_profiles.pdf

Berdahl, Paul, Donald Grether, Marlo Martin, and Michael Wahlig. California Solar Data Manual. Solar Energy Group, Energy and Environment Division, Lawrence Berkeley Laboratory. March 1978.

California Energy Commission Wind Atlas. Report No. P500-85-002. April 1985.

Final Report Submitted by Native American Photovoltaics, Inc. (NAPV) for Electrification of Remote Native American Residences Project. (Dilkon and Teesto chapters of the Navajo Reservation.) October 17, 2002.

www.eere.energy.gov/tribalenergy/pdfs/napv_final_report.pdf

Greacen, Christopher E. Community Context and Technology Options in the Yurok Tribal Electrification Project. Thesis for M.S. in Energy and Resources. University of California, Berkeley. May 1997.

Greenwood, Charles S. Miners Creek Hydroelectric Feasibility Study. Greenwood Engineering. January 18, 2004.

Hill, Roger, Mike Thomas, Ben Rinehart, and Randy Manion. Phase I Report on Renewable Energy Options for the Yurok Indian Reservation. Sandia National Laboratories/Idaho National Engineering and Environmental Laboratory/Western Area Power Administration. June 2000.

Hiner, Monica. Hydrological Monitoring in the Lower Klamath Basin, Water Year 2005. Yurok Tribe Environmental Program. October 2006.

Humboldt Engineering and Construction, Inc. Final Report: Yurok Power Project. March 2000 .

Jacobson, Arne. Memos and reports from work with Yurok Tribe as employee of KelsoStarrs and Associates, 1998-99.

Jacobson, Arne. "Yurok Alternative Energy Systems Billing Options: Preliminary Recommendations.” Report to Tribe. May 26, 1998.

Kruse, Sarah A. Scholz, Astrid J. Preliminary Economic Assessment of Dam Removal: The Klamath River. Ecotrust. January 31, 2006. 
Letter to Yurok Tribe members "Re: Bills for Use of the Yurok Tribe Alternative Energy Systems" from then- Director of Tribal Planning Sef Murguia. May 1999.

Ludington, Milt. "Engineering Report: Ke'pel Creek Hydroelectric Potential." September 26, 2001.

Maintenance and Operation of Stand-alone Photovoltaic Systems. A publication of the Photovoltaic Systems Assistance Center, Sandia National Laboratories. Prepared by Architectural Energy Corporation. December 1991.

Memo from Frank Masten, Yurok Planning to Robert Nulph, Public Utilities. RE: Lake Prairie Line Extension Project. March 8, 2004.

North Coast Unified Air Quality Management District Authorized Burn Data for Six Rivers National Forest, 2006 (provided by Lucy Salazar of Six Rivers National Forest).

Preliminary Feasibility Study For A Biomass Utilization Project on the Yurok Reservation. TSS Consultants. March 31, 2003.

Proposal that the Yurok Tribe work with Continental Resource Solutions, Inc. and National Power Partners to develop renewable electric generation resources and related businesses. PowerPoint Presentation. Not Dated.

Starrs, Thomas J. and Arne Jacobson. "The Yurok Tribe's 'Wireless' Electric Utility." Conference Proceedings, American Solar Energy Society, Portland, ME, June 12-16, 1999.

Tribal-State Gaming Compact Between the Yurok Tribe and the State of California. Undergoing ratification by the California state legislature as of June 2007. www.caltba.org/documents/40_the_yurok_tribe_of_california_unratified_2006_compac t.pdf

U.S. Department of Housing and Urban Development. Minimum Property Standards for Housing, 1994 Edition. Section 607-1.1: Energy Efficiency. From www.hudclips.org

Waananen, A.O. and J.R. Crippen. Magnitude and Frequency of Floods in California. U.S. Geological Survey. Water-Resources Investigations 77-21. June 1977.

Water Quality Control Plan for the Yurok Indian Reservation. Yurok Tribe Environmental Program. August 2004.

Wind Energy Assessment for Northwestern California: Three Interim Reports. California Energy Commission Consultant Report No. P500-82-042. June 1982.

Yurok Tribe Public Utilities District: Water Service Rules and Regulations. (not dated) 
Yurok Tribe

Tribal Utility Feasibility Study

June 2007

Yurok Indian Reservation Forest Management Plan. Pacific Meridian Resources. January 1996.

Yurok Tribal Telecommunications \& Electrification Projects. Winzler and Kelly Consulting Engineers. Not Dated.

Yurok Tribal Utility Authority and Public Utility District Ordinance (draft). February 5, 1997.

Yurok Tribe Annual Report 2006.

Yurok Tribe Strategic Energy Plan. Facilitated by the Council of Energy Resource

Tribes. December 17-19, 2003. 


\section{Appendices}

1. Map of Property Boundaries, Home Locations, and Electric Power Infrastructure on Yurok Reservation

2. Economic Analysis for Yurok Renewable Energy Program

3. Tool List for Renewable Energy System Maintenance Program

4. Maintenance Checklist for Renewable Energy System Maintenance Program

5. Yurok Tribe Strategic Energy Plan (CERT 2003)

6. Sample Yurok Water Bill

7. Draft Yurok Public Utilities District Ordinance

8. Foundation Profiles from Foundation Center's Online Database

9. Foundation Spreadsheet

10. Recommended Data Elements for Yurok Energy Geographic Information System (YEGIS) 
Appendix 1: Map of Property Boundaries, Home Locations, and Electric Power Infrastructure on Yurok Reservation 


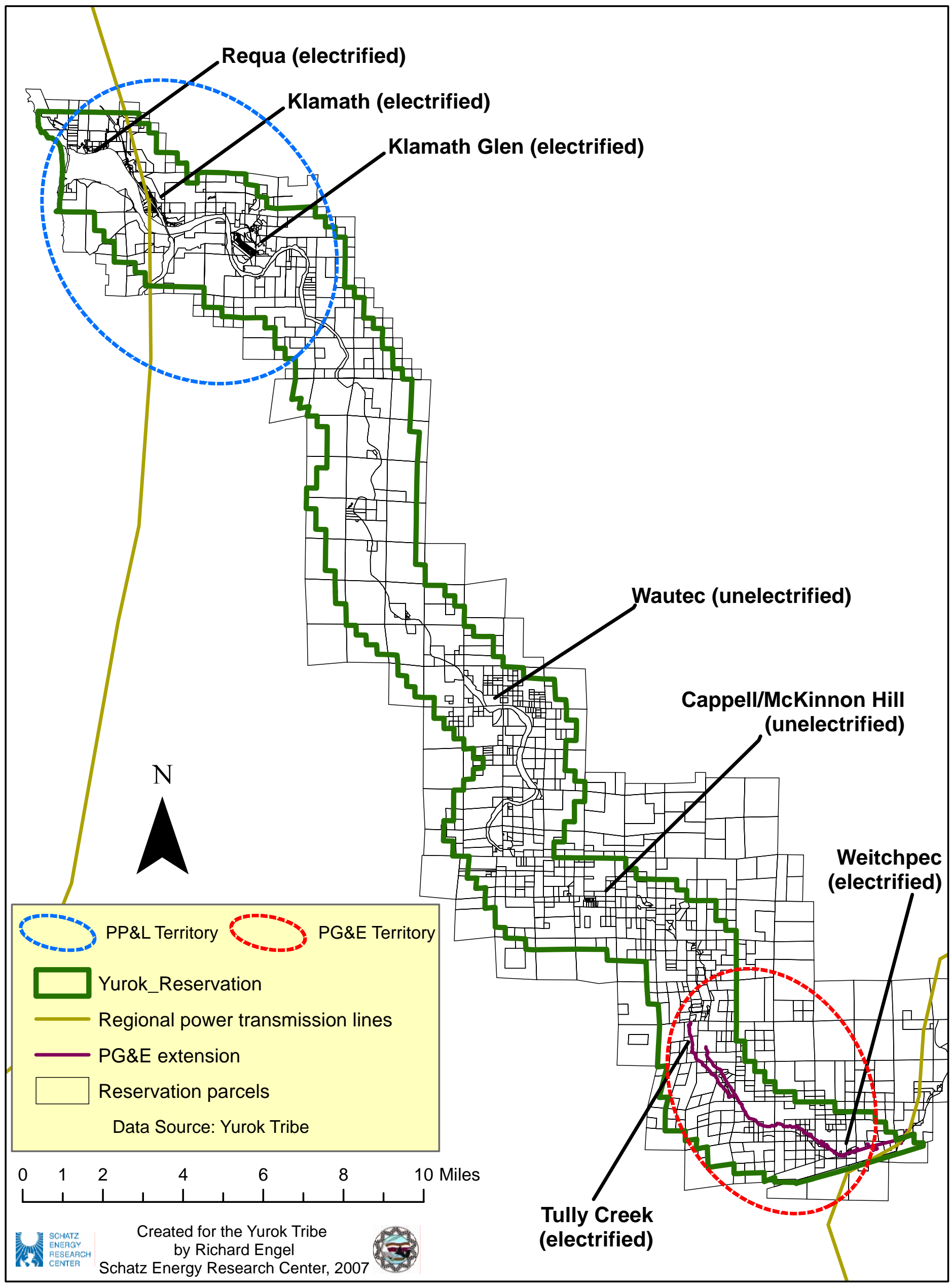




\section{Appendix 2: Economic Analysis for Yurok Renewable Energy Program}




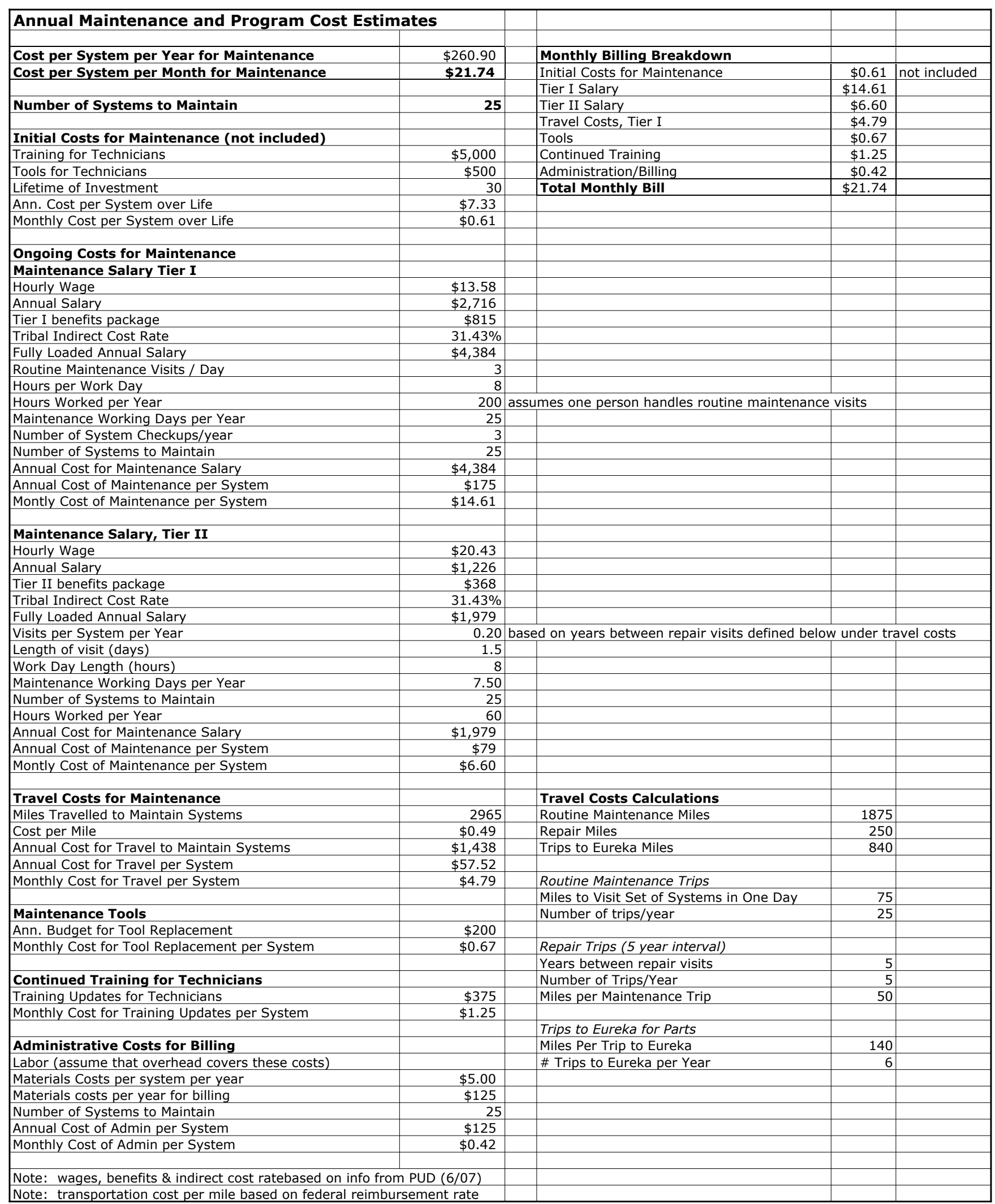




\section{Off-Grid Solar Elecric System (1.4 kW)}

Note: Most equipment costs based on AEE Solar dealer rates w/o volume discount, 10/05 pricing data

\section{Initial Costs}

\begin{tabular}{|c|c|c|c|c|}
\hline Component & Description & Lifetime (yrs) & & Initial costs \\
\hline PV array $(1.4 \mathrm{~kW})$ & 8 @ 175 Watts, Sharp & 30 & $\$$ & 5,584 \\
\hline Battery & (8) Surrette S-530, $800 \mathrm{AH} @$ & 5 & $\$$ & 1,448 \\
\hline Generator & $6.5 \mathrm{~kW}$ Honda & 15 & $\$$ & 3,200 \\
\hline Inverter & Outback $2.5 \mathrm{~kW}$ & 10 & $\$$ & 1,330 \\
\hline Charge Controller & Outback 60A & 10 & $\$$ & 454 \\
\hline Mounting Rack & & & $\$$ & 600 \\
\hline \multicolumn{2}{|c|}{ Balance of System (based on Lewis system) } & & $\$$ & 600 \\
\hline & Tax \& shipping $(15 \%)$ & & $\$$ & 1,982 \\
\hline & Total Equipment Cost: & & $\$$ & 15,198 \\
\hline & Installation Labor Cost: & & $\mathbf{\$}$ & $\mathbf{3 , 8 0 0}$ \\
\hline
\end{tabular}

\section{Maintenance Costs}

Frequency (yrs)

Annual Routine Maintenanc

Generator Overhaul

Battery replacement labor $\quad 16$ person-hrs @ $\$ 22 / \mathrm{hr}$

Inverter and controller replacement labor 16 person-hrs @ $\$ 22 / \mathrm{h}$

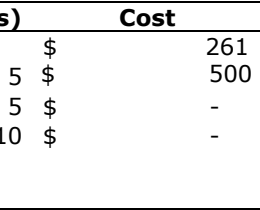

\section{System capacity (kW_DC)}

Installed cost $(\$ /$ watt $)$

Equipment cost ( $\$ /$ watt)

Total installed cost $(\$)$

Total Equipment cost $(\$)$

Rebate*

\section{Tax credit?}

Tax credit (self-install)?

Net installed cost

Net equipment cost

NPV Total O\&M Costs

kWh/yr generated by PV

kWh/day

\begin{tabular}{rr} 
& 1480 \\
$\$$ & 12.84 \\
$\$$ & 10.27 \\
& \\
$\$$ & 18,998 \\
$\$$ & 15,198 \\
$\$$ & - \\
$\$$ & - \\
$\$$ & - \\
& \\
$\$$ & 18,998 \\
$\$$ & 15,198 \\
$\$$ & 13,381 \\
& 1,426 \\
& 3.9 \\
\hline
\end{tabular}

*Rebate - system must either be installed by the owner or installed by a liscensed contractor

Tax Credit - Owner must pay sufficient federal taxes to claim benefit. Credit is $30 \%$ or maximum of $\$ 2000$.

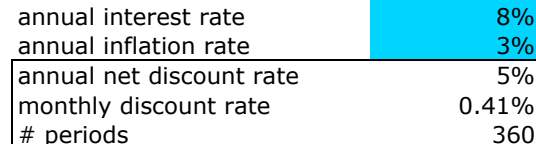

\# periods

360

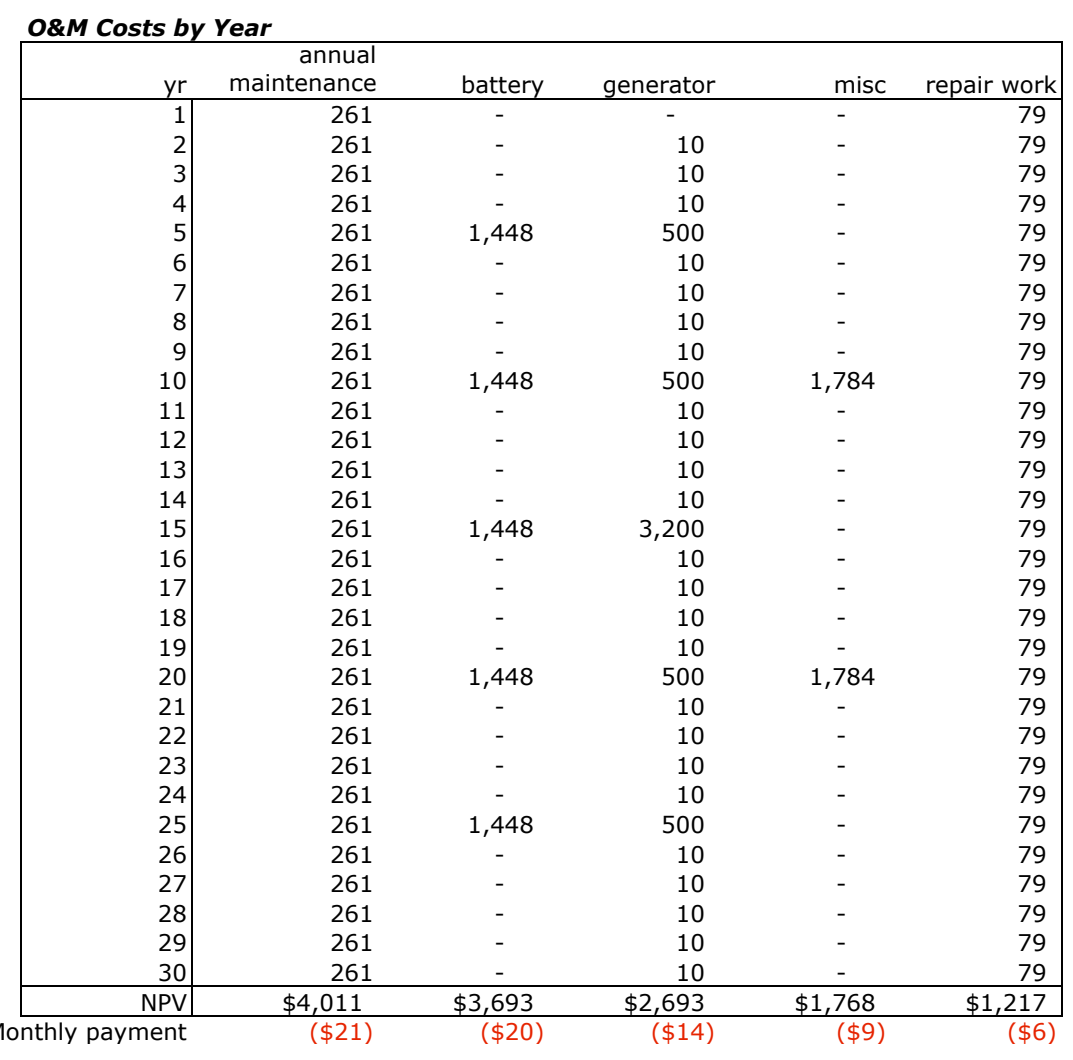

\begin{tabular}{|c|c|c|c|c|c|}
\hline \multicolumn{2}{|c|}{$\begin{array}{l}\text { NPV Cost to } \\
\text { Resident }\end{array}$} & \multicolumn{2}{|c|}{$\begin{array}{l}\text { NPV Cost to } \\
\text { Tribe }\end{array}$} & \multirow{2}{*}{$\begin{array}{l}\text { Monthly Flat } \\
\text { Fee } \\
\qquad(\$ 172)\end{array}$} & \multirow{2}{*}{$\begin{array}{l}\text { Scenario } \\
\text { Full Recovery of All Costs }\end{array}$} \\
\hline$\$$ & 32,380 & & - & & \\
\hline$\$$ & 28,580 & $\$$ & 3,800 & $(\$ 151)$ & Full Recovery Minus Installation cost \\
\hline$\$$ & 13,381 & $\$$ & 18,998 & $(\$ 71)$ & Recover O\&M Costs Only \\
\hline
\end{tabular}




\section{Off-Grid Solar Elecric System (700 Watt)}

Note: Most equipment costs based on AEE Solar dealer rates w/o volume discount, 10/05 pricing data

\section{Initial Costs}

\begin{tabular}{|c|c|c|c|c|}
\hline \multirow{2}{*}{$\frac{\text { Component }}{\mathrm{PV} \text { array }(700 \mathrm{~W})}$} & Description & Lifetime (yrs) & \multicolumn{2}{|c|}{ Initial costs } \\
\hline & 4 @ 175 Watts & 30 & $\$$ & 2,792 \\
\hline Battery & (4) Surrette S-530, $400 \mathrm{AH}$ & 5 & $\$$ & 724 \\
\hline Generator & $3.8 \mathrm{~kW}$ Honda & 15 & $\$$ & 2,100 \\
\hline $\begin{array}{l}\text { Inverter } \\
\text { Inte }\end{array}$ & Outback $2.5 \mathrm{~kW}$ & 10 & $\$$ & 1,330 \\
\hline Charge Controller & Trace C-35 & 10 & $\$$ & 83 \\
\hline Mounting Rack & & & $\$$ & 300 \\
\hline Balance of System & & & $\$$ & 500 \\
\hline & Tax \& shipping (15\%) & & $\$$ & 1,174 \\
\hline & Total Equipment Cost: & & $\$$ & 9,003 \\
\hline & Installation Labor Cost: & & $\$$ & 3,000 \\
\hline
\end{tabular}

Maintenance Costs

Frequency (yrs)

\section{Annual Routine Maintenance}

Generator Overhau

Inverter and controller replacement labor 16 person-hrs @ $\$ 22 / \mathrm{hr}$

\begin{tabular}{|lrr|}
\hline System capacity $(\mathrm{kW}$ _DC) & & 740 \\
Installed cost $(\$ /$ watt) & $\$$ & 16.22 \\
Equipment cost $(\$ /$ watt) & $\$$ & 12.17 \\
Total installed cost $(\$)$ & $\$$ & 12,003 \\
Total Equipment cost $(\$)$ & $\$$ & 9,003 \\
Rebate* & $\$$ & - \\
Tax credit? & $\$$ & - \\
Tax credit (self-install)? & $\$$ & - \\
Net installed cost & $\$$ & 12,003 \\
Net equipment cost & $\$$ & 9,003 \\
NPV Total O\&M Costs & $\$$ & 10,638 \\
KWh/yr generated by PV & & 713 \\
kWh/day & & 2.0 \\
\hline
\end{tabular}

* Rebate - system must either be installed by the owner or installed by a liscensed contractor

Tax Credit - Owner must pay sufficient federal taxes to claim benefit. Credit is 30\% or maximum of $\$ 2000$.

\begin{tabular}{|lr|}
\hline annual discount rate & $5.00 \%$ \\
monthly discount rate & $0.41 \%$ \\
\# periods & 360 \\
\hline
\end{tabular}

\section{O\&M Costs by Year}

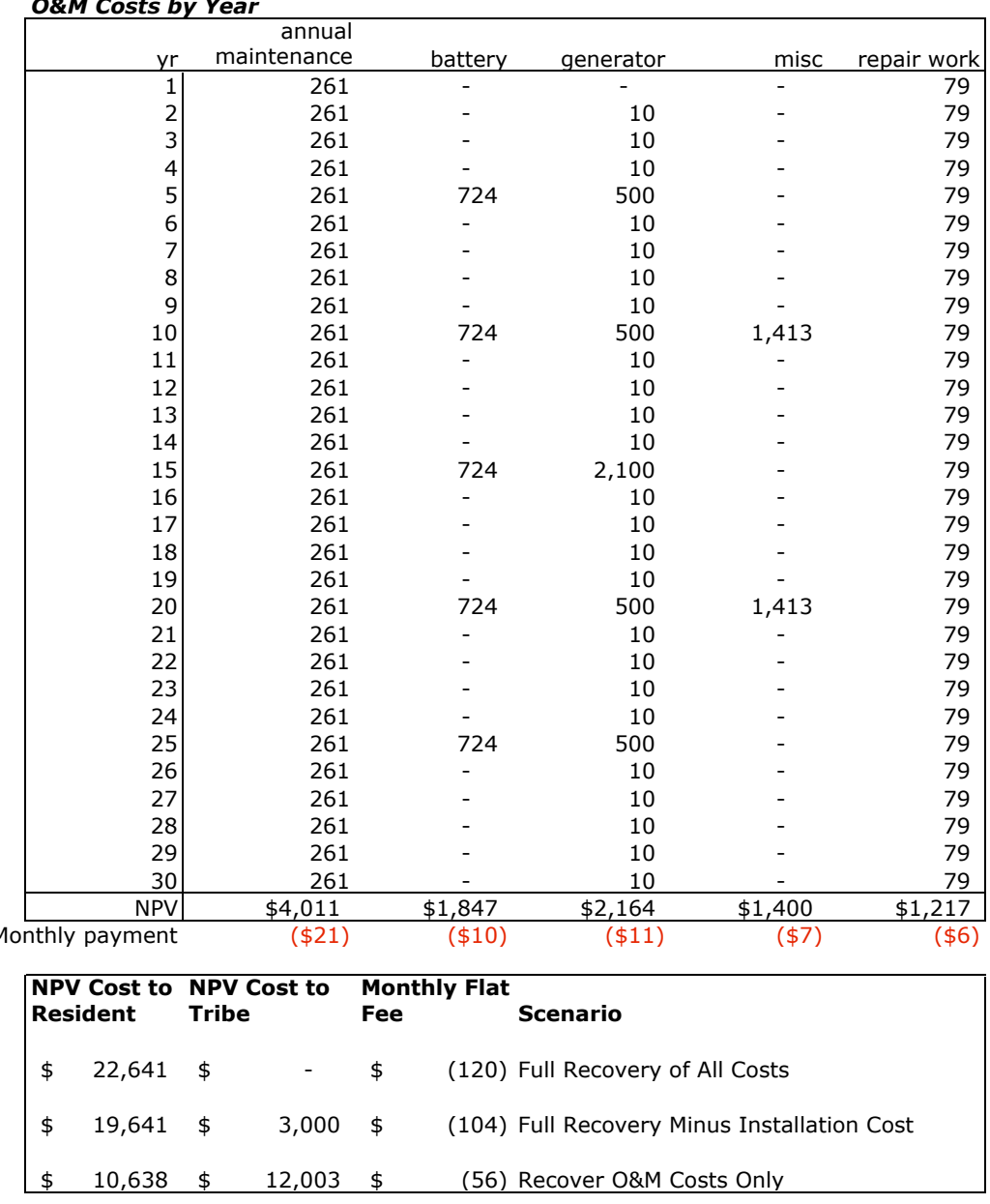




\section{Off-Grid Micro-Hydro / PV Hybrid System}

Note: Most equipment costs based on AEE Solar dealer rates w/o volume discount, 10/05 pricing data

\begin{tabular}{|c|c|c|c|c|}
\hline Component & Description & Lifetime (yrs) & & nitial costs \\
\hline PV array (700 W) & 4 @ 175 Watts & 30 & $\$$ & 2,792 \\
\hline Battery & (4) Surrette S-530, $400 \mathrm{AH}$ & & $\$$ & 724 \\
\hline Inverter & Outback $2.5 \mathrm{~kW}$ & 10 & $\$$ & 1,330 \\
\hline Diversion Controller & Trace C-35 & 10 & $\$$ & 83 \\
\hline PV Module Mounting Rack & & & $\$$ & 300 \\
\hline Harris Hydro Turbine & 300 -watts, $20 \mathrm{gpm}, 150$ ' he & 30 & $\$$ & 813 \\
\hline Penstock & $1200 \mathrm{ft}, 2$ in. Sched 40 & 30 & $\$$ & 1,200 \\
\hline Diversion Load & Diversion load & & $\$$ & 235 \\
\hline Balance of System & & & $\$$ & 1,000 \\
\hline \multirow[t]{4}{*}{ Generator } & 3.8 kW Honda & 15 & $\$$ & 2,100 \\
\hline & Tax \& shipping (15\%) & & $\$$ & 1,587 \\
\hline & Total Equipment Cost: & & $\$$ & 12,164 \\
\hline & Installation Labor Cost: & & $\$$ & 6,000 \\
\hline
\end{tabular}

\section{Maintenance Costs}

Annual Routine Maintenance

Micro-hydro Generator Overhau

Battery replacement labor

Inverter and controller replacement labor

Penstock repair

Generator Overhaul

System capacity (kW_DC)

Installed cost ( $\$ /$ watt)

Equipment cost (\$/watt)

Total installed cost $(\$)$
Total Equipment cost $(\$)$

Rebate*

Tax credit? (PV Only)

Tax credit (self-install)? (PV Only)

Net installed cost

Net equipment cost

NPV Total O\&M Costs

$\mathrm{kWh} / \mathrm{yr}$ generated by PV

$\mathrm{kWh} / \mathrm{yr}$ generated by microhydro

*Rebate - system must either be installed by the owner or installed by a liscensed contractor

Tax Credit - Owner must pay sufficient federal taxes to claim benefit. Credit is 30\% or maximum of $\$ 2000$.

\begin{tabular}{|lr|}
\hline annual discount rate & $5.00 \%$ \\
monthly discount rate & $0.41 \%$ \\
\# periods & 360 \\
\hline
\end{tabular}

\section{O\&M Costs by Year}

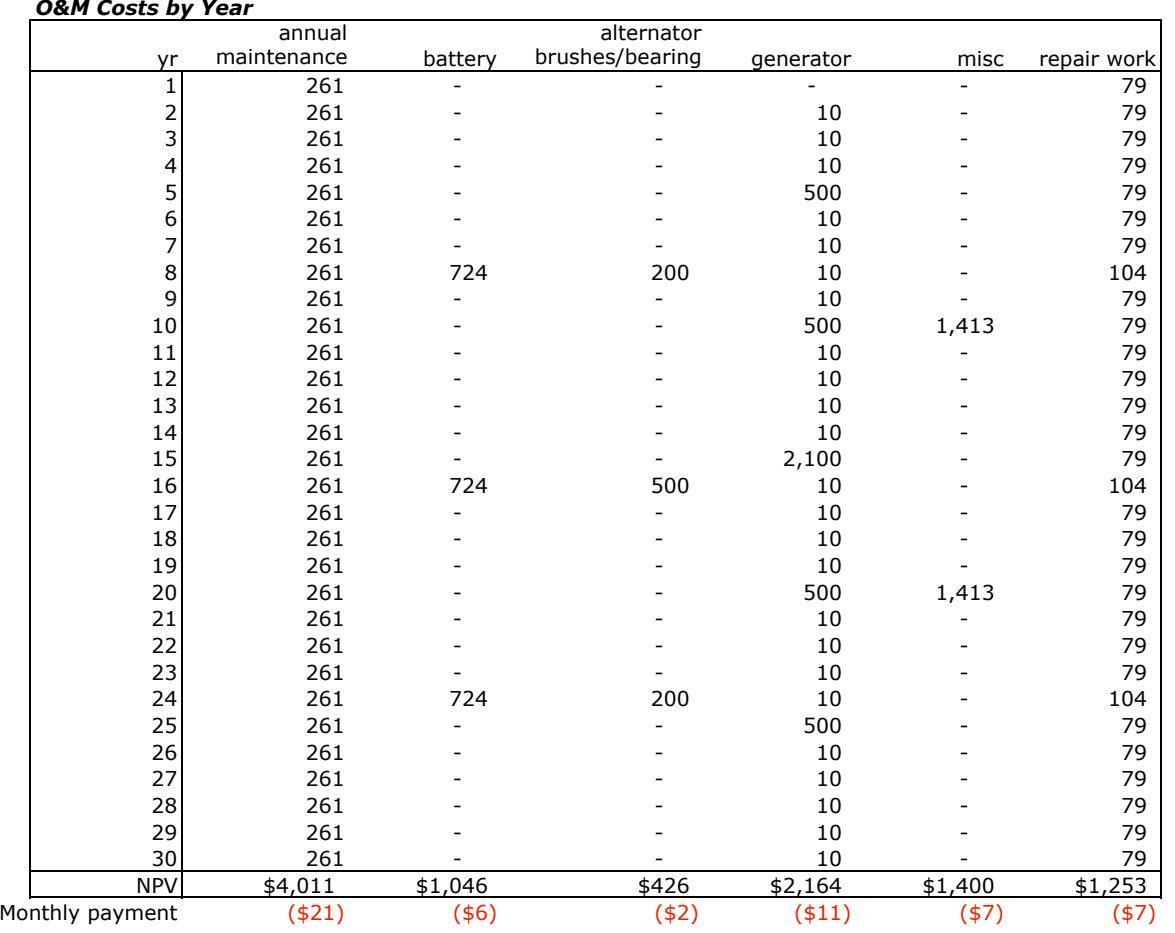

\begin{tabular}{|lrlrlrl|}
\hline $\begin{array}{l}\text { NPV Cost to } \\
\text { Resident }\end{array}$ & \multicolumn{2}{l}{$\begin{array}{l}\text { NPV Cost to } \\
\text { Tribe }\end{array}$} & \multicolumn{2}{l}{$\begin{array}{l}\text { Monthly Flat } \\
\text { Fee }\end{array}$} & Scenario \\
$\$$ & 28,463 & & 28,463 & $\$ 28,463$ & Full Recovery of All Costs \\
$\$$ & 22,463 & $\$$ & 22,463 & $\$ 22,463$ & Full Recovery Minus Installation Cost \\
$\$$ & 5,150 & $\$$ & 5,150 & $\$ 5,150$ & Recover O\&M Costs Only \\
\hline
\end{tabular}




\section{Appendix 3 \\ Renewable Energy System Assessment - Tool \& Materials List}

Ladder

Digital multimeter

Clamp-on ammeter for AC \& DC

Tool box with various hand tools (screwdrivers, pliers, wrenches, nut drivers, hacksaw, utility

knife, hammer, caulking gun, etc.)

Wiring tools: wire stripper/crimper, diagonal cutters, needle nose pliers, battery cable cutter, battery cable stripper, battery or gas powered soldering iron

Battery hydrometer

Battery terminal puller

Battery terminal cleaner

Tools for pruning trees/bushes (loppers, pole pruner, pruning saw)

Solar Pathfinder

Insolation meter

Compass

Tape measure

Flashlight

Rubber gloves

Safety goggles

Funnel (for filling batteries with distilled water)

Bucket

Rags

Workgloves

First aid kit

Notebook

Digital camera

Sandia PV O\&M Manual

Manufacture's literature

Consumables

Distilled water

Baking soda

Mild cleaning solution/glass cleaner

$\mathrm{pH}$ paper

Quick-Cote Anticorrosion Protectant

Assortment of electrical connectors: wire nuts, ring \& spade crimp connectors

Assortment of fuses

Assortment of wire

Solder

Cable ties

Electrical tape and duct tape

Caulk and silicone sealant

Assorted screws and nails

Sharpie black markers 
Appendix 4: Maintenance Checklist for Renewable Energy System Maintenance Program 


\section{Renewable Energy System Assessment}

Client Name:

Date:

\section{Client Questions:}

Are you happy with your system? Y / N Who maintains it? No one / resident / other:

How long ago was your system installed?

Are or have you experienced any problems with your system within the last year? $\underline{Y} / \mathrm{N}$

Explain:

Have you replaced any major equipment? $\underline{\mathrm{Y} / \mathrm{N}}$ If so, what and when?

On a typical day how many hours do you run your generator during the ...

summer? spring/fall? winter?

When did you last change the oil in your generator?

Do you maintain the water in your batteries? Y / N Type of water used? Distilled / other:

When did you last check the level of water in your batteries?

Do you give your batteries an equalization charge periodically? Y / N

When did you last equalize your batteries?

If you have microhydro, how many months of the year does it operate?

System Type: $\square$ PV $\square$ Microhydro $\square$ Other

PV Modules: Manufacturer Model

Rating: STC watts (OPTIONAL: Voc Isc

Total \# of modules in PV array

Batteries: Type: $\square$ vented lead-acid $\square$ sealed lead-acid $\square$ Other

Manufacturer Model

Individual battery voltage

Rating (amp-hours)

Battery dimensions (LxWxH):

(if no information available on model and AH rating)

\# Batteries in series per string

\# Strings in parallel

Charge Controller: Manufacturer Model Rating (amps)

Diversion Controller: Manufacturer Model Rating (amps)

Diversion Load: Type Rating (watts)

Inverter: Manufacturer Model Rating (watts continuous)

Generator: Fuel Type Make/Model Rating (watts) 


\section{PV System Assessment \\ Shading}

Assess shading of array with Pathfinder (take picture, label picture with residents name).

Do trees or shrubs need to be trimmed? $\mathrm{Y} / \mathrm{N}$ Were they trimmed during site visit? $\underline{\mathrm{Y}} / \mathrm{N}$

\section{$\underline{\text { System Condition }}$}

PV Array:

Are any PV modules broken or damaged? $\underline{\mathrm{Y} / \mathrm{N}}$ Do modules need to be cleaned? $\underline{\mathrm{Y} / \mathrm{N}}$

\section{Power Center:}

Is there an earth ground rod and is it intact? $\mathrm{Y} / \mathrm{N}$

Is there a disconnect switch between the array and the rest of the system? $\underline{\mathrm{Y}} / \mathrm{N}$

Is there a fuse(s) or circuit breaker(s) between the array and the rest of the system? $\underline{\mathrm{Y} / \mathrm{N}}$

Is there a disconnect switch between the batteries and the rest of the system? $\mathrm{Y} / \mathrm{N}$

Is there a fuse(s) or circuit breaker(s) between the batteries and the rest of the system? $\underline{\mathrm{Y} / \mathrm{N}}$

All wiring looks secure and in good condition? $\underline{\mathrm{Y} / \mathrm{N}}$

All components are securely mounted and are protected from the elements? $\underline{\mathrm{Y} / \mathrm{N}}$

Note comments or problems:

System Operational Status (measure the following parameters while the system is operating)

Array voltage _ V A $\quad$ Array current__ A

Battery voltage __ V B Battery current___ A Charging / Discharging?

Charge controller status (check controller indication, if any):

$\square$ Charging $\square$ Fully charged/floating $\quad \square$ Low voltage disconnect $\quad \square$ No indication

If system has an amp-hour counter, how many amp-hours from full are the batteries?

\section{Battery Assessment}

Battery tops are clean and dry and caps are secure? $\mathrm{Y} / \mathrm{N}$

Battery connections are secure and relatively corrosion free? $\mathrm{Y} / \mathrm{N}$

Battery enclosure, racks, and tie downs are in good condition? $\mathrm{Y} / \mathrm{N}$

Battery enclosure is adequately ventilated? $\underline{\mathrm{Y} / \mathrm{N}}$

Is there a temperature compensation probe installed? $\mathrm{Y} / \mathrm{N} /$ don't know

Are the electrolyte levels in the batteries adequate? $\underline{\mathrm{Y} / \mathrm{N}}$ Added distilled water? $\underline{\mathrm{Y} / \mathrm{N}}$

Draw a schematic of the battery bank and number the batteries and cells, then measure and record the voltage for each battery. Measure the specific gravity for every cell in one battery and at least one or two cells in every other battery. 


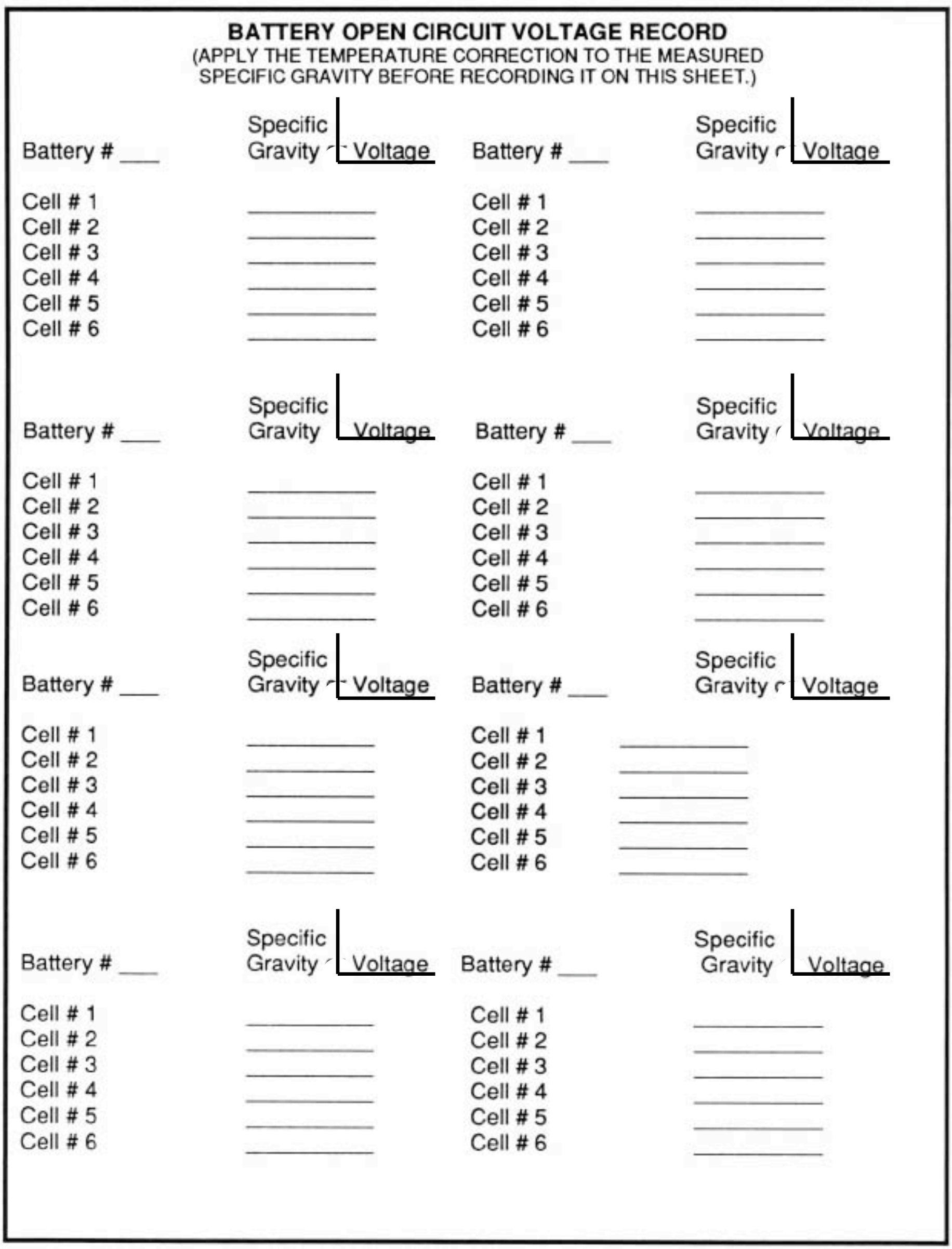




\section{Microhydro System Assessment}

\section{Intake}

Free of debris? $\mathrm{Y} / \mathrm{N}$ (clear out as needed)

Proper alignment? $\underline{Y} / \mathrm{N}$ (adjust as needed)

Condition of intake/headworks?

Penstock/Supply Line (walk the line)

Condition of penstock?

Adequately supported? $\mathrm{Y} / \mathrm{N}$

Operating Parameters

Is system operating? $\mathrm{Y} / \mathrm{N} \quad$ Dynamic pressure reading at turbine (if available)

Generator voltage Generator current

Battery voltage Battery current Charging / Discharging?

Diversion load controller status?

Is power being dissipated? $\mathrm{Y} / \mathrm{N}$ Power dissipation (watts)

Turbine and Generator

Type Make/Model Rating (watts)

\# of nozzles Shutoff valves? $\mathrm{Y} / \mathrm{N} \quad$ Noisy operation? $\mathrm{Y} / \mathrm{N}$

Tailrace (discharge from turbine) is clear and allows water to drain freely? $\mathrm{Y} / \mathrm{N}$

Diversion Load

Adequate? Y / N Condition?

\section{System Condition}

Is there an earth ground rod and is it intact? $\underline{\mathrm{Y} / \mathrm{N}}$

Is there a disconnect switch between the generator and the rest of the system? $\underline{\mathrm{Y} / \mathrm{N}}$

Is there a fuse or circuit breaker between the generator and the rest of the system? $\mathrm{Y} / \mathrm{N}$

Is there a disconnect switch between the batteries and the rest of the system? $\underline{\mathrm{Y} / \mathrm{N}}$

Is there a fuse or circuit breaker between the batteries and the rest of the system? $\underline{\mathrm{Y} / \mathrm{N}}$

All wiring looks secure and in good condition? Y / N

All components are securely mounted and are protected from the elements? $\underline{\mathrm{Y}}$ / N

NOTE: Make sure you complete the Battery Assessment 


\section{Generator Assessment}

Is the generator located immediately adjacent to the house? $\mathrm{Y} / \mathrm{N}$

Does it pose a $\mathrm{CO}$ hazard? $\mathrm{Y} / \mathrm{N}$ Is there adequate ventilation? $\mathrm{Y} / \mathrm{N}$

Is there adequate protection from the weather? $\mathrm{Y} / \mathrm{N}$

Generator Start? Automatic/Manual?

CHECK OIL

Proper oil level? Y / N Oil condition? Clean/dirty Need oil change? Y / N

CHECK AIR FILTER (if appropriate)

Air filter condition? Clean / dirty Need air filter change? Y / N

CHECK COOLANT (if appropriate)

Proper coolant level? Y Y N Coolant condition o.k.? Y / N

Need to add or change coolant? Y / N

Batterv Charging:

Is there a separate battery charger? $\mathrm{Y} / \mathrm{N} /$ ? Does the inverter have a battery charger? $\mathrm{Y} / \mathrm{N} /$ ?

If separate: Manufacturer Model __ Rating (amps) 
Appendix 5: Yurok Tribe Strategic Energy Plan 


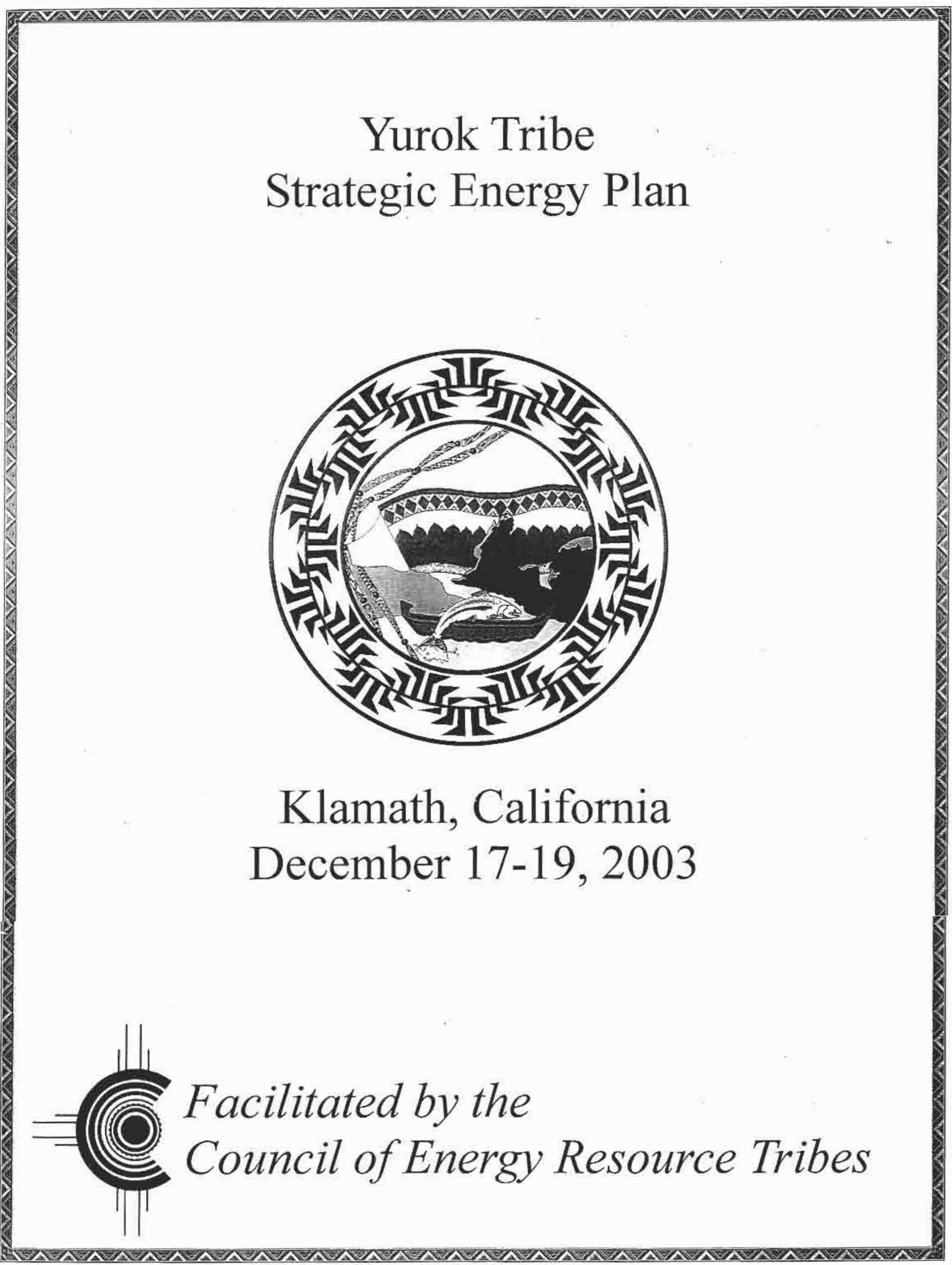




\section{INTRODUCTION}

The Yurok Tribe and the Council of Energy Resource Tribes (CERT) convened a two-day facilitated workshop to develop a strategic work plan for energy development. The Yurok planning department gathered staff from all departments including cultural resource management, housing, economic development, Tribal Council members and community members. The twoday workshop set out to provide general education on energy options available to the Tribe, as well as develop consensus on a strategic direction for energy development.

The Yurok Tribe has several small communities without access to electricity. Although the Yurok Tribe has participated in several studies and renewable energy technology demonstration projects, they have yet to find a sustainable solution to provide reliable, affordable electricity to remote communities. To this end, the Yurok planning department applied and received a Rural Utility Service (RUS) grant to extend electricity lines to two communities currently without electricity. The Tribe also received a U.S. Department of Energy grant to investigate advantages for developing a Tribal electric utility.

The Yurok Tribe expressed concern about adequately preparing for the future. With federal funding sources shrinking and Yurok's population growing at double rate for every 23 years, the Tribe must strategically optimize current funding available. CERT developed the workshop agenda to bring about discussion and action items on current and future energy requirements to accommodate the Tribe's growth, health, and economic development.

The workshop began with presentations by CERT staff on the background of CERT as an organization, "Energy 101," and the National Tribal Energy Vision. The morning session ensured that everyone participating in the planning process had a baseline understanding of energy and Tribal utility formation. The planning process depends on full participation of all interested and impacted parties. CERT's strategic planning process includes five workshops: Current Reality, Practical Vision, Underlying Contradictions, Strategic Directions, Implementation Timeline and 30-day task assignment timeline. At the end of two days, the Yurok Tribe developed a Tribal energy vision, developed energy goals, identified barriers to attaining energy goals and developed an action plan to overcome barriers and achieve the Yurok energy vision. This report contains a summary of the Yurok Tribe Energy Plan. 


\section{ANALYSIS and RECOMMENDATIONS}

The strategic planning results show that the Yurok Tribe has many energy opportunities that are time sensitive. Economic and community growth depends on access to affordable, reliable electricity. To this end, the Yurok energy strategic plan lays out steps and a process necessary to develop and implement a comprehensive energy plan that will accommodate the Tribe's population growth and necessary economic development.

CERT staff developed the attached flow chart from the actions identified through the strategic planning process to illustrate how actions are dependent on one another. There are three main threads of actions and several "individual" actions that are not dependent on any other action. Above each action box is a small number that represents that estimated time (in work days) necessary to complete the action. The boxes colored in red are critical actions. The project cannot continue until the actions in red are completed.

The overall concern CERT staff recognized is time-management. The Tribe must make major decisions in a very short time frame to meet USDA and DOE grant deadlines. However, the planning group emphasized the importance of community buy-in and input on the energy plan before moving forward as necessary to ensure success. To achieve community input and buyin, a series of educational meetings must be held with both on-reservation communities and offreservation communities. Holding community meetings, while imperative, will take valuable time away from the decisions the Council will have to make in order to move forward with the plan. This is one of the inherent conflicts Yurok staff will have to manage. 


\section{RESOURCES}

Additionally, the second conflict that the strategic plan presents is acquiring the necessary resources, both in terms of full-time employees (FTEs) and contracting dollars for technical assistance. Although the Tribe has great success in acquiring grant dollars, there is not enough funding to complete the necessary workload outlined by the strategic plan. Also, as the energy plan is developed, more dollars will be required to perform risk assessments, feasibility studies, legal . analysis, housing upgrades, etc., necessary to acquire financing. Federal grant dollars are often limited for energy planning. The Council will have to be prepared to support the planning process with resource allocations in term of dollars and designated FTE's to move forward with implementation of the energy planning process.

\section{Necessary Resource Allocations}

CERT staff estimates the Tribe will need, at the very minimum, the following to move the plan forward:

- One Yurok FTE assigned to management of the plan for 20 consecutive days.

- 2 Yurok part-time employees implementing various components of the plan.

- One energy expert FTE working with Tribal manager for 20 consecutive days.

- $\$ 45,000$ contract dollars for technical assistance and feasibility studies. 


\section{WORKSHOP SUMMARY}

The Council of Energy Resource Tribes conducts a two-day strategic planning workshop to facilitate discussion within the Yurok Tribal governmental departments and citizens to better define community economic and social development goals. CERT believes that a successful strategic plan is developed through full participation of all involved entities. To achieve this goal, CERT uses a facilitation method called "Technology of Participation" (ToP) developed by the Institute of Cultural Affairs. The ToPs method breaks down the strategic planning into five small workshops: current reality, practical vision, underlying contradictions, strategic direc-" tions and implementation. The ToPs participation process uses small discussion groups to brainstorm and generate multiple ideas. The ideas are then woven together and molded into action items and directions that the larger group agrees upon. The final workshop creates an implementation plan from the direction and action items revealed during the workshops.

\section{Current Reality Workshop}

The current reality workshop assesses the current situation the Yurok Tribe is experiencing as perceived by the group. The findings of this workshop show that energy is the integral foundation necessary for the Tribe to grow and develop. The Tribe s energy issues can be summarized as: need, want, control. The Tribe has over 80 households without access to electricity due to a large part of the reservation that is unserved by any electric utility. Currently, the Tribe has a grant from the Department of Agriculture, Rural Utility Services to electrify parts of the reservation without electricity. The Tribe's planning department is working to clear right-of-way paths for new lines to be built. The Tribe is waiting for Pacific Gas and Electric (PG\&E) to start construction on the first phase of the new power line.

There are several questions that the Tribe has yet to answer as the first phase of the RUS grant is completed. One of those questions is who is going to own the line after it is completed? The Tribe originally asked PG\&E to own the power line. However, due to PG\&E negligence to meet timelines and lack of communication, the Tribe questions the rationale of paying for a power line and then giving ownership to a company that is unresponsive to the Tribe's needs. The group drew consensus on the decision that the Tribe must own all energy activities taking place on the reservation including the new power line currently under construction. Ownership puts the Tribe in control of decisions that impact how and where energy development occurs and capitalizes on the Tribe's political clout and sovereign status.

The Tribe has a unique high-voltage transmission opportunity. The Tribe is currently served by two different investor-owned utilities that buy low-cost federal power from two different power market agencies, Western Area Power Administration (WAPA) and Bonneville Power Admnistration (BPA). Currently there is only one transmission line available to BPA to transmit low-cost hydropower from the Northwest to the California market, the largest energy market in the United States. This transmission line is over capacity making wheeling costs very expensive. The Yurok Tribe can build a transmission line that would connect a BPA line to a WAPA line thereby creating a second transmission corridor for BPA to send power to the California market. A second transmission corridor from the Northwest to California is important for national security, as well as creates more energy options for Yurok Tribal members to buy the lowest-cost electricity available on the market. This could lower some Tribal member electricity bills by half and provide high-quality, reliable electricity to the Tribe for economic development.

Facilitated by the Council of Energy Resource Tribes 


\section{Practical Vision Workshop}

The practical vision workshop establishes goals to achieve the Tribe's five year energy vision. The Tribe set five major goals:

- Implement Housing and Power

- Yurok Tribal Utility

- Facility Construction Needed for Economic and Social Development

- Educated Workforce and Job Creation

- Infrastructure Development

By achieving each of these broader goals, the Yurok Tribe will be able to gain energy security for social and economic development.

\section{Implement Housing and Power}

Many Yurok Tribal members live in houses that are in need of energy efficiency upgrades to meet current building codes. Energy efficitncy improvements will reduce overall energy consumption and allow Tribal members to use less fuel to heat and cool their homes. Energy efficiency upgrades can be completed on homes even if they do not have electricity. However, several homes that are scheduled to receive electricity are in need of upgraded electrical wiring before they are technically able to receive electricity. Most homes without electricity are not built to California electric codes, and must be brought up to standards. Without new and expensive upgrades, PG\&E will not transmit power to the homes. Even if the Tribe establishes its own utilities, electrifying homes without new upgrades would jeopardize both the Tribal utility and the Tribal member.

\section{Yurok Tribal Utility}

The Tribal group strongly agrees that the Tribe must be in control of all energy developments on the reservation. In order to achieve this goal, a Tribal utility must be formed. The Tribal utility has two functions, power for profit and electricity distribution to serve Tribal members on the reservation. Each function has different objectives; however they combine to achieve the Tribe's energy goals.

The Tribe wants to have 100 percent energy supply, the ability to buy and sell power through a Tribally owned and operated transmission line. There is also a need to build out the distribution grid from Wachapec to Wautec using culturally appropriate technology and building techniques that may not be economical but are in line with Tribal sensitivities. 


\section{Facility Construction Needed for Economic and Social Development}

The Tribal group recognized that to achieve balance, buildings needed to be constructed for social needs, as well as economic requirements. The Tribe will build two eldercare and social services building, one on each end of the reservation as well as a cultural center to support social development. To provide capital to construct and maintain the Tribe's social development requirements, the Tribe is planning to build a casino and town site development to create an economic foundation on the reservation.

\section{Educated Workforce and Job Creation}

The Yurok Tribe has a high unemployment rate and a low annual income rate in comparison to mainstream America. For this reason, a priority of the Tribe is job creation for Tribal members. The Tribal utility offers many opportunities for high paying jobs for Tribal members. However, a training program must be implemented to train Tribal members for the skilled positions the utility will require. A Tribal utility employing all non-Tribal members does not meet the first priority of the Tribal Council of job creation and education opportunities for Tribal members.

\section{Infrastructure Development}

The Yurok Tribe is in need of infrastructure to support community growth and economic development. Electricity and telecommunication are two key infrastructure requirements, but are by far from the only needs. Road access from Wautec to Wachapec is absolutely necessary for Tribal members to travel from one part of the reservation to another in a safe, timely fashion. Also, providing ten new houses for Tribal employees is a priority. The Tribe sustains heavy losses in terms of human capital because employees cannot live close to where they work due to a lack of housing. This requires employees to commute several hours a day and can put them at risk in adverse weather. Infrastructure is the key to any type of development, economic or social. Currently the Yurok Tribe has a focus on the electrical needs to support the economic development; which in turn will fund the social requirements needed for its members. This is a unified approach to development as the first step to solid and holistic approach to Tribal advancement.

\section{Underlying Contradictions Workshop}

An important step to every strategic plan is identification of barriers that could impede progress to achieving goals and objectives. There are five major barriers to overcome in order to achieve the Yurok Tribal Energy Vision within five years:

Lack of Unified Vision

Defining and Exercising Sovereignty

Land Acquisition and Use

Resources

Conflicting Priorities 


\section{Lack of Unified Vision}

The Tribal participants contributing in the meeting know that the biggest barrier they have to overcome is getting the entire Tribal membership and Council to work towards a unified vision. The energy field is complex and can be confusing for Tribal members to understand the importance energy plays in economic and social development. Without firm electricity at reasonable costs, new housing development for Tribal members becomes restrictive. The Tribe has limited on-reservation housing available to Tribal members. A significant amount of Tribal housing available on the reservation is outdated and unsafe. This presents problems for updating housing structures to receive electricity and implementing energy efficiency standards.

An obstacle that the Tribe must always work around is gaining off-reservation support for new, progressive projects. It is often hard for an individual Tribal member to understand the project or program's benefit if he/she is not directly receiving assistance. Energy projects are capital intensive and require a long-term buy in. Therefore, energy projects can be perceived as risky and only benefiting those Tribal members living on the reservation. The Tribe's constitution requires that all Tribal members are eligible for all benefits regardless of where the Tribal member is residing.

\section{Defining and Exercising Sovereignty}

The Yurok Tribe is the largest Indian reservation in California; however, a large part of the reservation is fee land owned by non-Indians. As a newly federally recognized Tribe, the Yurok struggles with exercising sovereignty involving land issue, regulations and code setting. A barrier the Tribe is working on overcoming is developing administrative procedures and peace and justice code. This is set up as a Tribal court system and provides a vehicle for the Tribe to enforce laws, codes and regulations.

Energy projects will require the Tribe to establish rights-of-way for power line extensions and related infrastructure requirements (i.e., sub-stations). The Tribe currently does not have land condemnation laws in place. This is a fundamental requirement that will enable the Tribe to establish rights-of-way for energy projects. Education of all Tribal departmental staff, Council members and Tribal members and non-member residents living on the reservation will be required to familiarize all involved entities with new laws and the Tribe's governmental authority.

\section{Land Acquisition and Use}

The Yurok Tribe plans to undertake three major barriers relating to land: acquiring land that can be developed, working around diverse land ownership status, and rugged land terrain. The Tribe is in the process of developing government and working hard and fast to establish necessary governmental infrastructure to support economic and community development. The Tribe will need to decide where within the reservation different types of development is appropriate and establish zoning laws and regulations codes to ensure that development is contained within those areas. Comprehensive land use planning will take into consideration fee, allotment, trust and non-Tribal land ownership, rugged land terrain that is expensive and problematic to develop, and determine areas that are culturally and/or environmentally sensitive. 


\section{Resources}

Energy projects are expensive in terms of financial capital and human resource assets. The Yurok Tribe faces limited financial capital. A large part of the Tribe's budget comes from federal grants and other restricted funding sources. The Tribe's dependence on restricted funding presents a significant barrier to sustain long-term projects, such as energy projects. Along with a limited financial portfolio, the Tribe is unable to hire and retain a work force with technical expertise in the energy field. Every Tribal government employee is required to be a jack-of-alltrades, able to multi-task split their time between programs and grants. Although the Tribe hired very capable and talented individuals, it becomes very difficult to hire experts in a very technical field such as energy. Also, the lack of public transportation, housing and adequate roads creates difficulty to acquiring and retain employees. Without a Tribal college and access to education and training programs, the Tribe faces an additional barrier in developing the technical capacity necessary for a Tribal utility from current employees and Tribal members.

\section{Conflicting Priorities}

The Yurok Tribe faces difficult decisions on how to divide limited financial and human resources between programs and projects. Due to the great need of the Tribe, all programs and projects are critical, making prioritization very difficult. Adding to the complexity, the Tribe must consider all off-reservation Tribal members and accommodate their need for housing, health and education. This creates difficulty in determining a strategic plan to proactively develop economic opportunities that will create revenues for the Tribal government to sustain health, housing and education programs.

The Tribe currently employs very knowledgeable and talented staff. This is evident by the Tribe's recent accomplishments and the amount of competitive grants the Tribe is able to secure. However, the Tribe will have to develop a mitigation plan to increase communication between Council and Tribal departments to eliminate conflicting inter-departmental coordinated initiatives. The mitigation plan will have to include a contingency measures for projects that are not completed and goals not reached.

A final and important barrier that the Tribe must alleviate is the fear of change and the perception that change is too risky. Tribal leadership acknowledges that proactive actions are better then being reactive to catastrophes; however, Tribal leaders must have community support for new initiatives. Communication, education and information dissemination will play an important role in energy development on the reservation and to address the perception that such a project is risky and too big for the Tribe to accomplish. 


\section{APPENDIX}
A Agenda
B Workshop Data
C Participant List
D Facilitation Description
E CERT contact info 


\section{Yurok Tribe Strategic Planning Session \\ December 15-17, 2003}

December 15

\begin{tabular}{|c|c|}
\hline $9: 00$ am & $\begin{array}{l}\text { Welcome } \\
\text { Chairperson McConnell } \\
\text { Sonya Tetnowski, CERT Director of Tribal Energy Strategies }\end{array}$ \\
\hline $9: 15 \mathrm{am}$ & $\begin{array}{l}\text { Invocation } \\
\text { Tribal Elder }\end{array}$ \\
\hline $9: 30 \mathrm{am}$ & Introductions \\
\hline \multirow[t]{6}{*}{$9: 45$ am } & CERT Presentation \\
\hline & $\begin{array}{l}\text { CERT History and Programs } \\
\text { Carly Hare, Energy Program Associate }\end{array}$ \\
\hline & $\begin{array}{l}\text { Energy } 101 \\
\text { Sonya Tetnowski }\end{array}$ \\
\hline & $\begin{array}{l}\text { Yurok Historical Update } \\
\text { Sonya Tetnowski }\end{array}$ \\
\hline & $\begin{array}{l}\text { National Energy Policy } \\
\text { Jessica Alcorn, Director of Policy and Program Development }\end{array}$ \\
\hline & $\begin{array}{l}\text { National Tribal Energy Vision } \\
\text { Jessica Alcorn }\end{array}$ \\
\hline $10: 45 \mathrm{am}$ & Break \\
\hline $11: 00 \mathrm{am}$ & Yurok Presentation \\
\hline $12: 00 \mathrm{pm}$ & Lunch \\
\hline \multirow[t]{3}{*}{$1: 00-3: 30 \mathrm{pm}$} & $\begin{array}{l}\text { Facilitated Sessions } \\
\text { Clint LeBeau, Facilitator }\end{array}$ \\
\hline & Current Realities \\
\hline & Yurok Energy Vision \\
\hline
\end{tabular}

December 16

9:00-11:45 am Facilitated Session

Contradictions

12:00 pm Lunch

1:00-3:30 pm Facilitated Session

Strategy

December 17

9:00-1145 am

Facilitated Session

Implementation Plan

12:00 pm Closing Remarks 


\section{DATA}

\section{CURRENT REALITY WORKSHOP}

The following questions were asked to the participants and their responses are the bulleted points.

\section{What are some of the basic facts and data that reveal our current situation?}

Control Growth on the Reservation

Energy Equals Power

$\$ 2$ Billion DOE Loan with $90 \%$ Guarantee

Tribe should Control Power

One line coming into California from Oregon

We Must Consider Impact on Our Youth

People Don't Have Access to Energy

Tribe has Resources to Develop Power

Funds and Resources are not available to us

Risk to Health and Safety

No Electricity

Council Needs Time and Information to Make Decisions Regarding Energy

Own Our Tribal Utility

Condemnation of Land for Use of P.U.

Opportunity, Yurok Tribe middleman with BPA and WAPA

Funding: Potential Grants, Loan Guarantees

Energy

-Need

-Want

-Control

Available Funding for Development Opportunities

Tribal Legal Department

- "The Law is On Our Side"

Vast Opportunities for Utility Development

What are global, national and local trends that are currently affecting the Tribe?

Wise Decisions

Water Issues

Tech Based Economies Need Power

Political Clout $=\$$

Electronic World Still Waiting for Us

Lack of Capacity

Federal Government not Sensitive to Our Tribal Lifestyle

Fossil Fuels Finite, Less Reliance

Sovereignty Increases Self Sufficiency

Federal and State Control Over Indian Territories

Environmental -Renewable -Green and Clean

Local Companies and Agencies are Unwilling to Provide Service

Need Infrastructure to Support Economic Development

Connection of Two Major Companies 
What are the current strengths and advantages as we move into the future?

Yurok Tribe -Sovereignty -Community -Members

Timing Legislation Increases Opportunity and Demand

Natural Resources

Resources -Information -Technical Assistance -Motivation

California is a "Consumer," the Northwest is the "Producer"

River and Forest

No Reason Not To

Membership and Tribal Organization is Growing $=$ Clout

$\$ 3$ Million $+\$ 1.5$ Million Energy Fund

Yurok Tribe is Progressive

Motivation

Need for Power

First Time Applicants

Untapped Resources

Funding For Local Development

Totally New System Not Old System with Old Ways

More Funding is Available for Energy

Tribe Working Together as a Whole 


\section{DATA}

\section{PRACTICAL VISION WORKSHOP}

FOCUS QUESTION: What do we want to see in place in 5 years?

Implementing Housing and Power

Energy Efficient Upgrades

Get Houses up to Date for Power

Upgrade Houses to Accept Power

Yurok Tribal Utility

Energy Business - Buy and Sell Power

Power for Profit Generation

Tribal Operated and Owned/Transmission

Real Energy Between

100\% Energy Supply

Line from Wachapec to Wautec

Real Synergy Between Programs, Facilities and Conmunities

Culturally Sensitive Energy Distribution System from Wachapec to Wautec

Facility Construction Needed for Economic and Social Development

Elder Care and Social Services Building

Cultural Center

Health and Wellness Facility at Both Ends of Reservation

Casino/Town Site Development

\section{Educated Workforce and Job Creation}

Job Creation Through Training: Education for Energy Building

Education/Training Programs

Tribal Utility Maintenance Department with Tribal Member Employees

PUB/O\&M Ability

\section{Infrastructure Development}

10 Jobs with Housing

Road Access from Wautec to Wachapec 


\title{
DATA
}

\section{UNDERLYING CONTRADICTIONS WORKSHOP}

FOCUS QUESTION: What are the blocks and obstacles that are keeping us from reaching our vision?

\author{
Lack of Unified Vision $\left(1^{\text {st }}\right)$ \\ Restricted Housing Development \\ Outdated and Unsafe Homes/Structures \\ Community Support, Off Reservation Support \\ Hard for Each Individual to Visualize Benefit
}

Defining and Exercising Sovereignty $\left(2^{\text {nd }}\right)$

Right of Way

Lack of Cooperation from Regulations and Codes and Jurisdiction

Education and Training

Land Acquisition and Use ( $\left.3^{\text {rd }}\right)$

Land Base: Need Land that can be Developed

Land Ownership: Fee, Allotment, Trust, Non-Tribal, Lack of

Terrain: Difficult/Expensive

Resources (4 $4^{\text {th }}$ )

Limited Funding

Limited Expertise on Energy Projects

Fair and Reasonable Public Transportation

Work Force

\section{Conflicting Priorities $\left(5^{\text {th }}\right)$}

Conflicts On-Reservation vs. Off-Reservation

Conflicting Coordinated Efforts

Other Projects

Limited Expertise

No Specific Focus

Over Lapping Priorities

Fear of Taking a Risk (Change)

Education, Communication, Prioritization

Information Distribution 


\title{
DATA
}

\section{STRATEGIC DIRECTIONS WORKSHOP}

FOCUS QUESTION: What are Specific Actions the Yurok Tribe needs to take in the next one year to address the contradictions and launch the vision?

\author{
Establish Tribal Energy Policy \\ Approve Ordinances for Utility \\ Form Tribal / Non-Tribal Community Utility Board \\ Form Tribal Leadership/Staff/Administration Utility Board \\ Renewable Energy Plan and Programs \\ Tribal Utility \\ -Decide What Type of Ownership? What That Meant? \\ -Training and Job Programs-Part of Utility Developments
}

\section{Council/Administration Accountability}

Accountability: "Sink or Swim" You're On Our Team or "Gone"

Mandate "No Excuses" Participation from Essential Players

-Legal, Administration, Departments, Council

Identify Time Wasters and Minimize or Eliminate Them

Hold Mandatory Meetings for Staff From Each Program to Coordinate Projects and Track Progress

Establish Time Line-Stick To Them

Create "Backwards Plan? -Specific Actions by Date Required

Establish Your "Team"

\section{Energy Funding Strategies}

Economic Summit

Form 501(c)3 for Grant Acquisitions

Develop Alliances with Surrounding Groups/Governments

Develop Funding Plan for ICDBG Program for Facilities

Work with Legislators to Support Projects

Identify Department Strengths and Skills

Historical Analysis

-Rights

-Usage

Create, Define and Communicate the Vision

Council/Staff/Community Communication

Teamwork, Teamwork, Teamwork

Public Outreach Plan

-Determine Need and Create Buy-In

-Establish a Grant Committee to Implementation

Implement/Mandate Team Building Culture

Focus on 1-3 Vision per Department, Create Master Vision

Construct Cell Phone Service: Weitchpec to Wautec

Education 


\section{Participant List}

$\begin{array}{ll}\text { Howard McConnell } & \text { Chairman } \\ \text { Thomas O'Rourke } & \text { Vice-Chairman } \\ \text { Sid Nix } & \text { Council Member } \\ \text { Walter Lara, Jr. } & \text { Council Member- Requa } \\ \text { Richard Myers } & \text { Council Member-Pecwan } \\ \text { Peggy O'Neil } & \text { Planning Director } \\ \text { Frank Masten } & \text { Planner I } \\ \text { Patti Norton } & \text { TERO Officer } \\ \text { Lisa Adams } & \text { Senior Attorney } \\ \text { William Guevera } & \text { Acting ED/YIHA } \\ \text { Nancy Atkinson } & \text { Engineer/Planning } \\ \text { Rose Sylvia } & \text { Personnel Director } \\ \text { Al Fischer } & \text { Assistant Finance Director } \\ \text { Kate Sloan } & \text { Cultural Department } \\ \text { Melva Severns } & \text { Planning Specialist } \\ \text { Shawn McMahon } & \text { Assistant Forest Program Manager } \\ \text { Dale O'Neil } & \text { Tribal Member } \\ \text { Ruby Grubbs } & \text { Legal Clerk } \\ \text { Kelly Gibson } & \text { Social Services Assistant Director } \\ \text { Bill Olsen } & \text { PRNewsletter }\end{array}$




\section{Introduction}

Learning the Technology of Participation and internalizing its intrinsic values of honor, respect, and compassion is the effective means of leadership development for a multicultural America. In a single process individuals and groups can find their own self-defined center and see a new paradigm of their intra and inter group relationships. The process humbles and empowers. The process liberates the individuals of the group and strengthens the group. Apparent contradictions are resolved not by conflict but through the revelation of higher principles. Inefficiency of consensus gives way to effectiveness of unity. The group moves not to its lowest common denominator as is often expected, but rises to its higher common values. The group is not pulled by a single dominating leader but is pushed by its members who take individual responsibility for leadership and followership. Each contributing and each benefiting in one another's process of being and becoming.

\section{A. David Lester}

Since 1990 the CERT Facilitation Program has provided facilitation to over 150 events with more that 60 Tribes, Indian Organizations and agencies that serve Tribes.

Facilitation and training services currently available through the CERT Facilitation Services Program are:

Participatory Strategic Planning Sessions provide a participatory process for articulating the action priorities of an organization. These workshops have been held with boards, Tribal Councils, Management Teams, Communities and Inter-Tribal Organizations throughout the country.

Facilitation Methods Training are two-day intensive workshops to train participants in effective group communication skills, workshop methods, action planning techniques for launching group projects, and strategic planning methods, using the Technology of Participation $\left(\mathrm{ToP}^{(\mathbb{8})}\right)$ Methods that have been developed by the Institute for Cultural Affairs.

Conference Facilitation Services help association, networks, and regional communities plan and carry-out lively conferences which use ToP ${ }^{\circledR}$ Methods to incorporate the wisdom and learning's of participants into the event itself.

Organizational and Management Development Services which offer opportunities for indepth reflection on current organizational and management practices, and the development of skills and processes to enhance organizational effectiveness and productivity. 


\section{ToP ${ }^{\circledR}$ Parcipatory Strategic Planning Process Overview}

The following is a brief description of To $P^{\circledR}$ (Technology of Participation)

Strategic Planning process which was used to create this document.

The document itself is made up of charts, which were the products

of each session, and the back-up data for various charts.

\section{Introducing Participatory Methods:}

Over the past twenty years a series of methods generally referred to as the "Technology of Participation" (ToP ${ }^{\circledR}$ Methods were developed by the Institute of Cultural Affairs). The Council of Energy Resource Tribes has been using To ${ }^{\circledR}$ Methods to facilitate Participatory Strategic Planning with tribes. The foundational values built into these $\mathrm{ToP}^{\mathrm{B}}$ Methods are quite straightforward:

- Participation - bringing together the insights of each participant in order to formulate the group consensus

- Teamwork - creating opportunities to work together in small teams to build the foundation for consensus

- Creativity - giving permission for the dialogue between rational and intuitive insights

- Action - moving from consensus to action through accountability based planning

How the ToP ${ }^{(\bar{x})}$ workshop process works...

First, individually and then in small groups everyone participates in intuitive brainstorming. Second, the facilitator works with the group to weave their ideas together into clusters with an eye to new relationships. Third, the group names the clusters in an attempt to articulate their profound insights on each. Finally, the facilitator leads the group in reflection on what has been accomplished, the new resolve and decisions that have been made.

\section{Strategic Planning with the ToP ${ }^{\circledR}$ Process}

ToP ${ }^{\circledR}$ Strategic Planning process is a four-step workshop series. Each workshop session can be done in the time frame of two hours to a full day depending on the amount of time the group has to lend to the process. The sessions are done in a basic workshop format. This strategic planning with the Sample Tribe was done in two days. Below is a brief description of four steps in this strategic planning process:

- Practical Vision Workshop in which the participants focus on articulating the shared vision

- Underlying Contradictions Workshop in which the participants analyze the fundamental obstacles to their desired common future

- Strategic Directions Workshop in which the participants decide the key strategic actions to target in the next two years

- Implementation Planning Workshop in which the participants take responsibility for particular areas of the strategy and build one year set out one-year accomplishments and 90day launch plans 


\section{PRACTICAL VISION WORKSHOP}

This workshop is designed to engage all the participants and elicit their wisdom and intuition as they look forward to where they believe the Tribe should be in five years, always keeping in mind that the primary focus was creating a Tribal Energy Plan to serve those needs. They were asked not to create a "dream" future, but a practical future that could be achieved based on their vast experience and knowledge of their Tribe. The individual ideas were grouped and through a participatory dialogue, five main interests were identified as where they saw that the Tribe should be in five years.

\section{UNDERLYING CONTRADICTIONS WORKSHOP}

The Underlying Contradictions workshop asks the question: What are the Blocks and Obstacles that are keeping us from reaching our vision?

The real issues facing an organization or Tribe manifest when placed under the light of a practical vision. Without a vision, problems and anxieties are relegated to "lists of things to do" or are explained away as personal conflicts. As a group considers the entire range of its issues together, root causes can be uncovered and objectified for sober consideration.

This workshop had the participants step back from the vision they had just created and ground themselves back in the current reality they had also outlined previously. While working first individually, then in small teams, they were asked to identify specific and broad barriers that would have to be considered and/or overcome in order to reach their vision. Through a group discussion that surrounded the barriers, the participants were able to articulate five areas of concern that were then essentially set up like dominos in that as the first one falls, that success would give the Tribe the ability, knowledge and strength to push the next one down. 


\section{Strategic Directions WORKSHOP}

The Strategic Directions workshop asks the question:

\section{What are Specific Actions the Yurok Tribe needs to take in the next one year to address the Contradictions and Launch the Vision?}

In the Strategic Directions workshop people are asked to focus on action strategies. If an organization plans only in relation to its vision, it runs the risk of being overly idealistic and unrealistic. By planning strategically, that is in relation to its real situation and the underlying contradictions, then it has a chance to realize its vision.

This workshop is designed to form the basic building blocks for an action plan. This time the participants were asked to identify actions, agendas, projects, programs, and first steps that would begin to address the contradictions they identified during the previous workshop. Through an interactive discussion, the participants were then able to group their main ideas to form five overall strategies that would assist the Tribe as they move forward toward their vision. 


\section{IMPlementation Workshop ANd ACtion Planning}

The effective implementation of any plan depends upon clarifying directions, aligning resources, designating leadership roles and responsibilities and building team trust and support. The final step in the strategic planning process is the implementation plan. At this point in the process participants build working teams, assign tasks, create calendars, and set meeting times all a part of constructing a motivating action plan.

This workshop consists of two steps, First is the creation of a Calendar of Accomplishments, and second is the creation Action Plans

These two workshops are designed to put action behind the strategies and ensure all the participants agree that they are moving in the same direction at the right time. The participants were once again asked to think individually, and then work in small teams to identify activities that would be necessary within the next six months to begin movement in each of the strategic directions they identified. They were then asked to sort through the activities and begin to look together at what are the necessary first steps and plot them out over a six month period. The group then came together and discussed the timeline that was created and made the necessary adjustments to ensure the strategies would support each other as they moved forward. Next the participants were asked to self select into teams and list the steps needed to carryout the activities they previously agreed would have to happen in the first month of the plan. These action plans include who is responsible for carrying out the steps as well as when they needed to be completed. Both the Implementation Timeline and 30 Day Action Plans are on the following pages. 


\title{
Council of Energy Resource Tribes \\ Contact Information
}

Council of Energy Resources Tribes

695 South Colorado Boulevard

Suite 10

Denver, CO 80246

(303) $282-7576$

\author{
A. David Lester \\ Executive Director \\ 303-669-3562 \\ adlester@qwest.net \\ Roger Fragua \\ Deputy Director \\ 720-220-7720 \\ rogerfragua@qwest.net
}

Sonya Tetnowski

Director of Tribal Energy Strategies

971-219-3622

stetnowski@qwest.net

Jessica Alcorn

Director of Energy Policy and Governmental Affairs

202-203-8248

jalcorn@qwest.net

Carly Hare

Energy Program Associate

carlyhare@qwest.net 
Appendix 6: Sample Yurok Water Bill 
SRND PAYMLNTI TO:

YUROK TRIAF:

* * PREVIEW BTLL

PO EDX 1027

KذAMATH, СA 95546

PHONE \#: (707) 482-1350

RCCOTW

\begin{tabular}{|c|c|c|c|}
\hline \multicolumn{2}{|c|}{ SरुKVICE } & & 11701 \\
\hline $\begin{array}{l}\text { YROW } \\
1 / 1 / 2007 \\
\end{array}$ & $1 / 30 / 2007$ & $\begin{array}{l}\text { DAXS USED } \\
29\end{array}$ & $\begin{array}{l}\text { DATE EILL MNILED } \\
5 / 1 / 2007\end{array}$ \\
\hline PREV. REASINO & RREI, RENDIMG & WNATS UERT & AMOUNT \\
\hline $\begin{array}{l}\text { Frovioua Gal, } \\
\text { EXYMENT "* } \\
\text { ELAT FFF }\end{array}$ & CHANK YOU * * & & $\begin{array}{c}\$ 28.00 \\
(\$ 28.00) \\
\$ 28.00\end{array}$ \\
\hline $\begin{array}{l}\text { AN: EAYMEATA } \\
\text { DATE MAY NOT }\end{array}$ & $\begin{array}{l}\text { RECENEE AFTER } \\
\text { SE RERLECTED OL }\end{array}$ & $\begin{array}{l}\text { THE DUE } \\
\text { S YOUR BILL }\end{array}$ & \\
\hline \begin{tabular}{|l|l|} 
DATE DUE & 5 \\
\end{tabular} & $15 / 2004$ CURR & CNT BALNNCE & 328.00 \\
\hline & 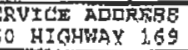 & & 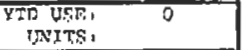 \\
\hline
\end{tabular}

\begin{tabular}{|c|c|}
\hline \multicolumn{2}{|c|}{ DLERSE RETHRN THIS STUB WITH PNYMRINT } \\
\hline ACCOUNT NLMEE: & 14701 \\
\hline $\begin{array}{l}\text { DATE DUE } \\
5 / 25 / 2007\end{array}$ & $\begin{array}{c}\text { TOTAL, EAYMENT DUE } \\
\$ 2 \mathrm{2B} .00\end{array}$ \\
\hline AMT, EACLOSED & \\
\hline
\end{tabular}

Pagn 4 of 74

Page 4 of 71

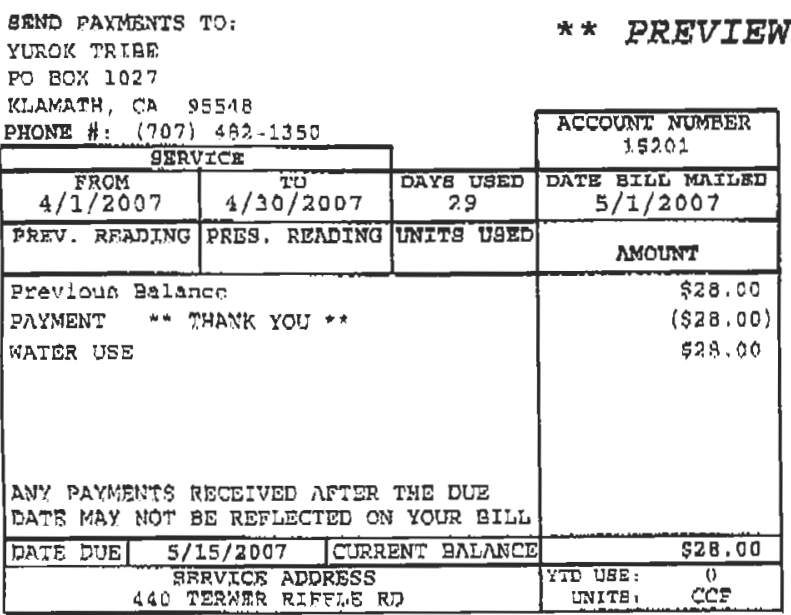

BEND FAXMENTS TO;

YUROK TRTAR

K!AMATH, CA 9554B

PHONE H: (707) 4 A -1350

\begin{tabular}{|c|c|}
\hline \multicolumn{2}{|c|}{ ACCOUNT NUMBER, 15201} \\
\hline $\begin{array}{l}\text { DATE DUE } \\
5 / 25 / 2007\end{array}$ & $\begin{array}{c}\text { TOTAL PAYMENT DUE } \\
\$ 28.00\end{array}$ \\
\hline AMT. ENCLOSED & \\
\hline HAKE C & $\begin{array}{l}\text { HECK PAYARLS TO: } \\
\text { UROK TRIAS }\end{array}$ \\
\hline
\end{tabular}

$\because$

...

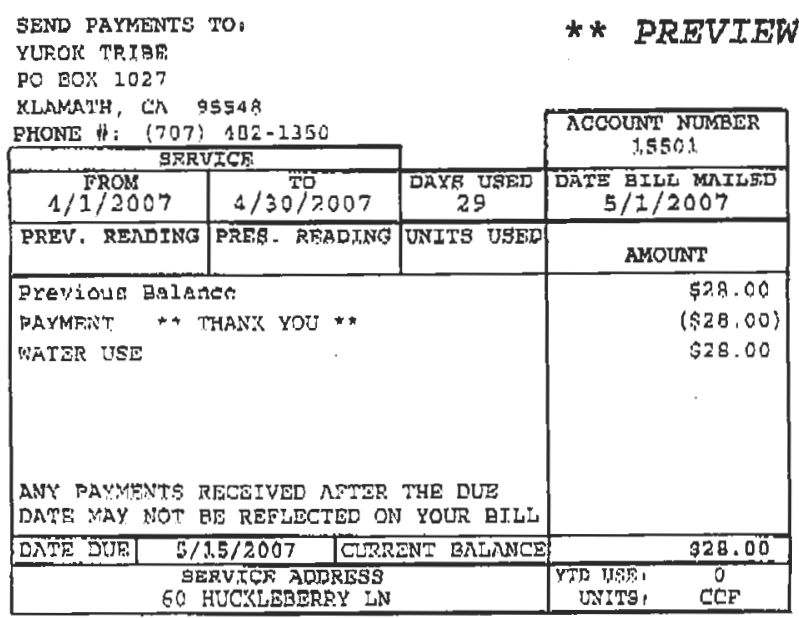

\begin{tabular}{|c|c|}
\hline \multirow{2}{*}{\multicolumn{2}{|c|}{ 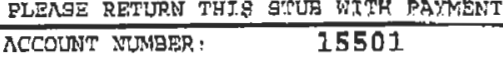 }} \\
\hline & \\
\hline $\begin{array}{l}\text { DATE DUE } \\
5 / 15 / 2007\end{array}$ & $\begin{array}{c}\text { TOTAL PAYMENT DUE } \\
\$ 28.00\end{array}$ \\
\hline AMT . ENCLOSED & \\
\hline$\sigma$ & $\begin{array}{l}\text { HECK } P A K A B L E \\
\text { UROK TRIBE }\end{array}$ \\
\hline
\end{tabular}

ANY BAVYYNTS RESEIVED NTTER THE DUE

DATE YAY NOT BE REFLECTED ON YOUR BJLL 60 HUCXLEGERSY LN 
Appendix 7: Draft Yurok Public Utilities District Ordinance 


\section{YUROK TRIBE}

\section{YUROK TRIBAL UTILITY AUTHORITY and}

Public Utility District ORDINANCE 
YUROK TRIBE

YUROK PUBLIC UTILITY DISTRICT

\section{TABLE OF CONTENTS}

\section{ARTICLE I: GENERAL PROVISIONS}

\author{
Section 1.01. \\ Section 1.02 . \\ section 1.03 \\ section 1.04
}

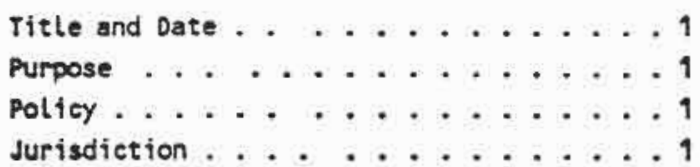

ARTICLE II: DEFINITION OF TERMS

Section 2.01. Section 2.02. section 2.03. section 2.04 . Section 2.05. Section 2.06 . Section 2.07. Section 2.08. section 2.09. Section 2.10.

Section 2.11. Section 2.12. section 2.13. section 2.14. Section 2.15. Section 2.16.

Section 2.17. Section 2.18. Section 2.19. Section 2.20. Section 2.21. Section 2.22.
General............ 2

Appurtenance. .......... 2

Customer. ............ 2

Customer Lines. . . . . . . . . 2

Garbage ........... 2

Distribution Systess Lines. . ..... 2

heter............. 2

Menager .............. 3

operator. ........... 3

On-site sewage Treataent

syatea. . . . . . . . . . 3

Off-Reservation. ........ 3

Regulation............ 3

Sewage Disposal Systen Cleaner. .... 3

Tribal comanity. ......... 3

contractor. .......... 3

Utilities and Environmental Service

Department. . . . . . . . . . 3

Utility Authority......... 3

Utility and Environmental Departwent. . . .4

Departaent ............. 4

Vendor. ............. 4

collection Lines. . . . . . .... 4

shall, May. ........... 4

ARTICLE III:

UTILITY AND ENVIRONMENTAL SERVICES DEPARTMENT AND UTILITY DISTRICT

Section 3.01.

Section 3.02 . Section 3.03 .

Section 3.04 .

Section 3.05 .

Section 3.06 .
Establishment of Utility District and Environmental Services ... 5 Utility District.......... . 5 Utility District - Operating organization . . . . . . . . . . 5 Utility District - Powers and Responsibilities......... . . 6 Utility District - Membersnip . . . . . 6 Tera of office......... 6 


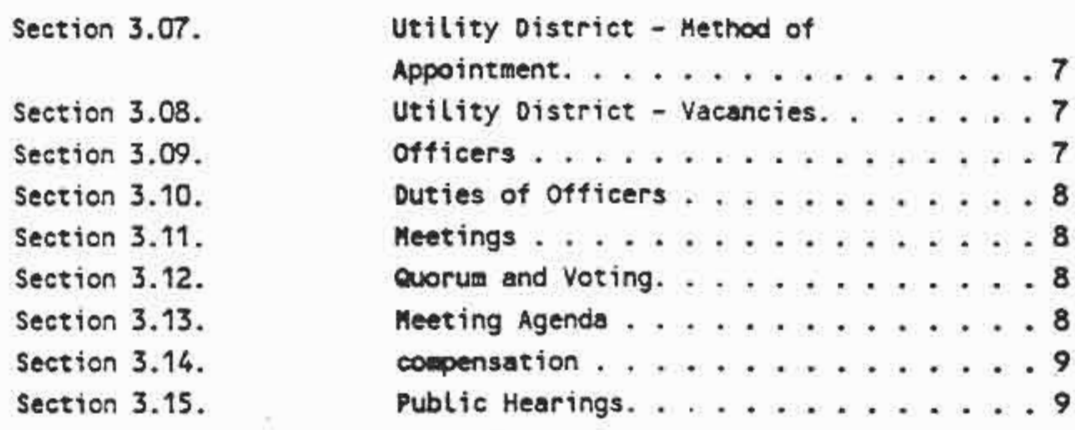

\section{ARTICLE IV: MANAGEMENT AND FINANCES}

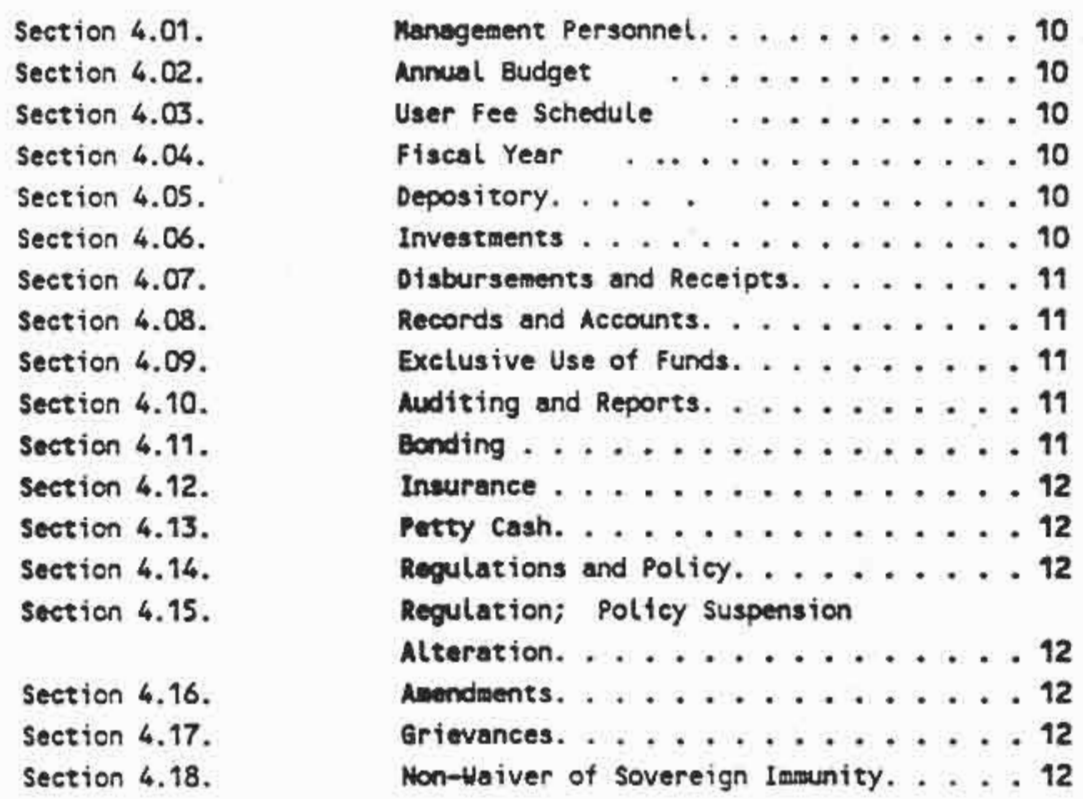

ARTICLE V: UTILITY AND ENVIRONMENTAL SERVICES - OPERATION

\begin{tabular}{|c|c|}
\hline Section & 5.01. \\
\hline Section & 5.02 . \\
\hline Section & 5.02. \\
\hline Section & 5.03. \\
\hline Section & 5.04. \\
\hline Section & 5.05 . \\
\hline Section & 5.06 . \\
\hline Section & 5.07 . \\
\hline Section & 5.08. \\
\hline Section & 5.09 . \\
\hline Section & 5.10. \\
\hline Section & 5.11. \\
\hline Section & 5.12. \\
\hline Section & 5.13. \\
\hline Section & 5.14. \\
\hline Secrion & 5.15 \\
\hline Section & 5.16 \\
\hline
\end{tabular}

Services Provided. . . . . . . . . 13

Alternative Energy Service....... 13

Water Service. ........... 13

Sewerage service.......... 13

Garbage Service. . . . . . . . 14

Future services. . . . . . . . . 14

Maintenance schedule....... 14

Personnel. . . . . . . . . . . . 14

Purchasing . . . . . . . . . 14

Equipment. . . . . . . . . . 14

Inventory. . . . . . . . . . 15

Public Relations........... 15

Emergency Notitication ........ 15

Staff Training ........... 15

Limits of Responsibility . . . . . . 16

Right of Entry - Inspections . . . . . 16

Disruptions of Service........ . . 16 


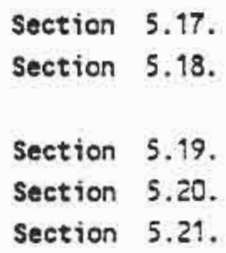

Permits. ............ 17

Hater Septic - Service

reference) . . . . . . . . . . 17

Unnecessary Waste of Water . . . . 17

Conservation of Resources. . . . . . . . 17

New Customer Services. . . . . . . 18

ARTICLE VI: CUSTOMER OBLIGATIONS

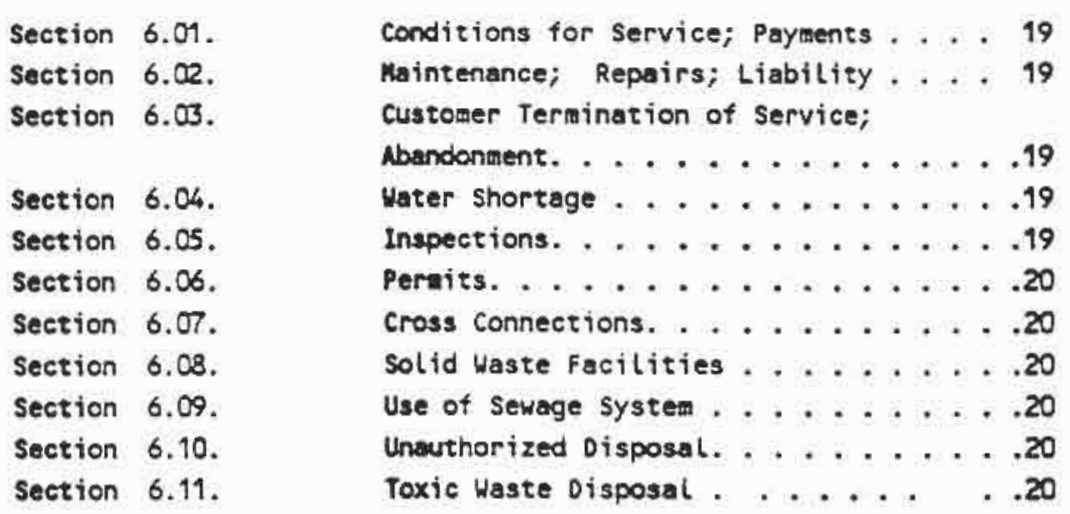

ARTICLE VII: FEE SCHEDULES AND BILLING

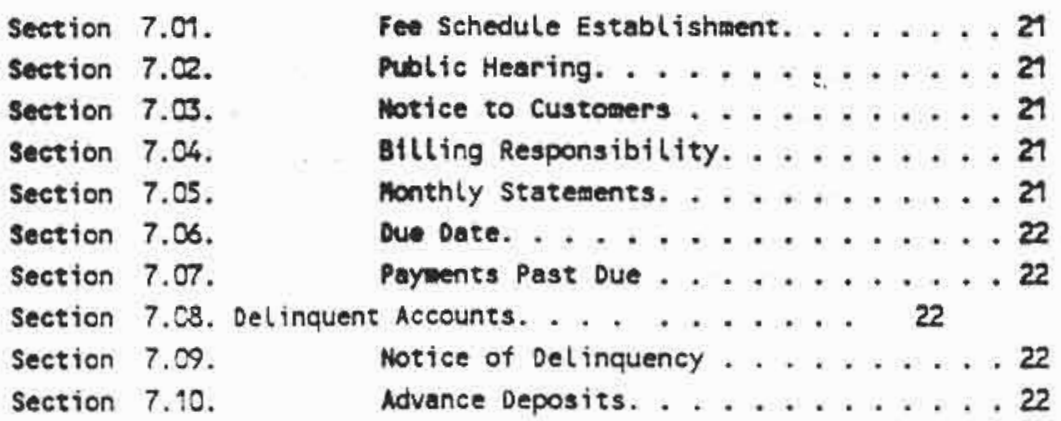

ARTICLE VIII: ENFORCEMENT; PENALTIES; SANCTIONS

$\begin{array}{ll}\text { Section } 8.09 . & \text { Authority and Enforcement....... } 24 \\ \text { Section } 8.02 . & \text { Attachment of Customers Property .... } 24 \\ \text { Section 8.03. } & \text { Penalty Schedule. . . . . . . } 24 \\ \text { Section 8.04. } & \text { Sanctions Authorized. ......... } 24 \\ \text { Section 8.05. } & \text { Sanctions Guidelines. . . . . . . } 25\end{array}$

ARTICLE IX: MISCELLANEOUS PROVISIONS
Section 9.09 .
Validity SEVERABILITY ....... 26
Section 9.02 .
Amendments. . . . . . . . . 26
Section 9.03. Suspension of Ordinance . . . . . 26 


\section{YUROK TRIBE \\ PUBLIC UTILITY DISTRICT ORDINANCE ARTICLE I}

\section{GENERAL PROVISIONS}

SECTION 1.01. TITLE AND DATE: This ordinance shall be titled; the Yurok Public Utility DistrictOrdinance. The ordinance shall become effective immediately upon adoption by resolution of the Yurok Tribal Council.

SECTION 1.02. PURPOSE: The purpose of the Yurok Public Utility Ordinance is to establish the Yurok Public Utiltities District (YPUD), define the policies and identify the necessary rules and regulations for the operation, maintenance and management of the various public utilities located within the exterior boundaries of the Yurok Reservation and management for the provision of essential community services within the Reservation and any annexed lands.

SECTION 1.03. POLICY: It shall be the policy of the Yurok Tribe to operate, maintain and manage the public utilities and essential environmental services on the Yurok Reservation and on designated contiguous lands so that the community residents are provided with a high level of environmental services designed to minimize exposure to adverse conditions which could negatively impact the physical and environmental health of any individual or the community. It shall also be the policy of the Yurok Tribe that the operation maintenance and management of the public utilities and environmental services shall be carried out through an efficient program and in a financially responsible cost-effective and selfsufficient manner.

SECTION 1.04. JURISDICTION: The authority to establish a Yurok Public Utiltites District and to levy appropriate user fees to all residents and organizations operating within the exterior boundaries of the Yurok Reservation is pursuant to the authority vested in the Yurok Tribe by its Consititution, and particularly by Article 1, Section 4 and Article IV Section D thereof. The boundaries of the Yurok Public Utility District shall be the exterior boundaries of the Yurok Reservation until amended to incorporate annexed lands.

\section{ARTICLE II DEFINITION OF TERMS}

SECTION 2.01. GENERAL: Unless the context specifically indicates otherwise, the meaning of terms used in this ordinance shall be set forth in this Article II.

SECTION 2.02. APPURTENANCES: "Appurtenances" are the real and personal property owned by the Yurok Public Utility District or the Tribe located on, near, or under the roadways and streets, such as fire hydrants and valves. 


\section{DRAFT

SECTION 2.03. CUSTOMER: "Customer" means a person, business, agency or other organization that benefits, uses, is entitled to use, or is obligated to pay for the maintenance, use, or receipt of services from the Yurok Public Utility District. For purposes of this ordinance "Customer" may include nonresident landowners who are beneficiaries by virtue of the establishment of community services by the Yurok Public Utility District.

SECTION 2.04. CUSTOMER LINES: "Customer lines" are the potable water lines located immediately adjacent to, inside of, or under a customer's residence or other building or property, which are either connected to utility service lines or are maintained by the customer separately from utility service lines.

SECTION 2.05. GARBAGE: "Garbage" shall mean all degradable and non-degradable refuse and solid waste without economic value that is generated through the course of normal living by the residents and organizations in the community.

SECTION 2.06. DISTRIBUTION SYSTEM LINES: "Distribution system lines" are those potable water lines maintained by the Utility and Environmental Services Department by which water utility services are provided to customers.

SECTION 2.07. METER: "Meter" is a device, owned by the Utility and Environmental Services Deparment, for measuring the amount of water utility services provided to a particular customer.

SECTION 2.08. MANAGER: "Manager" shall mean an individual hired by or appointed by the Yurok Tribal Utility District to oversee and manage the operation of the Yurok Public Utility District

SECTION 2.09. OPERATOR: "Operator" shall mean an individual hired by or appointed by the Utility District or manager to provide direct day to day preventive maintenance and operational service for the public water and sanitary sewer utilities.

SECTION 2.10. ON-SITE SEWAGE TREATMENT AND DISPOSAL SYSTEMS; "On-site sewage treatment and disposal system" shall mean individual or community septic tanks and subsurface drain fields and associated appurtenances that collect, treat and dispose of liquid waste generated by customers, which are maintained and operated by the Utility and Environmental Services Deparment.

SECTION 2.11. OFF-RESERVATION: "Off-reservation" is any area located outside of the exterior bouncaries of the Yurok Reservation.

SECTION 2.12. REGULATION: "Regulation" is a rule of law or procedure duly adopted by the Utility Authority for purposes of implementing the requirements of this ordinance.

SECTION 2.13. SEPTIC SYSTEM CONTRACTOR: "Septic system Contractor" shall mean any individual, firm, contractor or organization who the Utility District contracts with, to pump out on-site 


\section{DRAFT DRAFT DRAFT}

sewage treatment and disposal systems and dispose of the waste material and/or to repair the on-site sewage treament and disposal systems located on the Yurok Reservation

SECTION 2.14. TRIBAL COMMUNITY: "Tribal Community," for purposes of this ordinance, shall include, but not necessarily be limited to, enrolled Yurok Tribal members.

SECTION 2.15. CONTRACTOR: "Contractor" individual, firm, contractor or organization who with the Utility District to provide environmental or utility repairs, design, inspection, reconstruction operation.

SECTION 2.16. "UTILITIES AND ENVIRONMENTAL SERVICES" are those basic services necessary for supporting residential and commercial development, including, but not limited to, water, sewer, garbage collection, fire protection, communications, roads and appurtenances.

SECTION 2.17. UTILITY AUTHORITY: "Utility Authority" is the Board of Directors of the Yurok Public Utility District, as established by this ordinance.

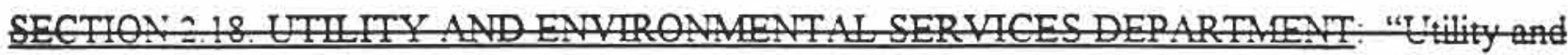
Envirenment Services Department" is govenment deparment of the YurokTribe atherized to operate the utility services provided by the Tribe.

SECTION 2. 19: DEPARTMENT: "Department" shall mean the Yurok Public Utility District, a dependent District of the Yurok Tribe.

SECTION 2.20. VENDOR: "Vendor" is any individual firm, contractor or organization who regularly supplies parts, equipment, supplies and services to the Utility and Environmental Services Department used in the operation maintenance and management of the Utilities and Environmental Services of the Yurok Reservation.

SECTION 2.21. COLLECTION LINES: "Collection Lines" are those sanitary sewerage lines maintained by the utility and Environmental Services Department by which sanitary sewer collection and disposal services are provided to customers.

SECTION 2.22. SHALL, MAY: "Shall" is mandatory; "may" is permissible. 


\section{ARTICLE III \\ YUROK PUBLIC UTILITY DISTRICT}

\section{SECTION 3.01. ESTABLISHMENT OF UTILITY DISTRICT AND ENVIRONMENTAL} SERVICES THEREUNDER: There is hereby established the Yurok Public Utility District having the responsibility for operating and maintaining the tribal public utilities and providing essential community environmental services directly or by contract.

SECTION 3.02. UTILITY AUTHORITY: There is hereby established the Yurok Tribal Utility Authority to serve as the advisory, administrative and management authority for the Yurok Public Utility District. The Yurok Tribal Utility Authority serves as the Board of Directors of the Yurok Utility District.

SECTION 3.03. UTILITY AUTHORITY - OPERATING ORGANIZATION: The Utility Authority shall operate as a Dependent Utility District, independent in its daily operation, but accountable to the Tribal Council for its actions. The methods of appointment, terms of office, and operating procedures of the Utility Authority shail be set forth, in this ordinance and in regulations adopted by the Board of Directors.

SECTION 3.04. UTILITY AUTHORITY - POWERS AND RESPONSIBILITIES: The District Board of Directors shall manage the public utilities of the Tribe, and obtain and disburse funds as required for operation, maintenance and expansion of the tribal public utilities. The Board of Directors shall establish and adopt an annual budget for its operations, and submit it to the Tribal Council for review. The Board shall have the power to solicit funds from federal or state sources, and to petition the Council for additional funding in the form of contributions from the general revenues of the Tribe, through the establishment of regular assessments, or implementation of a general levy within the boundaries of the district.

To fulfill these responsibilities, the Authority shall have the power to:

(1) Levy and collect reasonable fees for utility service;

(2) Provide for the hiring and compensation of appropriate management and maintenance personnel:

(3) Adopt appropriate by laws and regulations to implement the requirements of this Ordinance;

(4) Authorize disbursement of funds for operation, maintenance and repair of utility services.

(5) Contract with vendors and contractors to assure that safe and reliable environmental 


\section{DRAFT DRAFT DRAFT}

services are available to and utilized by the residents of the Yurok Reservation.

(6) Authorize investment of Utility and Environmental Service Department funds in interest bearing instruments or accounts with institutions chartered and insured for such purposes by the federal government.

SECTION 3.05. UTILITY AUTHORITY - MEMBERSHIP: The Utility Authority shall be composed of four persons nominated by the Council as a whole and appointed by the Chair of the Tribal Council, one each from the respective on-reservation Districts: Orick, Requa, Pecwan, and Weitchpec. The community members selected should be bonafide residents of the on-reservation Districts and customers of the Utility District. There shall be one Council Member from an "At-Large" District (North, South, or East) appointed by the Chair of the Yurok Tribal Council. Members of the Utility Authority Board shall be known as Directors.

SECTION 3.06. TERM OF OFFICE: Except for the initial Board of Directors, all members will serve two-year terms, except for the representative from the Tribal Council who shall serve a one-year term. Reappointment of the Council representative shall be at the discretion of the Chair of the Tribal Council. In order to establish a rotation for future appointments, Initial Terms for the Board shall be as follows:
Council Representative
Requa Representative
(Position - 1) - 1 year
Orick Representative
(Position - 2) - 2 year
Wautek Representative
Weitchpec Representative
(Position - 3) - 1 year
(Position - 4) - 2 year
(Position - 5) - 1 year

Terms for the Board of Directors of the Yurok Public Utility District shall expire on December 31 st of each year. The swearing in of newly appointed Directors will occur at the first regular meeting of the Tribal Council or the first Tuesday in January, whichever occurs first.

In the event that the Council Representative on the Utility Board loses or resigns her/his position on the Council, a new Council appointment to the Utility Board shall be made by the Tribal Cnair at the next regular meeting of the Tribal Council, after consultation with the other members of the Tribal Council.

SECTION 3.07. UTILITY AUTHORITY - METHOD OF APPOINTMENT: The Chair of the Yurok Tribal Council shall annually appoint persons to fill any Utility Authority vacancies which occur, after consultation with the other Council Members. The appointments will be made from a list of eligible and qualified people nominated by the Reservation communities, with the support of the Council Member from the District. 
SECTIO.Y 3.08. UTILITY AUTHORITY VACANCIES: If a Director resigns, moves from the local area, dies, or is found guilty of a felony or major crime in any court of law, the Tribal Council shall declare the Utility Board position vacant. If any Director misses two consecutive Utility Authority meetings without a valid excuse, the Tribal Chair, after due consultation with the Council, may declare the position vacant. All vacancies shall be filled within one month in accordance with this Section.

In the event that the mumber of unfilled Utility Board vacancies prevents gathering of a quorum for purposes of conducting business, the Tribal Council shall act as the interim Utility Authority, until such time as the filling of Utility Board' vacancies allows for a quorum.

SECTION 3.09. OFFICERS: Within ten days after the appointment of the initial Utility Board, there shall be an organizational meeting of the Utility Authority to elect a Chairman, Vice Chairman and a Secretary-Treasurer from among the Utility Authority Directors. The officers shall be elected anmually thereafiter, immediately following the appointment by the Tribal Council of the new Director.

SECTIO.V 3.10. DUTIES OF OFFICERS: Officers of the Utility Authority shall assume the following duties:

1. Chairman - Shall preside at all meetings; call and conduct all meetings; be responsible for all general management of the Utility Board's affairs: and perform all duties incidental to the office.

2. Vice-Chairman - shall perform all of the Chairman's duties in the absence of the Chairman: and shall assist the Chair as required in the conduct of meetings and in handling the Utility Authority's affairs.

3. Secretary-Treasurer - Shall keep or cause to be kept a complete and accurate record of all meenngs and shall cause to be maintained all correspondence, notices and records of the Utility District's Board of Directors.

SECTION 3.11. MEEIINGS: The Utility Authority shall meet when business demands and requires attention but in no case less than once per month. Regular and special meetings shall be called by the Chairman. Any three Directors may request the Chairman, in writing, to schedule a special meeting of the Utility Authority.

Meetings shall be held in public places, and the Utility Authority shall provide pubiic notice of Authority meetings. Emergency meetings maybe convened without notice, in cases of emergency where loss of life, limo or property is threatened, or where the continued operation or fiscal capability of the Tribal public utilities may be in jeopardy. All regularly scheduled meetings shall be open to members of the tribal community and to customers of the Yurok Public Utility District.

SECTION 3.12. QUORUM AND VOTING: A minimum of four Directors, including the Chair (or Vicechair in his or her absence) is required to establish a quorum and conduct Utility Authority business. Any ac:ion taken by the Utility Authority must be approved by a majority vote of those Directors present at a Utility Authority meeting. Each Director of the Utility Authority, except the Chairman, shall be 


\section{DRAFT DRAFT DRAFT}

entitled to vote on each matter coming properly before the Utility Authority. The Chairman shall vote only in the event of a tie.

SECTION 3.13. PARLIAMENTARY PROCEDURE AND MEETING AGENDA: Regular meetings of the Utility Authority shall be conducted according to Robert's Rules of Order. The agenda for the regular meetings will include at minimum the following agenda outline:

1. Call to Order

2. Roll call

3. Reading of minutes of previous meeting

4. Consent / Correspondence Agenda

5. General Manager's Report

6. Financial Report

SECTION 3.14. COMPENSATION: Directors of the Utility Authority shall receive $\$ 100$ per meeting for one meeting per month. The Board shall receive prevailing government rates for mileage, per diem, or other costs, consistent with established Tribal policy, and shall direct the District's Business Manager to approve such expenditures; provided that funds are available within the Utility District's budget for Board expenditures and have prior approved by the Utility Authority.

SECTION 3.15. PUBLIC HEARINGS: The Utility Authority, shall convene public hearings to discuss changes in utility rates or user fees, regulations affecting provision of service, addition of new services, or changes in the Utility District Boundary. All users of tribal public utilities shall be afforded seven days written notice of such hearings, and adequate notices shall be posted at appropriate public locations within the community.

\section{ARTICLE IV}

\section{MANAGEMENT AND FINANCES}

SECTION 4.01. MANAGEMENT PERSONNEL: The Utility Authority Board of Directors shall oversee the business and operating affairs of the Yurok Utility District. The Utility Authority shall provide for hiring and/or contracting for certified or otherwise qualified personnel for the implementation and maintenance of the District's services and shall establish compensation rates consistent with the District's approved budget. The Uitility Authority, through the Chair, shall delegate to its staff those management duties that are not specifically designated as duties. to be performed exclusively by the Utility Authority Board of Directors.

SECTION 4.02. ANNUAL BUDGET: The Utility Authority shall establish an annual budget for the provision of District services: Operation and Maintenance, Administration, Personnel, Public Liability and Other Insurance, a Capital Reserve Account for major repairs and replacements, Income from User Fees, Loans, and Grants, and Debt Service.

SECTION 4.03. USER FEE SCHEDULE: The annual budget shall be used to determine a Uniform Fee Schedule to be assessed to the Customers of Utilitiy Services. The budget and fee schedule shall be 
approved by the Utility Authority's Board of Directors, and will reflect the actual total costs of providing those services.

SECTION 4.04. FISC.II YEAR: The fiscal year for the Yurok Public Utility District shall be either the Calendar Year or the fiscal year of the Yurok Tribal Government and will be set by the Board of Directors at the first regular meeting of the Initial Board.

SECTION 4.05. DEPOSITORY: The depository of Department shall be a separate commercial account or accounts in any bank selected by the Utility Authority. Said account shall be in the name "Yurok Public Utility District".

SECTION 4.06, INVESTMENTS: Funds on deposit in excess of 30 days working capital may be invested in insured deposits at a commercial bank, savings and loan association or investment company offering the highest interest rate, provided that investment deposits shall have immediate liquidity. . Investment deposits shall be made by the Utility Authority's Treasurer. Withdrawals of investments require the approval of the Utility Authority Treasurer. Withdrawals from accounts shall be signed by two of the officers of the Utility Authority or their designated staff.

SECTION 4.07. DISBLRSEMENTS AND RECEIPTS: The Utility Authority shall determine the distribution of funds required for the operation, maintenance and management of the Tribal Public Utility District. Disbursements will be made by check upon presentation of invoices or vouchers. Disbursements shall be made by the Officers of the Utility Authority or employees properiy designated by the Utility Authority. The checks written on accounts shall be signed by two of the Officers of the Utility Authority. Cash receipts will be deposited intact, as to amount, in the depositor promptly. Receipts will be issued for all cash received and copies filed and retained for accounting.

SECTION 4.08. RECORDS AND ACCOUNTS: Suitable financial records shall be maintained for ail expenditures, receipts from payments for services,, investments and returns on investments, and any other financial matters necessary for operation of the Yurok Public Utility District. The separate accounting records for the Department shall be maintained in an appropriate business like manner. The records of accounts shall be made available to the Tribal Council as soon as financial reports for each period are available.

SECTION 4.09. EXCLLSIVE USE OF FUNDS: The funds accrued by the Utility Authority and kept on deposit are for the exciusive use of the Yurok Public Utility District for the necessary operation, maintenance, and management of the Tribal public utilities and environmental services. Utility Authority funds shall not be transierred or loaned to the Tribal General Fund or any other accounts of the Tribe or other Tribal departments, except to pay for services provided to the Utility Authority or the District by other Tribal Departments.

SECTION 4 10. AUDIT AND REPORTS: The accounts of the Utility Authority will be audited annually at the close of the fiscal year at the expense of the District. Annual and periodic reports will be submitted by the Utility Authority to the Tribal Council. 


\section{DRAFT DRAFT DRAFT}

SECTION 4.11. BONDING: Officers of the Utility Authority and any other person(s) designated to handle funds for the Yurok Public Utility District, shall be bonded for amounts up to $\$ 100,000$.

SECTION 4.12. INSURANCE: Fire and other insurance on property owned or used by the District or on property in which the District has an insurable interest shall be in amounts and type of coverage specified by the Utility Authority. Insurance may be part of the Tribal insurance policies, with the expenses thereof pro-rated to the District if approved by the Utility Authority Board and by the Yurok Tribal Council.

SECTION 4.13. PETTY CASH: A petty cash fund is authorized to be established in the amount determined by the Utility Authority with recommendations from District Staff. This fund may be used to pay small expenses, when necessary, and to pay small obligations when it is not feasible to pay by check on the official depository. The fund may be reimbursed periodically from the official depository of the Utility Authority in the amount of and upon the submittal of receipts, vouchers, and statements signed by the payees, of their proof of expenditure. Petty cash reimbursement vouchers shall be certified by the Treasurer.

SECTION 4.14. REGULATIONS AND POLICY: The Utility Authority shall have the authority to adopt appropriate regulations and policy as needed to implement the provisions contained in this ordinance.

SECTION 4.15. REGULATION: POLICY SUSPENSION ALTERATION: No regulation duly adopted by the Utility Authority may be suspended or altered by any person without prior written authorization of the Utility Authority.

SECTION 4.16: AMENDMENTS: The Utility Authority shall recommend amendments to this ordinance that it believes necessary to promote the efficient, cost effective and self-sufficient operation of the Yurok Public Utility District, and shall present such amendments to the Tribal Council for approval.

SECTION 4.17 GRIEVANCES: Any customer or any applicant for utility services, who is aggrieved by any action of the utility and Environmental service District or the Utility Authority may file a grievance with the Utility Authority. The Utility Authority shall abide by the regulation set forth in this ordinance and shall handle such grievances in a manner which provides for due process of law.

All decisions by the Utility Authority on matters that have been submitted for grievance under the District's grievance procedures shall be considered final. Final decisions of the Utility Authority may be appealed by an aggrieved party only on the basis that the District's grievance procedures were not followed, or that due process was denied.

SECTION 4 18 NON-WAIVER OF SOVEREIGN IMMUNITY: The Yurok Public Utility District is an agency of the Yurok Tribe, and thereby retains all rights of sovereign immunity of the Tribe. By providing services and entering into service agreements, the District shall not waive the sovereign immunity of the Yurok Tribe or any of its officers, agents. attorneys or employees, or any one else acting at the direction of and on behalf of the Yurok Tribe. 


\section{ARTICLE V}

\section{UTILITY AND ENVIRONMENTAL SERVICES-OPERATION}

SECTION 5.01. SERVICES PROVIDED: The services provided by the Yurok Public Utility District shall inciude alternative energy systems, community fire services, domestic water and sewer, and solid waste management. Additional services requested may be provided upon approval by the Utility Authority Board of Directors, acting on recommendations of the General Manager.

SECTION 5.02. WATER SERVICE: The Utility Authority is responsible for providing safe, adequate water for a fee to those houses, businesses and institutions connected to the mainlines of the community water system. Responsibility for maintenance will include water sources, storage tanks, controls, mainlines, valves and hydrants, and service lines to the curb stops only. The service line from the curb stop to the house and interior house plumbing are the responsibility of the customer. The individual househoid water meters are owned by the Utility Authority and it is the responsibility of the District to maintain the meters. The tribal community water systems shall be managed such that the regulatory requirements and standards of the Federal Safe Drinking Water Act, as established by the Environmental Protection Agency, are satisfied.

SECTION 5.03. SEWERAGE SERVICE: The Utility Authority is responsible for providing sanitary disposal of domestic liquid waste for a fee to those houses, businesses and institutions connected to the mainlines of the community sewerage system. Further, the Utility Authority is responsible for the maintenance and repair of community sanitary sewage disposal systems and storm sewer systems. Responsibility for maintenance includes treatment facilities, pumping stations, mainlines, manholes, and service lines to the individual property lines. Tribal sewerage collection, treatment and disposal systems shall be managed such that applicable Federal regulations of the Clean Water Act and the National Pollution Discharge Elimination System are satisfied.

The Utility Authority is responsible for maintenance of individual on-site sewage disposal systems installed under a District permit, inciuding individual pumping stations, and for pumping the septic tanks on a periodic basis. The service line from the property line to the house or the septic tank inlet to the house and interior house plumbing are and remain the responsibility of the customer.

SECTIO.: 5.04. GARBAGE SERVICE: Garbage collection and disposal service shall be provided by the Utility Authority for a fee for the houses located in the reservation community. The fee may include a user fee for collection at the established container site and a per parcel assessment on all property owners within the District boundary. The Utility Authority will provide this service directly or enter into a contract with a nearby solid waste collection contractor in order to provide this service to the community,

SECTIO.: 5.05. FUTURE SERVICES: At some future date the Utility Authority may elect to assume responsibility to provide other community development or public utility services as the needs of the Yurok Reservation and the customer population base warrants. 


\section{DRAFT DRAFT DRAFT}

SECTION 5.06. MAINTENANCE-SCHEDULE: The Utility Authority shall develop and follow a regular schedule of maintenance service for each system and components thereof provided to the customers of the District.

SECTION 5.07. PERSONNEL: The Utility Authority shall have the full authority to hire. evaluate and discipline or fire if necessary the personnel required to manage, operate and maintain the Public Utilities. Existing Tribal Staff may be used and employed by the Yurok Public Utility District to provide necessary maintenance and management services through agreements approved by the Tribal Council and the Utility Authority. The specific personnel policies of the Tribe shall be followed. Job descriptions for all employees will be developed and followed.

SECTION 5.08. PURCHASING: The Utility system operator may make or approve purchases from the petty cash fund for amounts up to $\$ 200$ (two hundred dollars). Above this amount, the Utility Authority Treasurer must give approval and disburse funds according to appropriate sections of this ordinance. An accurate account and receipts of all expenditures will be kept.

SECTION 5.09. EQUTPMENT: All utilities equipment shall be maintained according to the established maintenance schedule and quickly repaired when necessary so that disruptions in service are minimized.

Utility tools and equipment are not for personal use. Equipment shall not be loaned to other Tribal Departments. A record of tools and the individual to whom they were assigned shall be maintained. Individuals will be heid responsible for the security of tools and supplies that are assigned to them.

SECTION 5.10. INVENTORY: An accurate inventory of tools, equipment, and supplies will be kept up to date. A. reserve supply of repair parts and regularly used supplies will be maintained by the District. A listing shall be kept of local suppliers of repair parts, replacement equipment and expendable supplies.

SECTION 5.11. PUBLIC RELATIONS: The Utility Authority shall keep customers notified about changes in fees, rates, solid waste collection schedule, water quality regulatory compliance. levels of service and any other information which may affect customers use of sanitary facilities. Notices may be included in monthly billing statements or may be disseminated to the public through separate mailings, newsletters, tribal newspaper or posting throughout the community.

Any person filing a complaint or seeking information shall be given assistance in a courteous manner. Complaints may be presented verbally or in writing to any District Staff member for resolution and action. Compiaints that cannot be resolved within ten days should be referred to the Utility Authority in writing. The Utility Authority will resolve such complaints at the next regularly scheduled meeting of the Authority.

SECTION 5.12. EMERGENCY NOTIFICATION: An emergency notification plan will be developed by the Utility Authority and reviewed annually for notifying residents and visitors of:

A. Discontinued service for more than eight (8) hours duration.

B. Substandard conditions in water quality. This includes bacteriological, chemical or physical quality deficiencies. 
C. Changes in scheduling of refuse pick-up and septic tank pumping, if those services are offered by the District.

D. Any other conditions which may adversely affect the health of the community residents o: visitors.

SECTION 5.13. STAFF TRAINING: All employees that are newly assigned to operate the utility systems shall receive instruction from an experienced operator. A minimum of 32 hours of instruction should be received before the new employee assumes responsibility for operations. Regular operators should receive up to 40 hours of formal instruction per year. The Utility Authority will assure that operators maintain current knowledge of water system operation techniques.

A training plan for the water system operators shall be developed which will provide for upgrading of knowledge and skills in water utility operations, maintenance and management. The goal of the training program shall be Washington State certification as Water Distribution Manager.

SECTION 5.14. LIMITS OF RESPONSIBIITY: The District shall not be responsible for, nor shall it maintain or repair, any private domestic water or sewer system, garbage, roads or lighting except by specific agreement establishing fair rates of compensation to the District, and that is approved and signec by the Utility Authority and owner of such facilities. The District shall not be liable for any loss or damage beyond its control resulting from any defect in, or damage to, a customer's water or sewer lines or fixtures, garbage storage facilities, driveways or parking lots, hydrants or lighting.

SECTION 5.15. RIGHT OF ENTRY - INSPECTIONS: The District, or its authorized representative, is hereby authorized to make limited, reasonable inspections, at reasonable times, of any grounds, building or residence served by the Utility District to the extent necessary to insure that customer utility fixtures, lines and equipment are not being operated in a manner that would likely disrupt or interfere with utility services. Except in cases of emergency where life, limb, or property are threatened, or in cases of immediate water shortages, the District shall give the customer at least 24 hours notice prior to requesting permission to enter and inspect. If permission to enter and inspect is denied or impeded in any way, the District shall obtain a court order authorizing such entry and inspection. Where the permission to enter and inspect is unreasonably withheld, the District. may assess court costs and related expenses and add the-to the affected customer's bill.

SECTION 5.16. DISRUPTION OF SERVICE: The District may shut off water or sewerage service, or disrupt traffic on the public right-of-way to perform repairs, provided that advance notice has been given to affected customers. Provided, however, that in cases of emergencies where loss of life, limb or property is threatened, or in cases of immediate water shortage, service may be disrupted without advance notice. The District shall not be responsible for consequent damage as a result of lack of water or sewerage during authorized disruptions of service. The District shall not be liable for any associated damages or delay caused by the breaking or leaking of any pipe, vaive, fixture or other contrivance as a result of the lack of water or sewerage to or from any mains, services, hydrants, lines or reservoirs during authorized disruptions of service. 
SECTION 5.17. PERMITS: No connection, re-connection with, disconnection's from, or other private use of any District water or sewer system, road, appurtenance or other utility service or facility shall be made without a written permit by the Utility Authority. No construction of any private water or sewer system, or other private utility is authorized without written permission from the Utility Authority. The Utility Authority may require such site or plot plans or evidence of ownership or land assignment from the permit applicant as it determines are necessary to decide whether or not a permit should be issued.

SECTION 5.18. WATER SHORTAGE: SERVICE PREFERENCE: In cases of a water shortage prociaimed by the utility Authority, the District shall regulate the amount of water any customer may be allocated. The Utility Authority also may give preference to the customers and/or amounts of water to be allocated, provided the Utility Authority allocates water according to public necessity of convenience, and provides for fair allocations between customers. Any customer violating a legal allocation may have his water service discontinued. Service shall be resumed only upon payment of the approved reconnection fee and any penalties.

SECTION 5.19 UNNECESSARY WASTE OF WATER: The Utility Authority reserves the right to terminate customer's service when the customer has repeatedly, unduly wasted water. Such undue waste is evidenced by the fact that hydrants, taps, hoses and other fixtures are permitted to run continuously when not in productive use. Where such conditions have been observed, the Utility Authority having been notified of the condition, may terminate water to the premise if the condition is not corrected within 48 hours after receipt of the notice. Service shall be resumed only after correction the condition causing a wastage of water And payment by the customer of the approved reconnection fee, penalties and any other accounts in arrears to the Utility Authority.

SECTION 5.20. CONSERVATION OF RESOURCES: The District shall conduct operation, maintenance and repair services in a manner that will maximize the conservation of natural, financial, and property resources. Customers of the District shall be encouraged to conserve water resources and to limit water use as necessary to provide a comfortable, healthy, and aesthetically pleasing life style. The District may offer assistance and service to customers for water conservation and other material resources conservation and recovery as determined to be feasible by the Utility Authority.

SECTION 5.21. NEW CUSTOMER SERVICES: Any dwelling within the service area of the Utilities shall be eligible for services, provided all of the following conditions are met:

1. Facilities are adequate to meet additional load.

2. New customer agrees to adhere to this Ordinance.

3. Approval by the Utility Authority. 


\section{ARTICLE VI}

\section{CUSTOMER OBLIGATIONS}

SECTION 6.01. CONDITIONS FOR SERVICE, PAYMENTS: As a condition for receiving utility services trom the Yurok Public Utility District, the customer agrees to comply with all provisions of this ordinance, and any regulations duly adopted by the Utility Authority as well as any other applicable codes or regulations, including being current in the payment of all fees, penalties, costs, damages, or other charges assessed by the District.

SECTION 6.02. MAINTENANCE; REPAIRS; LIABILITY: The customer shall be responsible for maintaining and repairing water and/or sewer lines located on or in the customer's grounds, building or residence in compliance with applicable regulations. The customer shall notify the District in advance of major maintenance or repairs planned for water or sewer lines. The customer shall permit the District to inspect the work for compliance with applicable regulations. The customer shall be liable for any damage to the District's lines, equipment or other property caused by the customer, his family, requests, tenants, agents, employees, contractors, licensees or other persons under the customer's control or acting as an authorized agent of the customer.

\section{SECTION 6.03. CUSTOMER TERMINATION OF SERVICE; ABANDONMENT: A customer} planning to vacate any grounds, building or residence served by the District shall notify the District in writing one week prior to the date the customer plans to either vacate or terminate service, whichever is later. A customer who fails to give notice is responsible for all charges accrued up to one week after notice is received by the District, or up until service is terminated, whichever comes first.

SECTION 6.04. WATER SHORTAGES: During water shortages declared by the Utility Authority, the customer shall limit his use of water according to allocations established by the Utility Authority.

SECTIO.V 6.05. INSPECTIONS: The customer shall not unreasonably withhold permission for the District to enter and inspect the District's and customer fixtures, lines and equipment when necessary to insure that they are operating in a manner that would not likely disrupt or interfere with utility services. The customer shall be liable for any costs or related expenses caused by his unreasonable withholding of permission.

SECTION 6.06. PERMITS: The customer shall obtain written permission from the Utility Authority prior to making any connection, re-connection, with, disconnection from, or other private use of any District water or sewer system, road, appurtenance, or other utility service or facility. The customer shall obtain written permission from the Utility Authority prior to constructing any private water or sewer system, or other private utility.

SECTION 6.07. CROSS-CONNECTIONS: The customer shall not make a cross-connection with the Tribal Public Water supply. A cross-connection is defined as any physical connection between the Tribal Public Water system and another piping system, either water or waste. Any individual source must be totally disconnected from-the household plumbing prior to connection to the Tribal Public Water Supply: "Disconnection" done solely by a valve shall not be allowed. 
SECTION 6.08. SOLD WASTE FACILITIES: The customer shall provide his own refuse containers and shall maintain the cans and holding facility in a manner that prevents the harborage of rodents and vermin. There shall be no excessive accumulation of refuse, garbage or solid waste in the community or around individual homesites.

SECTION 6.09. USE OF SEWERAGE SYSTEM: The customer shall use, the sewerage collection, treatment and disposai system only for the disposal of normal household liquid waste including waste from toilet facilities, shower and bathing facilities and kitchen facilities.

SECTION 6.10 UNAUTHORIZED DISPOSAL: The customer shall not dispose of any material into the sanitary sewer which may cause the collection lines or subsurface drain field to become blocked or excessively loaded with solids, including but not limited to garbage, disposable diapers, sanitary napkins, paper material other than toilet paper, cigarette waste, cat litter, etc.

SECTION 6.11. TOXIC WASTE DISPOSAL: No customer shall dispose of any toxic, radioactive or otherwise hazardous waste into any Utility District or private sanitary or storm sewerage system. Toxic and hazardous waste include but are not limited to: oil, pesticides, gasoline, organic solvents, paint, poisons and other manufactured chemical compounds.

\section{ARTICLE VII \\ FEE SCHEDULES AND BILL}

SECTION 7.01. FEE SCHEDULE ESTABLISHMENT: The schedule of fees for utility services shail be set annually by the Utility Authority. The fee schedule shall be, based on the estimated average annual costs for operation of all utility services. The fee schedule shall include a basic rate for all services, payment of which shall required of each customer regardless of whether, or the extent to which, the customer uses any of the services, and; other fees, charges, penalties and assessments which the Utility Authority is authorized to levy as provided under various sections of this Ordinance. The fee schedule may be adjusted as needed to meet utility operating expenses.

SECTION 7.02. PUBLIC HEARING: The Utility Authority shall hold a public hearing whenever a new fee schedule is proposed for adoption. Five days in advance of the hearing, the proposed fee schedule shall be sent to each customer and shall be posted in appropriate places. Following the public hearing the Utility Authority shall set a fee schedule, taking into consideration comments received at the hearing.

SECTION 7.03. NOTICE To CUSTOMERS: A copy of the fee schedule adopted by the Utility Authority shall be sent to each customer at least 30 days prior to the date the established fees take effect.

SECTION 7.04. BILLING RESPONSIBILITY: The Utility Authority and/or Utility District is responsible for billing customers for Utility Services. The billing service, however, may be contracted to the Tribe, Housing Authority, or other agency or firm at the discretion of the Utility Authority Board of Directors.

SECTION 7.05. MONTHLY STATEMENT: Each month the District shall mail to all utility customers a statement detailing the following information: 
1. The custome:'s name and account number;

2. The types and levels of service used in the Current month:

3. The billed cost of the current month's service, plus an accounting of bills or charges past due, if any;

4. The date that payment is due; and

5. The location to mail or deliver payment.

SECTION 7.06. DUE DAIE: The monthly date on which payment will be due shall be established by Utility Authority regulation.

SECTION 7.07. PAYMENTS PAST DUE: Payments not received within 10 days after the established due date are considered past due. The District shall issue a notice of payment past due to the customer, detailing the payment owed and the consequences for failure to pay. The notice shall be sent no later than the date the next billing is sent out.

SECTION 7.08. DELINOLENT ACCOUNT: If-the payment past due is not paid within 10 days after the next regular monthly due date, the account shall be declared delinquent.

SECTION 7.09. NOTICE OF DELINOUENCY: The District shall immediately notify the customer in writing once his account has been declared delinquent, and list the sanctions that may be-imposed without further notice. Notice of delinquency shall be made by certified mail or such other means to provide proof of receipt by-the customer.

SECTION 7.10. ADVANCE DEPOSITS: The Utility Authority may require each new customer to pay an advance deposit equal in amount to the basic monthly rate fees for the first 2 months of service or $\$ 100.00$, whichever is greater, prior to receiving services. The deposits shall be retained by the Utility Authority no longer than one year. The deposits, with interest compounded at passbook rates, shall be credited to the individual customer's utility account balance at the end of the deposit period, providing that the customer's account is not delinquent and-in arrears. Any remaining deposit funds will be returned to the customer. 


\section{ARTICLE VIII}

\section{ENFORCEMENT: PENALTIES; SANCTIONS}

SECTION 8.01. AUTHORITY AND ENFORCEMENT: The Utility Authority is hereby authorized by the Tribal Council to collect established fees for service and to impose sanctions and penaities for nonpayment. The Utility Authority shall enforce its regulations, fee collections and provisions of this ordinance by shutting off water service of any and all vioiators and delinquent bill-payers or imposing other penalties and sanctions as authorized.

SECTION 8.02. ATTACHMENT OF CUSTOMERS PROPERTY: The Utility Authority shail not seek to attach customer's property, nor seek to have fines assessed by Tribal court, unless all other administrative remedies have been exhausted, or in those limited cases of blatant or continued abuses or destruction of District property (Example: destruction of meters, illegal connections to a system).

SECTION 8.03. PENALTY SCHEDULE: The Utility Authority shall develop and adopt a penalty schedule which outlines specific penalties, fines and assessments for violation and noncompliance with the provisions of this ordinance. The penalty schedule shall be reviewed for appropriateness annually by the Utility Authority.

SECTION 8.04. SANCTIONS AUTHORIZED: The following sanctions may be imposed by the Utility Authority for failure of the customer to comply with any provisions of this ordinance or with any duly adopted regulation of the Utility Authority:

(1) Termination of service(s)

(2) Assessment of penaities based on a penalty schedule adopted by regulation of the Utility Authority;

(3) Assessment of late charges based on a schedule adopted by regulation of the Utility Authority;

(4) Assessment of damages resulting from the customer's non-compliance;

(5) Forfeiture of all or part of a deposit and any accumulated interest;

(6) Filing of a lien against the customer's property after the account is declared delinquent;

(7) Enforcing a lien by seeking judgment, and satisfaction from the customer's property from a court of competent jurisdiction;

(8) Filing suit for damages in a court of competent jurisdiction; and

(9) Referring violations that may involve criminal conduct to the poiice or District Attomey.

SECTION 8.05. SANCTIONS GUIDELINES: The Utility Authority shall use the following guidelines when considering the appropriate sanctions to be imposed in any given case:

(1) Whether the sanction is required by this ordinance or other applicable law, or whether imposition is discretionary;

(2) The minimum sanction needed to effect compliance;

(3) The irreparable harm to operation of the District, and to the Tribe, if the sanction is not imposed;

(4) The customer's past record of compliance or noncompliance, or good faith efforts to achieve compliance,

(5) The irreparable harm to other persons or property if the sanction is not imposed; and

(6) The effectiveness of similar sanctions in securing compliance in other cases. 


\section{ARTICLE IX \\ MISCELLANEOUS PROVISIONS}

SECTION 9.01. VALIDITY, SEVERABILITY: The invalidity of any section, clause, sentence or provision of this ordinance shall not affect the validity of any part of this ordinance which can be given effect without such invalid part or parts.

SECTION 9.02. AMENDMENTS: The Tribal Council shall act upon proposed amendments to this ordinance, submitted for action by the Utility Authority, by approval or disapproval of such proposed amendments.

SECTION 9.03 SUSPENSION ORDINANCE: No employee, officer, contractor or agent of the Yurok Tribe is authorized to suspend or alter any of the provisions of this ordinance without the formal approval of the Yurok Tribal Council.
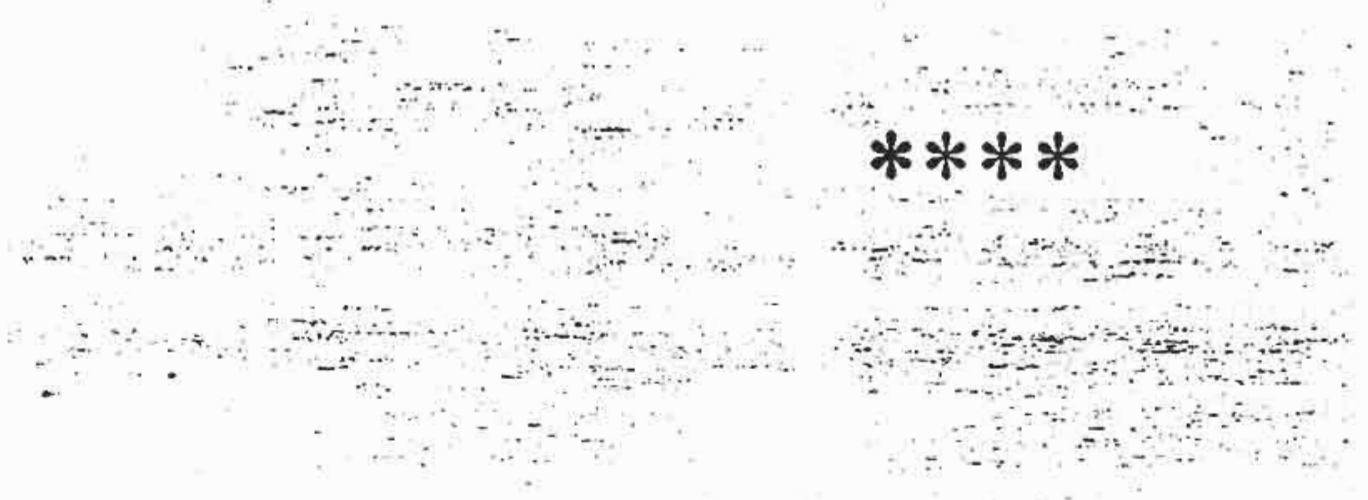
Appendix 8: Foundation Profiles from Foundation Center's Online Database 


\section{HP Corporate Giving Program}

Copyright $\odot 2007$ The Foundation Center

\section{Profile}

\section{Profile}

HP Corporate Giving Program

c/o Philanthropy Dept.

3000 Hanover St., M.S. 1029

Palo Alto, CA 94304-1112

E-mail: philanthropy_ed@hp.com

Contact for HP Scholars: Sandy Brooks, Mgr., HP Scholar Prog., E-mail: sandy.brooks@hp.com

URL: http:/ / www.hp.com/ hpinfo/ globalcitizenship

Sponsoring company: Hewlett-Packard Company

Type of grantmaker: Corporate giving program.

Purpose and activities: As a complement to its foundation, HP also makes charitable contributions to nonprofit organizations directly. Special emphasis is directed toward programs designed to promote educational opportunity and technology in underserved communities. Support is given on a national and international basis in areas of company operations.

Program area(s): The grantmaker has identified the following area(s) of interest:

Employee Matching Gifts: HP matches contributions made by its employees to nonprofit organizations on a one-for-one basis up to $\$ 1,000$ per employee, per year.

Employee Product Gift Matching Program: HP makes charitable contributions of HP equipment to nonprofit organizations, K-12 schools, and institutions of higher education when its employees agree to contribute 25 percent of the list price.

Higher Education HP Technology for Teaching Grant I nitiative: Through the Higher Education HP Technology for Teaching Grant Initiative program, HP annually awards 25 grants to institutions of higher education interested in using mobile technology in ways that positively impact student achievement. Special emphasis is directed toward schools serving low-income students and that have educational technology and instructional leadership support and programs designed to contribute toward achieving the institution's vision and plans for broader deployment of mobile technology solutions in the learning environment. Grant awards consist of HP equipment, $\$ 15,000$ to be used as stipends, and $\$ 500$ to be used for travel expenses for the Worldwide HP Mobile Technology Conference.

HP Scholars: HP awards four-year $\$ 3,000$ college scholarships to African American, Latino, and American Indian high school seniors and community college students planning on studying computer science, computer engineering, or electrical engineering at an HP Partner School.

HP Technology for Community Grant I nitiative: Through the HP Technology for Community Grant Initiative program, HP awards wireless technology packages valued at approximately $\$ 17,000$ to nonprofit organizations to enhance their effectiveness and to support the innovative use of mobile technology.

K-12 HP Technology for Teaching Grant I nitiative: Through the K-12 HP Technology for Teaching Grant Initiative program, HP annually awards 75 grants to K-12 public schools using a five-teacher collaborative, team-based approach to implementing technology integration projects. Special emphasis is directed toward schools serving low-income students and programs designed to include the integration of mathematics and/or science curriculum. Grant awards consist of HP equipment and $\$ 2,500$ to be used as teacher stipends.

Fields of interest: Africa; African Americans/Blacks; Asia; Canada; Community development, small businesses; Elementary/secondary education; Europe; General charitable giving; Higher education; Hispanics/Latinos; Japan; Latin America; Middle East; Native Americans/American Indians; Oceania.

Geographic focus: National; international

Types of support: Conferences/seminars; Donated products; Employee matching gifts; Employee 
volunteer services; General/operating support; Scholarships--to individuals.

Limitations: Giving on a national and international basis in areas of company operations; giving on a national basis for Technology for Teaching and Technology for Community; giving also to regional and national organizations. No support for churches, political organizations, or discriminatory organizations. No grants to individuals (except for scholarships), or for religious activities, advertising, sponsorships, contests, fundraising, promotional items, sports events, incentive programs, marketing, television and video production, research, or feasibility studies, sponsored programs, or political or military activities; no surplus, used, or obsolete equipment donations; no equipment donations to be used in a private residence. Publications: Corporate giving report.

Application information: The Philanthropy Department handles giving. The company has a staff that only handles contributions. A contributions committee reviews all requests. Application form required.

Applicants should submit the following:

1) copy of IRS Determination Letter

Initial approach: Complete online inquiry form; download application form for HP Scholars; complete online application form for Technology for Teaching and Technology for Community

Copies of proposal: 1

Deadline(s): Mar. 15 for HP Scholars; Feb. 15 for Technology for Teaching; Mar. 22 for Technology for

Community

Final notification: May 1 for HP Scholars and Technology for Teaching; Apr. 22 for Technology for

Community

Number of staff: 18 full-time professional; 2 full-time support.

Memberships: Association of Corporate Contributions Professionals; Council on Foundations; Philanthropy Roundtable; The Center for Corporate Citizenship at Boston College.

Financial data: (yr. ended 10/31/05): Total giving, $\$ 45,300,000$; giving activities include $\$ 18,000,000$ for grants and $\$ 27,300,000$ for in-kind gifts.

Sponsoring company information:

\section{Hew lett-Packard Company}

(also known as HP)

3000 Hanover St.

Palo Alto, CA 94304-1112

(650) 857-1501

Company URL: http:/ / www.hp.com

Establishment information: Established in 1939.

Company type: Public company

Company ticker symbol and exchange: HPQ/NYSE

Business activities: Manufactures and provides computing and imaging products, solutions, and services. Business type (SIC): Computer and office equipment

Financial profile for 2005: Number of employees, 150,000; assets, $\$ 77,317,000,000$; sales volume, $\$ 86,696,000,000$; pre-tax net income, $\$ 3,543,000,000$; expenses, $\$ 83,223,000,000$; liabilities,

$\$ 40,141,000,000$

Fortune 1000 ranking: 2005-11th in revenues, 67th in profits, and 60th in assets

Forbes 2000 ranking: 2005-24th in sales, 147th in profits, and 196th in assets

Board of directors: Lawrence T. Babbio; Sari M. Baldauf; Richard A. Hackborn; John H. Hammergren; Mark V. Hurd; George A. Keyworth; Thomas J. Perkins; Robert L. Ryan; Lucille S. Salhany.

Corporate officers: Mark V. Hurd, Pres. and C.E.O.; J on Flaxman, Exec. V.P. and C.A.O.; Randall D. Mott, Exec. V.P. and C.I.O.; Michael Holston, Exec. V.P., Genl. Counsel; Gilles Bouchard, Exec. V.P., Opers.; Marcela Perez de Alonso, Exec. V.P., Human Resources; Cathie Lesjak, C.F.O.; Jim Murrin, Sr. V.P. and Cont.

Subsidiaries and/ or Divisions: Compaq Computer Corporation, Houston, TX.

Plants and/ or Offices: Cupertino, CA; Mountain View, CA; Roseville, CA; San Diego, CA; Sunnyvale, CA; Colorado Springs, CO; Fort Collins, CO; Atlanta, GA; Boise, ID; Littleton, MA; Rockaway, NJ; Cincinnati, $\mathrm{OH}$; Corvallis, Oregon; Aguadilla, PR; Vancouver, WA.

International operations: Argentina; Australia; Austria; Barbados; Belgium; Bermuda; Bolivia; BosniaHerzegovina; Brazil; Canada; China; Colombia; Congo; Costa Rica; Croatia; Czech Republic; Denmark; Dominican Republic; Ecuador; Egypt; Finland; France; Germany; Greece; Guatemala; Hungary; India; 
Ireland; Israel; Italy; Japan; Korea; Lebanon; Malaysia; Mexico; Morocco; Netherlands; New Zealand; Nigeria; Norway; Oman; Panama; Peru; Philippines; Portugal; Qatar; Romania; Russia; Saudi Arabia; Serbia; Singapore; Slovakia; Slovenia; Spain; Sweden; Switzerland; Syria; Thailand; Trinidad \& Tobago; Turkey; United Arab Emirates; United Kingdom; Uruguay; Venezuela.

Affiliated grantmaker(s): Hewlett-Packard Company Foundation; HP Corporate Giving Program Company EI N: 941081436

Last updated: 06/02/2006 


\section{Surdna Foundation}

Copyright (c) 2007 The Foundation Center

$$
\text { Proflle }
$$

990s
«Previous Record| Next Record»

Print Page

Close Window

\section{Profile}

Surdna Foundation, Inc.

330 Madison Ave., 30th FI.

New York, NY 10017-5001

Telephone: (212) 557-0010

Contact: Edward Skloot, Pres.

FAX: (212) 557-0003

E-mail: questions@surdna.org

URL: http:/ / www.surdna.org

Donor(s): John E. Andrusł.

Type of grantmaker: Independent foundation.

Background: Incorporated in 1917 in NY.

Purpose and activities: The foundation's guidelines focus on five areas: 1) The Environment, specifically transportation and energy, urban and suburban issues, and biological and cultural diversity; 2) Community Revitalization, which takes a comprehensive and holistic approach to restoring communities in America; 3) Building an Effective Citizenry, to advance social and emotional learning, enhance conflict resolution theory, practice and expand opportunities for service and citizenship, and support character development and ethical behavior; 4) The Arts; and 5) The Nonprofit Sector. The foundation is particularly interested in fostering catalytic, entrepreneurial programs that offer solutions to difficult systemic problems.

Program area(s): The grantmaker has identified the following area(s) of interest:

Andrus Family Philanthropy Program (AFPP): The foundation's Board of Directors launched the Andrus Family Philanthropy Program (AFPP) in Jan., 2000 to engage and involve its larger family, in particular its younger generations, in philanthropy and public services. The program includes the Andrus Family Fund which was established to provide opportunities for younger family members to learn about and participate in organized philanthropy. The AFPP is an emerging alliance of programs within the Andrus family, designed to become the center of efforts to further inform, encourage and coordinate the family's philanthropic work. This will be accomplished by: 1) strengthening the existing family philanthropies; 2) creating new vehicles for the family's philanthropy, including the Andrus Family Fund; 3) linking existing and emerging philanthropic entities to make use of joint learning opportunities; 4) establishing opportunities for education, service and communication around philanthropy for the large family; and 5) being receptive to new, creative ways to encourage and develop family philanthropy.

Arts: The program is a national initiative focusing on arts and education. The foundation's goals are to contribute to the ability of young people to explore both their own identity and their relationship to the world, through high-impact, long-term experience with artists and the arts and deepen the ability of artists and arts organizations to contribute to the artistic expression of young people. The foundation has selected two program themes for primary attention (target ages 12 to 18): 1) Artist-Leaders and Young People: Creating Works of Art; and 2) Arts Institutions and Arts Magnet Schools: Augmenting Expertise. Generally, the program does not support: programs with the primary focus of serving elementary schools or children ages one to ten; providing general exposure and appreciation; expanding audience development; using the arts specifically to enhance learning in non-arts areas; or helping artists create curriculum integrating the arts into other subject areas. The foundation also invites art teachers from specialized, public arts high schools to apply for funding for artistic development through its Arts Teachers Fellowship Program. This program offers teachers the opportunity to immerse themselves in their own creative work, interact with other professional artists, and stay current with new practices. Recognizing that such teachers often lack the time and resources to reconnect with the artistic processes they teach, the program provides grants of 
up to $\$ 5,000$ to enable selected teachers to make art with professionals in their disciplines and stay current with new practices and resources. A complementary grant of $\$ 1,500$ is awarded to each fellow's school to support related post-fellowship activities.

Community Revitalization: The program seeks to transform environments and enhance the quality of life in urban places, increase their ability to attract and retain a diversity of residents and employers, and insure that urban policies and development promote social equity. In cities that are experiencing population growth, a surge in economic activity and strong real estate markets, the foundation seeks to maintain affordability and improve the lives of all residents by preserving diversity and mitigating the negative effects of unbalanced growth. In cities that are losing population, jobs, and wealth, the foundation aims to abate population loss and consequent economic and racial isolation by catalyzing efforts to make these places communities of choice by attracting a wide range of residents and businesses.

Effective Citizenry: The goal of the program is to support young people to take action with others to address meaningful problems in their schools, neighborhoods and the larger society. To accomplish this goal, the foundation funds efforts that: 1) Help young people (ages 13-29) be effective, problem-solving citizens; 2) Improve practices and performance of organizations that help young people move through leadership development and into productive action; and 3) Develop networks that can anchor and expand a field of effective citizenry through building and advancing theory, research, documentation, training, technical support, and policies.

Environment: The foundation's grantmaking principles in this program include: supporting government, private and voluntary actions; preferring redesign to eliminate problems rather than amelioration to deal with them after-the-fact; building bridges, defusing conflict and bringing diverse constituencies together; encouraging a diversity of people and interests to participate in addressing environmental concerns; supporting multi-sectorial approaches and partnerships, and recognizing the interdependence of sectors and disciplines; fostering a population of environmentally informed, responsible, activist citizens; and respecting community and grassroots perspectives. The foundation has four focus areas: 1) Biological Diversity and the Human Communities that Depend on it; 2) Realigning Human and Natural Areas; 3) Transportation and Urban/Suburban Land Use; and 4) Energy. Generally, the program does not support: programs addressing toxics, hazardous waste, environmental education, sustainable agriculture, food production and distribution; individuals; or academic research.

Nonprofit Sector Support: The program seeks to strengthen the effectiveness of nonprofit institutions and to promote increased and improved philanthropy, in particular through efforts to: 1) Strengthen nonprofit organizations by improving management, finance, leadership, and use of technology; 2) Support the creation of new sources of philanthropic funds, catalyze discussion on good stewardship practices, and further effective collaboration between nonprofit organizations and philanthropy; 3) Further the study of crosscutting issues such as tax exemption, commercialization, and decreasing public funding and to encourage broad collaboration within the sector--and among sectors--to develop effective public policy; and 4) Strengthen the nonprofit sector's ability to clearly articulate and widely communicate its role in American public life.

Organizational Capacity Building Grants: These grants are aimed at strengthening the organizational capacity of nonprofit organizations. Current and past Surdna grantees only are eligible to apply for grants of up to $\$ 15,000$ to address important management and governance issues that can be handled with a small amount of money in a short period of time. Projects may address issues including (but not limited to): board/staff development, marketing, strategic planning, strategic restructuring and communication. To apply by mail, the C.E.O. of the organization should send a two-page letter describing the need, the proposed project, the budget, the timeline, and anticipated outcomes to J onathan Goldberg, Grants Admin.

Fields of interest: Arts education; Community development; Disasters, 9/11/01; Dispute resolution; Economic development; Environment; Environment, energy; Environment, natural resources; Housing/shelter, development; Philanthropy/voluntarism; Public affairs, citizen participation; Urban/community development.

Geographic focus: National

Types of support: Continuing support; General/operating support; Program development; Technical assistance.

Limitations: Giving on a national basis. No support for international projects, or programs addressing toxics, hazardous waste, environmental education, sustainable agriculture, food production and distribution. No grants for individuals or for endowments or land acquisition, capital campaigns or for 
building construction.

Publications: Annual report (including application guidelines); Grants list.

Application information: Application form not required. Applicants should submit the following:

1) results expected from proposed grant

2) qualifications of key personnel

3) copy of IRS Determination Letter

4) brief history of organization and description of its mission

5) copy of most recent annual report/audited financial statement/990

6) listing of board of directors, trustees, officers and other key people and their affiliations

7) detailed description of project and amount of funding requested

8) contact person

9) copy of current year's organizational budget and/or project budget

10) listing of additional sources and amount of support

Initial approach: Letter by mail or online at foundation Web site

Copies of proposal: 1

Board meeting date(s): Feb., May, and Sept.

Deadline(s): None

Final notification: 90 days

Officers and Directors:* J ohn F. Hawkins,* Chair.; Michael S. Spensley, D.V.M.,* Vice-Chair.; Phillip Henderson, Pres.; John J. Lynagh,* Secy.; Marc de Venoge, C.F.O. and C.A.O.; Frederick F. Moon III,* Treas.; John E. Andrus III, Chair. Emeritus; Bruce Abernethy; Elizabeth H. Andrus; Jocelyn Downie; David Grant; Lawrence S.C. Griffith, M.D.; Josephine B. Lowman; Nadya K. Shmavonian; Edith D. Thorpe; Samuel S. Thorpe III.

Number of staff: 11 full-time professional; 5 full-time support.

Memberships: Consultative Group on Biodiversity; Council on Foundations; Environmental Grantmakers Association; Funders' Network for Smart Growth and Livable Communities; Grantmakers for Effective Organizations; Grantmakers In the Arts; Independent Sector; Maine Philanthropy Center; Neighborhood Funders Group; New York Regional Association of Grantmakers; Northern California Grantmakers; Philanthropy for Active Civic Engagement (PACE).

Financial data: (yr. ended 06/30/06): Assets, $\$ 859,153,983(\mathrm{M})$; gifts received, $\$ 1,413,702$; expenditures, $\$ 39,847,288$; total giving, $\$ 30,611,000$; qualifying distributions, $\$ 36,099,973$; giving activities include $\$ 30,611,000$ for 533 grants (high: $\$ 1,697,563$; low: $\$ 100$; average: $\$ 15,000-\$ 100,000$ ).

EI N: 136108163

Selected grants: The following grants were reported in 2006.

$\$ 1,000,000$ to Nature Conservancy, Minnesota Chapter, Minneapolis, MN, For Minnesota Forest Legacy Partnership Project for program support or purchase of easements in Minnesota's northern forest or both as needed, payable over 5 years.

$\$ 450,000$ to Center for Neighborhood Technology, Chicago, IL, To facilitate development of organizational transformation strategy to improve organization's positioning, impact and outcomes; and financial sustainability in order to establish it as 'urban sustainability innovations laboratory', payable over 3 years. $\$ 300,000$ to Jazz at Lincoln Center, New York, NY, For Essentially Ellington High School Jazz Band Program where Ellington introduces high school students to music of Duke Ellington and fosters mentoring relationships with professional jazz musicians, payable over 3 years.

$\$ 300,000$ to Philanthropic Research, Inc., Guidestar, Williamsburg, VA, For general operating support, payable over 3 years.

$\$ 300,000$ to Urban Homesteading Assistance Board (UHAB), New York, NY, To expand campaign to preserve federally subsidized housing throughout New York City by pursuing short-term preservation campaigns and large scale regulatory reform at local and national levels, payable over 2 years.

$\$ 200,000$ to Movement Strategy Center, Oakland, CA, For national growth of youth organizing groups by providing alliance building, framing and PR training, facilitation of emerging alliances, and networking groups via issue based gatherings and online community.

$\$ 157,000$ to Flathead Valley Community College Foundation, Kalispell, MT, For Flathead on Move, payable over 2 years.

$\$ 75,000$ to Neighborhood Economic Development Advocacy Project, New York, NY, For Fair Lending Initiative that seeks to combat unequal access to financial services and credit access as it affects 
predominantly low-income and immigrant neighborhoods and communities of color in NYC.

$\$ 75,000$ to Theodore Roosevelt Conservation Partnership, DC, For general support for efforts to engage American sportsmen and sportswomen and make possible their active participation in national conservation policy arena.

$\$ 50,000$ to Point Community Development Corporation, Bronx, NY, For arts training for teens at POI NT through ICP at POI NT photography program and to provide general operating support.

Last updated: 05/14/2007 


\section{The Educational Foundation of America}

Copyright @ 2007 The Foundation Center

Proflle

«Previous Record| Next Record»

Print Page

Close Window

\section{Profile}

The Educational Foundation of America

35 Church Ln.

Westport, CT 06880-3515

Telephone: (203) 226-6498

Contact: Diane M. Allison, Exec. Dir.

E-mail: efa@efaw.org

Letter of inquiry E-mail: loi@efaw.org

URL: http:/ / www.efaw.org

Donor(s): Richard P. Ettingerł; Elsie Ettinger‡; Richard P. Ettinger, Jr.‡; Elaine P. Hapgood; Paul R.

Andrewsł; Virgil P. Ettingerł.

Type of grantmaker: Independent foundation.

Background: Trust established in 1959 in NY.

Purpose and activities: Grants primarily for arts, education, energy and the environment, reproductive health and rights, population, and education programs benefiting Native Americans.

Program area(s): The grantmaker has identified the following area(s) of interest:

Matching Gifts Program: The foundation matches the monetary gifts of its employees to charitable organizations.

Fields of interest: Arts; Civil liberties, reproductive rights; Education; Environment; Environment, energy; Environment, natural resources; Native Americans/American Indians; Reproductive health, family planning.

Geographic focus: National

Types of support: Employee matching gifts; Matching/challenge support; Program development; Seed money.

Limitations: Giving limited to the U.S. No grants to individuals, annual fundraising campaigns, or for capital or endowment funds; no loans.

Publications: Annual report; Application guidelines; Grants list.

Application information: Letter of inquiry form is available on foundation Web site. Application form required. Applicants should submit the following:

1) copy of IRS Determination Letter

2) detailed description of project and amount of funding requested

3) copy of current year's organizational budget and/or project budget

4) listing of additional sources and amount of support

5) listing of board of directors, trustees, officers and other key people and their affiliations

6) contact person

7) name, address and phone number of organization

The foundation staff will review the letter of inquiry and notify the applicant whether or not to submit a full proposal.

Initial approach: Letter of inquiry sent via E-mail only

Copies of proposal: 2

Board meeting date(s): Varies

Deadline(s): None

Final notification: Usually within 2 weeks

Officers and Board Members:* Elaine P. Hapgood,* Pres.; Diane M. Allison, Exec. Dir.; David L.

Godfrey, Fin. Dir.; Matthew Hapgood,* Member, Adjunct Comm.; Jerry Babicka; Lynn P. Babicka; Barbara 
P. Ettinger; Christian P. Ettinger; Heidi P. Ettinger; Wendy W.P. Ettinger; Barbara Hapgood; Sven Huseby; Nancy Keenan; Derek McLane; John Powers; Trevor Renner; Frances Stott

Adjunct Committee Members: Ronene E. Anderson; Clarice Annegers; Jonathan Babicka; James Bohart, Jr.; Leland P. Ettinger; Matthew Ettinger; Nash Landesman; North Landesman; Christopher Renner; Austin Schumacher; Lauren Zuskin; Morey Zuskin.

Number of staff: 3 full-time professional; 2 part-time professional; 1 full-time support.

Memberships: Environmental Grantmakers Association; Funders Network on Population, Reproductive Health and Rights; Grantmakers for Effective Organizations; Peace and Security Funders Group.

Financial data: (yr. ended 12/31/04): Assets, $\$ 225,558,331$ (M); expenditures, $\$ 15,439,834$; total giving, $\$ 12,430,469$; qualifying distributions, $\$ 13,065,815$; giving activities include $\$ 12,406,169$ for 271 grants (high: $\$ 250,000$; low: $\$ 1,000$; average: $\$ 10,000-\$ 75,000$ ) and $\$ 24,300$ for employee matching gifts.

EI N: 133424750

Selected grants: The following grants were reported in 2005.

$\$ 400,000$ to Wilderness Society, Denver, CO, For Southern Rockies Conservation Alliance Coalition, payable over 2 years.

$\$ 240,000$ to Religious Coalition for Reproductive Choice Educational Fund, DC, For Spiritual Youth for Reproductive Freedom, payable over 2 years.

$\$ 220,000$ to Demos: A Network for Ideas and Action, New York, NY, For Election Reform and Voting Rights Project, payable over 2 years.

$\$ 160,000$ to National Priorities Project, Northampton, MA, For Abroad and at Home: Exploring Alternative Policies for a Misguided Superpower, payable over 2 years.

$\$ 155,050$ to Norwalk Public Schools, Norwalk, CT, For Ettinger Scholarship Awards.

$\$ 150,000$ to National Dance Institute New Mexico, Santa Fe, NM, For Albuquerque Program, payable over 2 years.

$\$ 140,000$ to University of California, San Francisco, CA, For Expanding Pregnancy Care by Advanced Practice Nurses (EPC-APN), payable over 2 years.

$\$ 100,000$ to Fund for Constitutional Government, DC, For OpenTheGovernment.org, payable over 2 years. $\$ 75,000$ to Container Recycling Institute, Alexandria, VA, For 2020 Vision: Setting One's Sights on Zero Beverage Container Waste, payable over 2 years.

$\$ 50,000$ to Cornerstones Community Partnerships, Santa Fe, NM, For Preservation Studies and Applied Learning Program, payable over 2 years.

Last updated: 04/04/2007 


\section{Blue Moon Fund}

Copyright (c) 2007 The Foundation Center

$990 \mathrm{~s}$

«Previous Record| Next Record》

Print Page

Close Window

\section{Profile}

Blue Moon Fund, Inc.

(formerly W. Alton Jones Foundation, Inc.)

433 Park St.

Charlottesville, VA 22902-5178

Telephone: (434) 295-5160

FAX: (434) 295-6894

E-mail: info@bluemoonfund.org

URL: http:/ / www.bluemoonfund.org

Donor(s): W. Alton Jonesł.

Type of grantmaker: Independent foundation.

Background: Incorporated in 1944 in NY as W. Alton Jones Foundation. Underwent restructure in 2001, and was renamed Blue Moon Fund (retaining original El number) and two new funds were created, Oak Hill Fund and Edgerton Foundation.

Purpose and activities: The fund supports initiatives that elevate the human condition by comprehensively addressing human consumption, the natural world, and economic advancement, including sponsoring a fellows program aimed at cultivating cutting-edge approaches to these issues.

Program area(s): The grantmaker has identified the following area(s) of interest:

Balancing Human and Natural Ecosystems I nitiative: This initiative promotes new economic and culture approaches to reducing resource pressure and preserving biodiversity. The fund is primarily concerned with the value of diverse ecosystems for human quality of life. The fund seeks economically sustainable development models that do not displace humans and that take advantage of market forces. Desired outcomes of the initiative are: 1) The creation and financing of community-based enterprises that are environmentally sound, have value in the global marketplace, and are replicable; 2) The sharing of knowledge among communities within and among countries; 3) Government commitment to policies that encourage the formation of and investment in micro-enterprises in remote areas; 4) Increase in demand for green products; 5) Preservation of biologically rich areas without displacing humans; 6) Poverty reduction.

Fellowships: The fund sponsors a fellows program designed to generate innovative approaches to the problems of human consumption and energy, balancing natural and human ecosystems, and reenergizing urban communities. Fellows are chosen by the fund based on their track record for progressive, multidisciplinary thinking. Fellows often hail from the private sector, and are placed in nonprofit organizations in an effort to expand their knowledge and gain hands-on experience. These individuals aid the fund in exploring new opportunities and expanding the body of knowledge relevant to its initiatives.

Reenergizing Urban Communities I nitiative: This initiative aims to improve human quality of life by empowering communities to create, respond to, and manage change. This is accomplished by cultivating new leaders, catalyzing new ideas, and providing and attracting capital to implement those ideas. The program takes a holistic approach to community-building, and places priority on women and children's growth and advancement, financial literacy, and environmentally sound choices for dwelling and mobility. Desired outcomes of the initiative are: 1) Emergence of new leaders in the cultivation and implementation of innovative approaches to community building; 2) Replication of financial literacy programs that assist people in improving their economic condition; 3) Measurable increases in the availability of green affordable housing units; and 4) Tangible opportunities for children and women in underserved communities.

Rethinking Consumption and Energy I nitiative: This initiative is aimed at developing environmentally- 
friendly, efficient, and economically competitive transportation and energy choices worldwide. The driver behind this program is climate change, which is on course to radically alter both human quality of life and the natural environment. Reversing this course will require financial and political commitments to technologies that reduce emissions and offer alternatives to fossil-fuel based economies. Desired outcomes of the initiative are: 1) Government commitments to pursue policies that encourage efficiency and alternatives to fossil fuel; 2) Private investment in financing mechanisms and businesses that are pursuing greater efficiency and new technology; 3) Continued creation of a market for carbon credits that encourages emissions reduction; 4) Measurable improvements in air quality and increases in efficiency worldwide; and 5) Greater NGO involvement in the market aspects of energy and transportation.

Fields of interest: Environment, energy; Environment, natural resources; Urban/community development.

Geographic focus: National; international

Types of support: Fellowships; General/operating support; Matching/challenge support; Program development; Program-related investments/loans.

Limitations: Giving in the Americas and Asia. No grants for lobbying, advertising, dissertations, thesis and other academic work.

Application information: The fund is an initiative-based organization and generally does not take unsolicited proposals. Staff review letters of inquiry submitted through the foundation's Web site and invite proposals.

Initial approach: Eligibility quiz on foundation Web site

Board meeting date(s): Apr. and Nov.

Officers and Directors:* Diane Edgerton Miller,* C.E.O. and Pres.; Adrian Forsyth, Ph.D., V.P., Progs.; Kristen Suokko, V.P., Strategic Implementation; Ji-Qiang Zhang, V.P., Progs.; Gordon Walker,* Secy.; Diane Schmidt, C.F.O.; Jaime Yordan,* Treas.; Beverly Lamb, Compt.; Patricia Jones Edgerton,* Tr.

Emeritus; Ethan A. Miller,* Tr. Emeritus.

Membership: Neighborhood Funders Group.

Financial data: (yr. ended 12/31/05): Assets, $\$ 198,913,473(\mathrm{M})$; expenditures, $\$ 9,233,043$; total giving, $\$ 5,714,716$; qualifying distributions, $\$ 7,842,689$; giving activities include $\$ 5,714,716$ for 54 grants (high: $\$ 976,000$; low: $\$ 300$; average: $\$ 250,000-\$ 250,000), \$ 10,874$ for 1 foundation-administered program and $\$ 602,500$ for 2 loans/program-related investments.

EI N: 136034219

Selected grants: The following grants were reported in 2004.

$\$ 500,000$ to Energy Foundation, San Francisco, CA.

$\$ 260,000$ to Natural Resources Defense Council, New York, NY.

$\$ 200,000$ to World Wildlife Fund, DC.

$\$ 190,000$ to Conservation International, Arlington, VA.

$\$ 160,000$ to Worldwatch Institute, DC.

$\$ 150,000$ to Enterprise Foundation, New York, NY.

$\$ 130,000$ to Nature Conservancy, Charlottesville, VA.

$\$ 120,000$ to New Jersey Institute of Technology, Newark, NJ.

$\$ 115,000$ to WildAid, San Francisco, CA.

$\$ 100,000$ to University of Cincinnati, Cincinnati, $\mathrm{OH}$.

Last updated: 02/20/2007 


\section{Funding Exchange}

Copyright ㄷ 2007 The Foundation Center 990s
«Previous Record| Next Record»

Print Page

Close Window

\section{Profile}

Funding Exchange, Inc.

666 Broadway, Ste. 500

New York, NY 10012-2317

Telephone: (212) 529-5300

Contact: Charlene Allen, Dir., Grantmaking

FAX: (212) 982-9272

E-mail: grants@fex.org

URL: http:/ / www .fex.org

Type of grantmaker: Public charity.

Background: Established in 1979.

Purpose and activities: The organization is a donor consortium committed to building a permanent institutional and financial base for progressive social change in the U.S. The organization defines social change as the process of enabling and encouraging community people to become part of an organization which works against social and economic injustices and educates and challenges the broader community. Social change also means changing the circumstances and the social and institutional systems that lead to oppression.

Program area(s): The grantmaker has identified the following area(s) of interest:

Criminal J ustice I nitiative: Provides two large grants to organizations that can provide regional media training and message development to a diverse group of criminal justice organizations.

Donor Advised Program: This program funds community-based organizations challenging social and economic injustice and working to change the circumstances and systems that lead to oppression.

Emergency Fund: Grants of up to $\$ 1,000$ are given in response to political crisis or opportunities, when a small amount of money can make a difference in educating or mobilizing for social change.

I gnacio Martin-Baro Fund for Mental Health and Human Rights: This fund supports projects which foster psychological well-being, social consciousness, and community-based action in response to violence, repression, and social injustice. Through grants, networking, and technical support, the fund works in partnership with grassroots projects that promote progressive social change.

Media J ustice Fund: The fund responds to the changing state of media policy and infrastructure and its critical impact on social justice organizations. The fund supports local and national organizations to reform media policy, build community-based media infrastructure, and hold media corporations accountable to community needs. The fund supports collaborative projects which integrate the core values and agendas of social justice and media advocacy organizations, to build strong coalitions and active constituencies.

OUT Fund for Lesbian and Gay Liberation: Support is given for progressive community organizing efforts to mitigate homophobia and heterosexism. The fund favors initiatives with progressive or radical perspectives, including organizing efforts in communities of color, lesbian empowerment projects, coalition-building efforts between lesbians and gay men, projects working in isolated areas, anti-racism campaigns, international solidarity, and anti-violence efforts.

Paul Robeson Fund for I ndependent Media: Grants are given for film and video projects in the preproduction and distribution phases, and radio programs which address critical social and political issues, reach a wide audience, and implement intellectual and creative uses of media for organizing purposes. The maximum grant amount is $\$ 20,000$; most grants range between $\$ 5,000$ and $\$ 15,000$.

Peace and Racial J ustice Fund: Supports efforts for peace, protecting civil liberties, and fighting racial injustice. The fund supports regional and national groups working to broaden the discourse, leadership, and analysis of the national peace and foreign policy debate to include diverse, community-based 
participation. On the local level, the fund supports organizations that address the impact of war and foreign policy on their communities, and work to build a base of local leadership and infrastructure, particularly in communities of color.

Saguaro Fund: Support is given to groups in the U.S. and Puerto Rico that are led by racial minority communities by addressing critical social issues; participate in alliances, networks, and coalitions; combat economic injustices; build unity among people's movements; demonstrate potential for national impact; experience difficulty obtaining funding because of their location or the political nature of their work; and foster leadership among women and youth.

The Middle East: Supports efforts that promote peace and racial, economic, and social justice in Palestine and Israel.

The Philippines: Supports effort that address the economic, social, and environmental effects of U.S. corporate and government policies and international lending practices on communities in the Philippines. U.S. Social Forum Scholarships: In conjunction with the Ms. Foundation for Women, Third Wave Foundation, and the Astraea Lesbian Foundation for Justice, funding is available for individuals to attend the annual U.S. Social Forum. Priority will be given to low-income women, women of color, young women (ages 15-30), women with disabilities, lesbians/queer women, formerly incarcerated women, and transgender people. Eligible applicants must be a resident of the U.S. and its territories, and must have a nonprofit organization serving as a fiscal sponsor; a 501(c)(3) letter and letter of support from fiscal sponsor must accompany application.

Fields of interest: Civil liberties, reproductive rights; Civil rights, gays/lesbians; Civil rights, race/intergroup relations; Community development; Crime/law enforcement; Economic development; Employment, labor unions/organizations; Environment; International peace/security; Media, film/video; Media/communications; Minorities; Native Americans/American Indians; Safety/disasters; Women; Youth development.

Geographic focus: National; international

Types of support: Emergency funds; General/operating support; Program development; Seed money; Technical assistance.

Limitations: Giving primarily in the U.S.; there is limited international funding. No support for organizations with access to traditional or mainstream funding sources, community groups with budgets exceeding $\$ 500,000$, cultural projects or publications not directly connected to organizing campaigns or used as tools for social change organizing, other foundations, or for social services that do not have a capacity for organizing recipients around specific issues. No grants to individuals, or for capital campaigns, equipment, endowments, deficit financing, research projects, or fellowships.

Publications: Annual report; Application guidelines; Grants list; Informational brochure (including application guidelines); Newsletter; Occasional report.

Application information: Accepts NNG Common Grant Application. Application form required. Initial approach: Telephone

Board meeting date(s): Varies

Deadline(s): Postmarked by Mar. 1 for general program; May 15 for Paul Robeson Fund for Independent Media

Final notification: 8 months after receipt of application

Officers and Directors:* Oona Chatterjee,* Co-Chair.; David Nicholson,* Co-Chair.; Geoff Green,* Secy.; Alice Eason Jenkins,* Treas.; Celeste Lacy Davis, Exec. Dir.; Nancy Aleck; Yee Won Chong; Case Cook; Marjory Hamann; Lillian Jimenez; Jane Kimondo; Cathy Miller; and 7 additional directors.

Number of staff: 10 full-time professional; 1 part-time professional; 4 full-time support.

Memberships: National Network of Grantmakers; Neighborhood Funders Group; New York Regional Association of Grantmakers; Nonprofit Coordinating Committee of New York; Women \& Philanthropy. Financial data: (yr. ended 06/30/05): Revenue, $\$ 5,214,959$; assets, $\$ 30,953,817$ (M); gifts received, $\$ 3,436,218$; expenditures, $\$ 6,400,494$; total giving, $\$ 4,443,731$; program services expenses, $\$ 5,538,214$; giving activities include $\$ 4,443,731$ for grants.

EI N: 133002025

Last updated: 05/07/2007 


\section{Sidney Stern Memorial Trust}

Copyright $\Subset 2007$ The Foundation Center

\section{Proflle}

990 s
«Previous Record| Next Record»

Print Page

Close Window

\section{Profile}

Sidney Stern Memorial Trust

c/o Wells Fargo Bank

P.O. Box 63954

San Francisco, CA 94163

Application address: Board of Advisors, P.O. Box 893, Pacific Palisades, CA 90272

Donor(s): S. Sidney Sternł.

Type of grantmaker: Independent foundation.

Background: Trust established in 1974 in CA.

Purpose and activities: Giving primarily for higher education, social service agencies, including aid to the handicapped; youth and child welfare agencies; scientific and medical organizations, including health associations; and cultural programs.

Fields of interest: African Americans/Blacks; Arts; Asians/Pacific Islanders; Children/youth, services; Civil rights; Civil rights, disabled; Disabilities, people with; Environment; Health care; Health organizations; Higher education; Hispanics/Latinos; Hospitals (general); Human services; Immigrants/refugees; Legal services; Native Americans/American Indians; Reproductive health, family planning.

Geographic focus: California

Types of support: Annual campaigns; Building/renovation; Emergency funds; Endowments; Equipment; General/operating support; Land acquisition; Matching/challenge support; Program development;

Research; Scholarship funds.

Limitations: Giving primarily in CA; all funds must be used within the U.S. No grants to individuals, or for conferences or redistribution; no loans.

Publications: Application guidelines.

Application information: Application form required.

Initial approach: Letter or proposal ( 1 1/2 pages describing preferred use of funds)

Copies of proposal: 1

Board meeting date(s): Monthly, except Aug.

Deadline(s): None

Officer and Board of Advisors:* Betty S. Hoffenberg,* Chair.; Peter H. Hoffenberg; Ira E. Bilson; David A. Hoffenberg; Marvin Hoffenberg; Howard O. Wilson.

Membership: Southern California Grantmakers.

Financial data: (yr. ended 08/31/05): Assets, $\$ 31,967,742(\mathrm{M})$; expenditures, $\$ 1,716,303$; total giving, $\$ 1,360,158$; qualifying distributions, $\$ 1,462,530$; giving activities include $\$ 1,360,158$ for 486 grants (high: $\$ 25,000$; low: $\$ 250$ ).

EI N: 956495222

Last updated: 12/20/2006 


\section{American I ndian Youth Running Strong}

Copyright @ 2007 The Foundation Center

\section{Profile}

990 s
«Previous Record| Next Record»

Print Page

Close Window

\section{Profile}

American Indian Youth Running Strong, Inc.

(also known as Running Strong for American Indian Youth)

2550 Huntington Ave., Ste 200

Alexandria, VA 22303-1499

Telephone: (703) 317-9881

Contact: Lauren Haas Finkelstein, Exec. Dir.

FAX: (703) 317-9690

E-mail: info@indianyouth.org

URL: http:/ / www.indianyouth.org

Type of grantmaker: Public charity.

Background: Established in 1986.

Purpose and activities: The organization seeks to help the American Indian people meet their immediate survival needs such as food, water, and shelter while implementing and supporting programs designed to create opportunities for self-sufficiency and self-esteem, particularly for tribal youth.

Fields of interest: Human services; Native Americans/American Indians; Youth development.

Geographic focus: National

Limitations: Giving on a national basis. No support for advertising, travel or for ads in souvenir journals.

No grants to individuals, or for scholarships, or conferences.

Publications: Annual report; Application guidelines; Financial statement; Informational brochure; Newsletter.

Application information: Application form required.

Initial approach: Letter or telephone

Copies of proposal: 1

Board meeting date(s): Quarterly

Deadline(s): Rolling for applications under $\$ 5,000$

Final notification: 8 weeks

Officers and Directors:* James J. O'Brien, Esq.,* Chair.; Eugene L. Krizek,* Pres.; Paul E. Krizek,* V.P.; Adeline R. Krizek,* Secy.; Clyde B. Richardson,* Treas.; Lauren Haas Finkelstein, Exec Dir.; Rev. Charles T. Holliday; Fred G. Kramer; and 5 additional directors.

Financial data: (yr. ended 06/30/05): Revenue, $\$ 2,712,547$; assets, $\$ 950,181$ (M); gifts received, $\$ 2,684,334$; expenditures, $\$ 2,597,964$; total giving, $\$ 2,181,350$; program services expenses, $\$ 2,532,930$; giving activities include $\$ 732,297$ for 94 grants (high: $\$ 100,000$; low: $\$ 194$ ), $\$ 92,247$ for 6 grants to individuals (high: $\$ 28,840$; low: $\$ 2,500$ ) and $\$ 1,356,806$ for 2 in-kind gifts.

EI N: 541594578

Last updated: 01/09/2007 


\section{Seventh Generation Fund}

Copyright $\odot 2007$ The Foundation Center

$$
\text { Proflle }
$$

«Previous Record | Next Record»

Print Page

Close Window

\section{Profile}

Seventh Generation Fund

(also known as Seventh Generation Fund for Indian Development, Inc.)

P.O. Box 4569

Arcata, CA 95518-4569

Telephone: (707) 825-7640

Contact: Christopher H. Peters, Pres. and C.E.O.

FAX: (707) 825-7639

E-mail: of7gen@pacbell.net

URL: http:/ / www.7genfund.org

Donor(s): America's Charities; Chumash Casino and Resort; Community Resource Alliance; Corporation of the Fine Arts Museums; Flowering Tree Permaculture; Fund for Santa Barbara, Inc.; Grant Distributing; Grousbeck Family Foundation; Hampshire Group Limited; Humboldt Area Foundation.

Type of grantmaker: Public charity.

Background: Established in 1977 in CA.

Purpose and activities: The fund is a national Native American advocacy and intermediary grantmaking organization dedicated to maintaining and promoting the uniqueness of Native peoples and the distinctiveness of their nations. The fund provides an integrated program of grants, management support, training and technical assistance, and advocacy to innovative indigenous grassroots projects throughout Native communities of the U.S., Canada, and South and Central America.

Program area(s): The grantmaker has identified the following area(s) of interest:

General Grants: Funds up to $\$ 10,000$ to cover administrative and operating costs for a project. Grants may be secured for up to three consecutive years.

Mini Grants: Awards grants ranging from $\$ 50$ to $\$ 500$ for projects that support the foundation's mission. Training and Technical Assistance Grants: Funds up to $\$ 5,000$ for project-specific training and organizational capacity building. Grants are also made for conference support.

Fields of interest: Canada; Central America; Environment; Environment, natural resources; Native Americans/American Indians; Religion; South America.

Geographic focus: National; international

Types of support: Annual campaigns; Building/renovation; Conferences/seminars; Continuing support; Emergency funds; Equipment; General/operating support; Program development; Publication; Seed money; Technical assistance.

Limitations: Giving limited to U.S., Canada, and Central and South America.

Publications: Annual report (including application guidelines); Occasional report.

Application information: See Web site for application guidelines and cover sheet. Application form not required.

Initial approach: Letter or telephone

Copies of proposal: 1

Board meeting date(s): Varies

Deadline(s): None

Officers and Directors:* Rosalie Little Thunder,* Chair.; Tonya Gonnella Frichner, Vice-Chair.; Christopher Peters, Pres. and C.E.O.; Ray Williams, Secy.; Tia Oros Peters,* Exec. Dir.; Tupac EnriqueAcosta; Susana Geliga; Luis Macas, M.D.; Henrietta Mann, M.D.

Number of staff: 2 full-time professional; 2 part-time professional; 1 full-time support; 2 part-time support. 
Memberships: Environmental Grantmakers Association; Grantmakers In the Arts; National Network of Grantmakers.

Financial data: (yr. ended 06/30/05): Revenue, $\$ 1,416,965$; assets, $\$ 863,805$ (M); gifts received, $\$ 1,406,580$; expenditures, $\$ 1,427,167$; total giving, $\$ 465,666$; program services expenses, $\$ 1,260,935$; giving activities include $\$ 465,666$ for 131 grants (high: $\$ 10,000$; low: $\$ 500$ ).

EI N: 680027247

Last updated: 04/12/2007 


\section{I nternational Partners in Mission}

Copyright @ 2007 The Foundation Center

\section{Proflle}

$990 \mathrm{~s}$

«Previous Record | Next Record»

Print Page

Close Window

\section{Profile}

International Partners in Mission

3091 Mayfield Rd., Ste. 320

Cleveland Heights, $\mathrm{OH} 44118$

Telephone: (216) 932-4082

Contact: Joseph F. Cistone, C.E.O. and Exec. Dir.

FAX: (216) 932-4084

E-mail: office@ipm-connections.org

URL: http:/ / www.ipm-connections.org

Type of grantmaker: Public charity.

Background: Established in 1974 in MO.

Purpose and activities: The organization works across borders of faith and culture on behalf of children, women, and youth to create partnerships that build justice, peace, and hope.

Fields of interest: Asia; Central America; Children/youth, services; Community development;

Environment; Europe; Health care; Middle East; Native Americans/American Indians; Northeast Africa;

South America; Sub-Saharan Africa; Women.

Geographic focus: National; international

Types of support: Emergency funds; Income development; Program development; Program-related investments/loans; Seed money; Technical assistance.

Limitations: Giving on an international basis to Sub Saharan and North Africa, Asia, Europe, the Middle East, and North, Central and South America. Giving in the United States is limited to Cleveland, $\mathrm{OH}, \mathrm{St}$. Louis, MO, and Native American communities.

Publications: Annual report; Application guidelines; Financial statement; Informational brochure; Newsletter.

Application information: Application form required.

Initial approach: Letter or e-mail

Officers and Trustees:* Sharon Milligan, Ph.D.,* Chair.; Florence Saeger, Chair.-Elect and Vice-Chair.; Christine E. Henry,* Vice-Chair.; J oseph F. Cistone, C.E.O. and Exec. Dir.; Elizabeth T. Reichard,* Secy.; Michael Mayor,* Treas.; Nadine Hopwood Feighan*; Leah Gary; Mark Schulte; and 14 additional trustees.

Number of staff: 4 full-time professional; 2 part-time professional.

Financial data: (yr. ended 12/31/05): Revenue, $\$ 1,175,724$; assets, $\$ 468,871$ (M); gifts received, $\$ 1,161,518$; expenditures, $\$ 913,930$; total giving, $\$ 273,145$; program services expenses, $\$ 767,385$; giving activities include $\$ 273,145$ for grants.

EI N: 431487311

Last updated: 10/06/2006 


\section{AMB Foundation}

Copyright $\odot 2007$ The Foundation Center Proflle
«Previous Record | Next Record» Print Page Close Window

\section{Profile}

AMB Foundation

P.O. Box 94717

Phoenix, AZ 85045

Contact: Marie Sloane, Dir.

E-mail: mail4amb@cox.net

Donor(s): Anne J. Wells.

Type of grantmaker: Independent foundation.

Background: Established in 1998 in IL.

Purpose and activities: Giving primarily for the health, education, and economic development of indigenous peoples of the Americas.

Fields of interest: Education; Health care; International economic development; Native

Americans/American Indians; South America.

Geographic focus: National; international

Types of support: Building/renovation; Curriculum development; Emergency funds; Equipment; Land acquisition; Program development; Program evaluation; Publication; Research; Scholarship funds;

Technical assistance.

Limitations: Giving in the Americas.

Publications: Application guidelines.

Application information: Application form required.

Initial approach: Request RFP by mail or e-mail

Copies of proposal: 3

Board meeting date(s): Twice yearly

Deadline(s): Varies

Directors: Finbarr C. Sloane; Marie W. Sloane; Anne J. Wells; Bridget B. Wells; Theodore E. Wells.

Number of staff: 1 part-time support.

Membership: Association of Small Foundations.

Financial data: (yr. ended 12/31/05): Assets, $\$ 2,644,892(\mathrm{M})$; expenditures, $\$ 236,295$; total giving, $\$ 206,210$; qualifying distributions, $\$ 206,210$; giving activities include $\$ 206,210$ for 23 grants (high:

$\$ 25,000$; low: $\$ 1,500)$.

EI N: 364188235

Selected grants: The following grants were reported in 2004.

$\$ 25,000$ to Companeros de Poqen Kanchay, Jupiter, FL.

$\$ 20,000$ to American Indian College Fund, Denver, CO.

$\$ 10,000$ to Friends Committee on National Legislation (FCNL) Education Fund, DC.

$\$ 10,000$ to Nature America, New York, NY.

$\$ 10,000$ to Plenty International, Summertown, TN.

$\$ 10,000$ to Red Cloud Indian School, Pine Ridge, SD.

$\$ 10,000$ to Red Feather Development Group, Bozeman, MT.

$\$ 10,000$ to Save the Children Federation, Westport, CT.

$\$ 10,000$ to Trust for Public Land, Los Angeles, CA.

$\$ 5,000$ to White Earth Land Recovery Project, Callaway, MN.

Last updated: 01/11/2007 


\title{
FOUNDATION DIRECTORY ONLINE

\section{Asea Brown Boveri I nc. Corporate Giving Program}

\author{
«Previous Record| Next Record» \\ Print Page \\ Close Window
}

Copyright @ 2007 The Foundation Center

\section{Profile}

\section{Profile}

Asea Brown Boveri Inc. Corporate Giving Program

501 Merritt 7

Norwalk, CT 06851-7000

FAX: (203) 750-7788

Sponsoring company: Asea Brown Boveri Inc.

Type of grantmaker: Corporate giving program.

Purpose and activities: Asea Brown Boveri makes charitable contributions to nonprofit organizations involved with education and energy conservation. Support is given on a national basis.

Fields of interest: Education; Environment, energy.

Geographic focus: National

Types of support: General/operating support.

Limitations: Giving on a national basis.

Application information: Contributions are currently very limited.

Sponsoring company information:

Asea Brown Boveri I nc.

501 Merritt 7

Norwalk, CT 06851-7000

(203) 750-2200

Establishment information: Established in 1988.

Company type: Subsidiary of a foreign company

Business activities: Operates holding company.

Business type (SIC): Holding company

Corporate officers: Barry Wentworth, Treas.

Plants and/ or Offices: San Ramon, CA; Windsor, CT; Lisle, IL; Portland, ME; Bloomfield, NJ; Roseland, NJ; Union, NJ; Melville, NY; Rochester, NY; Wellsville, NY; Columbus, OH; King of Prussia, PA; Muncy, PA; Lewisburg, WV.

Affiliated grantmaker(s): Asea Brown Boveri Inc. Corporate Giving Program

Last updated: 05/22/2003 


\section{First Nations Development I nstitute}

Copyright @ 2007 The Foundation Center

\section{Profile}

$990 \mathrm{~s}$
«Previous Record | Next Record»

Print Page

Close Window

\section{Profile}

First Nations Development Institute

703 3rd. Ave., Ste. B.

Longmont, CO 80501-5995

Telephone: (303) 774-7836

Contact: Michael E. Roberts, Pres.

FAX: (303) 774-7841

E-mail: info@firstnations.org

Additional address: 10707 Spotsylvania Ave., Ste. 201, Fredericksburg, VA 22408, tel.: (540) 371-5615,

FAX: (540) 371-3505

URL: http:/ / www.firstnations.org

Type of grantmaker: Public charity.

Background: Established in 1983 in VA.

Purpose and activities: The institute helps Native American tribal members to mobilize enterprises that are reform-minded, culturally suitable, and economically feasible by coordinating local grassroots projects with national program and policy development initiatives to build capacity for self-reliant reservation economies.

Program area(s): The grantmaker has identified the following area(s) of interest:

Eagle Staff Fund: This fund provides grants and technical assistance to models of culturally appropriate economic development that use asset-based strategies. The fund offers three different types of general grants: seed, start-up and working capital as well as special initiatives.

Leadership and Entrepreneurial Apprenticeship Development (LEAD) Program: The LEAD program is a one-year educational program designed to provide undergraduate, masters, or law students or rising nonprofit staff with hands-on experience at a reservation-based nonprofit organization. At the same time, the host organization will benefit from access to highly motivated American Indian students or professionals who can offer business planning, budgeting, feasibility planning, marketing, grantwriting, etc. Each host organization's executive director or president will serve as a mentor working with the apprentice to identify specific skill-building goals, objectives, and activities for an individual learning plan and project to be accomplished by the apprentice over the one-year period. Apprentices may either apply along with a mentor (with whom they are not currently employed) or choose to be paired with a mentor from a slate of host organizations that will be selected under a separate application process. Apprentice candidates must have demonstrated leadership potential and a commitment to pursuing a career in the Native nonprofit sector; have three years' full-time work experience that includes management of people and/or projects, as well as an applied understanding of fundraising, finance, and technology; and be affiliated with an Alaska Native, Native Hawaiian, or American Indian Tribe. Program participants will receive a one-year paid apprenticeship of $\$ 50,000$. Host organizations will be awarded a $\$ 20,000$ grant to compensate for the costs of the mentor spending time with the apprentice. Funds may also be used to meet the objectives of the program or nonprofit capacity-building project.

Fields of interest: Community development, business promotion; Economic development; Education; Native Americans/American Indians; Rural development; Youth development.

Geographic focus: National

Types of support: Conferences/seminars; Grants to individuals; Program development; Seed money; Technical assistance.

Limitations: Giving limited to Native American reservations and rural Native American communities. No support for non-Native Americans or media campaigns/projects (unless part of an overall project). No 
grants for scholarships, fellowships, construction, renovation, land acquisition, capital or endowment campaigns, or research which has no direct practical application.

Publications: Application guidelines; Biennial report; Grants list; Informational brochure; Newsletter; Occasional report.

\section{Application information:}

Initial approach: Letter of intent; Download application package for LEAD Program

Deadline(s): June 15 for LEAD Program

Officers and Directors:* B. Thomas Vigil,* Chair.; Michael E. Roberts,* Pres.; Marguerite Smith,* Secy.; W. Ron Allen,* Treas.; Siobhan Oppenheimer-Nicolau; Donald G. Sampson; Gelvin Stevenson.

Number of staff: 12 full-time professional; 4 part-time professional; 4 full-time support.

Memberships: Association of Small Foundations; Southeastern Council of Foundations.

Financial data: (yr. ended 06/30/05): Revenue, $\$ 3,295,524$; assets, $\$ 1,952,973$ (M); gifts received, $\$ 3,005,611$; expenditures, $\$ 3,219,860$; total giving, $\$ 825,548$; program services expenses, $\$ 2,550,301$; giving activities include $\$ 825,548$ for 25 grants (high: $\$ 130,200$; low: $\$ 925$ ) and $\$ 1,724,753$ for 6 foundation-administered programs.

Grantmaker's financial estimates: (yr. ended 6/30/06): Estimated assets, $\$ 3,147,716$; estimated total giving, $\$ 1,043,674$.

EI N: 541254491

Last updated: 06/14/2007 


\section{Columbia Foundation}

Copyright $\subset 2007$ The Foundation Center

$$
\text { Profile }
$$

«Previous Record| Next Record»

Print Page

Close Window

\section{Profile}

\section{Columbia Foundation}

1016 Lincoln Blvd., Ste. 205

P.O. Box 29470

San Francisco, CA 94129-1717

Telephone: (415) 561-6880

Contact: Susan Reed Clark, Exec. Dir.

FAX: (415) 561-6883

E-mail: info@columbia.org

URL: http:/ / www.columbia.org

Donor(s): Madeleine H. Russellf; Christine H. Russell.

Type of grantmaker: Independent foundation.

Background: Incorporated in 1940 in CA.

Purpose and activities: While the foundation's broad philanthropic purpose has given it flexibility to respond to changing social conditions, it has nevertheless maintained its long-standing interest in world peace, human rights, the environment, cross-cultural and international understanding, the quality of urban life, and the arts. Within each of these areas the board of directors sets new priorities as conditions change.

Program area(s): The grantmaker has identified the following area(s) of interest:

Arts and Culture: The goal is to enhance the quality of life through the arts with programs that are accessible to, and affordable for, a broad and diverse public. The foundation focuses its grantmaking on: 1) The creation of new work and the performance or exhibition of art by nonprofit organizations; 2) Art that encourages civic awareness of, and a focus on, the need to develop sustainable communities and economies, and to protect human rights. While wishing to avoid political sermonizing, the foundation is interested in supporting artistic activity that engages the public in the philosophical, aesthetic, personal, political, and practical aspects of these important contemporary issues; and 3) Art from a variety of cultures and perspectives, and art that engages people from diverse cultures. The application deadline is Apr. 1 for a full proposal. The foundation considers proposals for programs in the San Francisco Bay Area, with priority given to San Francisco-based organizations, and in the United Kingdom, with priority given to London-based organizations. San Francisco Bay Area grants may focus on specific productions/exhibits or on organizational development. Grants to U.K. organizations are limited to support for specific productions/exhibits.

Human Rights: The goal of this program is the protection of everyone's basic human rights, including the right to enjoy economic, social, and cultural freedoms, as well as civil and political ones. As defined by the Universal Declaration of Human Rights, these rights are not privileges granted by governments, nor can governments abrogate them. Columbia Foundation has a specific interest in the human right to food, including equitable access to land for food production, and in the right to equal suffrage where every vote is counted fairly. The foundation focuses its grantmaking on programs that work toward the following: 1) expansion of the availability of locally produced, affordable fresh food to meet the needs of people from diverse cultures in low-income communities, and strengthening of efforts to build a regional food economy that meets their needs; 2) Increased access to farmland for new and established farmers committed to practicing regional sustainable agriculture; and 3) Public finance of campaigns for public office, and electoral reform to ensure fair voting and vote-verification standards. The annual deadline is Aug. 1 for a full proposal. Geographic priorities include: San Francisco Bay Area for local projects, and California for statewide programs. Proposals for innovative national programs are considered on a case-by-base basis. 
Types of grant support given include: program, organizational development, and seed money for new programs. Over the course of 2005, the foundation will phase out of its previous human rights program priorities which supported work towards the: 1) elimination of prejudice and discrimination based on sexual and gender diversity; and 2) promotion of the right of citizens to make their own end-of-life decisions, including the right to legal physician-assisted death. Applications for new programs under those guidelines will no longer be accepted. Phase-out grants to existing programs will be determined on a caseby-case basis. The foundation maintains an interest in strategic opportunities to advance civil marriage equality and the right to die with dignity, however future grants in these areas will primarily be foundationinitiated.

Media: The foundation considers proposals for media projects in each program area if they address the foundation's current program priorities and relate to the work of organizations already funded by the foundation. If the issue already has received extensive media coverage, the foundation is unlikely to consider the project for funding. The foundation gives priority to San Francisco Bay Area film makers; to films or videos that will be used by Columbia Foundation-funded public-interest organizations to further their work on the issue; and to projects for which a grant of $\$ 5,000$ to $\$ 25,000$ makes a difference in getting the project started or completed. Applications for media projects should be submitted by the annual deadline for the relevant program area.

Sustainable Communities and Economies: The goal of this program is to advance community and economic development programs that work to secure - for the present and future, and within the means of nature - a just and equitable life for all species. The foundation focuses its grantmaking on the following: 1) Promotion of sustainable food systems that work toward: secure livelihood for farmers and farm workers; protection of natural resources and biodiversity; the viability of marine ecosystems and fisheries; protection of public and environmental health; access to affordable, nutritious food from local and regional sources to meet the needs of people of differing cultures and incomes (Applications for programs that address the human rights aspects of sustainable food systems are considered under the foundation's human rights program. The annual deadline for human rights program applications is Aug. 1), and creation of thriving regional food economies.; 2) Development of a zero-waste, closed-loop materials economy in which products are made to be re-used, repaired, and recycled to minimize and ultimately to eliminate waste; 3) Creation and dissemination of economic development models that work toward the goal of sustainability; and 4) Development of the intellectual and policy frameworks for sustainability. The annual deadline is Dec. 1 for a full proposal. Geographic priorities include: San Francisco Bay Area and Northern California for local projects, and California for statewide projects. Types of grant support include: program, organizational development, pilot projects, and seed money for new programs.

Fields of interest: Agriculture/food; Animals/wildlife, preservation/protection; Arts; Civil liberties, advocacy; Civil liberties, right to die; Civil rights, advocacy; England; Environment; Environment, natural resources; Social sciences; Urban/community development.

Geographic focus: California

Types of support: Building/renovation; Continuing support; Curriculum development; Film/video/radio; General/operating support; Management development/capacity building; Program development; Publication; Research; Seed money.

Limitations: Giving primarily in the San Francisco Bay Area, CA. Some foundation-initiated giving in the United Kingdom and other countries for the arts. No support for private foundations, institutions supported by federated campaigns or heavily subsidized by government funds, or projects in medicine or religion. No grants to individuals, (except for filmmakers with a fiscal sponsorship for their projects), or for scholarships, fellowships, ongoing programs, or operating budgets of established agencies.

Publications: Annual report (including application guidelines); Grants list; Program policy statement (including application guidelines).

Application information: Grants to programs based in the United Kingdom or other countries are initiated by the foundation; unsolicited proposals are not considered. Proposals sent by fax or e-mail not considered; they should be 2-sided and reproduced on recycled paper. Further guidelines available on foundation Web site. Application form required. Applicants should submit the following:

1) timetable for implementation and evaluation of project

2) qualifications of key personnel

3) statement of problem project will address

4) copy of IRS Determination Letter 
5) brief history of organization and description of its mission

6) copy of most recent annual report/audited financial statement/990

7) how project's results will be evaluated or measured

8) listing of board of directors, trustees, officers and other key people and their affiliations

9) detailed description of project and amount of funding requested

10) copy of current year's organizational budget and/or project budget

11) listing of additional sources and amount of support

Initial approach: Application form, 2-page summary, and proposal narrative

Copies of proposal: 1

Board meeting date(s): 4 times per year

Deadline(s): Arts and Culture: Apr. 1; Human Rights: Aug. 1; Sustainable Communities and Economies:

Dec. 1

Final notification: 10 weeks after deadline

Officers and Directors:* Christine H. Russell,* Pres.; Charles P. Russell,* Secy.; Alice C. RussellShapiro,* Treas.; Susan Reed Clark, Exec. Dir.

Number of staff: 2 full-time professional; 1 full-time support.

Memberships: California Association of Nonprofits; Council on Foundations; Environmental Grantmakers Association; Independent Sector; Northern California Grantmakers; Sustainable Agriculture and Food Systems Funders.

Financial data: (yr. ended 05/31/06): Assets, $\$ 80,883,408(\mathrm{M})$; gifts received, $\$ 28,848$; expenditures, $\$ 4,267,968$; total giving, $\$ 2,901,715$; qualifying distributions, $\$ 3,406,857$; giving activities include $\$ 2,901,715$ for 112 grants (high: $\$ 200,000$; low: $\$ 880$; average: $\$ 5,000-\$ 50,000$ ).

Grantmaker's financial estimates: (yr. ended 5/31/07): Estimated assets, \$88,000,000; estimated total giving, $\$ 3,284,000$.

EI N: 941196186

Selected grants: The following grants were reported in 2004. $\$ 250,000$ to Proteus Fund, Amherst, MA, For Civil Marriage Collaborative, donor-advised grant making program supported by institutional donors to bolster strategic state and local efforts to strengthen broad and diverse grassroots constituency to achieve civil marriage equality in the $\mathrm{U}$. S. and to oppose efforts to limit or deny civil marriage rights to lesbian, gay, bisexual, and transgender people.

$\$ 155,000$ to Creative Work Fund, San Francisco, CA, For final grant to provide funds for individuals artists to create new art works in collaboration with other artists or community organizations.

$\$ 150,000$ to California Polytechnic State University, Sustainable Agriculture Resource Center, San Luis Obispo, CA, To develop Institute on Sustainable Agriculture within College of Agriculture.

$\$ 100,000$ to Compassion and Choices, Portland, Oregon, For end-of-life education and advocacy programs in California, payable over 2 years.

$\$ 100,000$ to Death with Dignity National Center, Portland, Oregon, To defend Oregon death with dignity law from Federal challenge and to educate Federal officials about benefits of the law, payable over 2 years. $\$ 100,000$ to Gay-Straight Alliance Network, San Francisco, CA, For continuing programmatic and organizational development, payable over 2 years.

$\$ 75,000$ to Los Cenzontles Mexican Arts Center, San Pablo, CA, For organizational development to increase revenue from ticket income, marketing of products, corporate sponsorships of major events, and major donor campaign.

$\$ 75,000$ to San Francisco Opera, San Francisco, CA, For annual support and transition funding.

$\$ 70,000$ to Redefining Progress, Oakland, CA, For Scenarios for Sustainability: Forecasting the Economic, Social, and Environmental Impacts of Land Use Planning that will provide concrete tools (Genuine Progress Indicator and the Ecological Footprint) to help city planners, elected officials, and the public make better informed land-use decisions to strengthen economy of San Francisco Bay Area while reducing region's Ecological Footprint.

$\$ 60,000$ to National Center for Lesbian Rights, San Francisco, CA, For Safe Homes Project to improve care of lesbian, gay, bisexual, transgendered, and queer/questioning youth in California's foster care and juvenile justice systems.

Last updated: 05/22/2007 


\section{The California Endow ment}

Copyright $\odot 2007$ The Foundation Center

\section{Proflle}

«Previous Record| Next Record»

Print Page

Close Window

\section{Profile}

The California Endowment

1000 N. Alameda St.

Los Angeles, CA 90012-1804

Telephone: (800) 449-4149

FAX: (213) 928-8801

E-mail: questions@calendow.org

URL: http:/ / www.calendow.org

Type of grantmaker: Independent foundation.

Background: Established in 1996 in CA; converted from Blue Cross of California.

Purpose and activities: To expand access to affordable, quality health care for underserved individuals and communities and to promote fundamental improvements in the health status of all Californians.

Program area(s): The grantmaker has identified the following area(s) of interest:

Access to Health: The goal in this area is to improve the health of underserved individuals and families by expanding access to health and mental health services. The endowment believes that access to health can be achieved through a strong system of primary, preventive health services that are responsive to community needs, coupled with a comprehensive system of health coverage that is simple, affordable and available to all Californians. Under this goal the endowment funds proposals that are designed to expand health coverage, simplify enrollment in health programs and improve the effectiveness of health systems. The goal focuses on policy changes at the local, regional and state levels and seeks lasting reforms and improvements in the way health and mental health services are delivered. The focus also aims to expand access to comprehensive health services that demonstrate better health outcomes and utilize preventive services to maintain health. Examples of proposals eligible for funding include: supporting a capacity building project that will enable a small community clinic or health organization to more effectively provide health services; developing new models of care focusing on prevention and effective coordination of health and mental health services; or building a coalition across public and private sectors to expand access to health services for all Californians.

Agricultural Worker Health I nitiative: The vision of the initiative is to achieve optimal health for agricultural workers, their families and their communities. Through this special initiative, the endowment seeks to implement a multi-faceted approach that concentrates resources on: 1) addressing individual agricultural worker health issues such as chronic health conditions and infectious diseases; 2)

strengthening the social, economic and civic infrastructure of agricultural worker communities; and 3) improving systems of delivery of care and services for this population.

Center for Healthy Communities: The goal of the program is to be an innovative venue for mobilizing community and civic leaders, health providers, advocates and policymakers in the search for solutions to California's critical health and health care issues. The Center offers a variety of programs and services throughout California, as well as a conference center in Los Angeles.

Community Health and Elimination of Health Disparities: The goal in this area is to build healthy communities by improving the social and physical environments that shape health behaviors and outcomes. By focusing on social and physical environments the endowment aims to prevent disease and injury and eliminate conditions that lead to health disparities. Under this goal the endowment funds proposals that seek to provide the knowledge and skills to change unhealthy behaviors and to change the social and physical environments that contribute to those unhealthy behaviors. The focus of this goal is to change policies and systems to support health-promoting environments. The focus is also to identify a health disparity and implement activities that will contribute to reducing the disparity. Examples of 
proposals eligible for funding include: conducting a community needs assessment to determine the availability of opportunities for physical activity; organizing and community education to seek redress for the effects of pesticide over-spraying in a farm worker community; or developing youth "champions" to educate and advocate for healthy eating and physical activity.

Culturally Competent Health Systems: The goal in this area is to advance the knowledge, attitudes, skills and experience of health providers and health systems to effectively serve California's diverse communities. The goal in this area is to build healthy communities by improving the social and physical environments that shape health behaviors and outcomes. The endowment defines culturally competent health systems as ones that are engaged with and responsive to diverse individuals and communities. Culture is defined broadly and includes race, ethnicity, national origin, primary language, gender, age, sexual orientation, physical and mental ability, spirituality and religion. Under this goal the endowment funds proposals designed to increase the cultural and linguistic competency of health providers and systems to ensure that all persons will have access to the highest quality health services. The focus of this goal is to implement policies and best practices that support culturally and linguistically appropriate health services. In addition, the endowment also focuses on increasing the racial and ethnic diversity of the health work force and improving the geographic distribution of health providers, particularly in rural and underserved areas. Examples of proposals eligible for funding include: training of health care interpreters; implementing new models of health promotion or health services specifically tailored for a particular underserved population; or advocating for increasing recruitment, retention and promotion of racial and ethnic minorities in a health care organization.

Matching Gifts: The foundation matches the monetary gifts of its employees to charitable organizations. Mental Health Special I nitiative: The vision of the endowment's five-year Mental Health Special Initiative is to improve the mental health and well-being for populations at high risk of acute or chronic mental illness with a focus on ethnic minority or linguistically isolated populations, and adolescents in the child welfare and probation systems. The initiative seeks to improve mental health and well-being among these populations by increasing access to services, enhancing the pool of a culturally competent mental health work force, and policy development and advocacy.

Fields of interest: Economically disadvantaged; Health care; Minorities.

Geographic focus: California

Types of support: Building/renovation; Conferences/seminars; Employee matching gifts;

General/operating support; Management development/capacity building; Program evaluation; Programrelated investments/loans; Technical assistance.

Limitations: Giving primarily in CA. No support for political purposes, medical or scientific research, or uncompensated care for direct clinical services. No grants to individuals for scholarships; fellowships or grants, or for endowments, operating deficits or retirement of debt, media projects not part of a broader project or strategy, medical supplies, laboratory fees, X-ray services, medications, vaccines or prescriptions; capital funding for purchase, construction or renovation of facilities or other physical infrastructure; indirect costs that exceed $15 \%$ of the total of requested personnel and operating costs.

Publications: Annual report; Application guidelines; Occasional report.

Application information: See foundation Web site for grant application guide and downloadable grant application coversheet. Application form required. Applicants should submit the following:

1) timetable for implementation and evaluation of project

2) results expected from proposed grant

3) qualifications of key personnel

4) statement of problem project will address

5) copy of IRS Determination Letter

6) copy of most recent annual report/audited financial statement/990

7) how project's results will be evaluated or measured

8) listing of board of directors, trustees, officers and other key people and their affiliations

9) detailed description of project and amount of funding requested

10) copy of current year's organizational budget and/or project budget

11) listing of additional sources and amount of support

12) geographic area to be served

13) population served

Eligible organizations are 501(c)3 exempt non-profits; independent projects with a 501 (c) 3 sponsor or 
government/public agencies.

Initial approach: Application including application coversheet

Copies of proposal: 4

Board meeting date(s): Feb, Apr., July, Oct. and Dec. (Optional)

Deadline(s): None

Final notification: Four months

Officers and Directors:* Arthur Chen, M.D.,* Chair.; Daniel Boggan,* Vice-Chair.; Robert K. Ross, M.D.,* C.E.O. and Pres.; Irene M. Ibarra, Exec. V.P.; B. Kathlyn Mead, Sr. V.P. and C.O.O.; Michael J . Januzik, V.P. and C.F.O.; Brytain Ashford, V.P., Human Resources; Alonzo Louis Plough, Ph.D., V.P., Progs., Planning, and Eval.; Kathleen Brown; Jesse Casso, Jr.; John E. Bryson; Tessie Guillermo; Beverly Hamilton; James Keddy; James Lewis Kyle II, M.D.; Maurice Lim Miller; Hugo Morales; E. Lewis Reid; Rita Scardaci; Cynthia Ann Telles, Ph.D.; Fernando M. Torres-Gill, Ph.D.; Maria Tripp; Winnie O. Willis, Sc.D.

Number of staff: 168 full-time professional; 11 full-time support; 2 part-time support.

Memberships: Animal Grantmakers; Asian Americans/Pacific Islanders in Philanthropy; California Association of Nonprofits; Consortium of Foundation Libraries; Council on Foundations; Disability Funders Network; Grantmakers for Effective Organizations; Hispanics in Philanthropy; Independent Sector; Neighborhood Funders Group; Northern California Grantmakers; San Diego Grantmakers; Southern California Grantmakers; Women \& Philanthropy.

Financial data: (yr. ended 02/28/06): Assets, $\$ 4,405,938,934(\mathrm{M})$; expenditures, $\$ 207,419,360$; total giving, $\$ 149,911,050$; qualifying distributions, $\$ 242,218,069$; giving activities include $\$ 149,664,870$ for 1,639 grants (high: $\$ 1,644,000$; low: $\$ 200$; average: $\$ 2,000-\$ 500,000$ ), $\$ 246,180$ for employee matching gifts and $\$ 2,814,310$ for 4 foundation-administered programs.

Grantmaker's financial estimates: (yr. ended 2/28/07): Estimated assets, $\$ 3,700,000,000$; estimated total giving, $\$ 163,500,000$.

EI N: 954523232

Selected grants: The following grants were reported in 2005.

$\$ 4,294,537$ to Children Now, Oakland, CA, To expand 100 Percent Campaign, policy and advocacy activities which serve as anchor in support of Children's Coverage Program to achieve health coverage for all children in California.

$\$ 4,056,779$ to Public Health Institute, Building Communities for Healthy Eating and Physical Activity Program Office, Oakland, CA, To provide program support and coordination of statewide technical assistance providers for up to five local collaboratives working to increase opportunities for physical activity and healthy eating for children and families in targeted neighborhoods, and to advance policy agenda that supports community-based public health and increased resources for primary prevention. $\$ 3,383,088$ to University of California, Los Angeles, CA, To increase availability, accessibility and utility of California Health Interview Survey (CHIS) 2005 health data by collecting oversamples of key populations, administering specific survey topics that support California Endowment program interests, conducting and publishing studies on asthma, diabetes and access to health insurance and health care, and broadly disseminating survey data and studies to community-based organizations, state and local officials, researchers and decision-makers.

$\$ 2,600,000$ to Rural Community Assistance Corporation, West Sacramento, CA, For Agricultural Worker Community Health and Housing Assistance Program, strategic partnership with Agricultural Worker Health Initiative's Poder Popular Program to provide management assistance, training, and related technical support with primary focus on improving local community infrastructure and housing for agricultural workers in California.

$\$ 1,869,555$ to University of California, San Francisco, CA, To implement key organizational change strategies in LEADing Organizational Change-Advancing Quality Through Culturally Responsive Care, initiative to integrate culturally and linguistically appropriate services into public hospitals and health systems in California.

$\$ 1,203,950$ to California Teachers Association, Burlingame, CA, To expand Teachers for Healthy Kids, teacher-to-parent outreach program to increase children's enrollment in free and low-cost health coverage programs in targeted low-income school districts in California.

$\$ 1,000,000$ to K C E T Community Television of Southern California, Los Angeles, CA, For public health policy television programming aimed at increasing California residents' participation in health policy advocacy, and increasing awareness of health policy issues among California policymakers in order to have 
impact on local and statewide policy change.

$\$ 988,000$ to National Public Radio, DC, To increase coverage of health care issues affecting minorities and underserved populations in California including coverage on disparities in health status and treatment; access to quality, affordable health care; obesity prevention, and children's health issues.

$\$ 955,725$ to Institute for Health Policy Solutions, DC, Toward development of local children's health initiatives throughout state and to facilitate transfer of innovation and best practices from local programs statewide to advance health coverage for all children in California.

$\$ 950,000$ to Santa Clara Family Health Foundation, Campbell, CA, To provide one year of full medical, dental and vision coverage through Healthy Kids program to uninsured, ineligible children 6-18 years of age in Santa Clara County.

Last updated: 05/04/2007 


\section{Charles Stewart Mott Foundation}

Copyright @ 2007 The Foundation Center

$$
\text { Proflle }
$$

990s
«Previous Record| Next Record»

Print Page

Close Window

\section{Profile}

Charles Stewart Mott Foundation

c/o Office of Proposal Entry

Mott Foundation Bldg., 503 S. Saginaw St., Ste. 1200

Flint, MI 48502-1851

Telephone: (810) 238-5651

FAX: (810) 766-1753

E-mail: info@mott.org

Additional e-mail: publications@mott.org

URL: http:/ / www.mott.org

Donor(s): Charles Stewart Mottł; and family.

Type of grantmaker: Independent foundation.

Background: Incorporated in 1926 in MI.

Purpose and activities: To support efforts that promote a just, equitable and sustainable society with the primary focus on civil society, the environment, the area of Flint, MI and poverty. The foundation makes grants for a variety of purposes within these program areas including: philanthropy and voluntarism; assisting emerging civil societies in Central/Eastern Europe, Russia and South Africa; conservation of fresh water ecosystems in North America; reform of international finance and trade; improving the outcomes for children, youth and families at risk of persistent poverty; education and neighborhood and economic development. The foundation also makes grants to strengthen the capacity of local institutions in its home community of Flint, MI.

Program area(s): The grantmaker has identified the following area(s) of interest:

Civil Society: The mission of this program is to support efforts to assist in democratic institution building, strengthen communities, promote equitable access to resources, and ensure respect of rights and diversity. Three core themes that have been central since 1998 are strengthening the nonprofit sector; promoting rights, responsibilities and participation; and improving race and ethnic relations. The program consists of four grantmaking areas: Central/Eastern Europe and Russia; South Africa; United States; and Special Initiatives - International.

Employee/ Trustee Matching Grants: The foundation matches gifts of trustees and employees to charitable organizations on a three-to-one basis.

Environment: The mission of this program is to support the efforts of an engaged citizenry working to create accountable and responsive institutions, sound public policies, and appropriate models of development that protect the diversity and integrity of selected ecosystems in North America and around the world. Program areas are Reform of International Finance and Trade, Conservation of Freshwater Ecosystems in North America, and Special I nitiatives. In Reform of International Finance and Trade, there are two objectives: policy reform and implementation, and strengthening international constituencies for reform. In Conservation of Freshwater Ecosystems in North America, there are three objectives: site-based conservation efforts, strengthening the environmental community, and policy work. In Special Initiatives, there are two objectives: growth management and urban revitalization in Michigan, and special opportunities nationally and internationally.

Exploratory and Special Projects: The mission of this program is to support unusual or unique opportunities addressing significant international and/or national problems.

Flint Area: The mission of this program is to foster a well-functioning, connected community that is capable of meeting the economic, social and racial challenges ahead. Grantmaking categories are: 1) Arts, Culture, and Education; 2) Community Revitalization and Economic Development; and 3) Special 
Initiatives.

Pathways Out of Poverty: The mission of this program is to identify, test and help sustain pathways out of poverty for low-income people and communities. Program areas are: 1) Improving Community Education through community-driven reform, vulnerable youth and learning beyond the classroom; 2) Expanding Economic Opportunity through income security, reducing barriers to employment, and retention and wage progression; 3) Building Organized Communities by building infrastructure; and 4) Special Initiative which focuses on transitions and exploratory and special projects.

Fields of interest: Child development, services; Children, services; Civil rights, race/intergroup relations; Community development; Eastern Europe; Economic development; Economically disadvantaged; Education; Environment, natural resources; Environment, pollution control; Family services, parent education; Human services; Latin America; Leadership development; Minorities; Rural development; Russia; South Africa; Urban/community development; Voluntarism promotion.

Geographic focus: National; international

Types of support: Conferences/seminars; Continuing support; Employee matching gifts;

General/operating support; Matching/challenge support; Program development; Program evaluation; Seed money; Technical assistance.

Limitations: Giving nationally and to emerging countries in Central and Eastern Europe, Russia, and South Africa. No support for religious organizations for religious purposes. No grants to individuals, or for building or endowment funds in general or for research, film or video projects, books, scholarships, or fellowships.

Publications: Annual report (including application guidelines); Financial statement; Informational brochure (including application guidelines); Newsletter; Occasional report; Program policy statement.

Application information: Applicants strongly encouraged to submit proposals during first quarter of the year. Application form not required. Applicants should submit the following:

1) timetable for implementation and evaluation of project

2) how project will be sustained once grantmaker support is completed

3) results expected from proposed grant

4) qualifications of key personnel

5) population served

6) copy of IRS Determination Letter

7) brief history of organization and description of its mission

8) copy of most recent annual report/audited financial statement/990

9) how project's results will be evaluated or measured

10) listing of board of directors, trustees, officers and other key people and their affiliations

11) detailed description of project and amount of funding requested

12) copy of current year's organizational budget and/or project budget

Proposals should be submitted at least 4 months prior to start of proposed grant period.

Initial approach: Letter of inquiry or proposal

Copies of proposal: 1

Board meeting date(s): Mar., June, Sept., and Dec.

Deadline(s): None; grants are determined by Aug. 31 of any given year

Final notification: 60 to 90 days

Officers and Trustees:* William S. White,* Chair., C.E.O. and Pres.; William H. Piper,* Vice-Chair.; Maureen H. Smyth, Sr. V.P., Progs. and Comms.; Phillip H. Peters, V.P., Admin. Group and Secy.-Treas.; Michael J. Smith, V.P., Investments and C.I.O.; Gavin T. Clabaugh, V.P., Inf. Svcs.; Marilyn S. LeFeber, V.P., Comms.; A. Marshall Acuff, Jr.; Rushworth M. Kidder; Tiffany W. Lovett; Webb F. Martin; Olivia P. Maynard; John Morning; Maryanne Mott; Douglas X. Patino; John W. Porter; Marise M.M. Stewart; Claire M. White.

Number of staff: 60 full-time professional; 1 part-time professional; 26 full-time support.

Memberships: Africa Grantmakers' Affinity Group; Consortium of Foundation Libraries; Consultative Group on Biodiversity; Council of Michigan Foundations; Council on Foundations; Environmental

Grantmakers Association; Funders Concerned About AIDS; Funders' Network for Smart Growth and Livable Communities; Grantmakers for Effective Organizations; Independent Sector; Interfaith Funders; Michigan Nonprofit Association; Neighborhood Funders Group; The Canadian Environmental Grantmakers' Network (CEGN); Women \& Philanthropy. 
Financial data: (yr. ended 12/31/05): Assets, $\$ 2,480,562,766(\mathrm{M})$; expenditures, $\$ 132,786,159$; total giving, $\$ 113,334,381$; qualifying distributions, $\$ 128,373,677$; giving activities include $\$ 112,752,932$ for 1,401 grants (high: $\$ 7,150,000$; low: $\$ 75$; average: $\$ 25,000-\$ 250,000$ ) and $\$ 581,449$ for 11 foundationadministered programs.

Grantmaker's financial estimates: (yr. ended 12/31/06): Estimated assets, $\$ 2,500,000,000$; estimated total giving, $\$ 116,000,000$.

EI N: 381211227

Selected grants: The following grants were reported in 2006.

$\$ 6,153,000$ to Grand Traverse Regional Land Conservancy, Traverse City, MI, For efforts to acquire Lake Michigan Coastal Preserve for protection from development, payable over 5 years.

$\$ 2,500,000$ to Bishop International Airport Authority, Flint, MI, Toward construction of intermodal hub, which will allow cargo and goods to move from one form of transportation to another, and will increase region's capacity to recruit and retain employers that use cargo infrastructure, and will help diversify regional economy, support and expand existing industries, and create and retain good jobs.

$\$ 2,500,000$ to United Way of Genesee County, Flint, MI, For operating support for Bridges to the Future, before- and after-school program for elementary and middle school students that encourages positive youth development through safe, accessible, and challenging activities that appeal to students' diverse interests.

$\$ 1,750,000$ to University of Michigan, Flint, MI, For operating support for Student Housing, payable over 15 years.

$\$ 1,330,000$ to Carpathian Foundation International, Eger, Hungary, For general support, payable over 2 years.

$\$ 1,000,000$ to German Marshall Fund of the United States, DC, For Balkan Trust for Democracy, payable over 10 years.

$\$ 600,000$ to National Economic Development and Law Center, Oakland, CA, For Workforce Training and Technical Assistance Project which will assist in implementation of sector employment initiatives in Mississippi Delta. Through this work, NEDLC will help people relocated by Hurricane Katrina to connect to livable-wage careers, and assist several communities, including New Orleans, prepare residents to resume permanent employment, payable over 2.25 years.

$\$ 300,000$ to Vital Voices Global Partnership, DC, For general support, payable over 3 years.

$\$ 200,000$ to State Educational Technology Directors Association, Glen Burnie, MD, To develop mobile classrooms for schools in areas affected by Hurricanes Katrina and Rita.

$\$ 105,000$ to Peregrine Environmental Consulting, Takoma Park, MD, For research, policy analysis and coordination for non-governmental organizations working to strengthen global environmental standards for public and private lending institutions.

Last updated: 05/08/2007 


\section{The Ford Foundation}

Copyright (c) 2007 The Foundation Center

\section{Profile}

990 s

\section{Profile}

The Ford Foundation

320 E. 43rd St.

New York, NY 10017-4801

Telephone: (212) 573-5000

Contact: Secy.

FAX: (212) 351-3677

E-mail: office-secretary@fordfound.org

URL: http:/ / www fordfound.org

Donor(s): Henry Ford‡; Edsel Fordł.

Type of grantmaker: Independent foundation.

Background: Incorporated in 1936 in MI.

Purpose and activities: The foundation's mission is to serve as a resource for innovative people and institutions worldwide. Its goals are to: strengthen democratic values, reduce poverty and injustice, promote international cooperation, and advance human achievement. Grants are made primarily within three broad categories: (1) asset building and community development; (2) knowledge, creativity, and freedom; and (3) peace and social justice. Local needs and priorities, within these subject areas, determine program activities in individual countries.

Program area(s): The grantmaker has identified the following area(s) of interest:

Community and Resource Development: The area coordinates work in three fields and aims to create conditions for the development of sustainable and equitable communities. 1) Environment and Development: help people and groups acquire, protect, improve and manage land, water, forests, wildlife and other natural assets in ways that help reduce poverty and injustice. 2) Community Development: seek to improve the quality of life and opportunities for positive change in urban and rural communities. The foundation supports community-based institutions that mobilize and leverage philanthropic capital, investment capital, social capital and natural resources in a responsible and fair manner. 3) Sexuality and Reproductive Health: the foundation focuses on the social, cultural and economic factors that affect sexuality and reproductive health. Grant making emphasizes community-based responses to growing needs for prevention strategies and appropriate policies. It also focuses on empowering women and youth to participate in improving reproductive health and related policies.

Economic Development: The area seeks to make durable economic improvements in the lives of the disadvantaged. The area coordinates efforts in two fields: 1) Development Finance and Economic Security: support organizations that help businesses create employment opportunities and help low-income people acquire, develop and maintain savings, investments, businesses, homes, land and other assets. 2) Workforce Development: support organizations that help improve the ways low-income people develop marketable job skills and acquire and retain reliable employment that provides livable wages. The Economic Development area administers program-related investments (PRIs) for the foundation's programs.

Education, Sexuality, Religion: The area works in three fields: 1) Education and Scholarship: seek to increase educational access and quality for the disadvantaged, to educate new leaders and thinkers and to foster knowledge and curriculum supportive of inclusion, development and civic life. Grant making supports policy, research and reform programs in both schools and higher education institutions around the world, with particular emphasis on enhancing the performance of educational systems through improving finance, access, accountability and training. Scholarship is supported to deepen understanding of such issues as gender, identity, pluralism and social change. 2) Sexuality and Reproductive Health: 
supports efforts to build knowledge, develop policy and deepen public understanding of sexuality and its relationship to human fulfillment, culture, religion and identity. 3) Religion, Society and Culture: examine the role of religious traditions of the world in shaping social values, with the goal of strengthening the contribution of these traditions to creating just, healthy and pluralistic societies. Grant making also seeks to support the participation of historically marginalized groups in the interpretation of diverse religious and cultural traditions and to examine the moral resources they offer contemporary societies.

Governance and Civil Society: The area works in two fields: 1) Governance: strengthen the responsiveness of state and local governments, improve the ability of national government institutions to secure peace and social justice, and build democratic global governance in the arenas of international economics, conflict and security. The area supports efforts to improve government performance, build public awareness of budget and tax issues and confront the challenges posed by the trend toward government decentralization. Additional areas of work promote the value of political equality in America through sound reforms in electoral procedures and campaign financing. The global dimensions of governance are addressed through grant making to improve the management of the international economy and to prevent, mediate and address the consequences of conflict within and between nations. 2) Civil Society: seek to increase the impact of citizens' groups working for peace and social justice, strengthen the philanthropic community that supports them, and encourage citizen oversight of the public and private sectors. The foundation believes in the value of associational life and in nurturing strong, independent and democratic civil societies. Grants seek to increase participation in public affairs beyond the act of voting and to strengthen civil society organizations. Another initiative aims to foster philanthropy that contributes to social justice outcomes. Other work strengthens global civil society and the ability of transnational citizens' coalitions to address public policy problems.

Human Rights: The area works in two fields: 1) Human Rights: promote access to justice and the protection of civil, political, economic, social and cultural rights, especially for the most vulnerable individuals and groups in society. Grant making emphasizes implementation of human rights protections by strengthening advocacy groups, supporting research and promoting outreach and education. Women's rights and racial justice programming builds on the historic victories of these movements in the United States and supports antidiscrimination efforts and the struggles of women and minority groups in Latin America, South Asia and elsewhere. Other programming supports the protection of refugees and the human rights of immigrants domestically and around the world. 2) Sexuality and Reproductive Health: works to secure recognition and enforcement of reproductive rights as embodied in the Plan of Action that emerged from the 1994 United Nations International Conferences on Population and Development in Cairo. This work combines the protection of human rights with the promotion of public health. Grant activities include HIV/AIDS prevention and efforts to end HIV/AIDS-related stigma and discrimination; halting sexrelated trafficking, exploitation and violence; and promoting access to reproductive health services and technologies.

Matching Gifts: The foundation matches the monetary gifts of its employees to charitable organizations.

Media, Arts, and Culture: The area seeks to strengthen the arts and media as important contributors to the communities and societies in which they function, and works in two fields to accomplish these goals: 1) Media: strengthens free and responsible media that address important civic and social issues, and promotes policies and regulations that ensure media and information systems serve the public's diverse constituencies and interests. In addition, the foundation supports high-quality productions that enrich public dialogue on such core issues as building democratic values and pluralism. 2) Arts and Culture: the goal is to increase opportunities for cultural and artistic expression for people of all backgrounds; to foster documentation, dissemination and transmission of both new and traditional creative art forms; to broaden audience involvement and access; and to improve the livelihoods of artists and their opportunity to contribute to civic life.

Fields of interest: Africa; Agriculture; AIDS; Arts; Asia; Civil rights; Civil rights, race/intergroup relations; Community development; Crime/violence prevention, abuse prevention; Economically disadvantaged; Economics; Education; Education, early childhood education; Elementary school/education; Employment; Environment; Environment, natural resources; Government/public administration; Higher education; Housing/shelter, development; Human services; Immigrants/refugees; International affairs; International affairs, arms control; International affairs, foreign policy; International economic development; International human rights; International studies; Latin America;

Law/international law; Leadership development; Legal services; Media, film/video; Media/communications; 
Middle East; Minorities; Minorities/immigrants, centers/services; Museums; Performing arts; Performing arts, dance; Performing arts, music; Performing arts, theater; Philanthropy/voluntarism; Public affairs, citizen participation; Public health, STDs; Public policy, research; Religion, interfaith issues; Reproductive health; Reproductive health, sexuality education; Rural development; Russia; Secondary school/education; Social sciences; Southeast Asia; Urban/community development; Women; Women, centers/services; Youth development.

Geographic focus: National; international

Types of support: Conferences/seminars; Consulting services; Continuing support; Curriculum development; Employee matching gifts; Endowments; Fellowships; Film/video/radio; General/operating support; Grants to individuals; Income development; Management development/capacity building; Matching/challenge support; Program development; Program evaluation; Program-related investments/loans; Publication; Research; Seed money; Technical assistance.

Limitations: Giving on an international basis, including the U.S., Africa and the Middle East, Asia, Russia, Latin America and the Caribbean. No support for programs for which substantial support from government or other sources is readily available, or for religious sectarian activities. No grants for routine operating costs, construction or maintenance of buildings, or undergraduate scholarships; graduate fellowships generally channeled through grants to universities or other organizations; no grants for purely personal or local needs.

Publications: Annual report (including application guidelines); Application guidelines; Informational brochure (including application guidelines); Newsletter; Occasional report.

Application information: Prospective applicants are advised to review the foundation's Web site for information or current funding guidelines. Foreign applicants should contact foundation for addresses of its overseas offices, through which they must apply. Application form not required. Applicants should submit the following:

1) timetable for implementation and evaluation of project

2) qualifications of key personnel

3) statement of problem project will address

4) brief history of organization and description of its mission

5) detailed description of project and amount of funding requested

Initial approach: Brief letter of inquiry

Copies of proposal: 1

Board meeting date(s): Jan., May, and Sept.

Deadline(s): None

Final notification: Initial indication as to whether proposal falls within program interests within 6 weeks Applications accepted in the following language(s): French; Spanish; Russian

Officers and Trustees:* Kathryn S. Fuller,* Chair.; Susan V. Berresford,* Pres.; Barron M. Tenny, Exec. V.P., Secy., and Genl. Counsel; Linda B. Strumpf, V.P. and C.I.O.; Alison R. Bernstein, V.P., Knowledge, Creativity, and Freedom; Pablo J. Farias, V.P., Asset Building and Community Devel.; Mary E. McClymont, V.P.. Peace and Social Justice; Marta L. Tellado, V.P., Comms.; Nicholas M. Gabriel, Treas. and Dir., Financial Svcs.; Nancy P. Feller, Assoc. Genl. Counsel; Afsaneh M. Beschloss; Anke A. Ehrhardt; Juliet V. Garcia; I rene Y. Hirano; J. Clifford Hudson; Wilmot G. James; Yolanda Kakabadse; Thurgood Marshall, Jr.; Richard Moe; Yolanda T. Moses; Carl B. Weisbrod; W. Richard West.

Number of staff: 281 full-time professional; 220 full-time support; 3 part-time support.

Memberships: Africa Grantmakers' Affinity Group; Consultative Group on Biodiversity; Council of Michigan Foundations; Council on Foundations; Disability Funders Network; Donors Forum of Chicago; Environmental Grantmakers Association; European Foundation Center; Funders Concerned About AIDS; Funders' Network for Smart Growth and Livable Communities; Grantmakers for Effective Organizations; Grantmakers In the Arts; Grants Managers Network; Hispanics in Philanthropy; Independent Sector; International Funders for Indigenous People; Native Americans in Philanthropy; Neighborhood Funders Group; New York Regional Association of Grantmakers; Nonprofit Coordinating Committee of New York; Northern California Grantmakers; Peace and Security Funders Group; Philanthropy for Active Civic Engagement (PACE); Philanthropy Roundtable; Southeastern Council of Foundations; Southern California Grantmakers; Technology Affinity Group; The Communications Network; Women \& Philanthropy.

Financial data: (yr. ended 09/30/05): Assets, $\$ 11,615,906,693$ (M); expenditures, $\$ 663,979,509$; total giving, $\$ 516,907,177$; qualifying distributions, $\$ 621,924,695$; giving activities include $\$ 515,157,652$ for 
3,034 grants (high: $\$ 15,814,025$; low: $\$ 2$; average: $\$ 100,000-\$ 250,000), \$ 619,169$ for 12 grants to individuals (high: $\$ 100,000$; low: $\$ 503$; average: $\$ 5,000-\$ 25,000), \$ 1,130,356$ for employee matching gifts, $\$ 5,919,996$ for 4 foundation-administered programs and $\$ 15,672,579$ for loans/program-related investments.

EI N: 131684331

Selected grants: The following grants were reported in 2005.

$\$ 3,500,000$ to International Center for Transitional Justice, New York, NY, Toward general support for activities to help countries respond to legacy of human rights abuse, to advance accountability, respond to needs of victims, and to prevent recurrence of such violence.

$\$ 1,270,000$ to African Virtual University, Nairobi, Kenya, To secure and oversee delivery of low-cost bandwidth for research and scholarly activities to consortium comprising Association of African Universities and 33 universities, payable over 3 years.

$\$ 1,100,000$ to Anti-Defamation League of Bnai Brith, New York, NY, For on-line platform to deliver teacher education programs for A World of Difference Institute.

$\$ 800,000$ to Public Radio Capital, Englewood, CO, For general support to expand choices for public radio programming in United States by protecting and expanding public radio's scarce broadcast assets, payable over 2 years.

$\$ 605,000$ to University of Michigan, Ann Arbor, MI, To evaluate effectiveness of student dialogues for bridging inter-group differences in ten universities, payable over 3 years.

$\$ 600,000$ to National Commission on Violence Against Women, Jakarta, Indonesia, For work to rebuild women's human rights and promote women's legal and economic empowerment in post-tsunami Aceh, payable over 2 years.

$\$ 300,000$ to Advancement Project, DC, For Voter Protection Program to coordinate nonpartisan efforts to educate public about voting rights policies to ensure that all eligible Americans participate in democratic process.

$\$ 260,000$ to Charities Aid Foundation (UK), West Malling, England, For small grants competitions and technical assistance to build capacity of self-help groups of people living with HIV-AIDS across Russia, payable over 2 years.

$\$ 225,000$ to Centre for Research and Innovation in Social Policy and Practice (CENTRIS), Newcastle Upon Thyme, England, To evaluate International Initiative to Strengthen Philanthropy, payable over 2.50 years. $\$ 200,000$ to Watershed Research and Training Center, Hayfork, CA, To undertake regional organizing and training for community-based forestry groups, payable over 1.50 years.

Last updated: 05/04/2007 


\section{Public Welfare Foundation}

Copyright @ 2007 The Foundation Center

$$
\text { Proflle }
$$

990s
«Previous Record| Next Record»

Print Page

Close Window

\section{Profile}

Public Welfare Foundation, Inc.

1200 U St. N.W.

Washington, DC 20009-4443

Telephone: (202) 965-1800

Contact: Review Comm.

FAX: (202) 265-8851

E-mail: reviewcommittee@publicwelfare.org

URL: http:/ / www . publicwelfare.org

Donor(s): Charles Edward Marsh

Type of grantmaker: Independent foundation.

Background: Incorporated in 1947 in TX; reincorporated in 1951 in DE.

Purpose and activities: Support primarily for organizations that address human needs in disadvantaged communities, with strong emphasis on organizations that include service, advocacy and empowerment in their approach: service that remedies specific problems; advocacy that addresses those problems in a systemic way through changes in public policy; and strategies to empower people in need to play leading roles in achieving those policy changes and in remedying specific problems. Also grants for organizations that link their community and local work to other efforts to effect broader public policy change.

Program area(s): The grantmaker has identified the following area(s) of interest:

Community Development: Giving primarily for: 1) Grassroots or Local Organizations: Programs that are guided by and actively involve low-income people in addressing problems including homelessness, the affordable housing crisis, and predatory lending. Particular interest in organizations that provide services and link those services to community organizing, leadership development and community-building efforts. 2) Low-Wage Workers: Programs that strengthen and support organizing efforts among low-wage workers to improve working conditions, seek improved wages, and address broader economic issues. 3) Technical Assistance to Grassroots or Local Organizations: Programs that enhance the effectiveness of organizations by providing technical assistance, training or analysis on issues affecting low-income communities. 4) Advocacy and Policy Development: Advocacy and empowerment programs that promote local, state or national policies that reflect the needs of low-income communities. The community development program's focus also includes support for the foundation's 2007 launch of a two-year, \$1 million Special Initiative on Paid Sick Days. The goal of this initiative is to put in place policies that will secure paid sick days for American workers. Many people in this country are under the impression that full-time workers routinely receive paid sick days. But that impression is wrong. In fact, 47 percent of full-time, private sector workers in the United States have no paid sick days. Seventy-six percent of low-wage workers have no paid sick days. And 86 percent of food service workers - who are mostly women and among the lowest paid workers - have no paid sick days. Thus, being sick means that a low-wage worker - who often lives from paycheck to paycheck and cannot easily afford to lose a day's pay - either has to go to work sick or go without pay. The worker in this situation who does call in sick faces not only lost pay but also disciplinary action that can result in a lost job. Additionally, in most states, the worker who loses his job is not eligible for unemployment insurance because the reason for his termination does not meet qualifying standards. The foundation seeks proposals that will work toward establishing paid sick leave as a minimum labor standard, so that workers will no longer have to choose between going to work sick or losing pay and facing disciplinary action. The foundation is open to any number of strategies to achieve this goal and will consider work at the local, state, and national levels. Proposals should be specific about their goals and intended impact, and the time frame in which that impact would occur. Among the areas to be considered 
are: 1) Organizing at the local, state, and/or national levels for paid sick leave policies. Proposals should discuss the types of activities that would be undertaken, such as public education, coalition building, educational meetings with policymakers, and media campaigns. They should also articulate whether the location where the work would be based has particular strategic value; 2) Policy work to assess existing sick day policies and laws as well as to develop new policy proposals; 3) Research and efforts to engage the business community by demonstrating the benefits of paid sick days in terms of employee satisfaction, employee retention, and public health; and 4) Coordination of efforts, so that organizations engaged in work to promote paid sick days can share lessons and strategies. The foundation will also welcome additional ideas. Interested applicants should send a letter of inquiry to the foundation. via the foundation web site. The letter should outline the proposed initiative, stating the problem to be addressed, the planned approach, and the expected impact. Foundation staff will review the letter of inquiry within 30 days and request a proposal for promising ideas.

Criminal J ustice: Giving primarily for: 1) Alternatives to Incarceration: Programs that emphasize community-based sanctions, such as victim restitution, community service and community supervision, and include education and vocational training, and employment and counseling services. Also programs that provide help at arrest, detention, sentencing, probation, parole or release. 2) Advocacy and Policy Development: Programs that promote changes in public policy and practice to foster a more equitable criminal justice system, including programs to ensure that prisons and jails provide humane treatment and policies aimed at returning offenders to the community as productive, law-abiding citizens. Also programs that offer services to offenders and their families during incarceration and transition, and that remove barriers to a successful return to the community. 3) Legal Representation of Low-Income Persons: Programs that promote fair and effective legal representation for low-income defendants. 4) Violence Prevention: Programs that reduce violence in communities, especially violence involving the use of firearms.

Environment: Giving primarily for: 1) Grassroots or Local Organizations: Programs in local communities that are organized to address environmental problems, particularly those that pose a present or imminent health threat, especially in communities where there are the least resources to respond. 2) Technical Assistance to Grassroots or Local Organizations: Programs that provide technical assistance to grassroots organizations in a wide range of disciplines including science, public health, environmental law, media and organizational development. 3) Advocacy and Policy Development: Local, state, regional, national and international advocacy efforts that address environmental problems, with emphasis on efforts that increase the participation of affected communities in policy decisions concerning health and the environment. 4) Sustainable Development: Programs that promote environmentally sound stewardship of resources in the United States and other countries.

Health: Giving primarily for: 1) Health Advocacy, Access and Reform: Local and state service and advocacy organizations that interact with providers and government to improve community and statebased health care delivery systems, including community-based long term care; ensure that the medically underserved participate in systemic reform; and seek to ensure the provision of services to underserved people, including the disadvantaged elderly. 2) Hunger and Nutrition: Organizations that promote changes in food policy to eradicate hunger, especially among vulnerable populations including children, the elderly and the disabled. 3) Mental Health Advocacy and Services: Mental health advocacy organizations that promote the empowerment, self-help and recovery of mental health care consumers.

Human Rights and Global Security: Giving primarily for: 1) Global Security: Programs that provide information, public education and advocacy on reducing weapon systems, eliminating biological and chemical weapons and land mines and restraining the spread of nuclear arms. 2) Countering HateMotivated Activity and Discrimination: Efforts that address hate-motivated activity and discrimination directed at people because of their race, religion, gender, sexual orientation or national origin and that understand the connections between various forms of hate and discrimination and the necessity to address these problems comprehensively. 3) International Human Rights: Efforts to promote and protect economic, social, political and civil rights and to promote the development of democratic institutions around the world, with a focus on countries that are in political transition, including El Salvador, Haiti, Mexico, Northern Ireland and South Africa. 4) Immigrant Communities: Community-based programs that provide services to and advocacy for immigrants and refugees in the United States.

Reproductive and Sexual Health: Giving primarily for: 1) Reproductive Health for Teens: Programs that provide comprehensive teen sexuality education focusing both on preventing unplanned pregnancies and 
other reproductive health issues, including AIDS, and especially those programs that reach high-risk youth, work with parents and adults responsible for youth and involve teens in program design and implementation and in advocacy promoting improvements in public policy on reproductive health. 2) International Reproductive Health: Organizations that link reproductive health care to the status of girls and women, with a particular interest in efforts to abandon female genital mutilation/cutting in Africa. 3) AIDS Prevention, Education and Advocacy: Programs that work to prevent the spread of HIV/AIDS in populations in which the rate of infection is growing most rapidly and that work to improve public policy on HIV/AIDS. 4) Reproductive Rights: Programs that promote the right of all women to make informed, consensual, safe and affordable choices on all aspects of reproductive health.

Youth Program: Giving primarily for: 1) Employment, Training and Alternative Education: Programs that provide quality education, employment readiness services with job placement and other assistance for young people who have dropped out of school, experience chronic unemployment and have minimal or no job skills, so that they may achieve independent living for themselves and their families. 2) Early Intervention: Programs that promote positive youth development through services designed to prevent educational failure, delinquency, developmental delays, adverse health or neglect. Services also include assistance to children whose parents are adolescents, affected by HIV/AIDS, involved in substance abuse or incarcerated. 3) Youth Leadership Development: Programs that provide opportunities for leadership development primarily through youth-led organizing to address problems facing young people and their communities. 4) Violence Prevention: Primary prevention services to reduce violence in neighborhoods and families, especially violence caused by the availability of guns and other weapons. 5) Advocacy and Policy Development: Programs that promote systemic responsiveness to the needs of low-income young people within federal, state and local policies and practices.

Fields of interest: AIDS; Children/youth, services; Civil rights; Civil rights, race/intergroup relations; Community development; Crime/violence prevention, gun control; Economically disadvantaged; EI Salvador; Environment; Haiti; Health care; Health organizations; Homeless; Homeless, human services; Housing/shelter, development; Immigrants/refugees; International affairs, arms control; International human rights; Legal services; Mexico; Minorities; Minorities/immigrants, centers/services; Nutrition; Offenders/ex-offenders, prison alternatives; Offenders/ex-offenders, rehabilitation; Reproductive health; Reproductive health, family planning; South Africa; Youth development, services.

Geographic focus: National

Types of support: Continuing support; General/operating support; Matching/challenge support; Program development; Seed money.

Limitations: Giving is generally limited to the U.S. (more than 90 percent). No grants to individuals, or for building funds, capital improvements, endowments, government projects, scholarships, graduate work, foreign study, conferences, seminars, publications, research, workshops, or annual campaigns; no loans.

Publications: Annual report (including application guidelines); Financial statement; Grants list.

Application information: All renewal applicants must use the downloadable full proposal format on the foundation Web site. Application form not required. Applicants should submit the following:

1) timetable for implementation and evaluation of project

2) statement of problem project will address

3) population served

4) name, address and phone number of organization

5) copy of IRS Determination Letter

6) copy of most recent annual report/audited financial statement/990

7) detailed description of project and amount of funding requested

8) contact person

9) copy of current year's organizational budget and/or project budget

10) listing of additional sources and amount of support

Initial approach: Online letter of inquiry (must be completed by all first time applicants)

Copies of proposal: 1

Board meeting date(s): Board (or a committee of the board) meets 3 times annually

Deadline(s): None

Final notification: 3 to 4 months

Officers and Directors:* Thomas J. Scanlon,* Chair.; Robert H. Haskell,* Vice-Chair.; Deborah Leff, Pres.; C. Elizabeth Warner,* Secy.-Treas.; Phillipa P. Taylor, C.F.O. and C.A.O.; Peter Edelman; Thomas 
Ehrlich; Juliet Villarreal Garcia; Brent L. Henry; Myrtis H. Powell; Thomas W. Scoville; Michael C. Williams. Number of staff: 13 full-time professional; 5 full-time support.

Memberships: Council on Foundations; Funders Network on Population, Reproductive Health and Rights; Grantmakers for Effective Organizations; Peace and Security Funders Group; Washington Regional Association of Grantmakers.

Financial data: (yr. ended 10/31/06): Assets, $\$ 535,898,092(\mathrm{M})$; expenditures, $\$ 23,515,357$; total giving, $\$ 20,037,575$; qualifying distributions, $\$ 23,526,443$; giving activities include $\$ 20,037,575$ for grants.

Grantmaker's financial estimates: (yr. ended 4/1/07): Estimated assets, \$515,000,000; estimated total giving, $\$ 20,700,000$.

EI N: 540597601

Last updated: 05/01/2007 


\section{Jessie Smith Noyes Foundation}

Copyright @ 2007 The Foundation Center

\section{Profile}

\section{0 s}

\section{Profile}

Jessie Smith Noyes Foundation, Inc.

6 E. 39th St., 12th FI.

New York, NY 10016-0112

Telephone: (212) 684-6577

Contact: Victor De Luca, Pres.

FAX: (212) 689-6549

E-mail: noyes@noyes.org

URL: http:/ / www.noyes.org

Donor(s): Charles F. Noyesł.

Type of grantmaker: Independent foundation.

Background: Incorporated in 1947 in NY.

Purpose and activities: The foundation seeks to protect and restore the planet's capacity for renewal by supporting grassroots organizations and movements whose work promotes healthy, just and sustainable social and natural systems. The foundation views the Earth as one community, an indivisible web of life with human society an integral part. The foundation's grantmaking addresses two general themes: 1) healthy, just and sustainable environments and communities; and 2) reproductive rights. Grants are designed to help organizations increase and sustain their effectiveness. With first time grants, the foundation tries to bring diverse voices and approaches into the movements it supports.

Program area(s): The grantmaker has identified the following area(s) of interest:

Advance Environmental J ustice: Supporting organizations, led by people most heavily affected, that: work to counter environmental degradation in low-income communities and communities of color.

Ensure Quality Reproductive Health Care as a Human Right: Supporting organizations that: 1) Broaden the base and agenda of the reproductive rights movement through the involvement of new constituencies, primarily at the state level and in communities of color; and 2) Advocate for legal and policy initiatives to safeguard reproductive freedom.

Foster an Environmentally Sustainable New York City: Supporting community-based organizations that: 1) Organize to protect the city's environment and the health of its residents; 2) Develop effective coalitions and networks; and 3) Promote public policies and improved responsiveness by public agencies to environmental concerns.

Promote a Sustainable Agricultural and Food System: Supporting rural and urban organizations that:

1) Work with farmers and consumers on issues involving sustainable agriculture and community food security; 2) Advocate for governmental policies and funding allocations that advance sustainable agriculture and community food security; and 3) Counter the actions of public and private sector institutions and corporations that further the concentration of food production and the industrialization of agriculture.

Protect the Health and Environment of Communities Threatened by Toxics: Supporting organizations, primarily at the state and regional levels, that: 1) Bring together activists to work on toxics exposure and contamination; and 2) Promote initiatives and public policies that reduce the use of toxins and hold corporations accountable for their impact on the environment.

Fields of interest: Agriculture; Civil liberties, reproductive rights; Environment; Environment, toxics. Geographic focus: National Types of support: Continuing support; General/operating support; Program development; Seed money. Limitations: Giving limited to the U.S. No grants to individuals, or for scholarships, fellowships, endowment funds, deficit financing, capital construction funds, or general fundraising drives; generally no 
support for conferences, research, college and university based programs, or media; no loans.

Publications: Application guidelines; Financial statement; Grants list; Newsletter; Occasional report. Application information: Applications not accepted for discretionary or founder-designated funds. Accepts National Network of Grantmakers Common Application Form, which can be downloaded from the foundation website. Full proposal will be requested after review of letter of intent, background of organization, summary of activities for funding and expected outcome. The foundation encourages requests that address multiple priorities, as well as those that bring together organizations and activists from diverse movements. The foundation prefers to make general support grants and does not limit the number of renewal grants. Application form not required. Applicants should submit the following:

1) timetable for implementation and evaluation of project

2) copy of IRS Determination Letter

3) brief history of organization and description of its mission

4) detailed description of project and amount of funding requested

5) copy of current year's organizational budget and/or project budget

6 ) listing of additional sources and amount of support

Initial approach: 1- or 2-page letter of inquiry, including budget estimate

Copies of proposal: 1

Board meeting date(s): Spring, summer, and fall

Deadline(s): None

Final notification: Within 6 weeks of receipt of letters; within 2 weeks of board meetings for final proposals Officers and Directors:* Leslie Lowe,* Chair.; Chitra Staley, Vice-Chair.; Victor De Luca, Pres.; Pamela Kingfisher,* Secy.; Nicholas Jacangelo,* Treas.; Dorothy Anderson; George Beardsley; Jerry Beardsley; Peter Bedell, Jr.; Betty Emarita; Stephen Falci; Jenifer Getz; Betty Hung; Carol Kuhre; LaDonna Redmond; Belvie Rooks; Ann Wiener.

Number of staff: 2 full-time professional; 3 part-time professional; 2 part-time support.

Memberships: Council on Foundations; Environmental Grantmakers Association; Funders Network on Population, Reproductive Health and Rights; Grantmakers for Effective Organizations; National Committee for Responsive Philanthropy; Neighborhood Funders Group; New York Regional Association of Grantmakers; North Carolina Network of Grantmakers.

Financial data: (yr. ended 12/31/05): Assets, $\$ 59,053,806(\mathrm{M})$; gifts received, $\$ 150$; expenditures, $\$ 4,472,549$; total giving, $\$ 2,991,499$; qualifying distributions, $\$ 4,035,148$; giving activities include $\$ 2,991,499$ for 84 grants (high: $\$ 75,000$; low: $\$ 250$; average: $\$ 1,000-\$ 10,000$ ) and $\$ 14,260$ for foundation-administered programs.

Grantmaker's financial estimates: (yr. ended 12/31/06): Estimated assets, $\$ 60,964,000$; estimated total giving, $\$ 3,436,000$.

EI N: 135600408

Selected grants: The following grants were reported in 2006. $\$ 100,000$ to Gulf Coast Fund for Community Renewal and Ecological Health, New York, NY, Toward Fund created in aftermath of Hurricanes Katrina and Rita, which works to rebuild New Orleans and Gulf Coast, with focus on human rights for low-income and minority populations affected by the Hurricanes.

$\$ 100,000$ to White Earth Land Recovery Project, Callaway, MN, For Jessie Smith Noyes Foundation Award. $\$ 90,000$ to Organizacion en California de Lideres Campesinas, Farmworker Women's Leadership Project, Pomona, CA, For general support to develop leadership among farmworker women for political, social and economic change, payable over 2 years.

$\$ 80,000$ to Agriculture and Land-Based Training Association, Salinas, CA, To participate in Diversifying Leadership for Sustainable Food Policy Initiative, payable over 3 years.

$\$ 80,000$ to Anew America Community Corporation, Berkeley, CA, To participate in Diversifying Leadership for Sustainable Food Policy Initiative, payable over 3 years.

$\$ 80,000$ to Strategic Progressive Information Network (SPIN), San Francisco, CA, For general support to train community-based organizations working in area of toxics clean-up and control in media skills,

payable over 2 years.

$\$ 40,000$ to Third Wave Foundation, New York, NY, For general support to build long-term capacity among participating groups, engage in joint projects, and expand outreach to next generation of reproductive rights activists and supporters, payable over 2 years.

$\$ 30,000$ to Association for Neighborhood and Housing Development, New York, NY, For program support 
for Initiative for Neighborhood and City-Wide Organizing, which strengthens capacity of community-based groups to engage in local organizing, and carry out citywide policy campaigns that link environmental justice and affordable housing, payable over 2 years.

$\$ 25,000$ to Grassroots Global Justice, San Pedro, CA, For general support for alliance of U.S.-based grassroots groups organizing to build agenda for power for working and poor people, with focus on environmental justice related to toxics.

$\$ 20,000$ to Rural Coalition, DC, For general support to increase equity in delivery of U.S. Department of Agriculture programs, and have impact on policies that shape agricultural opportunities for farmers globally.

Last updated: 06/21/2007 


\section{The Nathan Cummings Foundation}

Copyright @ 2007 The Foundation Center

$$
\text { Profile }
$$

990 s
«Previous Record| Next Record》

Print Page

Close Window

\section{Profile}

The Nathan Cummings Foundation

475 10th Ave., 14th FI.

New York, NY 10018-9715

Telephone: (212) 787-7300

Contact: Lance E. Lindblom, C.E.O. and Pres.

FAX: (212) 787-7377

E-mail: info@nathancummings.org

URL: http:/ / www.nathancummings.org

Donor(s): Nathan Cummingsł.

Type of grantmaker: Independent foundation.

Background: Established in 1949 in IL.

Purpose and activities: The foundation is rooted in the Jewish tradition and committed to democratic values and social justice, including fairness, diversity, and community. It seeks to build a socially and economically just society that values and protects the ecological balance for future generations; promotes humane health care; and fosters arts and culture that enriches communities.

Program area(s): The grantmaker has identified the following area(s) of interest:

Arts and Culture: The goal of the program is to support artistic practices, programs and policies that encourage cross-cultural and multidisciplinary collaborations and give voice to the issues and experiences of underrepresented communities in order to build a stronger society. The arts and culture program consists of two components: 1) Art and Social Justice - Supporting arts and cultural organizations partnering with community groups that engage in responsive processes, collective problem solving, crosscultural initiative or the education of a broader public about social justice issues and shared community concerns. These programs should have national or multi-state impact and might include: residencies; new works of performing art or exhibitions of visual art that have more than one committed venue;

documentation initiatives that have commitments for comprehensive distribution plans; cross-cultural and multi-state collaborations; and the dissemination of existing works that have resonance in other

communities; and 2) Public Policy and Corporate Accountability - Defending against adverse public, private and corporate policies, arts censorship, and other legal and social challenges that impact the well being of the nonprofit cultural community. For more information contact the foundation via e-mail:

arts@nathancummings.org.

Environment: This program consists of two objectives: 1) To facilitate the accountability of corporations, governments, and other institutions for their environmental practices; and 2) To facilitate environmental justice by ensuring that communities, especially those vulnerable due to low to moderate socioeconomic status, race, or ethnicity, are protected from environmental degradation. For more information contact the foundation via e-mail: enviro@nathancummings.org.

Health: This program has two objectives: 1) To assure access to quality health care, goods and services, especially those who confront barriers due to low to moderate socioeconomic status, race, ethnicity or gender; and 2) To assure that people, especially those that are vulnerable, can grow-up, live, and work in a healthy environment and have access to products and food that have not been contaminated in ways that could undermine health. For more information contact the foundation via e-mail:

health@nathancummings.org.

I nterprogram I nitiatives for Social and Economic J ustice: The goal of interprogram initiatives for social and economic justice is to support social and economic justice in order to encourage equitable and sustainable development that promotes democracy as well as community, cultural, social, spiritual, and 
individual well-being. The program will advance this goal by supporting the exploration, development and implementation of public policy, private efforts and activities for institutional and systematic change. Interprogram Initiatives for Social and Economic Justice grants will be recommended for projects that meet elements of both of the following objectives, and are in support of, or in conjunction with, at least one of the foundation's other program areas: 1) To establish the accountability of economic, social or governmental institutions, especially corporations, for the consequences and effects of their activities on the environment, and on people, their health, well-being, cultures, and communities; and 2) To address these social, political, economic, environmental, cultural or health issue interests and by race, religion, gender, class, ethnicity, and national origin--into crosscutting constituencies based on common economic, social, and ethical concerns; and creating both the possibilities and the demand for development of more systematic solutions to these issues, as well as the social basis needed for their implementation.

Additionally, funding priority will be given to projects having impacts at the state, multi-state, or national level. For more information contact the foundation via e-mail: interprogram@nathancummings.org.

Jewish Life Program: This program is comprised of two parts, the Jewish Life and Values and Contemplative Practices. The goal of the Jewish life and values program is to extend the presence and influence of the values of tolerance, social justice, loving kindness, mutual respect and ethical behavior within the J ewish world both to enhance Jewish life and to assist in the promotion of a more just society. The Jewish Life and Values part of this program consists of four objectives: 1) To promote a leadership and organizational culture within key Jewish institutions that reflects these values; 2) To promote a Jewish spirituality and practice that reflects these values; 3) To promote these values by strengthening the capacity of Jews and the Jewish community to engage with major issues of social and economic justice and stewardship of the earth; and 4) To promote communication, understanding and partnerships between Jews and peoples of other faith traditions through programs that focus on shared values and common goals. The focus of the Contemplative Practice part of this program is to promote the development and dissemination of contemplative practice programs, from all traditions, which address the foundation's core values: concern for the poor, disadvantaged and underserved; empowerment of communities in need; respect for diversity; and promotion of understanding across cultures. The Contemplative Practice part of this program consists of two objectives: 1) To cultivate the development and teaching of contemplative practices linked to engagement with areas of concern to the foundation; and 2) To enable the teachers, practitioners and organizations devoted to contemplative practice to make their work available as a resource for nonprofit organizations devoted to social, economic and environmental justice. For more information contact the foundation via e-mail: jlife@nathancummings.org.

Fields of interest: Arts; Environment; Health care; Health organizations; Human services; Israel; Jewish agencies \& temples.

Geographic focus: National; international

Types of support: Continuing support; General/operating support; In-kind gifts; Program development; Program evaluation; Research; Seed money.

Limitations: Giving primarily in the U.S. and I srael. No support for specific diseases, general support for Jewish education, Holocaust-related projects, foreign-based organizations, or local synagogues or institutions with local projects. No grants to individuals, scholarships, sponsorships, projects with no plans for replication, endowments or capital campaigns.

Publications: Annual report; Application guidelines; Financial statement; Grants list.

Application information: Application form required. Applicants should submit the following:

1) timetable for implementation and evaluation of project

2) qualifications of key personnel

3) statement of problem project will address

4) name, address and phone number of organization

5) copy of IRS Determination Letter

6) brief history of organization and description of its mission

7) listing of board of directors, trustees, officers and other key people and their affiliations

8) detailed description of project and amount of funding requested

9) contact person

10) copy of current year's organizational budget and/or project budget

11) listing of additional sources and amount of support

Initial approach: 2- to 3-page letter of inquiry 
Copies of proposal: 1

Board meeting date(s): Spring and fall

Deadline(s): None

Final notification: 60 days

Officers and Trustees:* Adam N. Cummings,* Chair.; Ernest Tollerson,* Vice-Chair.; Lance E. Lindblom,* C.E.O. and Pres.; Leisle Lin, V.P., Finance and Admin.; James K. Cummings,* Secy.; Robert N. Mayer,* Treas.; Roberta Friedman Cummings; Sonia Simon Cummings; Rachel Durchslag; Stephen P. Durchslag; Andrew Golden; Sara Horowitz; Andrew Lee; Beatrice Cummings Mayer; Ruth Cummings Sorensen; Debra Weese-Mayer.

Number of staff: 9 full-time professional; 12 full-time support; 1 part-time support.

Memberships: Association of Black Foundation Executives; Consultative Group on Biodiversity; Council on Foundations; Environmental Grantmakers Association; Funders for Lesbian and Gay Issues; Grantmakers for Children, Youth and Families; Grantmakers In Health; Grantmakers In the Arts; Grants Managers Network; Jewish Funders Network; Neighborhood Funders Group; New York Regional Association of Grantmakers; Nonprofit Coordinating Committee of New York; Women \& Philanthropy.

Financial data: (yr. ended 12/31/05): Assets, $\$ 481,024,999(\mathrm{M})$; expenditures, $\$ 21,395,907$; total giving, $\$ 17,371,600$; qualifying distributions, $\$ 17,371,600$; giving activities include $\$ 16,857,000$ for 250 grants (high: $\$ 990,000$; low: $\$ 800$; average: $\$ 10,000-\$ 100,000$ ).

EI N: 237093201

Selected grants: The following grants were reported in 2005.

$\$ 990,000$ to New Israel Fund, DC.

$\$ 500,000$ to Rockefeller Philanthropy Advisors, Philanthropic Collaborative, New York, NY.

$\$ 475,000$ to Union for Reform Judaism, New York, NY.

$\$ 403,000$ to American Institute for Social Justice, New Orleans, LA.

$\$ 400,000$ to Center for American Progress, DC.

$\$ 350,000$ to Earthjustice, Oakland, CA.

$\$ 265,000$ to National Womens Law Center, DC.

$\$ 250,000$ to Research Foundation of the City University of New York, New York, NY.

$\$ 245,000$ to Community Catalyst, Boston, MA.

$\$ 200,000$ to Bread and Roses Cultural Project, New York, NY.

Last updated: 04/12/2007 


\section{Steven and Michele Kirsch Foundation}

Copyright $\Subset 2007$ The Foundation Center

\section{Profile}

990 s
«Previous Record| Next Record»

Print Page

Close Window

\section{Profile}

Steven and Michele Kirsch Foundation

60 S. Market St., Ste. 1000

San Jose, CA 95113-2336

Telephone: (408) 278-2278

Contact: Taryn Ishida, Exec. Asst.

FAX: (408) 278-0280

E-mail: staff@kirschfoundation.org

E-mail for Taryn Ishida: tishida@kirschfoundation.org

URL: http:/ / www.kirschfoundation.org

Type of grantmaker: Public charity.

Background: Established in 1999 as a supporting organization of the Silicon Valley Community Foundation.

Purpose and activities: The foundation is actively engaged in making grants, lobbying and advocacy activities, and educating on subjects ranging from environmental issues to nuclear non-proliferation to philanthropy.

Program area(s): The grantmaker has identified the following area(s) of interest:

Environmental Grants: Due to limited funding, this program is by invitation only. Proposals will not be accepted for this program for the foreseeable future.

Political Reform and Global Theme Grants Program: Due to limited funding, all grant funds for this program are currently allocated. Proposals will not be accepted for this program for the foreseeable future. Silicon Valley Community Grants: Due to limited funding, this program is by invitation only. Proposals will not be accepted for this program for the foreseeable future.

Fields of interest: Environment; Medical research; Science.

Geographic focus: California

Types of support: Annual campaigns; General/operating support; Program development; Publication;

Research.

Limitations: Giving primarily in the San Joaquin Valley, CA, area.

Publications: Annual report; Grants list; Newsletter.

Application information: Currently, all grants programs are by invitation only. See Web site for more information.

Board meeting date(s): Quarterly

Officers and Directors:* Steven T. Kirsch,* Chair.; Perry Olson,* Vice-Chair. and C.F.O.; Susan Frank, Pres. and C.E.O.; Peter Decourcy Hero,* Secy.; Bill Johnson.

Number of staff: 4 full-time professional.

Memberships: Environmental Grantmakers Association; Peace and Security Funders Group.

Financial data: (yr. ended 06/30/05): Revenue, \$588,220; assets, $\$ 8,096,907$ (M); expenditures, $\$ 2,288,257$; total giving, $\$ 1,237,950$; program services expenses, $\$ 2,005,044$; giving activities include $\$ 1,237,950$ for 99 grants (high: $\$ 200,000$; low: $\$ 500)$.

EI N: 770502997

Last updated: 06/18/2007 


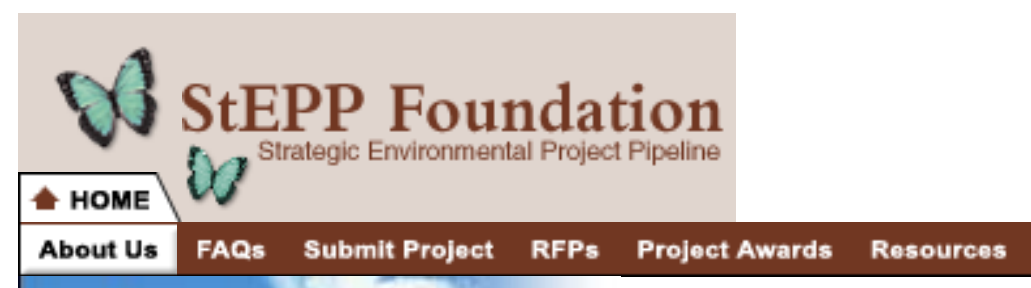

Contact Information Board of Directors

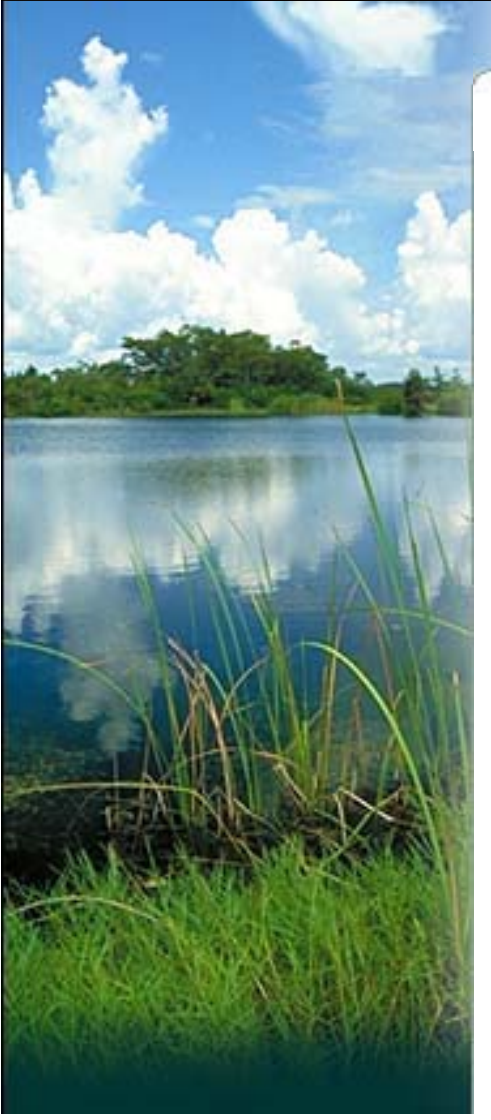

\section{About the StEPP Foundation}

The StEPP Foundation is a 501(c)(3) organization dedicated to helping organizations realize their vision of a clean and safe environment by nationally matching projects with funders. The StEPP Foundation provides project oversight to enhance the success of projects increasing the number of energy efficiency, clean energy and pollution prevention projects implemented at the local, state and national levels for the benefit of the public.

The StEPP Foundation offers opportunities for organizations across the country to demonstrate the positive benefits of energy efficiency, renewable energy and pollution prevention projects in their communities. The StEPP Foundation works with governmental authorities, non-profit organizations, academic resources and other entities that have a need or requirement to fund environmental projects. The Foundation conducts a project selection process several times during the year, in search of projects to best match the requirements of funding sources. In most cases the initial search is done from projects already entered in the StEPP Project Pipeline which meet one or more of the following core principles:

- To provide a direct strategy for improving air and water quality, and reducing solid and hazardous waste (multi-media quantifiable benefits);

- To provide the state or area impacted with a winning public and environmental health strategy;

- To provide incentives for the development and implementation of energy efficiency and renewable energy projects;

- To maximize environmental benefit for each dollar invested;

- To support investments in opportunities that have environmental benefits from renewable related projects;

- To support energy efficiency/renewable energy (EERE) products, services and technologies;

- To increase the number of renewable energy projects;

- To increase the number of renewables in the marketplace;

- To connect land use and ecosystem health; and

- To connect environmental and public health issues.

To enter your project idea for funding consideration, visit StEPP Online Project Submittal System.

The Foundation supports pluralism and equal opportunity in its throughput of funds. Applications are considered throughout the year and monies are awarded based on funding available. The Foundation monitors projects through regular financial and narrative reporting. The Foundation's funds are limited in relation to the many worthwhile proposals received. The Foundation supports applicants that present the best match, with the greatest environmental benefit, for the funds available. Funding is not normally given for routine operating costs. Visit Request For Proposals to view a current listing of open RFP's.

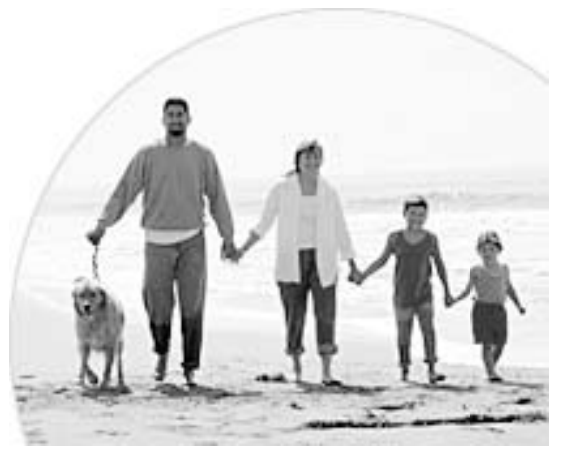

Terms of Use Privacy Policy

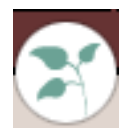




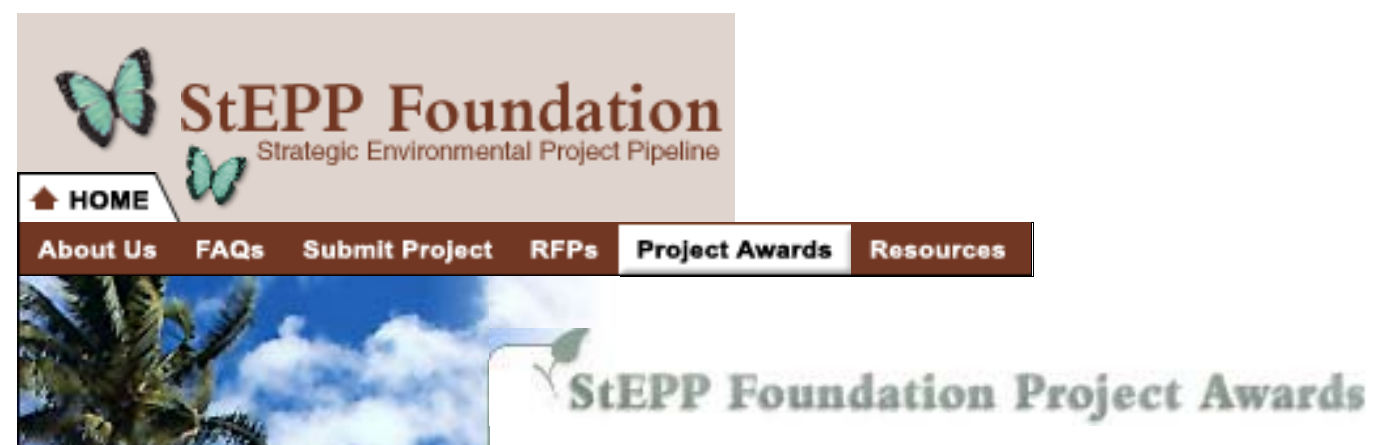

The StEPP Foundation operates throughout the United States and is dedicated to helping organizations realize their vision of a clean and safe environment by matching projects with funders. The Foundation was incorporated in July 2001 and our first series of project awards were made in Colorado, StEPP's home state. We are, however, soliciting project ideas nationally and are working with funding sources across the country. To input a project idea for consideration, please check out the Submit Project section of this website.

\section{September 2004 Project Awards}

Jefferson County Department of Health and Environment

$\$ 27,000$ to evaluate existing individual sewage disposal system (ISDS) programs statewide, and develop recommendations for improvements through a collaborative stakeholder process.

\section{January 2004 Project Awards}

\section{Battlement Mesa Service Association, Parachute, COBrush School District, Brush,} CO $\$ 20,000$ to re-seed a ten acre bluegrass playfield with a low-water, turf-quality buffalo grass that will save both water and the electricity used to run the irrigation pumps.

\section{Western Colorado Botanical Society, Grand J unction, COCity of Fort Morgan, Fort Morgan, CO \\ $\$ 27,000$ to purchase a compressed natural gas maintenance truck for the Fort Morgan Parks Department, that will replace a 1960's conventional gas truck, reduce air pollution and costs for gas and maintenance.}

\section{Summit Blue Consulting, LLC, Adams County, CO}

$\$ 10,250$ to perform energy audits on two Adams County School District 50 schools to develop a prioritized list of energy efficiency measures that will save money, decrease air emissions, and increase student comfort. Completed.

\section{August 2003 Project Awards}

Battlement Mesa Service Association, Parachute, CO

$\$ 75,000$ : to actively repair fire damaged areas through weed management and the reintroduction of native plants.

Western Colorado Botanical Society, Grand J unction, CO

$\$ 94,302$ : to build new xeric gardens, including a native garden, japanese garden, english cottage garden and a mediterranean garden to promote water conservation by providing an educational yet recreational opportunity for the public to witness several different xeriscape gardens.

Sunsense, I nc., Rio Blanco County and Mesa County, CO

$\$ 115,000$ : to showcase resource efficient technoliges (renewable energy, energy efficiency and alternative fuels) and to assist in the operation of the Rio Blanco and Mesa County Fairgrounds through the use of these technologies.

Ranch Learning Center, Mesa County, co

$\$ 210,000$ : to create a Sustainability Lab on this 450 -acre working ranch, incorporating 
green building techniques, wind power and other alternative energy sources, constructed wetlands, no-till agriculture techniques, etc. as an educational demonstration site.

\section{January 2003 Project Awards}

\section{Aspen Skiing Company, Aspen, CO}

$\$ 10,080$ : to create a model hydroelectric project tied to the Snowmass Ski Areas snowmaking system, thus demonstrating the viability of incorporating this renewable energy technology into the existing infrastructure at ski resorts.

\section{December 2002 Project Awards}

\section{Colorado Energy Assistance Foundation, Denver, CO}

$\$ 180,000$ : to incorporate energy efficiency technologies, such as passive cooling systems and the conversion of electric heating systems to natural gas, in an affordable housing development in the Northeast Metro area.

\section{Boulder Energy Conservation Center, Denver, CO}

$\$ 90,000$ : to support the installation of solar domestic hot water systems and upgraded weatherization in Northeast Metro area low - income households.

\section{Northeast Metro Pollution Prevention Alliance (NEMPPA), Denver, CO}

$\$ 90,000$ : to assist small businesses located in the Northeast Metro area take advantage of cost savings by utilizing renewable energy technologies in their operations.

\section{Weld County School District 6, Greeley, CO}

$\$ 127,500$ : to allow for energy efficiency upgrades in four elementary schools in the Weld County School District.

Posada, Pueblo, co

$\$ 253,000$ : to support the incorporation of alternative energy technologies, such as photovoltaics, in the Via Don Carlos housing development and community center for migrant workers.

Pueblo County Public Works - Fleet Division, Pueblo, CO $\$ 102,000$ : to convert a portion of the Pueblo City County Fleet from gasoline to hybrid vehicles.

\section{Colorado Governor's Office of Energy Management} and Conservation, Pueblo, CO

$\$ 65,000$ : to allow for the installation of cost-effective energy efficiency technologies, such as geo-exchange systems, in Pueblo School District 60.

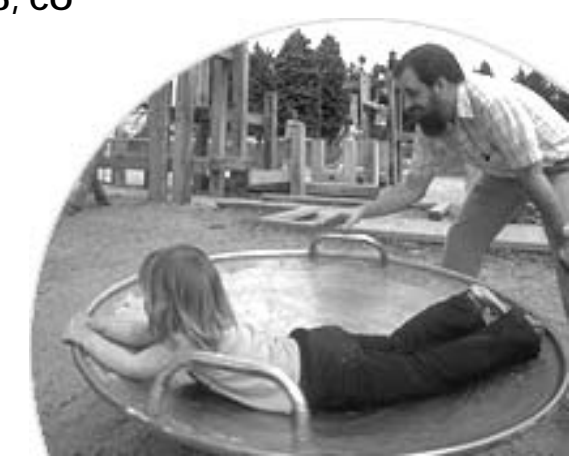


Appendix 9: Foundation Spreadsheet 
Foundation Name

Pew Charitable Trusts, The

Community Foundation Silicon Valley

\section{Intel Foundation}

Surdna Foundation, Inc.

Daimerchrysler Corporation Fund

Energy Foundation

Educational Foundation of America, The

Lannan Foundation

Shell Oil Company Foundation

Wallace Global Fund

Burlington Northern Santa Fe Foundation

Blue Moon Fund, Inc.

Gannett Foundation, Inc.

Funding Exchange, Inc.

Ben \& Jerry's Foundation, Inc.

Stern Memorial Trust, Sidney

American Indian Heritage Foundatio

American Indian Youth Running Strong, Inc.

First Nations Development Institute

Seventh Generation Fund

Abelard Foundation, Inc., The

Level Playing Field Institute

International Partners in Mission

Ernst Foundation, Richard C. \& Susan B.

AMB Foundation

Gaea Foundation, The

Santa Fe Natural Tobacco Company Foundation

World Emergency Relief

E\&CO.

Harburg Foundation, Inc., Yip, The

Social Venture Capilal Forr

Rudolph and Sletten, Inc. Corporate Giving Program

Asea Brown Boveri Inc. Corporate Giving Program

(O)2007 The Foundation Center

Total Giving
$\$ 198,477,867$ info@pewtrusts.org
$\$ 75,366,593$ info@cfsv.org
$\$ 45,300,000$ philanthropy_ed@hp.com
$\$ 43,102,949$ intel.foundation@intel.com
$\$ 30,608,760$ request@surdna.org
$\$ 25,954,013$ mek@dcx.com
$\$ 17,579,462$ energyfund@ef.org
$\$ 12,430,469$ loi@efaw.org
$\$ 10,627,962$ info@lannan.org
$\$ 9,680,081$ socfoundation@shellus.com
$\$ 8,053,713$ tkroll@wgf.org
$\$ 6,283,557$ N/A
$\$ 3,994,308$ info@bluemoonfund.org
$\$ 3,967,514$ foundation@gannett.com
$\$ 3,686,734$ grants@fex.org
$\$ 1,904,072$ N/A
$\$ 1,360,158$ N/A
$\$ 1,350,206$ kathryn_carey@ahm.honda.com
$\$ 997,975$ N/A
$\$ 861,259$ info@indianyouth.org
$\$ 825,548$ info@firstnations.org
$\$ 465,666$ of7gen@pacbell.net
$\$ 453,500$ N/A
$\$ 421,523$ info@lpfi.org
$\$ 273,145$ office@ipm-connections.org
$\$ 166,000$ N/A
$\$ 206,210$ mail4amb@cox.net
$\$ 179,920$ N/A
$\$ 166,200$ N/A
$\$ 75,840$ info@wer-us.org
$\$ 62,000$ N/A
$\$ 33,500$ e@yipharburg.com
$\$ 6,900$ jeff.svcf@att.net
$\$ 3,375$ N/A
N/A N/A
N/A N/A

emailed snail mailed rec'd reply contact

1/9/2007 1/18/2007 Joann McGuire

$1 / 9 / 2007$

$1 / 9 / 2007$

$1 / 9 / 2007$

$1 / 9 / 2007$

$1 / 9 / 2007$

$1 / 9 / 2007$

$1 / 9 / 2007$

$1 / 9 / 2007$

$1 / 9 / 2007$

$1 / 9 / 2007$

$1 / 9 / 2007$

$1 / 9 / 2007$

$1 / 9 / 2007$

failed

$1 / 9 / 2007$

1/15/2007
1/26/2007 Jonathan Goldberg

1/26/2007 Molly Holcomb

$1 / 10 / 2007$

ailed

$1 / 9 / 2007$

Tina Kroll-Guerch

1/9/2007 Richard A. Russack, Pres.

1/9/2007 Stefan Jirka

1/10/2007 Pat Lyle

1/9/2007

1/9/2007 1/30/2007 Debby Kessler

$1 / 9 / 2007 \quad 1 / 23 / 2007$

1/9/2007

$1 / 9 / 2007$

Princess Pale Moon, Pres.

$1 / 9 / 2007$

$1 / 9 / 2007$

$1 / 9 / 2007$

$1 / 9 / 2007$

$1 / 9 / 2007$

$1 / 9 / 2007$

1/9/2007

1/22/2007 Andrea Strahan

1/9/2007 Chris Peters

3/21/2007 Lindsay Wall

1/31/2007 Marie Sloane

1/9/2007 2/14/2007 Karen Gupta

1/9/2007

1/9/2007

Richard M. Sanders, Pres

$1 / 9 / 2007$

1/9/2007

$1 / 9 / 2007$

$\begin{array}{lll}\text { 1/9/2007 } & \text { 1/18/2007 Allen Rudolph, Pres. and C.E.O. } & \text { returned - address no good } \\ \text { 1/9/2007 } & \text { 2/5/2007 Julietta Guarino } & \text { sent app guidelines }\end{array}$

1/9/2007 Jeff Schwartz

Jean Christophe Fuster

2/5/2007 Julietta Guarino sent app guidelines

aka ABB Foundation, Inc. notes

作

only fund school programs

sent link to LOI guidelines

not interested

elping Tribe w/ litigation

ot interested

ent link to inquiry form

only in Gannett communities

ot interested

and guidelines

sent app guidelines

meeting Jan. 11

sent app guidelines

sent app forms

no longer making grants sent link to app instructions 
Additional Foundations Recommended by Chris Peters (Seventh Generation Fund) as Possible Funders

Foundation Name

Columbia Foundation

California Endowment - state HQ

California Endowment - N. state regional office

Charles Stewart Mott Foundatio

Ford Foundation

Public Welfare Foundation

Jesse Smith Noyes Foundation

Nathan Cummings Foundation
$\underline{U R L}$

Www. firstnations.org/gEagle.asp www.columbia.org www.calendow.org

www.mott.org

www.fordfound.org

www.publicwelfare.org

www.noyes.org

www.nathancummings.ne
Fax

Email

303-774-7836303-774-7841 info@firstnations.org

415-561-6880415-561-6883 info@columbia.org

Contact Person

Kimberly Craven

800-449-4149 213-928-8801 questions@calendow.org

916-443-4355 916-567-3037 SACquestions@calendow.org

810-238-5651 810-766-1753 info@mott.org

212-573-5000 212-351-3677 office-secretary@fordfound.org

202-965-1800 202-265-8851 reviewcommittee@publicwelfare.org

212-684-6577 212-689-6549 noyes@noyes.org Millie Buchanan

212-787-7300 212-787-7377 enviro@nathancummings.org
Contact Person's Title

tmaking

Grants Manager

Toxics and Env. Justice 
Selected Foundations Listed in "Funding Opportunities: A Directory of Energy Efficiency, Renewable Energy, and Environmental Protection Assistance Programs" Published by US EPA, April 2004

These are foundations from the above EPA publication that passed an initial screening for suitability for Yurok Tribe funding

\section{Foundation Name}

Ford Foundation

Kirsch Foundation

N. American Fund for Environmental Cooperation

Public Welfare Foundation

Strategic Environmental Project Pipeline (StEPP) Foundation
$\frac{\mathrm{URL}}{\text { www.fordfound.org }}$

www.kirschfoundation.org/how/environmental/environment.htm

www.cec.org/grants/about/index.cfm?varlan=English

www.publicwelfare.org

www.steppfoundation.org

\begin{tabular}{|c|c|c|}
\hline Phone & $\underline{\text { Fax }}$ & Email \\
\hline $212-573-5000$ & 212-351-3677 & office-secretary@fordfound.ors \\
\hline 408-278-2278 & $408-278-0280$ & questions@kirschfoundation. \\
\hline 514-350-4357 & 514-350-4314 & nafec@ccemtl.org \\
\hline 202-965-1800 & 202-265-8851 & general@publicwelfare.org \\
\hline 303-277-0932 & $303-384-3636$ & info@steppfoundation.org \\
\hline
\end{tabular}




\section{Appendix 10: Recommended Data Elements for Yurok Energy Geographic Information System (YEGIS)}

\begin{tabular}{|c|c|c|c|c|c|}
\hline RESOURCE & Biomass & Microhydro & Solar & Wind & $\begin{array}{l}\text { Electric } \\
\text { Demand }\end{array}$ \\
\hline \multirow[t]{9}{*}{ PARAMETERS } & $\begin{array}{l}\text { Types of } \\
\text { vegetation }\end{array}$ & $\begin{array}{l}\text { Stream } \\
\text { location }\end{array}$ & $\begin{array}{l}\text { Existing } \\
\text { solar } \\
\text { electric } \\
\text { systems }\end{array}$ & $\begin{array}{l}\text { Wind } \\
\text { resource } \\
\text { availability }\end{array}$ & $\begin{array}{l}\text { Commercial } \\
\text { and } \\
\text { residential } \\
\text { electric } \\
\text { demand }\end{array}$ \\
\hline & $\begin{array}{l}\text { Density of } \\
\text { vegetation }\end{array}$ & $\begin{array}{l}\text { Stream } \\
\text { gradient }\end{array}$ & $\begin{array}{l}\text { Potential } \\
\text { sites for } \\
\text { new solar } \\
\text { electric } \\
\text { systems } \\
\end{array}$ & $\begin{array}{l}\text { Available } \\
\text { ridgeline } \\
\text { terrain }\end{array}$ & \\
\hline & $\begin{array}{l}\text { Land } \\
\text { ownership }\end{array}$ & Stream flow & $\begin{array}{l}\text { Potential } \\
\text { sites for } \\
\text { village } \\
\text { scale solar }\end{array}$ & $\begin{array}{l}\text { Land } \\
\text { ownership }\end{array}$ & \\
\hline & $\begin{array}{l}\text { Existing } \\
\text { roads }\end{array}$ & Fish habitat & $\begin{array}{l}\text { Solar } \\
\text { energy } \\
\text { resource } \\
\text { availability }\end{array}$ & $\begin{array}{l}\text { Existing } \\
\text { roads }\end{array}$ & \\
\hline & $\begin{array}{l}\text { Steepness } \\
\text { of terrain }\end{array}$ & $\begin{array}{l}\text { Cultural } \\
\text { sites }\end{array}$ & & $\begin{array}{l}\text { Steepness } \\
\text { of terrain }\end{array}$ & \\
\hline & $\begin{array}{l}\text { Mill } \\
\text { location }\end{array}$ & $\begin{array}{l}\text { Land } \\
\text { ownership }\end{array}$ & & $\begin{array}{l}\text { Type and } \\
\text { density of } \\
\text { vegetation }\end{array}$ & \\
\hline & $\begin{array}{l}\text { Mill } \\
\text { ownership }\end{array}$ & $\begin{array}{l}\text { Proximity to } \\
\text { electric } \\
\text { loads }\end{array}$ & & $\begin{array}{l}\text { Cultural } \\
\text { sites }\end{array}$ & \\
\hline & $\begin{array}{l}\text { Treatment } \\
\text { of mill } \\
\text { waste }\end{array}$ & & & $\begin{array}{l}\text { Proximity } \\
\text { to electric } \\
\text { loads }\end{array}$ & \\
\hline & $\begin{array}{l}\text { Forest fuel } \\
\text { reduction } \\
\text { efforts }\end{array}$ & & & & \\
\hline
\end{tabular}

